\title{
Mujeres y Derecho
}

\section{Nieves Montesinos Sánchez y}

MẼ del Mar Esquembre Valdéśs (courds.) Nieves Montesinas Ś́nchez (ed.)

\section{Feminismo/s}





\section{FEMINISMO/S}

Revista del Centro de Estudios sobre la Mujer

de la Universidad de Alicante

Número 8, diciembre de 2006

\section{Mujeres y Derecho}

Nieves Montesinos Sánchez y M $\mathrm{M}^{\mathrm{a}}$ del Mar Esquembre Valdés (coords.) Nieves Montesinos Sánchez (ed.) 



\title{
FEMINISMO/S \\ Revista del Centro de Estudios sobre la Mujer de la Universidad de Alicante
}

\author{
Revista Semestral \\ Editada por el Centro de Estudios sobre la Mujer de la Universidad \\ de Alicante con la colaboración del Vicerrectorado de Calidad y Armonización Europea
}

Número 8, diciembre de 2006

\section{CONSEJO EDITORIAL}

Dirección: Mónica Moreno Seco (Universidad de Alicante)

Secretaria: Helena Establier Pérez (Universidad de Alicante)

Vocales: Ma del Mar Esquembre Valdés (Universidad de Alicante)

Nieves Montesinos Sánchez (Universidad de Alicante)

Carmen Mañas Viejo (Universidad de Alicante)

\section{CONSEJO ASESOR}

Mabel Burín (Universidad de Ciencias Empresariales y Sociales, Buenos Aires)

Silvia Caporale Bizzini (Universidad de Alicante)

Angels Carabí (Universitat de Barcelona)

Pilar Cuder Domínguez (Universidad de Huelva)

Joaquín De JuAn (Universidad de Alicante)

$\mathrm{M}^{\mathrm{a}}$ José Frau Llinares (Universidad de Alicante)

Eddy GIL DE MEjIA (Fachhochschule Oldenburg/Ostfriesland/ Wilhelmshaven University of Applied Sciences)

$M^{a}$ Victoria Gordillo Álvarez-Valdés (Universidad Complutense de Madrid)

Albert Gras (Universidad de Alicante)

Marina MaYoral (Universidad Complutense de Madrid)

Montserrat PaLAU (Universitat Rovira $i$ Virgili)

$M^{a}$ Dolores Ramos (Universidad de Málaga)

$M^{a}$ Dolores Reventós (Universidad de Murcia)

Carmen RIERA (Universitat de Barcelona)

Ana SÁnchez Torres (Universitat de València)

Begoña San Miguel Del Hoyo (Universidad de Alicante)

Marta Segarra (Universitat de Barcelona)

Cristina Segura Graiño (Universidad Complutense de Madrid)

Julia Sevilla (Universitat de València)

$M^{a}$ Carmen SIMÓN (CSIC)

Ruth Teubál (Universidad de Buenos Aires)

Meri TorRas (Universitat de Barcelona) 


\section{REDACCIÓN}

Centro de Estudios sobre la Mujer de la Universidad de Alicante

Campus de Sant Vicent del Raspeig

Apdo. 99 E-03080 Alicante

Tel. 965909415 - Fax 965909658

e-mail: cem@ua.es -web: http://www.ua.es/cem

\section{SUSCRIPCIÓN}

Centro de Estudios sobre la Mujer de la Universidad de Alicante

Campus de Sant Vicent del Raspeig

Apdo. 99 E-03080 Alicante

Tel. 965909415 - Fax 965909658

e-mail: cem@ua.es -web: http://www.ua.es/cem

Precio de cada ejemplar: $12 €$

Edita:

Centro de Estudios sobre la Mujer de la Universidad de Alicante con la colaboración del Vicerrectorado de Calidad y Armonización Europea

Revisión de los abstracts: Clive Bellis

Preimpresión e impresión:

\section{E Espagrafic}

ISSN: $1696-8166$

Depósito Legal: A-910-2003

Feminismo/s no se identifica necesariamente con los contenidos de los artículos firmados. Prohibida la reproducción total o parcial de los artículos sin la autorización previa. 


\section{ÍNDICE}

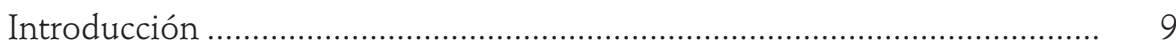

Nieves Montesinos Sánchez

\section{COLABORACIONES}

«Mujeres, Poder y Derecho».

Concepción Collado Mateo

«Género y ciudadanía, mujeres y Constitución».

$M^{a}$ del Mar Esquembre Valdés

«La igualdad entre mujeres y hombres en la Constitución española de 1978".

$M^{a}$ Ángeles Moraga García

«La tributación familiar»

María Teresa Soler Roch

«Notas sobre la configuración de las uniones de hecho en Roma»

Walenka Arévalo Caballero

«La filiación materna y paterna en el Derecho Islámico.

Derecho sustantivo y reformas en los sistemas jurídicos actuales».

$M^{a}$ Magdalena Martínez Almira

«La posición jurídica de la mujer a través de las reformas del Derecho de Familia».... 
"Conciliación de la vida familiar y laboral»....

Sol Ruiz de la Cuesta Fernández e Irene Bajo García

"Algunos aspectos procesales de la Ley Orgánica de medidas de protección integral contra la violencia de género»

Carmen Cuadrado Salinas y Mercedes Fernández López

«Matrimonio y homosexualidad».

Nieves Montesinos Sánchez

«Dilemas éticos sobre la reproducción humana. La gestación de sustitución»

Beatriz Souto Galván

Resúmenes

Abstracts 203

Reseña bio-bibliográfica de las colaboradoras del volumen 209

Normas editoriales de Feminismo/s 215 


\title{
INTRODUCCIÓN
}

NIEVES MONTESINOS SÁNCHEZ

Universidad de Alicante

\begin{abstract}
"La mujer nace libre y permanece igual al hombre en derechos»*
"Tenéis el derecho que os ha dado la ley, la ley que hicisteis vosotros, pero no tenéis el Derecho Natural, el Derecho fundamental que se basa en el respeto de todo ser humano, y lo que hacéis es detentar un poder; dejad que la mujer se manifieste y veréis cómo ese poder no podéis seguir detentándolo...»**.
\end{abstract}

Desde su creación en 1994 el Seminario Universitario sobre los Derechos de las Mujeres ha centrado su trabajo y estudio en los derechos de las mujeres, organizando diferentes cursos, jornadas etc., de debate y difusión para profesionales y alumnado ${ }^{1}$. Inicialmente se utilizó en el tratamiento de los temas una perspectiva interdisciplinar, para en los últimos años centrarnos en la dimensión jurídica, conscientes de la importancia de la misma, aunque sin renunciar por ello a incluir diferentes miradas.

Desde esta óptica, en el año 2004 y coincidiendo con la celebración del XXV aniversario de creación de la Universidad de Alicante y de su Facultad de Derecho, a la que el Seminario pertenece, entendimos interesante la realización

\footnotetext{
* Olympe de Gouges, 1791. Declaración de los Derechos de la Mujer y de la Ciudadana. "Defendí en las Cortes Constituyentes los derechos femeninos. Deber indeclinable de toda mujer que no puede traicionar a su sexo, si, como yo, se juzga capaz de actuación, en virtud de un sentimiento sencillo y de una idea clara que rechazan por igual: la hipótesis de constituir un ente excepcional, fenomenal; merecedor, por excepción entre las otras, de inmiscuirse en funciones privativas del varón, y el salvoconducto de la hetaira griega, a quien se perdonara cultura e intervención a cambio de mezclar el comercio del sexo con el espíritu» (Discurso).

** Discurso de Clara Campoamor en las Cortes Constituyentes el 1 de octubre de 1931.

1. De entre las realizadas, dos fueron objeto de publicación: MontesinOS, N.; ROMÁ, M.T. y CATALÁ, C. (eds.): Mujeres,Derecho y Salud, Alicante, Publicaciones de la Universidad de Alicante, 1998 y Romá Ferri, M.T.; Montesinos SÁnchez, N.; Ballester AÑón, R.; SeVilla Merino, J.; Romero lacasa, M.D.; Catalá Pérez, M.T.; Catalá Pérez, C. y García Martínez, T., (eds.): Derecho de las mujeres a su imagen. Los trastornos del comportamiento alimentario (anorexia y bulimia), Alicante, Publicaciones de la Universidad de Alicante, 2002.
} 
de un curso sobre Mujeres y Derecho en el que tuvieran cabida y participaran todas las áreas de conocimiento de la Facultad. Tarea que a muchos les pareció difícil y ardua inicialmente, pero que vivimos con ilusión como proyecto, y de manera muy gratificante cuando todas las áreas confirmaron su participación. La cuestión no era baladí o carente de importancia ya que, para nosotras, era necesario subrayar la envergadura del tema visibilizando las dos vertientes: la subjetiva y la objetiva.

Poco tiempo había transcurrido desde que celebramos los 25 años de la aprobación de la Constitución española, de modo que todo constituía el marco idóneo para, desde la totalidad de las diferentes disciplinas jurídicas, preguntarnos acerca del lugar, condición y poder de las mujeres en la sociedad y en la construcción y evolución del Derecho y por ende en la génesis y desarrollo de la democracia en España y, así analizar las cuestiones más problemáticas que las diferencias entre sexo y género producen en el ámbito jurídico y las soluciones en las actuales regulaciones de igualdad de sexos concebidas por los vigentes sistemas jurídico-políticos occidentales.

Aun cuando han sido muchas las modificaciones legislativas sobre la igualdad entre hombres y mujeres desde la Constitución de 1978, la realidad nos muestra que las diferencias de sexo y género producen desvíos significativos en la creación, interpretación y aplicación del Derecho, circunstancia que no se traduce en los planes de estudio. Las trabas de diferente naturaleza que impiden la inserción de asignaturas específicas de género o la adecuación de los programas a esa realidad, hacen necesarios -entendemos- cursos como el realizado, y muchos otros, para completar esta carencia en la formación universitaria y colmar esta laguna en la formación de quienes pretenden ser profesionales del Derecho. También publicaciones como la que ahora tiene en sus manos a fin de que el debate jurídico que a todas las personas afecta, trascienda en y más allá del ámbito estrictamente jurídico.

Mujeres y Derecho fue un curso y es hoy una publicación con la que queda constancia de que género y Derecho constituyen un binomio en permanente construcción que a todos atañe y más cuando se han cumplido recientemente tan sólo los 75 años de la aprobación del sufragio femenino en España.

En este número de la Revista Feminismo/s el tema que nos ocupa es objeto de estudio y análisis en diferentes artículos: La primera aportación, «Mujeres, Poder y Derecho", es obra de Concepción Collado Mateo. En ella la autora reflexiona, y nos invita a hacerlo, sobre cuáles son las causas que impiden todavía a las mujeres ejercer y disfrutar de los derechos que le están reconocidos por la Constitución y las leyes. Comienza por explicar qué significan las relaciones de poder social que denominamos relaciones de género, relaciones que todavía perviven, en la medida en que pervive la estructura patriarcal. Tras una somera exposición de las características de esa estructura y una breve definición de lo que denominamos relaciones de género y la posición de los varones y las mujeres en ellas, se da algún ejemplo de la construcción histórica del género, para detenerse por último, en una de las más graves manifestaciones de la desigualdad y discriminación que sufren las mujeres: la violencia de género. 
"Género y ciudadanía, mujeres y Constitución» es el título de la aportación realizada por $M^{a}$ del Mar Esquembre Valdés. La autora aborda el incompleto reconocimiento de las mujeres como sujetos de derechos y, por tanto, como ciudadanas plenas. Situándose en los orígenes del constitucionalismo realiza un repaso sobre la construcción del sujeto de derechos, del sujeto de la modernidad que será el protagonista del nuevo Estado. Así se inicia un recorrido por las transformaciones operadas sobre la moderna titularidad de la soberanía que culmina con los actuales textos constitucionales, en los que el principio de igualdad y los derechos definen a la ciudadanía contemporánea, desvelando una situación estructural de desventaja de las mujeres respecto de los hombres. Plantea el texto además las deficiencias de los modelos constitucionales del denominado Estado del Bienestar, analiza los intentos recientes de superación de estas deficiencias, no exentos de tensiones, de las dos últimas décadas y propone una revisión de los postulados constitucionales que, de un lado, permitan la definición de las mujeres como sujetos de derechos y, de otro, impidan regresiones o involuciones en los logros de la igualdad en el actual contexto de la globalización económica y el multiculturalismo.

Este primer bloque de estudios finaliza con el trabajo "La igualdad entre mujeres y hombres en la Constitución española de 1978", cuya autora es $\mathrm{M}^{a}$ Ángeles Moraga García. Aún cuando la igualdad entre mujeres y hombres es un valor, un principio y un derecho constitucionalmente reconocido en nuestro ordenamiento jurídico, la realidad viene a demostrar continuamente la persistencia de importantes escenarios de desigualdad por razón de género, que sitúan a las mujeres en una posición de desventaja, cuando no de clara inferioridad, frente a la de los hombres. Por ello, y partiendo de los antecedentes, la autora analiza el concepto de igualdad en la Constitución: igualdad ante la ley o en la aplicación de la ley; igualdad en la ley o igualdad de trato; igualdad y discriminación; tratamiento diferenciado y medidas de acción positiva; para finalizar con los recientes y significativos avances legislativos en materia de igualdad.

El siguiente estudio desarrolla la conferencia inaugural del curso: «La tributación familiar», realizado por María Teresa Soler Roch. Se aborda en él la evolución de la tributación familiar en el Derecho tributario español con referencia a la imposición directa: Impuesto sobre la renta de las personas físicas, Impuesto sobre el Patrimonio e Impuesto sobre Sucesiones y Donaciones. En los dos primeros se analiza el tratamiento de la unidad familiar desde la perspectiva de los principios constitucionales de capacidad económica e igualdad y las distintas reformas en el tratamiento de la unidad familiar como consecuencia de la jurisprudencia constitucional, tanto en el caso de la tributación conjunta como en el de la tributación separada y sus consecuencias en relación con el régimen económico del matrimonio en Derecho civil, el trabajo de la mujer, las deducciones por cargas familiares, las consecuencias fiscales de los procesos de separación y divorcio y la situación de los no residentes. Al tratar el Impuesto sobre Sucesiones y Donaciones, se alude a la situación de cónyuge, hijos y hay una especial referencia al problema de las parejas de hecho. 
A partir de aquí las siguientes colaboraciones constituyen otro bloque que va de lo general e histórico a lo particular y específico en las relaciones familiares y en el seno de las mismas. De la primera, "Notas sobre la configuración de las uniones de hecho en Roma», es autora Walenka Arévalo Caballero. En ella se subraya cómo las uniones de hecho, tanto en Roma como en la actualidad, se caracterizan por ser parejas estables y no de mera relación sexual que deben cumplir determinados requisitos, recogidos por la jurisprudencia, en los que se evita la voluntad de los convivientes de contraer matrimonio conforme a las normas del Ordenamiento jurídico. Por lo que se refiere a las uniones de hecho en Roma, se exponen, en primer lugar, las líneas generales de matrimonio romano, analizando, en segundo lugar, los hechos que dan lugar a la formación de uniones que no podían considerarse matrimonio, bien porque la Ley las prohibía, bien porque la voluntad de los contrayentes así lo estimaba. Finaliza el texto con una referencia a la Ley 1/2001, que regula las uniones de hecho en la Comunidad Valenciana, en la que se destacan los principios vigentes provenientes del Derecho romano.

La contribución de $\mathrm{M}^{a}$ Magdalena Martínez Almira versa sobre «La filiación materna y paterna en el Derecho Islámico. Derecho sustantivo y reformas de los sitemas jurídicos actuales». La autora llama la atención sobre la necesidad y obligación para el jurista, en un asunto absolutamente actual, de conocer las instituciones que en el Derecho europeo comprende el Derecho de familia cuando nos encontramos ante demandas de separación y divorcio entre personas que han contraído matrimonio mixto con musulmanes, así como las demandas respecto a la filiación y otras medidas en matrimonios entre musulmanes. Se subraya cómo la determinación de la filiación de los hijos habidos dentro y fuera de estos matrimonios plantea ante la Administración de justicia española cuestiones diversas, teniendo en cuenta la pluralidad legislativa que engloba lo que generalmente se conoce como Derecho Islámico. La presunción de paternidad, su reconocimiento y los derechos y deberes inherentes a los padres son objeto de revisión y adecuación a las exigencias actuales en virtud de supuestos legales.

El siguiente estudio, "La posición jurídica de la mujer a través de las reformas del Derecho de Familia", corresponde a María Luisa Vallés Amores. En él expone, dentro del contexto del Derecho Civil y concretamente en el ámbito del Derecho de Familia, el desarrollo evolutivo de la situación jurídica de la mujer, con independencia de su situación matrimonial, desde la redacción originaria del Código civil. El sexo ha sido considerado tradicionalmente como una de las causas modificativas de la capacidad de obrar, en el sentido de que las diferencias existentes entre el hombre y la mujer hacían aconsejable restringir la libre iniciativa de esta última. La consecuencia de ello se tradujo en que la redacción originaria del Código civil de 1889 reflejaba algo tan evidente como que durante siglos la mujer ha desempañado un papel secundario en la sociedad y que dicha realidad ha sido siempre objeto de diverso tratamiento por las normas jurídicas. Con la Constitución de la Segunda República se abre un período alentador al sentar como principio a desarrollar la igualdad entre ambos sexos, 
siendo objeto de consideración expresa en diversos artículos. Y si bien durante el régimen del general Franco las circunstancias sociológicas van determinando una nueva legislación tendente a abolir las discriminaciones más evidentes entre el hombre y la mujer, la evolución hacia una consideración más igualitaria entre la mujer y el varón parece iniciarse en la década de los años setenta, subrayando la autora las transformaciones legales que llegan hasta nuestros días.

La aportación de las profesoras Sol Ruiz de la Cuesta Fernández e Irene Bajo García versa sobre la "Conciliación de la vida familiar y laboral». El proceso de incorporación de la mujer al trabajo en nuestro país ha tenido lugar en los últimos años, aumentando de forma creciente el número de mujeres trabajadoras por cuenta ajena. Sin embargo, no se ha producido, con carácter general, un paralelo proceso de incorporación del hombre a las tareas domésticas, incluyendo como tales las de cuidado de hijos y personas dependientes. Así, la mujer trabajadora con responsabilidades familiares se encuentra en una clara situación de desventaja. Desde el ordenamiento jurídico laboral se arbitran una serie de medidas legales que tienden, precisamente, a mejorar la posición de la mujer en el binomio trabajo-familia. El objetivo de este estudio es el de valorarlas, a fin de poder concluir si son realmente eficaces $y$, en su caso, identificar las razones por las que resultan escasamente operativas. A este respecto señalan las autoras diferentes propuestas que abren la puerta a una más real y eficaz conciliación entre vida familiar y laboral.

La violencia de género desde el ámbito procesal es objeto del estudio: «Algunos aspectos procesales de la Ley Orgánica de medidas de protección integral contra la violencia de género", cuya autoría corresponde a Carmen Cuadrado Salinas y Mercedes Fernández López. En este trabajo las autoras analizan dos de los aspectos más interesantes - pero quizás por ello también más polémicos- que aborda la Ley Orgánica 1/2004, de 28 de diciembre, de medidas de protección integral contra la violencia de género: la creación de los Juzgados de Violencia sobre la Mujer y la regulación de la orden de protección de las víctimas de malos tratos. En el primero, se parte del enfoque constitucional, para seguidamente prestar especial atención a su configuración legal, deteniéndose tanto en el examen de la competencia objetiva y funcional, como en la territorial. En el segundo, tras los aspectos generales, se estudian las medidas cautelares penales, mereciendo un apartado específico la eficacia de la medida de alejamiento. Se trata, en suma, de dos instrumentos claves en la lucha jurídica contra el fenómeno cada vez más preocupante de la violencia sobre las mujeres.

La problemática suscitada acerca del acceso al matrimonio de personas del mismo sexo constituye el eje central de mi aportación: «Matrimonio y homosexualidad». En este estudio, y partiendo del análisis de las proposiciones y proyectos presentados por los grupos parlamentarios para regular las uniones de hecho en el ámbito nacional -tanto homosexuales, como heterosexuales-, se analizan las actuaciones y demandas de los colectivos homosexuales: reivindicaciones, ley 'de máximos'/ley 'de mínimos', entre otras. Y se ponen finalmente sobre el tapete los temas que continúan abiertos o que todavía son objeto de 
debate político, social y jurídico, fundamentalmente: el modelo matrimonial y familiar, la adopción, la objeción de conciencia, y el futuro pronunciamiento del Tribunal Constitucional ante el recurso presentado por el Partido Popular.

Y, por último, Beatriz Souto Galván nos presenta una contribución sobre una temática actual y controvertida: «Dilemas éticos sobre la reproducción humana. La gestación de sustitución». Los avances científicos en el campo de la genética y de la biología han obligado al legislador a adoptar soluciones jurídicas concretas, generalmente partiendo de determinados criterios éticos que, en ocasiones, entran en conflicto con la ética individual o libertad de conciencia. Una de estas cuestiones es la llamada "gestación de sustitución", que ha suscitado un intenso debate en el ámbito social, ético y jurídico, que continúa vigente porque en la práctica seguimos encontrando casos que generan conflictos, de difícil solución, y que revelan, sin duda, la complejidad de este fenómeno. Expuestos los términos del conflicto, la autora concluye que, en todo caso, el derecho a procrear de la pareja o persona comitente podría quedar limitado por la protección de la dignidad de la mujer gestante, dignidad que sí sería vulnerada en los supuestos en los que la gestación se comercialice. En su opinión, la libertad de disposición del cuerpo no puede incluir la comercialización del proceso generativo, sometiendo la voluntad de la mujer a cláusulas limitativas de su libertad respecto al desarrollo del proceso gestacional y de las decisiones que deba tomar respecto al feto mientras dure la gestación. En caso contrario, cuando la gestación no posee finalidad lucrativa la respuesta al conflicto difiere, porque la gratuidad de la prestación y la libertad de la mujer en el proceso gestación impediría su cosificación, y, por tanto, la vulneración de su dignidad, dejando de suponer un límite para el ejercicio de la libertad de autodeterminación de la gestante.

Para concluir, a todas, nuestro reconocimiento por su colaboración, así como a cuantos profesionales participaron en su día y a los que diferentes compromisos u obligaciones han impedido que sus ponencias quedaran reflejadas en esta publicación. Agradecimiento que hacemos extensivo a cuantas personas e instituciones hicieron posible la realización de un curso tan significativo como el de Mujeres y Derecho.

Y por último, quisiera dejar constancia y agradecer también el trabajo realizado por las evaluadoras, trabajo que no siempre se visibiliza pero que es absolutamente imprescindible, y necesario para lograr los índices de calidad requeridos. En esta ocasión y dada la temática objeto del volumen ha sido realizado por profesionales expertas en género, la mayoría pertenecientes a la Red Feminista de Derecho Constitucional ${ }^{2}$.

2. Constituida en la Sede de Biar de la Universidad de Alicante, en julio de 2004. 


\title{
MUJERES, PODER Y DERECHO
}

\author{
CONCEPCIÓN COLLADO MATEO \\ Abogada, Profesora Asociada de Derecho Constitucional \\ Universidad de Alicante
}

\begin{abstract}
«En todas las partes del globo el colectivo de mujeres permanece bajo el poder simbólico y real del colectivo completo de los varones...las mujeres detentan menos de un uno por ciento de la riqueza total del planeta, menos de un uno por ciento de los puestos de decisión política, prácticamente no cuentan siquiera como mano de obra en ningún cómputo del PIB, y ello a pesar de que desarrollan la mayor parte del trabajo, forman la mayor parte de la infraestructura administrativa de un tipo peculiar de puestos políticos (alta responsabilidad, baja capacidad de decisión) y, en este momento, al menos en algunos países, tiene por lo general, en los estratos de edad medios e inferiores, una educación igual o superior a la de los varones. Y, como escribía Concepción Arenal, son el colectivo menos problemático, menos conflictivo desde el punto de vista social y penal, y que, por el contrario, la gran parte de la masa de delitos se comete precisamente contra ellas.»
\end{abstract}

Amelia Valcárcel

\section{LOS DERECHOS DE LAS MUJERES}

La Declaración Universal de los Derechos Humanos de noviembre de 1948 significó el unánime y universal reconocimiento de que «todos los seres humanos nacen libres e iguales en dignidad y derechos» $y$, en consecuencia, prohibió globalmente la discriminación. La Asamblea General de las Naciones Unidas, consciente de la importancia capital de la lucha por la igualdad, desde el principio centra la actividad en defensa de los derechos humanos en este objetivo, mediante normas e instrumentos de acción, destacando los instrumentos para la eliminación de la discriminación por razón de raza y sexo.

Sin embargo, para la efectividad de esos derechos y para el concepto mismo de igualdad seguimos encontrando deficiencias y demasiados obstáculos como 
la explotación, la marginación y la exclusión de multitud de seres humanos por otros y con distintas formas de discriminación, que se manifiesta especialmente en el trato de inferioridad a una persona o colectivo (raza, sexo, nacionalidad, otros), por su pertenencia a ese colectivo; en tratar desigualmente y de forma perjudicial a un individuo por su pertenencia a un grupo determinado o tratar negativamente al colectivo mismo, colectivo cuya esencia se basa en la posesión por parte de sus miembros de una característica concreta de la cual ellos no son responsables en absoluto -sexo, raza, origen nacional- o que deriva del ejercicio por su parte de un derecho fundamental personalísimo, como la libertad religiosa o la de afiliación política o sindical ${ }^{1}$.

Por ello, para que tal reconocimiento universal de derechos no quede en una proclamación abstracta, no pueden desconocerse las situaciones reales en las que las personas, los sujetos de derecho, se encuentran y les permiten existir como tales, como la raza, el sexo, la posición social o la lengua, y que todos los seres humanos tienen todos los derechos y libertades declarados «sin distinción de cualquiera otra condición».

Los sujetos de los derechos proclamados, hombres y mujeres, no son seres abstractos supuestamente iguales sino que son personas en unas condiciones reales, estructurales, que hay que tener en cuenta para que efectivamente puedan ejercer y disfrutar de esos derechos.

De las condiciones reales de algunas de esas personas, las mujeres, es a las que nos vamos a referir pues, aunque podamos y debamos prestar atención a otras manifestaciones de desigualdad y discriminación, la lucha más importante contra la discriminación sigue planteada en la discriminación de las mujeres que la sufren en todos los ámbitos con independencia (o además) de su raza, religión, pensamiento o posición social.

El argumento propuesto en la Conferencia Mundial de los Derechos Humanos de Viena de 1993 y recogido en la Conferencia de Beijing, «los derechos de las mujeres son derechos humanos» no es una reiteración inútil ${ }^{2}$, sino un mensaje necesario porque las mujeres necesitan ser reconocidas por sí mismas con su propia historia, como sujetos de derecho, en la medida en que, determinadas estructuras, como las relaciones de género, siguen actuando en la realidad del disfrute de los derechos y en la visión pretendidamente universal de los derechos humanos.

\section{LOS OBSTÁCULOS DE LAS MUJERES}

La Constitución Española de 1978 proclama que «la dignidad de la persona y los derechos inviolables que le son inherentes son el fundamento del orden

1. MARTín VIDA, María Ángeles: Fundamento y límites constitucionales de las medidas de acción positiva, Madrid, Cívitas, 2002, p. 56.

2. LUCAS, Javier de: "La lucha contra la discriminación", en Consolidación de derechos y garantías: los grandes retos de los derechos humanos en el siglo XXI (Seminario conmemorativo del 50 aniversario de la Declaración Universal de los Derechos Humanos), Madrid, Consejo General del Poder Judicial, 1999, pp. 143-162. 
político y la paz social», reconoce el derecho a la igualdad y prohíbe la discriminación, por «razón de nacimiento, raza, sexo, religión, opinión o cualquiera otra condición o circunstancia personal o social», derechos que tutelan, entre otros instrumentos, todos los órdenes jurisdiccionales y el Tribunal Constitucional. Así mismo, consciente la Constitución de que hay obstáculos para la igualdad, ordena a los poderes públicos «promover las condiciones para que la libertad y la igualdad sean reales y efectivas y remover los obstáculos que impidan o dificulten su plenitud».

Pero cabe que nos preguntemos ¿los obstáculos son los mismos para las mujeres que para los hombres?

Con frecuencia, cuando las mujeres reivindican sus derechos, que se les haga Justicia, se argumenta que en el ordenamiento jurídico español no existe ya un solo precepto jurídico que las limite y que nada les impide exigirlos a los poderes públicos y a la administración de justicia.

Sobre la primera afirmación podríamos estar de acuerdo pues, efectivamente, desde la Constitución, e incluso durante la transición, a partir de los años ochenta se acometieron importantes transformaciones en el ordenamiento jurídico español que empezaron a eliminar las leyes que trataban a las mujeres de manera discriminatoria, fruto, sin duda, de los cambios sociales que se habían ido produciendo y de la propia realidad de la progresiva incorporación de la mujer al trabajo fuera del hogar y otros aspectos de la vida pública, además del cambio cultural y legal, el de la Constitución democrática.

Sin embargo, podemos preguntarnos por qué las mujeres, que constituyen más de la mitad de la población mundial, hasta hace bien poco, y en algunos lugares, en muchos del mundo, así continúa, es esa gran mayoría invisible, en inferioridad, sin poder real en la sociedad, "el grupo mayoritario no representado en el poder» ${ }^{3}$; por qué precisamente ahora cuando las mujeres están más preparadas que nunca y han demostrado que son capaces de hacer cualquier trabajo o desempeñar cualquier función (hacer la «doble jornada») y, se supone, que pueden controlar la natalidad, siguen ostentando un menor nivel de empleo, las profesiones mayoritariamente ocupadas por mujeres son en categorías inferiores, con dificultades de promoción, menor salario, o en trabajos a tiempo parcial, pues son ellas las que deben seguir ocupándose de los hijos y personas mayores; por qué su escasa representación en puestos de dirección o representación política, por no contar la violencia contra las mujeres, que ahora se manifiesta más terriblemente, si cabe. La tradicional inferioridad de los salarios de las mujeres (femeninos) y las dificultades para su promoción, son un ejemplo que evidencia la menor valoración social del trabajo de las mujeres y, en último término, de la mujer misma.

Por esto, sobre la segunda afirmación de que nada impide que las mujeres puedan ejercer y demandar sus derechos, debemos reflexionar sobre cuáles son

3. VALCÁRCEL, Amelia: «Feminismo y poder político», Foro Internacional "Mujer, Poder Político y Desarrollo", Madrid, Ministerio de Asuntos Sociales/Instituto de la Mujer, 1994, p. 44. 
las circunstancias que impiden o dificultan que las mujeres, ya en el siglo XXI, puedan, efectivamente, gozar de aquellos derechos que, formalmente, les están reconocidos por la Constitución y las leyes.

Para esta reflexión partamos también de afirmar que, ni la Constitución, ni las leyes, por sí solas, cambian los comportamientos, aunque efectivamente den cuenta también de los cambios sociales que se van produciendo; si tenemos en cuenta, además, que, durante mucho tiempo, demasiado, el derecho, las leyes, han expresado y legitimado la desigualdad entre los seres humanos y más específicamente, la desigualdad y discriminación de las mujeres en todos los ámbitos. Afirmemos, así mismo, que, a pesar de estar plenamente conseguida la igualdad formal y las indudables transformaciones legales, sociales y culturales, la situación de subordinación y exclusión que han padecido las mujeres en todos los tiempos, como consecuencia de estructuras discriminatorias, y la pervivencia, cuando no perpetuación, de determinados roles tradicionales junto a la perenne infravaloración de la actividad femenina, limitan en la práctica la capacidad de las mujeres para ejercitar plenamente y en igualdad con los varones, los derechos fundamentales de las que son titulares ${ }^{4}$.

Esta limitación de las mujeres para ejercer sus derechos no sólo es un atentado a los derechos fundamentales, humanos, sino un atentado a los principios esenciales del Estado social y democrático de Derecho, que pone en evidencia la insuficiencia de la visión formalista del derecho a la igualdad y la necesidad de remover los obstáculos que impiden y dificultan su plenitud, mediante instrumentos para la igualdad material, como las medidas de acción positiva, las leyes de igualdad u otros, que permitan el cumplimiento de los fines constitucionales.

Por último, para esta reflexión, conviene recordar que las mujeres no sólo han tenido y tienen que reivindicar sus derechos, sino que son las mujeres las que tuvieron y tienen que seguir estudiando cuáles eran las estructuras sociales, económicas, psicológicas y políticas que las había marginado y excluido y que siguen originando y reproduciendo su falta de poder y la subordinación.

\section{LAS ESTRUCTURAS DE DISCRIMINACIÓN}

Las distintas estructuras económicas, sociales e ideológicas han determinado históricamente que personas o grupos de personas hayan estado o estén discriminadas (marginadas o en desventaja) por su pertenencia (activa o no, consciente o no) a un cierto colectivo configurado por la posesión de sus componentes de un rasgo inmutable (sexo, raza) e íntimamente ligado, en tanto que definitorio de su identidad, a su dignidad de ser humano.

Como señala Martín Vida, lo que define los fenómenos de discriminación es, precisamente, que la marginación obedece a que el colectivo, definido por la posesión de sus miembros de ese rasgo inmutable, que por sí mismo no

4. MARTín Vida, María Ángeles: Op. cit., p. 22. 
determinaría inferioridad de las personas que lo poseen, ha sido o es objeto de discriminación que acaba alcanzando carácter estructural.

Esta discriminación estructural alcanza, en mayor o menor medida, a todos los miembros del grupo y, de una manera u otra, condena a esos colectivos y sus miembros a la subordinación y a que queden en una real situación de desventaja frente a los miembros del colectivo dominante ${ }^{5}$.

Si bien la prohibición de discriminación por razón de sexo en nuestro ordenamiento jurídico protege tanto a los hombres como a las mujeres (comprendida también la libertad de opción sexual), la historia real de la discriminación por razón de sexo es la discriminación de las mujeres, dentro de la cual se enmarca la violencia que se ejerce contra las mismas, una de cuyas fatales expresiones es la violencia contra las mujeres en el ámbito familiar.

El Tribunal Supremo vino a señalar que «... la discriminación por razón de sexo comprende aquellos tratamientos peyorativos que se fundan, no sólo en la pura y simple constatación del sexo de la víctima, sino en la concurrencia de razones y circunstancias que tengan en el sexo de la persona una conexión directa e inequívoca» (STS 136/1996, de 23 de julio).

\subsection{La dominación de las mujeres}

Tras estudio de las diferentes estructuras sociales históricas, podemos constatar que, en función de variados elementos, en todas las sociedades se ha producido la dominación de unas personas sobre otras, de unos grupos sobre otros, que conformaron unas relaciones de poder y distintos modos de dominación, manifestación o expresión de la desigualdad social.

Junto a las distintas formas de dominación de unos hombres sobre otros, de unos grupos sobre otros, observamos la dominación de todos los hombres sobre todas las mujeres: el feminismo recuperó el término patriarcado ${ }^{6}$, para definir el sistema completo de poder, dentro del cual las mujeres habían de moverse en una posición sistemáticamente minorizada ${ }^{7}$ y que, como estructura político-social que valora a los hombres más que a las mujeres ${ }^{8}$, ha pervivido y todavía pervive.

Tal dominación no pudo y no puede mantenerse sino mediante elementos consensuales, pues toda relación de poder necesita para mantenerse de una justificación, de una legitimación: la creencia, de quien obedece, en que, quien manda, tiene derecho a hacerlo.

Desde sus orígenes, la dominación sobre las mujeres se justifica, en su supuesta naturaleza inferior y su vinculación «natural» al espacio privado-doméstico, crianza de los hijos y cuidado de los demás, división sexual del trabajo, con exclusión de las mujeres de la esfera pública. Se crean así, un tipo de relaciones,

5. Ibíd., p. 56.

6. Para el estudio del patriarcado, una referencia fundamental es la de Celia Amorós: Hacia una crítica de la razón patriarcal, Barcelona, Anthropos, 1985.

7. VALCÁRCEL, Amelia: Op.cit., p.45.

8. WEST, Robin: Género y teoría del derecho, Santafé de Bogotá DC, Ediciones Uniandes, p. 74. 
entre hombres y mujeres, diferentes: desiguales y asimétricas; jerárquicas: superioridad masculina, inferioridad femenina; excluyentes: a las mujeres se les define por exclusión.

Se subordina lo femenino a lo masculino: la mujer sometida al varón en todos los ámbitos, tanto en la esfera privada (al padre, al marido) como en la pública, de la que se la excluye, y se produce la valoración social de lo masculino e infravaloración de lo femenino.

Históricamente, la filosofía y la religión han sido elementos fundamentales de justificación y legitimación del poder, pero la forma más efectiva y practica de imponerse ha sido mediante el derecho, las normas jurídicas.

No se trata ahora de detenernos en el estudio de las normas jurídicas, lo que por otra parte corresponde a la teoría del derecho, pero sí de recordar que, con el derecho, los seres humanos han pretendido regular las relaciones de poder e intereses sociales, promoviendo algunos y prohibiendo otros y que lo que distingue a las normas jurídicas de otras normas de comportamiento colectivo, en su función de articulación y regulación de las relaciones sociales, es que no sólo han sido y son una manifestación de los poderes sociales existentes en cada estructura social histórica, sino que ellas mismas configuran relaciones de poder y estructuras de poder pues otorgan a ciertos individuos o grupos la capacidad de afectar a los intereses de otros individuos y grupos?.

Como señala la crítica feminista a la teoría del derecho, el derecho, como producto de las sociedades patriarcales, ha sido construido desde el punto de vista masculino y por eso refleja y protege sus valores y atiende a sus necesidades e intereses y se ha mostrado que, incluso cuando el derecho protege a los intereses y necesidades de las mujeres e introduce su punto de vista, en su aplicación por instituciones e individuos, moldeados por la ideología patriarcal, ha desfavorecido a las mujeres ${ }^{10}$. Baste señalar, a pesar de que las distintas formas de violencia contra las mujeres están penalizadas, los márgenes amplísimos todavía de impunidad y cómo, siempre a las mujeres, se les exige la prueba de su actuación correcta.

En 1998, la Asamblea General de las Naciones Unidas instó a los gobiernos a que "examinen o evalúen su legislación, principios, procedimiento y prácticas legales vigentes en materia penal (....) a fin de determinar si tienen un efecto negativo para la mujer y, de ser así, los modifiquen para que la mujer reciba un trato imparcial en la justicia penal».

\subsection{La discriminación por razón de sexo: las relaciones de género}

Desde las teorías feministas se resalta que lo que caracteriza al patriarcado es que es una constante social hondamente arraigada y que se ha manifestado y se

9. AtienZa, Manuel y Ruiz Manero, Juan: Las piezas del Derecho. Teoría de los enunciados jurídicos, Barcelona, Ariel, 1996.

10. JARAMILLO, Isabel Cristina: "La crítica feminista al derecho», estudio preliminar a WeST, Robin: Op. cit., p. 52. 
manifiesta en todas las formas políticas, sociales y económicas, aunque muestre variaciones tanto históricas como geográficas, pues se ha demostrado funcional a todos los modos de producción y sistemas de dominación que tiene sus orígenes, como ya apuntara Engels ${ }^{11}$, en la necesidad de apropiación y control de la fuerza de trabajo humana $y$, especialmente de las mujeres como productoras y reproductoras de esa fuerza de trabajo.

El sistema patriarcal crea y justifica una esfera diferente para las mujeres, y crea un patrón de dominación y superioridad masculina / sumisión e inferioridad femenina; la mujer, todas las mujeres, sometidas a varón tanto en la vida privada, designadas en su función social de esposa y madre, como en la pública, sometida a todo tipo de limitaciones y exclusiones; esferas diferentes para hombres y mujeres que refuerzan la falta de poder de las mismas y su sumisión a la dominación y supone la creación de dos espacios: público y privado-doméstico y la creación de dos arquetipos: viril y femenino.

La esfera de lo público reservada a los varones entendida como aquélla que se desarrolla fuera del entorno familiar y del que quedan excluidas las mujeres, a la que se le asignan las funciones del trabajo fuera del hogar, de la organización familiar y de la organización social, tanto a nivel ideológico como político y la esfera privada-doméstica reservada (recluidas) a las mujeres entendida como aquélla que se desarrolla en el ámbito familiar "de puertas adentro», a la que se le asignan el cuidado de la casa, la prole, esposo, ancianos.

Para cumplir la función que se les ha asignado, a cada uno de los sexos se les atribuyen características (cualidades y valores distintos, pautas de comportamiento), las más idóneas, para cumplir dicha función:

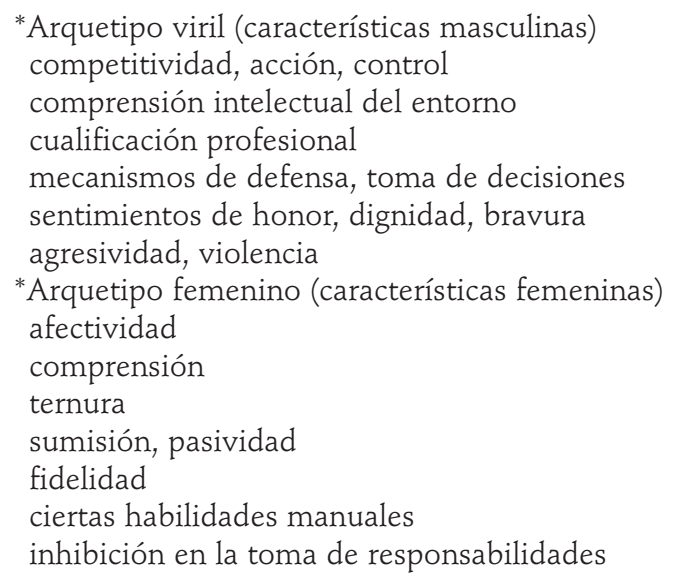

Se produce así la institucionalización de esas relaciones sociales cuando se definen y estabilizan esos modelos de comportamiento y su función; cultural e históricamente, se construyen un tipo de relaciones sociales entre hombres y

11. ENGELS, Federico: El origen de la familia, la propiedad privada y el Estado, Madrid, Ayuso, 1970. 
mujeres, en donde se produce la confusión entre sexo y género, entre naturaleza y cultura.

Modelos, pautas, valores y estereotipos sociales y culturales admitidos, cuando no potenciados, en nuestras sociedades y en los que, de un modo u otro, todos y todas seguimos participando.

Las relaciones sociales que este sistema de poder crea es lo que denominamos relaciones de género, término con el que designamos a las relaciones sociales entre hombres y mujeres construidas cultural e históricamente en todos los ámbitos y que han dado lugar a unos modelos determinados de feminidad y masculinidad.

Mientras sexo sería el término para aludir a las diferencias biológicas relacionadas con la reproducción y otros rasgos fisiológicos entre los seres humanos, género se referirá a las características que socialmente se atribuyen a las personas de uno y otro sexo, masculino y femenino ${ }^{12}$; características que suponen cualidades y funciones desiguales, jerarquizadas y excluyentes y que han supuesto discriminación, infravaloración y subordinación en todos los ámbitos.

Las mujeres, ignoradas como sujeto histórico y como sujeto de derechos, a partir del período de entreguerras, empiezan a incorporarse al trabajo fuera del hogar, a la educación y a la cultura y, tras la primera oleada del movimiento feminista, junto con las primeras conferencias internacionales sobre mujeres celebradas en los años setenta, aparecen los primeros estudios de género.

Desde la perspectiva de género es desde la que deberemos afrontar el análisis de cómo se justifica la desigualdad e inferioridad de las mujeres a lo largo de la historia y de cómo se institucionaliza su papel minorado y subordinado en las distintas estructuras sociales históricas, que nos permita comprender las dificultades de las mujeres para ejercer sus derechos.

\section{ALGUNOS EJEMPLOS}

En las culturas primitivas, en función de la supervivencia y reproducción, con escasa división del trabajo, las relaciones de dominación son inexistentes o son muy difusas y no institucionalizadas. Es con el patriarcado, cuando se inicia el control de la naturaleza, de la acumulación y de la propiedad, lo que supone la necesidad de controlar la fuerza de trabajo ajena (de unos y otras) y de quienes la producen (las mujeres), a la vez que se inicia la conformación de las relaciones de poder y la ideología.

La pieza fundamental de la estructura social de poder es la familia y el matrimonio $($ mater $/$ matris = madre y manu = poder $)$, que asocia a un hombre con una o varias mujeres, y que se convierte en una de las instituciones básicas por su utilidad social, económica y jurídica: para la procreación y control de la misma, la legitimidad de la descendencia y la subordinación de la mujer al hombre, junto con la legitimación de la poligamia, la repudiación, las concubinas.

12. JARAmillo, Isabel Cristina: Op. cit., p. 29. 
No podemos repasar ahora la historia de la humanidad y de la construcción del género a lo largo de la misma, por lo que sólo señalaré, brevemente, algún ejemplo de quienes han sido fundamentales, para la explicación y justificación de las relaciones de poder sociales y políticas, en la historia del pensamiento occidental, del pensamiento masculino.

Si nos remontamos al origen de nuestra cultura, en la Grecia antigua, el modo de producción dominante, el esclavismo, desarrolló unas relaciones de poder sociales y políticas que además de excluir de la participación política, de la ciudadanía, a multitud de varones, excluía a todas las mujeres. Los varones podían ser esclavos, no esclavos, propietarios y, unos pocos, propietarios ciudadanos; las mujeres todas trabajan y paren, las no esclavas trabajadoras eran mano de obra barata, como recomendaban Hesíodo o Aristóteles, y las del grupo de varones dominante, tenían que llevar la casa, supervisar a los esclavos y esclavas, y realizar el trabajo tradicional de hilar y tejer, pero ninguna era ciudadana; el grupo de varones dominante que se libera de los trabajos más duros y manuales, excepto la guerra, y les permite ejercer «el supremo bien» de la filosofía; poseen el poder y construyen la ideología, la política y desprecian y minusvaloran el trabajo manual y de todo lo relacionado con é $1^{13}$.

Demóstenes lo resume muy bien en su obra Contra Nerea «Nosotros tenemos cortesanas para el placer, concubinas para el cuidado diario del cuerpo, y esposas para criar hijos legítimos y ser guardianas fidedignas de confianza de las posesiones de puertas a dentro".

No obstante, es Aristóteles el que nos explica con claridad la funcionalidad del sistema de género para el concreto modo de producción existente y en su obra Política expresa las virtudes que cada cual debe poseer, en virtud de la función asignada en la estructura social, determinada fundamentalmente por el esclavismo.

En el Libro Primero, que trata de la sociedad civil, de la esclavitud, de la propiedad y del poder doméstico, en el Capítulo I, Origen de estado y de la sociedad, leemos:

"La naturaleza, teniendo en cuenta la necesidad de la conservación, ha creado a unos seres para mandar y a otros para obedecer. Ha querido que el ser dotado de razón y de previsión mande como dueño, así como también que el ser capaz por sus facultades corporales de ejecutar las órdenes, obedezca como esclavo, y de esta suerte el interés del señor y del esclavo se confunden. La naturaleza ha fijado, por consiguiente, la condición especial de la mujer y la del esclavo. (...) En la naturaleza un ser no tiene más que un solo destino, porque los instrumentos son más perfectos cuando sirven, no para muchos usos, sino para uno solo. Entre los bárbaros, la mujer y el esclavo están en una misma línea, y la razón es muy clara; la naturaleza no ha creado entre ellos un ser destinado a mandar (...)».

13. MORENO MARIMÓN, Montserrat: «Educación y ciencia: Una doble encrucijada», en Del silencio a la palabra. Coeducación y reforma educativa, Madrid, Ministerio de Asuntos Sociales, Instituto de la Mujer, 1992, pp. 10-34. 
En el Capítulo V, Del poder doméstico, dice:

«(...) la administración de la familia descansa en tres clases de poder: el del señor, el del padre y el del esposo. Se manda a la mujer y a los hijos como seres igualmente libres, pero sometidos, sin embargo, a una autoridad diferente, que es republicana respecto de la primera y regia respecto de los segundos. El hombre, salvo algunas excepciones contrarias a la naturaleza, es el llamado a mandar más bien que la mujer, así como el ser de más edad y de mejores cualidades es el llamado a mandar al más joven y aún incompleto. La naturaleza ha creado en [el alma] dos partes distintas: la una destinada a mandar, la otra a obedecer, siendo sus cualidades bien diversas, pues que la una está dotada de razón y privada de ella la otra. Esta relación se extiende evidentemente a los otros seres, y respecto de los más de ellos la naturaleza ha establecido el mando y la obediencia. Así, el hombre libre manda al esclavo de muy distinta manera que el marido manda a la mujer y que el padre al hijo; $y$, sin embargo, los elementos esenciales del alma se dan en todos estos seres, aunque en grados muy diversos. El esclavo está absolutamente privado de voluntad; la mujer la tiene, pero subordinada; el niño sólo la tiene incompleta. Lo mismo sucede necesariamente respecto de las virtudes morales. Se las debe suponer existentes en todos estos seres, pero en grados diferentes, y sólo en la proporción indispensable para el cumplimiento del destino de cada uno de ellos. El ser que manda debe poseer la virtud moral en toda su perfección. Su tarea es absolutamente igual a la del arquitecto que ordena, y el arquitecto en este caso es la razón. En cuanto a los demás, deben estar adornados de las virtudes que reclamen las funciones que tienen que llenar. Reconozcamos, pues, que todos los individuos de que acabamos de hablar tienen su parte de virtud moral, pero que el saber del hombre no es el de la mujer, que el valor y la equidad no son los mismos en ambos, como lo pensaba Sócrates, y que la fuerza del uno estriba en el mando y la de la otra en la sumisión».

Por último, en su obra Metafísica, nos dice que "las hembras son por naturaleza más débiles y más frías, y hay que considerar su naturaleza como un defecto natural».

En el desarrollo de esta estructura político-social, la ideología y las estructuras jurídicas fueron atribuyendo a las mujeres, en su función fundamental de esposa y madre, un status diferente al de los varones y basado en principios del Derecho Romano, cristaliza en una discriminación por razón de sexo, que hacía a las mujeres de peor condición que los hombres, justificada en una supuesta debilidad y simpleza del sexo femenino.

Esta tradición, enlaza con la tradición judeo-cristiana y, en la Edad Media, en lo que se conoce por "La querella de las mujeres» los hombres de prestigio, religiosos, académicos y magistrados, discutían sobre la valía de las mujeres. De secretis mulierum (Sobre los secretos de las mujeres), libro anónimo compuesto en latín a finales del siglo XIII, se convirtió en un clásico de la misoginia bajomedieval.:

«...las mujeres están tan llenas de veneno en el tiempo de su menstruación que ellas envenenan animales con su mirada; infectan a los niños en sus cunas; ensucian el más limpio de los espejos; y cuandoquiera que los hombres tienen contacto sexual con ellas se convierten en leprosos y a veces cancerosos. Y porque un demonio no puede ser evitado a menos que sea conocido, aquellos que quieran evitarlo deben 
abstenerse de este coito impuro, y de muchas otras cosas que son enseñadas en este libro».

En el momento de aparición del Estado, como nueva forma de organización política que se impondrá con el desarrollo del capitalismo, en los siglos XVI y XVII, los discursos sobre el nuevo poder político de sus más destacados representantes, son discursos excluyentes. Así, uno de los representantes más notables de la teoría del estado y formulador de la doctrina moderna de la soberanía, Bodino, define a la República (que equivale aquí al Estado: la cosa pública, la riqueza común), como «el recto gobierno con poder soberano de varias familias y de lo que les es común" y al presentar a un estado protagonizado por el monarca, nos dice que "va en contra de la naturaleza que gobiernen las mujeres»; Bossuet, uno de los más destacados defensores de la teoría providencialista de justificación del poder absoluto del monarca, señala que «la institución monárquica, que es la forma más antigua y natural (del pueblo elegido)...que se perpetúa hereditariamente a través de la primogenitura ...excluidas las mujeres...cuyo sexo ha nacido para la obediencia pues cada mujer al casarse se da un dueño", justificando así ambos la Ley de sucesión a la corona francesa que prohibía a las mujeres ocupar el trono.

Ya en el siglo XVIII, con el liberalismo y las revoluciones burguesas, las mujeres quedan excluidas de las Declaraciones de Derechos, manifiestos básicos del liberalismo; del constitucionalismo, como modo de limitar el poder político $y$ de la idea del pacto o contrato entre los hombres, como origen y justificación de ese poder, de la racionalidad, en definitiva, así como del concepto de ciudadanía que se va desarrollando y de los derechos que ella comporta. Baste el ejemplo de Rousseau, supuestamente paradigma de la democracia moderna, de esa exclusión de las mujeres, cuando en su obra Emilio, o de la educación, podemos leer:

"Cultivar en la mujer las cualidades del hombre y descuidar las que le son propias, es trabajar en detrimento suyo...Creedme, madres juiciosas, no hagáis a vuestra hija un hombre de bien, que es desmentir a la naturaleza; hacedla mujer de bien, y de esta forma podréis estar seguras de que será útil para nosotros y para sí misma (...) La mujer esta hecha especialmente para agradar al hombre (...). Bien dirigida, hasta la sujeción en que se la tiene, lejos de debilitar su cariño, no hará otra cosa que aumentarlo, porque siendo la dependencia el estado natural de las mujeres, propenden a la obediencia (...). Por la misma razón que deben tener poca libertad, se extralimitan en el uso de la que les dejan...»

Para Rousseau, como resume Amelia Valcárcel, «la política pertenece a los varones, al igual que les pertenece la racionalidad, la jerarquía, la cultura, el temple, el valor, el carácter y el acuerdo; las mujeres deben estar excluidas de la política y limitarse al buen arreglo de su casa, la obediencia, la dulzura y, en general, facilitar el éxito de los varones a cuya autoridad han sido subordinadas» ${ }^{14}$.

14. VAlCÁrCel, Amelia: Op. cit., p. 45. 
Mientras tanto, ¿acaso no había mujeres que aportarán a la ciencia, al pensamiento, o que reivindicaran sus derechos? Sí, las había, pero el discurso excluyente en todos los ámbitos les impedía manifestarse o, aquéllas que si se expresaron y lo dejaron por escrito, fueron silenciadas de un modo u otro y han sido las mujeres las que están teniendo que escudriñar en la historia y en todas las ramas del saber, para encontrarlas. Si se consulta a cualquier reputado autor de obras sobre, por ejemplo, historia de las ideas políticas, veremos cómo se ignora a estas mujeres; simplemente, no han existido.

No es ahora el momento de repasarlas a todas desde la antigüedad, pero sí recordar, al menos, los discursos igualitarios de alguna contemporánea al discurso dominante y excluyente, antes señalado, como a Cristine de Pizan, una de las primera mujeres que intervino con voz propia en su obra contra la misoginia La ciudad de las damas (1405) en la que defiende la imagen positiva del cuerpo femenino y asegura que hubiera sido otra la historia de las mujeres si no hubiesen sido educadas por hombres. Elogia la vida independiente y reclama la consideración de las mujeres como "ciudadanas», reivindicándolas como sujetos políticos.

En plena revolución francesa, Olympe de Gouges, guillotinada en 1793, frente a la Declaración de los derechos del hombre y del ciudadano de 1789, redactó en 1791 la Declaración de los derechos de la mujer y la ciudadana y Mary Wollstonecraft, que contestó brillantemente a Rousseau, en su Vindicación de los derechos de las mujeres de 1792, alzaron la voz reivindicando, para todas las mujeres, los derechos, oportunidades y condiciones que los varones.

A pesar de estas voces $y$, algunas otras que no hemos señalado, la codificación napoleónica, a principios del siglo XIX, supuso la institucionalización máxima del papel minorado subordinado de las mujeres. Obra capital de enorme influencia en el mundo como vehículo de las ideas de la revolución francesa y respuesta de la ideología típica del liberalismo burgués: individualismo, igualdad ante la ley, carácter absoluto del derecho de propiedad o la sustracción del matrimonio a la Iglesia Católica, esa igualdad era sólo para los varones.

Las llamadas revoluciones democráticas en la Europa de 1830 en adelante, en las que apareció en escena el proletariado y sus reivindicaciones, significaron la progresiva transformación hacia la democracia de los sistemas políticos europeos, mediante el reconocimiento constitucional de derechos tales como los de asociación, participación y sufragio, de todos los varones. Sin embargo, siguió dejando fuera a las mujeres de dicha participación, pues la función asignada a la mujer de productora y reproductora de la fuerza de trabajo humana y de la ideología, seguía siendo funcional al sistema, a burgueses y a proletarios. A finales del siglo XIX, las mujeres reivindicaron el derecho a intervenir en los asuntos públicos, primero mediante el sufragio (sufragistas), el derecho al voto, que les permitiera reivindicar y obtener otra serie de transformaciones como el derecho a la instrucción, a una educación superior, el derecho al ejercicio de todas las profesiones, el derecho a disponer de sus bienes, etc. Las mujeres inglesas lograron el derecho al voto en 1918 y las estadounidenses en 1919. 
Hasta mediado del siglo XIX, el 86\% de las mujeres eran analfabetas y, sólo, a partir de las primeras décadas del siglo XX, cuando las mujeres tuvieron que asumir trabajos y funciones reservadas a los varones que se fueron a la guerra, empiezan cambios cualitativos a pesar de enormes resistencias para la incorporación de las mujeres al voto y al trabajo.

El constitucionalismo social a partir de los años cuarenta del siglo XX, en el que se enmarca la Constitución española de 1978, fue el resultado de la nueva fase del capitalismo y del pacto capital y trabajo ${ }^{15} \mathrm{y}$, sin duda, un avance en la consolidación de los derechos y para el reconocimiento del derecho a la igualdad y no discriminación de las mujeres. Sin embargo, sólo desde la perspectiva de género, podremos advertir las dificultades aún de las mujeres para ejercer plenamente sus derechos.

El Tribunal Constitucional en su sentencia 128/1987 vino a declarar que la prohibición de discriminación por razón de sexo halla su razón concreta «en la voluntad de terminar con la histórica situación de inferioridad en que, en la vida social y jurídica, se había colocado a la población femenina» situación histórica que no puede ignorarse "si no se quieren dejar vacíos de contenido los preceptos constitucionales contrarios a la discriminación de la mujer».

En 1998, la Comisión de la Condición Jurídica de la Mujer de la ONU advirtió sobre la importancia de introducir la perspectiva de género en todas las políticas públicas, especialmente en las dirigidas a tratar la violencia contra las mujeres, la violencia de género, que definimos como la violencia que ejercen los hombres contra las mujeres fundamentalmente por causa de ese distinto papel social asignado a unos y a otras por la cultura y por la historia.

\section{LA VIOLENCIA DE GÉNERO16}

Cuando las mujeres, ya reconocidas como sujetos de derecho, pretenden afirmarlos y ejercerlos y quieren salir de la relación dominación / sumisión, entre los obstáculos que todavía encuentran, para ejercitar plenamente su derecho a la ciudadanía, es esta violencia como manifestación extrema de la desigualdad. En palabras de Tribunal Supremo, "la violencia familiar se caracteriza por una situación de dominación o intento de dominación sobre la mujer» (STS, Sala $2^{\text {a }}$, de 26 de diciembre de 2002).

La IV Conferencia Mundial sobre la Mujer, en 1995, proclamó que «la violencia contra las mujeres constituye un obstáculo para alcanzar la igualdad, una

15. Para un análisis del constitucionalismo social, DE CABO MARTín, Carlos: Teoría histórica del Estado y del Constitucionalismo, volumen II, Barcelona, PPU, 1993 y La crisis del Estado Social, Barcelona, PPU, 1986.

16. Para este apartado se ha tenido en cuenta el Informe de Amnistía Internacional "No hay excusa» [Violencia de género en el ámbito familiar y protección de los derechos humanos de las mujeres en España], Amnistía Internacional, Noviembre 2002 y la Comunicación de la Agrupación de Mujeres Abogadas del Colegio de Abogados de Alicante, para el I Congreso de la Abogacía Valenciana, "La defensa jurídica de las mujeres víctimas en el ámbito familiar», Consejo Valenciano de Colegios de Abogados, Benidorm, marzo 2003. 
violación de los derechos humanos y un reducto de anacrónicas concepciones basadas en relaciones de superioridad/inferioridad entre los hombres y las mujeres». La Declaración de la Asamblea General de las Naciones Unidas de 20 de diciembre de 1993 sobre la Eliminación de la Violencia contra las mujeres, la define como «todo acto de violencia basado en la pertenencia al sexo femenino que tenga o pueda tener como resultado un daño o sufrimiento físico, sexual o psicológico para la mujer, así como las amenazas de tales actos, la coacción o la privación arbitraria de la libertad, tanto en la vida pública como en la privada». El Informe del Comité Especial Plenario de la Asamblea General de las Naciones Unidas (2000) concluyó que «el hecho de que no se comprendan suficientemente las causas profundas de todas las formas de violencia contra las mujeres y las niñas obstaculiza las actividades que se realizan para eliminar dicha violencia».

De este modo, tanto el Tribunal Constitucional, como los organismos internacionales, constatan y plantean que, para afrontar con éxito las distintas formas de discriminación de las mujeres y las distintas formas de violencia contra las mismas, es necesario conocer cuáles son sus raíces y contextualizarla: las relaciones de género.

Analizada en este contexto, lo que esencialmente define y distingue la violencia de género de otros tipos de violencia es el componente sexista: lo que supone ser mujer en un contexto global que sigue discriminando e infravalorando a las mujeres, que es una única violencia cuyas víctimas son mujeres y niñas en razón de esa posición subordinada en las estructuras sociales, que se manifiesta en distintos ámbitos como en el trabajo, en el hogar y en las relaciones de pareja y en los diversos espacios en forma de atentado contra la libertad sexual. Nadie duda de que también los hombres y los niños pueden sufrir todo tipo de violencia y que también las mujeres pueden ejercerla sobre las demás personas con independencia de su sexo, edad etc., pero por violencia de género sólo debemos entender aquella violencia que refleja jerarquía social de lo masculino sobre lo femenino.

Las distintas disposiciones de la ONU, vienen utilizando las acepciones violencia sexista o por razón de sexo, violencia de género o violencia contra las mujeres en el ámbito familiar, para referirse a la violencia que sufren las mujeres en el espacio en que más habitualmente se manifiesta la violencia de género: el ámbito de las relaciones familiares incluidas las distintas formas de relación de pareja constante o no, donde la violencia hacia las mujeres está más extendida y goza aún de un amplio margen de impunidad.

Este tipo de violencia reviste múltiples formas: agresiones físicas, psíquicas, sexuales (las más visibles y que han sido consideradas por los Organismos Internacionales como forma de tortura), injurias, vejaciones, otras formas de coacción, como el control social, económico y otras formas de infligir sufrimiento, entre las que cabe destacar, las amenazas; normalmente no se producen de forma aislada sino que forman un conjunto de actos cotidianos que producen ese sufrimiento que tantas mujeres soportan a lo largo de su vida; entre el agresor y la víctima se ha creado un círculo de dependencia, de origen y motivaciones 
distintas: afectivas, económicas u otras, y la que se produce como consecuencia de las agresiones y amenazas.

Las características de esta violencia trae como consecuencias la quiebra del proyecto de vida de la mujer maltratada, además de las lesiones físicas y psíquicas, consecuencia directa de la agresión, junto a las denominadas a largo plazo, aparecidas como consecuencia de una mantenida situación de maltrato, como miedo, inseguridad, extrema ansiedad (se llega a verdaderas situaciones de pánico), falta de autoestima, culpabilidad, vergüenza, sumisión, etc.; las agresiones y / o amenazas debilitan a la víctima, la aíslan de sus fuentes de apoyo (familia y amistades) y el temor y la pérdida personal refuerzan la dependencia con el agresor, conformando el cuadro del denominado "síndrome de la mujer maltratada", en el cual es muy difícil llegar a un adecuado conocimiento de la situación que está viviendo y la gravedad de su estado, teniendo en cuenta que se produce sobre la base de una relación sentimental, familiar y un determinado grado de dependencia ${ }^{17}$.

Estas características y el propio entorno socio-cultural que desconoce o prefiere desconocer o minimiza los hechos, puede explicarnos porqué resulta difícil salir de esta situación y denunciarla. Además, cuando las mujeres se deciden a denunciar la violencia sufrida, aparece lo que se ha denominado la doble victimización o victimización secundaria, uno de los aspectos en los que se incide y tratan de evitar distintas resoluciones europeas, con la que se hace referencia al sufrimiento añadido que padecen las mujeres a lo largo de los procesos judiciales. Se sienten desasistidas por el resultado de sus denuncias y aprecian como ineficaz e injusta la actuación de los órganos jurisdiccionales, pues son ellas las que tienen que salir de su casa, pérdida eventual de comunicación con sus hijos, ingresos, trabajo, pertenencias, o refugiarse, huir, además de tener que soportar el examen adicional por los distintos operadores jurídicos reticentes e incrédulos a su declaración, después de haber soportado, en la mayoría de los casos, tantos años esta situación.

\subsection{El marco jurídico internacional y comunitario}

A pesar de las exigencias del Pacto Internacional de Derechos Civiles y Políticos de 1966, y de la Convención para la Eliminación de Todas las Formas de Discriminación contra las Mujeres (CEDAW) de 1979, hasta la década de los noventa no se tuvo en cuenta la responsabilidad de los Estados por actos de violencia hacia las mujeres perpetrados por personas particulares. En 1992, el Comité de vigilancia de la CEDAW, en su Recomendación General 19 sobre violencia contra las mujeres, después de afirmar que esta violencia se enmarca dentro de la discriminación por razón de sexo, y constituye una violación de los derechos humanos, subraya que «los Estados también pueden ser responsables

17. De entre la ya abundante bibliografía sobre las circunstancias de las víctimas de violencia de género en el ámbito familiar, se ha tenido en cuenta a LORENTE ACOSTA, Miguel: Agresión a la mujer: maltrato, violación y acoso. Entre la realidad social y el mito cultural, Granada, Comares, 1998. 
de actos privados si no adoptan medidas con la diligencia debida para impedir la violación de los derechos o para investigar y castigar los actos de violencia y proporcionar indemnización».

En 1993, meses después de la Declaración de Viena, la Declaración de la ONU sobre la Eliminación de la Violencia contra las Mujeres, instaba a los Estados a «proceder con la debida diligencia a fin de prevenir, investigar y, conforme a la legislación nacional, castigar todo acto de violencia contra la mujer, ya se trate de actos perpetrados por el Estado o por particulares». A partir de la Conferencia de Beijing de 1995, se redactó el Protocolo Facultativo de la CEDAW que amplía los mecanismos de protección internacional de los derechos humanos de las mujeres frente a los atentados producidos tanto en los ámbitos públicos como en la familia.

La obligación de los Estados de «actuar con la debida diligencia» significa: 1) arbitrar leyes contra la violencia de género en el ámbito familiar y actuar legislativamente a través no sólo de sanciones sino también a través de mecanismos de protección y de reparación, 2) desarrollar mecanismos para el cumplimiento efectivo de las leyes y 3 ) evaluar la efectividad de esta medidas para el logro de sus objetivos.

En el marco de la Unión Europea, desde la consagración de la promoción de la igualdad entre hombres y mujeres como uno de los objetivos de la Comunidad, en el artículo 2 del Tratado de la CEE, pasando por la Carta de los Derechos Fundamentales de la Unión Europea del año 2000, la violencia hacia las mujeres ha sido objeto, en diferentes Conferencias, de distintos niveles de actuación como la Recomendación de la Comisión Europea (Conferencia de Colonia de marzo de 2002), sobre medidas legislativas y de otro carácter para la protección de las víctimas y control de los agresores; la Resolución del Parlamento Europeo de 16 de septiembre de 1997 sobre Campaña Europea de Tolerancia Cero en la que, tras constatar la insuficiente legislación en el cometido, se proponen una serie de medidas y recomendaciones de prevención y protección, legislativas, de revisión de los procedimientos judiciales para dotarlos de eficacia y de organización y mantenimiento de servicios apropiados, además de las contenidas en el Programa de acción comunitario para 2001-2005.

\subsection{El marco jurídico español}

En el ordenamiento jurídico-político español, hasta 1931, con la Constitución de la II ${ }^{a}$ República, no se produce la primera declaración de igualdad de las mujeres: el derecho al trabajo, al voto, a funciones y cargos públicos, divorcio, pero el franquismo significó un brutal retroceso. Hasta 1961 no se regula el ingreso de las mujeres en la Administración y hasta los años 70 en la Administración de Justicia; hasta 1975, en el derecho civil no se suprime la fórmula consagratoria de la supremacía del marido «el marido debe proteger a la mujer y la esposa obedecer al marido" por la de "el marido y la mujer se deben respeto y protección recíprocos» y por las mismas fechas, las autorizaciones del marido a la mujer para trabajar y otras limitaciones que las mujeres españolas soportaban. 
Ya en plena transición democrática, el día 13 de abril de 1977, el Estado español ratificó el Pacto Internacional de Derechos Civiles y Políticos de 1966, pero hasta mayo de 1978 no despenaliza el amancebamiento y el adulterio y hasta junio de 1981 no se modifica la regulación del matrimonio y se regula el divorcio y no fue hasta julio de 1985 en donde, de manera muy restrictiva, se despenalizan algunos supuestos de aborto, aún vigente. En 1984, firmó y ratificó la Convención de la CEDAW de 1979 y, con ello, el compromiso en la eliminación de la discriminación por razón de sexo, tanto en la ley como en la sociedad española, lo que supuso importantes modificaciones legislativas en todos los campos, si bien en el derecho civil es el campo en donde hasta 1990, han tenido que producirse modificaciones que permitieran la efectiva igualdad jurídica y sólo, muy recientemente, las diferentes leyes en pos de la igualdad material y real.

El 6 de julio de 2001, España ratificó el Protocolo Facultativo de la CEDAW $y$, junto con los distintos Planes de Igualdad que se han venido sucediendo desde la década de los ochenta, a partir de estos últimos compromisos internacionales, los Planes contra la Violencia Doméstica como instrumentos de trabajo que presentan medidas interdisciplinares sobre la violencia doméstica.

A pesar de la especificidad de la violencia contra las mujeres, y en especial la que se produce en el ámbito familiar como conducta delictiva, este tipo de violencia no se había tipificado en España como delito específico. El origen de la tipificación fue sin duda la toma de conciencia de que esta violencia contra las mujeres había dejado de ser una cuestión "privada» para pasar a ser un problema social e inaceptable. No obstante, la redacción del artículo 153 Código Penal a pesar de sus sucesivas reformas, seguía dejando pendiente la necesaria contextualización de este tipo de violencia.

Con el concepto de violencia doméstica y la ubicación del delito, se seguía desconociendo que uno de los criterios básicos, para combatir la violencia contra las mujeres, no es compartimentarla en función del ámbito en el que se produce, sino identificar las causa últimas de la misma y a las víctimas y autores de esta violencia global.

Cualquier actuación en defensa jurídica de una víctima, requiere los conocimientos y técnica adecuados pero, en el caso de la violencia contra las mujeres en el ámbito familiar, las circunstancias señaladas y tantas otras que podríamos añadir, hace que nos encontremos con específicas dificultades para la persecución y castigo del delito, lo que obliga a la necesaria formación y especialización de quienes más directamente están llamados a perseguirlo. La creación de registros de actos similares cometidos por el mismo sujeto y la coordinación entre los mismos han sido recomendadas por los organismos internacionales como método de coordinación judicial y de análisis de datos.

Desde diferentes organismos internacionales y europeos se viene insistiendo en que esta violencia requiere de una respuesta específica, especializada y multidisciplinar y en la importancia de que todas las personas, que por su ámbito profesional deban atender a las mujeres que sufran violencia, estén debidamente formadas y coordinadas entre sí. 
La Resolución del Parlamento Europeo sobre Tolerancia Cero subraya «la importancia de la formación de las personas que trabajan con mujeres que ha sido objeto de violencia, tanto de los servicios policiales, jurídicos y sanitarios, como de los servicios de vivienda y sociales» y considera que «dicha formación debe ser obligatoria para los jueces que conocen de asuntos de violencia por razones de sexo» (párrafo 8); la Relatora Especial de la ONU (2002), consideraba prioritario que los Estados tomen medidas «para garantizar que los funcionarios públicos encargados de hacer cumplir la ley tengan formación adecuada que los sensibilice respecto de las necesidades específicas de las mujeres».

\subsection{La ley integral contra la violencia de género}

La violencia de género es una discriminación por razón de sexo en donde las mujeres son las destinatarias porque el varón quiere mantener la situación de dominación / sumisión y ataca a la dignidad de la persona y sus derechos inherentes tales como el derecho a la igualdad, integridad física y moral, además de a su libertad.

Por todo ello, si la mujer es el sujeto pasivo de este tipo de violencia, que causa no sólo lesiones, cuando no la muerte, graves daños físicos y síquicos a sus víctimas, sino que además quiebra su proyecto de vida, hasta modificar las condiciones de existencia de la mujer, el Estado, los poderes públicos, como ordena el artículo 9.2 de nuestra Constitución, están obligados a adoptar cuantas medidas sean necesarias (a actuar con la debida diligencia), para erradicar esta violencia mediante la prevención, protección y sanción y reparación de la mujer que ha sido la víctima y la restitución de su proyecto de vida.

Desde distintos ámbitos, en especial desde distintos grupos y asociaciones de mujeres, se fueron sucediendo numerosos y diferentes estudios y propuestas que señalaban que este tipo de violencia no puede considerarse sólo como expresión de conflictos individuales entre determinadas personas, sino como una de las expresiones concretas, y en tantas ocasiones fatales, de la violencia de género, que en todo el mundo se produce, y la necesidad de afrontar la violencia de género como un problema social unitario con un mismo origen y unos mismos autores y víctimas.

Al respecto, en anteriores legislaturas, desde los grupos parlamentarios del PSOE e IU en el Congreso, se hicieron propuestas legislativas para una Ley Integral contra la Violencia de Género, hoy finalmente aprobada en las Cortes por unanimidad.

Mediante la Ley Orgánica de medidas de protección integral contra la violencia de género, se establecen «medidas de sensibilización prevención, detección e intervención en diferentes ámbitos», en el educativo, en el de la publicidad, en el sanitario, laboral, tutela institucional, además del establecimiento de tipos penales específicos y la correspondiente tutela judicial.

El reconocimiento expreso de una violencia específica contra la mujer en un tipo penal específico, en el que consta que la mujer es el sujeto pasivo, sirve no sólo como coacción y persuasión, sino que cumple una función pedagógica 
fundamental: la violencia contra las mujeres por el hecho de ser mujeres está prohibida ${ }^{18}$.

\section{ALGUNAS BREVES CONCLUSIONES Y PROPUESTAS}

En la clausura de la IV Conferencia de la Mujer en Beijing, el entonces Secretario General de la ONU, B.Gali afirmaba que «la igualdad entre hombres y mujeres es el mayor proyecto político del siglo» y, antes, alguien había dicho que la incorporación de las mujeres al espacio público era el fenómeno social más importante del siglo XX. Algunas pensamos también que ha supuesto (o está suponiendo) la única y verdadera revolución.

Efectivamente, en estos últimos veinte o veinticinco años, las cosas han cambiado pues la mayor incorporación de la mujer al trabajo, el acceso a la educación y el acceso a la cultura y a la independencia económica ha obligado a cambios tanto materiales como ideológicos, permitiendo cambios en la estructura familiar y en otros campos, pero todavía son insuficientes.

Las mujeres, que hemos mejorado y avanzado en nuestra situación, sabemos que es un avance no universal y no homogéneo. Baste recordar que la pobreza en el mundo sigue golpeando especialmente a las mujeres, las violaciones como arma de guerra o el no reconocimiento siquiera de los derechos básicos, y que este avance, que sólo se produjo porque las mujeres luchamos por él, sólo se seguirá produciendo si estamos prevenidas y no permitimos ni un paso atrás, pues el modelo patriarcal, el patrón dominación / sumisión, con el que es necesario acabar, sigue vigente.

No podemos perder de vista que, a pesar de las transformaciones y los indudables cambios, hoy los mecanismos de dominación han cambiado: son más sutiles, menos evidentes y por ello más peligrosos. Se ataca la autoestima: delgadas, bellas, inteligentes, buenas pareja sexual, mujeres "de carrera», no para satisfacernos a nosotras mismas sino para ser aceptadas en ese espacio hasta ahora sólo de los hombres y pensado sólo en masculino.

Las mujeres, que hemos roto el dualismo espacio público, marcado por lo masculino / espacio privado, marcado por lo femenino, podemos - de hecho lo hacemos- plantearnos y discutir nuestro tradicional papel en la familia y en la sociedad y exigir y propiciar esos cambios. Las acciones políticas, establecidas desde y para los varones que eran los únicos titulares de derechos, de acceso a la cultura, etc. y, por tanto, imponían sus prioridades, han de estar pensadas de otras formas.

Las alternativas radican en que los dos sexos ocupemos todos los espacios, todos los aspectos de la vida, públicos y privados (humanos) y exijamos su reorganización y socialización.

Por ello, para acabar con ese patrón dominación / sumisión que impera aún en tantos ámbitos y que, sin duda, impide unas relaciones más justas y satis-

18. DURÁN FEBRER, María: El proyecto de ley orgánica de medidas de protección integral contra la violencia de género. Fundamentación Jurídico Feminista.www.e-leusis.net/25/Maria_Duran_Febrer.pdf- 
factorias, es necesario el reconocimiento de las mujeres como seres completos y equivalentes a los hombres, que, además, gestamos, parimos, amamantamos. Hay que pensar y proponer (realmente están pensadas y propuestas) otro tipo de relaciones en la familia, en el trabajo, en la política y hay que reorganizarlas ${ }^{19}$.

Las mujeres partimos de una desigualdad, no sólo histórica, sino real. De lo que se trata ahora es de que si durante siglos hemos sido excluidas por el hecho ser mujeres, ahora se nos deba incluir, precisamente, por ser mujeres y dotar de contenido material a la igualdad: en las manifestaciones presentes, de carácter estructural, de las discriminaciones padecidas históricamente por las mujeres, encontraremos las razones para las medidas de acción positiva en su favor ${ }^{20}$.

Las diferencias valiosas de las que somos poseedoras, las prácticas de las mujeres, que pertenecen a nuestra experiencia entre la educación tradicional que recibimos y la nueva formación que nos hemos procurado, «las buenas prácticas» privadas, deben ser respetadas, conservadas e integradas, en definitiva asumidas en «lo público» y no, como hasta ahora, menospreciadas o ignoradas.

Los aspectos negativos en la lucha por los derechos de las mujeres no deben suponer retrocesos, sino la evidencia de que no todo está corregido. Debemos seguir reflexionando, proponiendo y conseguir que las propuestas se hagan realidad. "Lo masculino" como valor, hasta ahora, indiscutible y absoluto, no problemático, ahora se pone en cuestión -problemático-. Ahora los varones se sienten agredidos, incómodos, confusos y empiezan a plantearse si el modelo al que se deben ajustar es en el que se encuentran a gusto y cómodos. Empieza a ser el momento en que reflexionemos sobre que «de lo masculino» y que «de lo femenino" son realmente "valores", virtudes humanas a conservar, propiciar y practicar. Seguro que esta reflexión será enriquecedora para todos los seres humanos, mujeres y hombres.

19. Simón, Elena: Democracia vital: Mujeres y hombres hacía la plena ciudadania, Narcea, Madrid, 1999.

20. MARTín VidA, María Ángeles: Op. cit., p. 22. 


\title{
GÉNERO Y CIUDADANIA, MUJERES Y CONSTITUCION
}

\author{
Ma DEL MAR ESQUEMBRE VALDÉS \\ Universidad de Alicante
}

\begin{abstract}
"iel contrato constitutivo que se invoca como legitimación del orden moderno puede ser extendido a nuevos contratantes, o bien el irrumpir en escena de estos nuevos participantes impone pensar en un contrato radicalmente diverso?»*
\end{abstract}

\begin{abstract}
Abordar el concepto de ciudadanía desde la perspectiva constitucional significa no sólo su consideración desde la vertiente política sino también desde el Derecho, desde la perspectiva jurídica, porque el Derecho sirve para perpetuar situaciones de poder, pero también para transformar la sociedad. El Derecho, además del principal instrumento de ordenación social conocido, es «un sistema configurador de formas de vida y de relación» o, lo que es lo mismo, "creador de modelos, de principios y de valores» ${ }^{1}$, y la Constitución, como norma suprema, aparece como máximo exponente de ello. Si el Derecho, y, por tanto, la Constitución, regula las relaciones sociales, ello incluye las relaciones entre los sexos. Y, en este plano, el discurso jurídico (también el jurídico-político o constitucional) ha reflejado (cuando lo ha hecho) históricamente la idea de complementariedad de los sexos más que la de igualdad de éstos ${ }^{2}$, única forma
\end{abstract}

* PITch, Tamar: Un Derecho para dos. La construcción jurídica de género, sexo y sexualidad, Madrid, Trotta, 2003, p. 22.

1. Rubio, Ana: «Igualdad y diferencia. ¿Dos principios jurídicos?», Derechos y Libertades. Revista del Instituto Bartolomé de las Casas, 4 (1995), p. 268.

2. ARnAud-Duc, Nicole: "Las contradicciones del derecho", en Georges Duby y Michelle Perrot (dirs.): Historia de las Mujeres, vol. 4, Madrid, Taurus, 2000, p. 148. La teoría complementaria de los sexos constituye el más amplio y desarrollado discurso sobre la inferioridad de las mujeres que hace fortuna en el siglo XVIII y subsiste en la actualidad. Rousseau sería el ejemplo paradigmático de ese discurso, como refleja claramente el capítulo quinto de su célebre Emilio. 
de «legitimar una subordinación en un mundo regulado ideológicamente por la igualdad $»^{3}$.

La inclusión del principio de igualdad y no discriminación por razón de sexo es relativamente reciente en los textos constitucionales contemporáneos ${ }^{4}$ y se ha configurado como el cauce para el reconocimiento de las mujeres como ciudadanas y como sujetos de derechos. Sin embargo ni la consagración de la igualdad en las Constituciones ni su desarrollo normativo ha posibilitado la erradicación de la situación secular de desigualdad de mujeres y hombres, lo que equivale a afirmar que el reconocimiento de las mujeres como sujetos de derechos no se ha completado.

En este texto sostendré la necesidad de reformar la Constitución a fin de incluir como sujetos políticos y jurídicos a las mujeres para posibilitar la configuración de las relaciones humanas en igualdad. Para ello, necesariamente, habremos de realizar un breve repaso a la historia del constitucionalismo situando el punto de partida en el momento del nacimiento del sujeto en el ámbito jurídico-político, que se vincula a una determinada forma de organización del poder político, social, económico y jurídico, o mejor, a las transformaciones que en esos ámbitos tienen lugar desde el Renacimiento, precursor de la Modernidad, hasta la actualidad.

\section{EL CONSTITUCIONALISMO LIBERAL: EL «HOMBRE» Y EL "CIUDADANO"}

El artículo 16 de la Declaración de los Derechos del Hombre y del Ciudadano de 1789 sentaba los presupuestos básicos para que pudiese hablarse de la existencia de una Constitución:

«Toda sociedad en la que la garantía de los derechos no esté asegurada, ni la separación de los poderes determinada, no tiene constitución»

El origen del moderno constitucionalismo es también, por tanto, el origen del sujeto, del sujeto individual. El análisis del proceso de aparición de este sujeto de los derechos permite identificarlo, en términos reales, como varón, de raza blanca y propietario (o, al menos, susceptible de serlo), caracteres de la burguesía, el sujeto político protagonista de las revoluciones liberales.

\subsection{El sujeto individual, piedra angular del nuevo orden}

El sujeto de Derecho, el sujeto jurídico, nace cuando desaparece la correspondencia entre realidad y norma $\mathrm{y}$ "se hace posible la igualdad formal $»^{5}$. E1

3. Amorós, Celia y Cовo, Rosa: «Feminismo e Ilustración», en Celia Amorós y Ana De Miguel (eds.): Teoría feminista: de la Ilustración a la globalización, vol. 1, Madrid, Minerva Ediciones, 2005, p. 137.

4. El orden en el que se sitúa el sexo, por detrás del nacimiento y la raza, obedece a la evolución histórica en el acceso al ámbito público, al ámbito propio de la toma de decisiones.

5. CABO MARTín, Carlos de: «El sujeto y sus derechos», Teoría y Realidad Constitucional, 7 (2001), p. 118. 
concepto de sujeto se trata de un concepto histórico generado «en el proceso de descodificación de la antigua sociedad estamental» ${ }^{6}$. Este proceso vendría determinado, siguiendo a De Cabo, a partir de supuestos de carácter material o real, teórico-jurídicos y jurídico-positivos ${ }^{7}$.

Así, entre los primeros supuestos, el citado autor señala las causas institucionales y socioeconómicas a las que se vincula el surgimiento del sujeto. En el plano institucional el origen del Estado moderno se corresponde con el origen del sujeto, del individuo, en la medida en que éste y aquel surgen por las mismas razones $^{8}$. Por lo que se refiere a las causas socioeconómicas, es la aparición del capitalismo la que posibilita el surgimiento del sujeto, pues sólo entre éstos es posible el intercambio9. La igualdad formal entre sujetos (que permite ocultar la desigualdad real) se manifiesta pues como exigencia, como requisito funcional del sistema capitalista.

En cuanto a los supuestos teórico jurídicos, si bien se podrían situar los orígenes del individualismo moderno ideológicamente en el nominalismo del siglo XIV y su desarrollo en el Renacimiento, principalmente en la obra de Duns Escoto ${ }^{10}$, son el iusnaturalismo y el liberalismo los que configuran el origen del sujeto moderno, siendo Kant el máximo exponente de su formulación filosófico-jurídica. La definición del Derecho de Kant dimana de sus ideas de la autonomía de la voluntad y del reino de los fines o comunidad ética, articulándose, por tanto en torno al sujeto, pues define el derecho como «el conjunto de condiciones por las que el libre arbitrio de uno puede concordarse con el de los demás según una ley general de libertad». El Estado de Naturaleza presupone la existencia del sujeto, a partir del cual surge, mediante pactos y como su garantía, no sólo el Estado, sino el Derecho tanto público como privado.

6. AMorós, Celia: Tiempo de feminismo. Sobre feminismo, proyecto ilustrado y posmodernidad, Madrid, Ed. Cátedra, col. Feminismos, $2^{\mathrm{a}}$ ed., 2000, p. 25.

7. CABO MARTín, Carlos de: Op.cit., pp. 119 y ss.

8. «Las mismas causas que dieron lugar al Estado (moderno) son las que, simultáneamente, crearon las condiciones para el surgimiento del sujeto: la crisis definitiva de rentabilidad del Feudalismo que producirá la crisis de la aristocracia y posibilita la concentración de poder en el Monarca y su fortalecimiento, conlleva la supresión de los demás vínculos y jerarquías; y la unificación jurídico-política territorial, implica la eliminación del "privilegio» como elemento jurídico propio del sistema». Ibíd., p. 119.

9. «Precisamente el capitalismo se va a diferenciar de los sistemas anteriores en la «separación» del trabajador de los medios de producción y su conversión en «individuo», «libre» para participar en el mercado e «igual» a los demás, de manera que el formal intercambio de (mercancías) -aparentemente- equivalentes se corresponde con la formal (aparente) igualdad de quienes lo realizan. Capitalismo y sujeto (libre e igual) son, pues, inseparables». Ibíd., p. 119.

10. Como apunta Celia Amoros: Tiempo de feminismo..., op. cit., pp. 30 y ss. Aunque ironiza la citada autora a este respecto al afirmar que si «la historia del sujeto moderno comienza con los nominalismos, las mujeres todavía no hemos accedido a ese estadio", ya que en el lenguaje cotidiano -incluso el científico, podríamos afirmar- todavía se utiliza la expresión «la Mujer» como genérico representativo de todas las mujeres. Así, afirma, es habitual encontrar mensajes como «La Mujer accede al ejército» pero nos causaría, cuanto menos extrañeza oír que «El Negro entra en la judicatura». Op. cit., p. 74. 
Para Kant la libertad ética interior de cada ser humano, para manifestarse como tal libertad, necesita exteriorizarse. Y ello sólo es posible si dicha libertad se puede proyectar sobre una "cosa", que para Kant, coincidiendo con las tesis liberalistas de Locke, es la propiedad (sobre todo la del suelo) ${ }^{11}$. Así, la idea de sujeto va irrescindiblemente ligada a la propiedad "como condición de autodeterminación de la existencia y de la relación con los otros (propietarios) de manera que la propiedad es una determinación necesaria del proceso de identificación del yo y del desarrollo de su individualidad ${ }^{12}$. Así, pues la identificación entre individualidad y propiedad será la piedra angular sobre la que pivota la teoría política de la modernidad, de tal forma que el Derecho y el Estado nacen de la propiedad para hacerla posible, para garantizarla, configurándose ésta como un «principio de organización social» ${ }^{13}$.

Por lo que se refiere a los supuestos jurídico-positivos, se produce la positivización del sujeto tanto en el ámbito del Derecho Público, a través de las Declaraciones de Derechos, como en el del Derecho privado, a través del proceso de codificación ${ }^{14}$.

La virtualidad de la Declaración de Derechos de 1789 es, de un lado, la configuración jurídica de la persona individualmente considerada como sujeto universal de derechos (aunque esta universalidad formal cede cuando se trata de conformar la voluntad de la colectividad, cuando ha de expresarse el cuerpo de todos los ciudadanos con una sola voz), y, de otro, supone el establecimiento de la separación entre la esfera privada de las personas (derechos) y la del Estado (división de poderes) ${ }^{15}$.

Respecto del Derecho privado, interesa destacar cómo se perfila la subjetividad jurídica en los códigos civiles principalmente a través de la formulación de la personalidad jurídica y capacidad jurídica que hace posible "la igualdad formal, un concepto de propiedad «despersonalizada» (estrictamente económico en cuanto se configura al margen de todo vínculo personal y por consiguiente «libre» y objeto de cambio) y una disponibilidad sobre sí mismo (sobre su tra-

11. CRAmPe-CASNABET, Michelle: «Las mujeres en las obras filosóficas del siglo XVIII», en Georges Duby y Michelle Perrot (dirs.): Historia de las Mujeres, vol. 3, Madrid, Taurus, 2000, pp. 344384.

12. Cabo Martín, Carlos de: Op. cit., p. 120.

13. Ibíd., p. 120.

14. Ibíd., pp. 120 y ss.

15. Así, mientras el lugar de las relaciones sociales, de las relaciones privadas, va a ser el mercado, la articulación de las relaciones entre la sociedad y el Estado (lo público) se efectuará únicamente a través del mecanismo de la representación parlamentaria. El régimen representativo será pues la consecuencia de la soberanía nacional. Al ser la nación un ente abstracto y colectivo, la soberanía sólo podrá ser ejercida por los representantes de la nación y no por los ciudadanos por sí mismos, apareciendo aquí las bases para la exclusión de la democracia directa. Además, la forma de articular el principio representativo mediante la prohibición del mandato imperativo como contraposición a la sociedad estamental provocó que sólo aquellos que reunieran ciertas condiciones de idoneidad para ejercer tan alta responsabilidad pudieran elegir y ser elegidos como representantes; en definitiva, se consagró el sufragio censitario (en el que fue determinante el criterio de la propiedad, además, como veremos, del sexo). 
bajo) de manera que su despliegue como sujeto le permite, sin dejar de serlo, ser también objeto». Formalizados objeto y sujeto de esta forma, la figura del negocio jurídico aparece como expresión normativa de la relación, del acuerdo entre sujetos y se caracteriza principalmente por su permisividad en el sentido de valorar dicho acuerdo por su mera existencia, es decir, "con un carácter abstracto formal, que no tiene en cuenta ni la cualidad del sujeto ni la del objeto de la relación». Así, mediante estas abstracciones se formaliza un sujeto que "no sólo oculta y elude las desigualdades y por tanto el conflicto real, sino que lo que hace fundamentalmente es impedir que la desigualdad, el conflicto (que es intersubjetivo) se traslade al orden jurídico político» ${ }^{16}$.

Recapitulando, la correspondencia entre norma y realidad se rompe a través de dos construcciones que hacen posible la igualdad formal y permite la aparición del sujeto jurídico individual en dos dimensiones o ámbitos: en el ámbito privado (mercado) mediante la capacidad jurídica y de obrar (reconocimiento de la autonomía de la voluntad, capacidad para contratar y para ser propietario), y en el ámbito público (ámbito de decisión y exigencia de derechos) a través de la ciudadanía. Su diseño, estructurado en torno a la propiedad, impide que las desigualdades reales entre individuos (conflictos) se trasladen al Derecho.

Hasta el momento hemos hecho referencia al surgimiento del sujeto, del individuo, sin tener en consideración su sexo y obviando la construcción social del género. Incluir esta perspectiva desvela la exclusión de las mujeres de este concepto de sujeto si tenemos en cuenta que esta ruptura entre norma y realidad no se produce en el ámbito en el que se había recluido a las mujeres y que denominaremos como el ámbito doméstico o "privado-privado».

\subsection{Los «iguales" y las «idénticas". Separación de espacios según el sexo/género y negación de la subjetividad jurídica a las mujeres ${ }^{17}$}

Afirmábamos más arriba que el nacimiento del sujeto jurídico es posible cuando desaparece la correspondencia entre realidad y norma. Y, en efecto, con la modernidad y las revoluciones liberales, esta ruptura se produce en todos los ámbitos salvo en uno: aquél más íntimo en el que la relación entre los sexos es presupuesto de su existencia a través de una institución secular: el matrimonio. En este ámbito no se produce transformación alguna, salvo una mayor definición o delimitación del mismo, si bien a costa del surgimiento de no pocas contradicciones que, no obstante, lejos de suscitar viva polémica, son interesadamente ocultadas, ignoradas.

16. CABO MARTín, Carlos de: Op. cit., pp. 120-121.

17. Utilizo aquí la conocida expresión acuñada por Celia Amorós para evidenciar la construcción de la modernidad del espacio ocupado por los varones, reconocidos como iguales (como individuos) y del espacio asignado a las mujeres (como colectivo, sin reconocimiento de la individualidad, que es la que hace posible la igualdad) y el ejercicio del poder. Vid. Amorós, Celia: La gran diferencia y sus pequeñas consecuencias...para las luchas de las mujeres, Valencia, Ed. Cátedra, col. Feminismos, 2005, pp. 451 y ss. 
Efectivamente, cuando apuntábamos las causas de carácter material o real que determinaron el proceso de surgimiento del sujeto jurídico nos referíamos a la eliminación del "privilegio jurídico» como elemento definidor del antiguo sistema estamental. Sin embargo dicho privilegio no desaparece en las relaciones entre los sexos y se mantiene por los hombres sobre las mujeres ${ }^{18}$. Ello penetra en el resto de aspectos, en mayor o menor medida, aunque tendrá en el futuro a medio plazo una importancia crucial en el plano socioeconómico, como veremos más adelante.

Por lo que se refiere a los supuestos teórico-jurídicos, la exclusión de las mujeres como sujetos individuales y libres tiene su anclaje en su exclusiva adscripción-identificación con la naturaleza que es inferior a la razón (cualidad exclusivamente masculina) y a la cual ha de plegarse ${ }^{19}$. No es más que la justificación de lo que Carole Pateman definió como el contrato sexual, presente ya en el estado de naturaleza y previo, por tanto, al pacto de la sociedad civil, que sólo se realiza entre los varones, igualmente libres ${ }^{20}$.

Finalmente, en cuanto a los supuestos jurídico-positivos, la Declaración de Derechos del Hombre y del Ciudadano supondrá la consolidación de dos esferas: pública y privada, separando así la sociedad civil de la sociedad política. De la esfera pública quedarán las mujeres excluidas, en la esfera privada se las mantendrá en una situación de dependencia ${ }^{21}$. Ello permite intuir la existencia de otra esfera dentro de esta última, de otro espacio, en el que se articulan las relaciones entre los sexos desde un principio de jerarquía: el espacio doméstico (o privado-privado, o vital) 22 .

La exclusión de las mujeres de la ciudadanía no estuvo exenta de polémica, pues suponía la negación misma y sin justificación de los supuestos de la razón ilustrada que habían hecho posible el proyecto emancipador del individuo. Así lo puso de manifiesto la revolucionaria Olympe de Gouges, con su original contribución a la Declaración francesa de derechos ${ }^{23}$, o Condorcet, cuando sostenía

18. Las vindicaciones feministas de la época utilizan este argumento para denunciar la irracionalidad de la subsistencia de la dominación de los hombres sobre las mujeres en una suerte de "aristocracia» masculina.

19. Ya desde la antigüedad se venía produciendo esta identificación de las mujeres con la naturaleza. En su Política (Libro I, capítulo primero) Aristóteles afirma que la naturaleza «ha creado a unos seres para mandar y a otros para obedecer» y, por consiguiente, "ha fijado (...) la condición especial de la mujer». Este discurso no sólo no desaparece a lo largo de la historia, sino que es retomado por Hobbes, Locke, Kant o Rousseau, por citar sólo algunos de los más relevantes teóricos del Estado.

20. PATEMAn, Carole: El contrato sexual, Barcelona, Anthropos, 1995.

21. FraISSE, Geneviève y PERROT, Michelle: «La ruptura política y el nuevo orden del discurso", en Georges Duby y Michelle Perrot (dirs.): Historia de las Mujeres, vol. 4, Madrid, Taurus, 2000, pp. 29-30.

22. Martinez Sampere, Eva: "Hacia la plena ciudadanía», en Teresa Freixes Sanjuán y Julia Sevilla Merino (coords.): Género, Constitución y Estatutos de Autonomía, Madrid, Instituto Nacional de Administración Pública, 2005, p. 46.

23. Declaración de Derechos de la Mujer y de la Ciudadana, 1791. Un estupendo análisis, comparándolo con la Declaración de Derechos del Hombre y del Ciudadano de 1789 lo realiza Simón RODRIGUEZ, Elena, en Canelobre, n 23-24 (1983). 
como exigencia de la razón la equiparación del estatus jurídico de mujeres y hombres:

"O bien ningún individuo de la especie humana tiene verdaderos derechos, o bien todos tienen los mismos derechos; y quien vota contra el derecho de otro, sea cual fuere su religión, su color o su sexo, reniega en ese mismo momento de los suyos ${ }^{24}$

Y frente a los argumentos que asentaban la imposibilidad de las mujeres de ejercer como ciudadanas en una incapacidad natural derivada de su capacidad de reproducción argüía:

"¿Por qué los seres expuestos a embarazos y a indisposiciones pasajeras no podrían ejercer los derechos de los que jamás se ha soñado siquiera con privar a quienes padecen de gota todos los inviernos o a quienes se resfrían fácilmente?» ${ }^{25}$

No obstante esta situación se legitimó desde el ámbito científico, religioso y filosófico mediante la construcción de un concepto de «mujer» complementaria y absolutamente funcional al nuevo hombre (libre e igual a sus semejantes), otorgándole nominalmente el apelativo de "ciudadana», pero con un significado radicalmente distinto, tal y como se aprecia en el Emilio de Rousseau:

«Cultivar en la mujer las cualidades del hombre y descuidar las que le son propias, es trabajar en detrimento suyo... Creedme, madres juiciosas, no hagáis a vuestra hija un hombre de bien, que es desmentir a la naturaleza; hacedla mujer de bien, y de esta forma podréis estar seguras de que será útil para nosotros y para sí misma.» ${ }^{26}$

Respecto del Derecho privado, y por lo que a la capacidad jurídica se refiere, ésta viene atribuida no sólo por un criterio de madurez moral ${ }^{27}$, sino en función del sexo, pues las mujeres quedarán excluidas de la misma y su estatus se definirá como hijas, esposas o madres, es decir, "en relación con el hombre, único verdadero sujeto de derecho ${ }^{28}$. Al ser la "dependencia el estado natural de las mujeres» ${ }^{29}$, son incapaces de comportarse como sujetos autónomos de sus actos, lo que, a sensu contrario, significa la imposibilidad de ser considera-

24. Sobre la admisión de las mujeres en la ciudadania (julio 1790).

25. Ibíd.

26. También en su discurso Sobre el origen y los fundamentos de la desigualdad entre los hombres se refiere a este extremo, limitando la capacidad de gobierno de las mujeres a la influencia que puedan ejercer sobre sus maridos. RousseAu, J.J.: Del Contrato social. Discursos, Madrid, Alianza, 1989, p. 191. Como observa Amelia Valcárcel «la complementariedad se transforma en la palabra clave y de ella está excluida la justicia simétrica. No es conveniente ni deseable que los sexos neutralicen sus características normativas, sino que las exageren. Ello es garantía de orden. No son iguales, sino complementarios». VALCÁRCEL, Amelia: "La memoria colectiva y los retos del feminismo", en Amelia Valcárcel, Ma Dolors Renau y Rosalía Romero (eds.): Los desafíos del feminismo ante el siglo XXI, Sevilla, Hypatia, Instituto Andaluz de la Mujer, 2000, p. 27.

27. Lo que excluye a menores y «locos».

28. ARnAUd-DUC, Nicole: Op. cit., p. 109.

29. J.J. Rousseau lo afirma con estos términos en el Emilio. 
das como sujetos de derecho ${ }^{30}$. La autoridad marital se considera conforme al derecho natural y así se consagra en el Código civil napoleónico de 1804, que no supone más que una amalgama de Derecho romano y máximas consuetudinarias de inspiración germánica ${ }^{31}$, configurando a la mujer como propiedad del hombre cuya tarea fundamental es la producción de hijos ${ }^{32}$. Así, las relaciones entre los sexos se han articulado históricamente en torno a prácticas que, en la sociedad, marcan el camino de la diferencia sexual: el matrimonio y la procreación (familia) 33. $^{33}$

\section{EL CONSTITUCIONALISMO DEL ESTADO SOCIAL}

La ciudadanía, pues, nace con el Estado liberal de Derecho y su titularidad se amplía con los movimientos revolucionarios de los siglos XIX-XX. Pero no podemos hablar de Estado democrático porque se trata de una democracia formal, es decir, se amplía el elenco de sujetos (todos los varones, sin distinción de capacidad económica ni de raza) llamados a actuar en el ámbito público, en la toma de decisiones, pero no va más allá, pues el contenido del pacto social (homogéneo) permanece inalterado.

Mientras tanto, la industrialización es el vehículo en el que el sistema capitalista avanza, transformando radicalmente la totalidad de las relaciones sociales, en especial las relaciones en el denominado ámbito doméstico, perfilando los sujetos políticos que serán protagonistas del pacto constitucional contemporáneo.

\subsection{La industrialización y sus efectos: las bases del futuro «Estado del Bienestar"}

Cuando en el siglo XIX la industrialización ocupa gran parte de la producción que antes dominaban las familias, se produce una más tajante división entre el ámbito público y el privado que la que existía desde la época revolucionaria. Como afirma Nicholson, «la condición indispensable de la industrialización está en que la producción de bienes deje de ser una actividad familiar organizada en función de las relaciones de parentesco» ${ }^{34}$, por lo que si la separación entre lo político y lo económico es imprescindible para una economía de mercado, también resulta esencial a su desarrollo la separación entre lo económico y lo doméstico. De esta forma, las mujeres permanecen en este último ámbito, aje-

30. SLEDZIEWSKI, Elisabeth G.: «Revolución Francesa. El giro», en Georges Duby y Michelle Perrot (dirs.): Historia de las Mujeres, vol. 4, Madrid, Taurus, 2000, p. 55.

31. ARnAUd-DUC, Nicole: Op. cit., pp. 129 y ss.

32. KÄPPELI, Anne-Marie: «Escenarios del feminismo», en Georges Duby y Michelle Perrot (dirs.): Historia de las Mujeres, vol. 4, Madrid, Taurus, 2000, p. 523.

33. Sin olvidar la religión y los discursos legitimadores del sistema, desde la filosofía a los más diferentes discursos científicos.

34. Nicholson, Linda: Gender and History, Nueva York, Columbia University Press, 1986, citada por JenNingS, Ann L.: «¿Público o privado? Economía institucional y feminismo», en Marianne A. Ferber y Julie A. Nelson (eds.): Más allá del hombre económico, Madrid, Ed. Cátedra, col. Feminismos, 2004, p. 176. 
nas al mercado. El ámbito doméstico, pues, queda así «subordinado al mundo de la producción para el intercambio y el beneficio» ${ }^{35}$.

Eso no significa que las mujeres no accediesen al mercado de trabajo, pero sí que no lo hacen en las mismas condiciones que los varones. La nueva economía industrial requiere de la máxima disposición de tiempo para dedicarlo a la producción y, huelga decirlo, las mujeres no dispondrán del mismo tiempo que los varones debido a sus "obligaciones naturales» de cuidado del hogar y de la familia ${ }^{36}$. En este contexto hay que entender las reivindicaciones obreras por la consecución del denominado "salario familiar»" ${ }^{37}$, si bien éstas también deben explicarse en el contexto de la lucha de clases desde la perspectiva de género. Las aspiraciones de la clase obrera por mejorar su nivel de vida tienen como modelo el de la burguesía y es a ésta, precisamente, a quien se asocian las normas dominantes de género ${ }^{38}$, de tal forma que la adecuación a las mismas se asimila a un ascenso en la posición social, de acuerdo con la «teoría de la clase ociosa» según la cual los hombres mostrarían su estatus a través de sus mujeres $^{39}$.

35. Longino, Helen E.: «El debate y las críticas», en Marianne A. Ferbder y Julie A. Nelson (eds.): Más allá del hombre económico, Madrid, Ed. Cátedra, col. Feminismos, 2004, p. 236.

36. MARTINez SAMPere, Eva: Op. cit., p. 54.

37. Así como también la legislación falsamente proteccionista para las mujeres, como la prohibición del trabajo nocturno o de tipo nocivo, peligroso o insalubre. Excedería los límites de este trabajo explicar el fenómeno con toda su complejidad pero no podemos dejar de señalar que la incorporación de las mujeres al trabajo asalariado producía rechazo por los varones de su clase al considerar que la mayor oferta de mano de obra que éstas representaban impedía la consecución de una mejora, en términos globales, de sus condiciones de trabajo. Ya en 1869 Harriet Taylor recoge en su ensayo los argumentos que se esgrimen para impedir o dificultar a las mujeres su incorporación al mercado: «se arguye que conceder la misma libertad de ocupación a los hombres y a las mujeres daría lugar a un aumento peligroso del número de competidores que obstruyen el camino hacia casi todos los trabajos, con lo cual la retribución descendería», TAYLOR MILL, Harriet: «La emancipación de la mujer», en John Stuart Mill y Harriet Stuart Mill: La igualdad de los sexos, (trad. de J. Villa), Madrid, Guadarrama, 1973, p. 57.

38. Jennings, Ann L.: "iPúblico o privado? Economía institucional y feminismo», en Marianne A. Ferbder y Julie A. Nelson (eds.): Más allá del hombre económico, Madrid, Ed. Cátedra, col. Feminismos, 2004, p. 186.

39. Esta teoría fue formulada en 1899 por Thortein Veblen, fundador del institucionalismo económico estadounidense. Ann Jennings la resume de la siguiente forma: «a través de la historia, las mujeres han sido primero objetos poseídos, luego productoras de bienes de consumo para sus dueños y, finalmente, objetos inactivos dedicados a lucir la riqueza de los hombres. Los hombres pueden mostrar con mayor efectividad su estatus, que en la sociedad moderna depende de la propiedad y de la capacidad de consumir sin esfuerzo personal, a través de las mujeres. La reputación social del hombre depende de que su mujer se abstenga de un esfuerzo productivo en público. El vestido de la mujer, aunque se hizo más sencillo, continuó siendo un signo externo de riqueza suficiente para eximirla de la necesidad de un esfuerzo rentable; en cuanto al hombre, incluso cuando tenía que trabajar para ganar un sueldo, salvaba su buena fama manteniendo la ilusión de que su esposa disfrutaba de una vida ociosa. En consecuencia, la mujer aprendía a ser consumidora y ama de casa, ornamento del hombre; sólo las desacreditadas trabajan a cambio de dinero". JeNNINGS, Ann L.: Op. cit., pp. 167-168. 
Como sostiene Jennings «la asociación de la mujer con la familia y la del hombre con la economía de mercado forman el pilar que sostiene la distinción de género desde el siglo XIX ${ }^{40}$. No en vano, Adam Smith, el padre de la teoría económica convencional, ya sustentaba esta en una dicotomía: egoísmo en el mercado y altruismo en la casa, en la familia ${ }^{41}$. Ello supone que el hombre, como "cabeza de familia», es el gozne que une ambos ámbitos. El hombre, de forma absolutamente altruista, decide lo que es mejor para su familia. De esta forma la familia puede ser tratada, en términos económicos, como un agente individual en el mercado.

\subsection{La Constitución del Estado social: un nuevo pacto incluyente... sólo en apariencia}

El constitucionalismo posterior a la II Guerra Mundial supuso el robustecimiento de las estructuras del Estado de Derecho, convirtiendo a éste en Estado Constitucional, adquiriendo ahora la Constitución un significado diferente al del periodo del primer constitucionalismo. Las constituciones de posguerra normativizan la nueva forma de Estado, que es ahora el Estado social. A él se llega como consecuencia de la extensión de la representación política y de intereses (de clase) que concibe ahora al Estado no como un ente Soberano, sino como el lugar idóneo donde se produce la mediación, por medio de las instituciones de participación política de naturaleza tanto directa como representativa, entre los diferentes intereses presentes en la sociedad, una vez probado que el mercado, por sí solo, no produce esa mediación ${ }^{42}$, no garantiza un acuerdo entre los diferentes intereses, sino que lo que realmente produce es el sometimiento de unos intereses (los del capital) a otros (los del trabajo).

La Constitución del Estado social, supone la juridificación del conflicto de intereses presentes en la sociedad, se reflejan en su contenido los cambios en las relaciones sociales generados por el capitalismo, presentándose como un pacto o acuerdo entre el Capital y el Trabajo. Las constituciones de posguerra recogen así tanto supuestos del Estado liberal (derecho de propiedad, economía de mercado) como supuestos del Estado social (derechos laborales y otros de justicia social). Un pacto que, sin ser agradable para el capital, le permitía, no obstante, asegurarse la pervivencia de su modo de producción.

40. Ibíd., p. 183.

41. StRASSMANN, Diana: «No existe el mercado libre: la retórica de la autoridad disciplinal en la economía», en Marianne A. Ferbder y Julie A. Nelson (eds.): Más allá del hombre económico, Madrid, Ed. Cátedra, col. Feminismos, 2004, p. 89. En el mismo volumen FOLBRE, Nancy: «Socialismo feminista y socialismo científico", p. 143.

42. Asensi SABATER, J.: Introducción al Derecho Constitucional (Apuntes de cátedra), Alicante, Ganma, 1995, pp. 69 y 71. 
Ello conlleva un cambio no sólo de las estructuras políticas ${ }^{43}$ sino, principalmente, de las jurídicas: la supremacía normativa y la rigidez constitucional son las garantías jurídicas de la pervivencia del pacto constitucional (constituyente) entre capital y trabajo, aseguradas por nuevos órganos de justicia constitucional.

Así, con el advenimiento del Estado Social, que se concreta de forma generalizada en las Constituciones posteriores a la II Guerra Mundial, se renueva el pacto o contrato social entre sujetos que se reconocen tanto en el ámbito público (Estado) como en el privado (mercado: derechos ligados al Estado social). Las Constituciones propias del Estado Social pueden ser consideradas como las verdaderas Constituciones (normativas) porque suponen un marco jurídico integral de la sociedad. Son precisamente estas Constituciones las que permiten que ciertas desigualdades existentes en la realidad queden reflejadas en ellas, trasladándose, de esta forma, el conflicto al Derecho a través de la consagración en los textos constitucionales de los derechos sociales que, en la mayor parte de los casos, implica el reconocimiento de las relaciones privadas (entre individuos) como una relación de clase. Las Constituciones del Estado Social suponen la juridificación de la interrelación de clase, pero excluyen cualquier otra situación en que puedan encontrase los sujetos y cualquier otro tipo de relación entre los mismos ${ }^{44}$.

En este supuesto el concepto de ciudadanía deja, parcialmente, de ser una categoría jurídico formal en la medida en que el criterio de igualdad formal se compensa o corrige con un criterio de igualdad material, que tiende a corregir la disparidad de posiciones individuales en la sociedad (que no de intereses), intentando una igualdad de oportunidades. Se define así la ciudadanía, en el interior del Estado, como un estatuto legal de igualdad (real) de derechos y deberes, aunque la situación de igualdad real sigue siendo un objetivo no alcanzado, puesto que apenas alcanza a la categoría de trabajador ${ }^{45}$. No fructificó, en este aspecto, la idea de ciudadanía definida por Marshall como conjunto de derechos y deberes que va unido a la pertenencia plena a una sociedad, estando por definición dicha condición separada de las contingencias del mercado ${ }^{46}$.

43. Como consecuencia ahora de las políticas prestacionales y de intervención que la nueva forma de organización jurídico-política impone. Así, la pasada centralidad del Parlamento es ahora puramente formal por efecto de las organizaciones representativas de intereses y cede ante un predominio del Poder Ejecutivo en la fórmula del parlamentarismo racionalizado.

44. O, si no la excluyen, al menos su reflejo es sumamente débil, de tal forma que se deja a la coyuntura política la consideración de las desigualdades. Eso, por ejemplo, es lo que sucede con la Constitución española, cuyo art. 9.2, no se configura como derecho y, por tanto, no goza de las máximas garantías constitucionales reconocidas a éstos.

45. Salvando el derecho a la educación (indispensable de otro lado para conseguir mejores aptitudes de cara al ingreso en el mercado laboral) los derechos que se pueden catalogar como producto del Estado social y que reciben la más alta protección constitucional son los derechos de sindicación y huelga (art. $28 \mathrm{CE}$ ).

46. MARShall, T.: Ciudadanía y clase social, Madrid, Alianza Editorial, 1998. 
Pero ello supone que la parte de ámbito privado que pasa a tener consideración pública (con su consagración constitucional) se hace tal y como había quedado conformado ya en el XIX: a costa de la existencia del ámbito doméstico. Si afirmábamos, con Fraisse, que la Declaración de Derechos del Hombre y del Ciudadano de 1789 consagró la división del espacio público y privado, podríamos decir que las constituciones del Estado social consagran la división entre éstos y el denominado "doméstico» (o «vital» $)^{47}$.

Es funcional al mantenimiento de ese pacto (sobre todo por lo referente a la esfera privada del mercado) la subsistencia de las condiciones que permiten la vigencia del mismo. De esta forma, o bien permanece ignorado para el Derecho el ámbito privado-privado (el de la vida cotidiana o comúnmente denominado doméstico), de tal forma que hay una ausencia de regulación o bien se consagran las diferencias en el Derecho, asegurando la sujeción de las mujeres en el ámbito doméstico. Al ignorar esta realidad o reflejarla como tal en la norma no se puede hacer posible la igualdad formal, pues la correspondencia entre realidad y norma o bien es ignorada o bien subsiste ${ }^{48}$.

Por tanto, respecto de las mujeres esta correspondencia no desaparece. Sigue subsistiendo la correspondencia entre norma (no jurídica, sino social) y realidad, es decir, a las mujeres se les atribuye una categoría estamenta ${ }^{49}$. Las mujeres poseen una capacidad jurídica limitada en lo que se refiere al ámbito privado y ello, precisamente, hace que ya en este ámbito, se consagre normativamente la desigualdad respecto de los hombres. Desigualdad que, lógicamente, traspasa al ámbito público, impidiendo el acceso de las mujeres a la ciudadanía en sentido amplio hasta bien entrado el siglo $\mathrm{XX}^{50}$.

Así, a pesar del principio de igualdad formal, se acentúa la división (mayor separación, alejamiento) entre el ámbito público y el doméstico y eso precisamente es lo que hace posible el pacto interclase al que da origen el denominado

47. Sobre estas sucesivas conformaciones de espacios y sus implicaciones en los usos del tiempo que inciden en una diferente construcción del concepto de "privacidad» para hombres y mujeres véase MURILlo, Soledad: El mito de la vida privada. De la entrega al tiempo propio, Madrid, Siglo XXI, 2006.

48. Aunque el principio de igualdad formal y no discriminación por razón de sexo es una característica de las Constituciones del Estado social, su aplicación al resto del ordenamiento jurídico se ha realizado de forma paulatina, de tal manera que las normas directamente discriminatorias se han mantenido, hasta su depuración, durante periodos más o menos extensos de tiempo. Más extensamente vid. BALAGUeR CALlejón, $M^{a}$ Luisa: Mujer y Constitución. La construcción jurídica del género, Valencia, Cátedra, col. Feminismo, 2005.

49. Сово BeDíA, Rosa: Fundamentos del patriarcado moderno. Jean Jacques Rousseau, Madrid, Cátedra, 1995.

50. Entendiendo por ciudadanía amplia no sólo la más alta manifestación de ésta ejerciendo el derecho de sufragio activo y pasivo, sino también el derecho a recibir instrucción, a trabajar y gozar de la protección de las leyes. En todos los casos las mujeres han sido las últimas en acceder a los mismos. Una cronología detallada del reconocimiento a las mujeres del derecho de sufragio la ofrece SeVIlla Merino, Julia: Mujeres y ciudadanía. La democracia paritaria, Valencia, Institut d'Estudis de la Dona, 2004, pp. 155-156. 
Estado del bienestar ${ }^{51}$ y abunda en la teoría de la complementariedad de los sexos en que históricamente se ha basado la familia tradicional a través del matrimonio (institución garantizada constitucionalmente). Son las familias (entiéndase las mujeres) las que asumen obligaciones, servicios y cuidados, en definitiva prestaciones sociales que deberían ser responsabilidad pública. Las tareas de asistencia social (cuidado de niñas, niños, personas enfermas y/o ancianas) que constituyen unas necesidades mínimas de bienestar se hacen descansar en las familias, es decir, en las mujeres. La emancipación de las mujeres no es más que un mito si persiste la desigualdad privada. Y ello pasa por la reformulación del pacto fundador, de nuevo, del Estado, esta vez sí, social ${ }^{52}$.

\section{CIUDADANAS, SÍ, PERO SÚBDITAS, TAMBIÉN}

Las mujeres hemos tenido que «encajarnos» en el principio de igualdad formal, representado por la ciudadanía, tal y como se recoge en nuestras constituciones. Pero la ignorancia de una parcela de la realidad a la que históricamente se nos ha adscrito a las mujeres (ámbito doméstico) provoca que nuestra participación en el proceso de toma de decisiones (y, por tanto, en la configuración de derechos) sea limitada y claramente insuficiente para acabar de conformarnos como sujetos de derechos ${ }^{53}$.

No se puede ignorar la rémora que supone nuestra reclusión en el ámbito privado-privado ${ }^{54}$, pues tanto el ámbito público como el privado (entendido como el mercado y el ámbito de las relaciones sociales extrafamiliares) ya están conformados con arreglo a unas pautas (masculinas) que no hemos podido diseñar pero hemos tenido que aceptar y adoptar y a las que se nos conmina

51. Sobre el componente estructural de género del Estado de bienestar realiza un acertado análisis ASTELARRA, Judith: "Nuevos desafíos para el ejercicio de la ciudadanía de las mujeres», en Amelia Valcárcel, Ma Dolors Renau y Rosalía Romero (eds.): Los desafíos del feminismo ante el siglo XXI, Sevilla, Hypatia, Instituto Andaluz de la Mujer, 2000, pp. 237 y ss.

52. CAMPS, Victoria: "La emancipación femenina y el estado del bienestar», Meridiam, 29 (2003), pp. 6-7. Aunque la citada filósofa no se refiere directamente a la necesidad de reforma de la Constitución, sino a la necesidad de ampliación de la agenda pública que suponga el ejercicio de una política "auténticamente social», considerando a estos efectos que el mejor instrumento para ello es la democracia paritaria. Sobre la democracia paritaria véase SEVILLA MERINO, Julia: Op. cit., y de la misma autora «Paridad y Constitución» en Teresa Freixes Sanjuán y Julia Sevilla Merino (coords.): Género, Constitución y Estatutos de Autonomía, Madrid, Instituto Nacional de Administración Pública, 2005, pp. 205-236.

53. SeVIlla Merino, Julia: Mujeres y..., op. cit, p. 29 y ss. La misma autora lo expresa muy gráficamente al asimilar la incorporación de las mujeres al pacto social "como si de un contrato de adhesión se tratara, firmando en bloque, sin que les cupiese definir los posibles términos de ese contrato», SeVILla Merino, Julia: «Paridad...», op. cit., p. 216.

54. Incluso se ha hecho referencia a esta reclusión con la expresión «la trampa de la familia». Vid. ARNAUD-DUC, Nicole: Op. cit., p. 129. 
a adaptarnos ${ }^{55}$. Así, mientras se proclama la ciudadanía de las mujeres en lo público, seguimos siendo con frecuencia súbditas en lo privado ${ }^{56}$.

El principio de igualdad formal y no discriminación ha sido la brecha que se ha abierto para incluir en el pacto a otras relaciones entre individuos más allá de la clase. Ello ha provocado un desbordamiento de los sistemas sociopolíticos occidentales y democráticos, pues ha sido el resquicio por el que los sujetos «no esperados, incluso de no llamados (...) se han colado casi a hurtadillas por las puertas abiertas de los estatutos de ciudadanía, y que se hallan aún en fase de acomodo. Mientras tanto, se les mantiene en precario y se les subsidia para que sobrevivan, pero se les acusa de su retraso en la integración plena. Se les distingue cuando obtienen un logro importante contra viento y marea, pero no se les allanan los escollos para que logren más. Cuando no superan algún obstáculo se argumenta que no quieren, no pueden o no saben $»^{57}$.

Resulta ya casi ocioso afirmar que el acceso de las mujeres a todos los ámbitos (excluido el doméstico) se realiza desde posiciones diferentes a las de los varones, pues éstos no están gravados por el denominado «impuesto reproductivo", de un lado, y, de otro, se apropian de la que Rosa Cobo ha dado en llamar -siguiendo a Jónasdóttir- "plusvalía de dignidad genérica» ${ }^{58}$. Efectivamente, el trabajo realizado por las mujeres en el ámbito doméstico es la consecuencia (y condición de existencia, a la vez) del pacto que da lugar a las Constituciones del Estado social, que consagran al trabajador (varón) como único o principal proveedor económico de la familia. Frente al trabajo gratuito (y, por tanto, carente de valor, en términos de mercado, y, por tanto, de reconocimiento social) de las mujeres se alza el trabajo remunerado de los varones, único trabajo considerado como tal y al que se le otorga valor y reconocimiento. De otro lado, no hay que menospreciar el hecho de que, en el seno familiar, las tareas de cuidado y amor proporcionadas por las mujeres tienen un único sentido, son unidireccionales, pues el varón se apropia de ellas sin compensación o aportación equitativa. Es una suerte de explotación que agota las reservas emocionales de las mujeres ${ }^{59}$.

55. En palabras de Elena Simón «las sociedades aparente y formalmente avanzadas viven ajenas a las reformas que sobre las divisiones sexo-género se deben efectuar, instaladas en un cierto limbo de igualdad formal y por eso asistimos a una evolución mucho más lenta de lo que cabría esperar, de lo que sería previsible. Se espera y se pretende que sean exclusivamente las mujeres las que se adapten con sus propias fuerzas, individualmente, con uñas y dientes si fuera menester y que peleen por arrancar para ellas parcelas del bien común.(...) Las democracias no avanzarán ni saldrán de su crisis si no se plantean un giro ideológico que tenga sus prioridades en la atención a las personas, consideradas éstas como seres sexuados, y al tipo de relaciones que mantienen entre ellas». SimÓN RODRíGUEZ, Elena: Democracia vital. Mujeres y hombres hacia la plena ciudadanía, Madrid, Ed. Narcea, 2002, p. 141.

56. RENAU, Mª Dolors: «De súbditas a ciudadanas», Meridiam, 36 (2005), p. 13.

57. Simón RodríGUeZ, Elena: Democracia vital...op. cit., p. 24.

58. Сово, Rosa: «Globalización y nuevas servidumbres de las mujeres», en Celia Amorós y Ana De Miguel (eds.): Teoría Feminista: de la Ilustración a la globalización, vol. 3, Madrid, Minerva Ediciones, 2005, pp. 287 y ss. La autora recuerda que ha sido la economista Ingrid Palmer la que ha acuñado el término «impuesto reproductivo».

59. СовО, Rosa: «Globalización..., pp. 288. 
Todo ello explica, en buena medida, la costosa y precaria inserción de las mujeres en el ámbito laboral, los obstáculos en la promoción profesional, la minoritaria presencia en las instituciones políticas y en puestos de responsabilidad; en definitiva, la subsistencia de la posición subordinada, en términos generales, de las mujeres.

La cuestión, pues, se reconduce una y otra vez a la necesidad de una nueva reformulación del pacto, a la inaplazable articulación de una "Constitución sustancialmente diferente ${ }^{60}$.

\section{HACIA UN NUEVO PACTO}

Si las actuales democracias constitucionales, se configuran de una forma pluridimensional ${ }^{61}$, es decir, no significan sólo una democracia formal (quién y cómo se adoptan las decisiones) sino, fundamentalmente, una democracia material (que determinados contenidos - principios y derechos- condicionan la toma de decisiones, o sea, se erigen en límites de la democracia formal), necesariamente hay que concluir que son incompletas porque condicionan la existencia de las mujeres como sujetos de derecho.

En tanto no logremos asegurar nuestros derechos e introduzcamos así el «ámbito doméstico» en el espacio jurídico político a través de su inclusión en el pacto de manera irreversible no seremos sujetos de derechos. Se exige, pues, el reconocimiento pleno de la igualdad de mujeres y hombres como principio fundamental del sistema democrático y del Derecho, de la democracia constitucional ${ }^{62}$. Esta inclusión hay que hacerla en sentido "fuerte», es decir, en las normas jurídicas supremas en las que se regula la convivencia de una comunidad. Se plantea, por tanto su introducción en la Constitución, pues hasta ahora dicho reconocimiento se realiza a través de leyes u otras categorías normativas inferiores jerárquicamente ${ }^{63}$, si bien es cierto que en el último decenio se han reformado textos constitucionales históricos de nuestro entorno. Así Alemania, Francia, Portugal, Bélgica e Italia han reformado sus normas supremas a fin de

60. Ventura Franch, Asunción: «Igualdad real y reforma constitucional», en Teresa Freixes Sanjuán y Julia Sevilla Merino (coords.): Género, Constitución y Estatutos de Autonomía, Madrid, Instituto Nacional de Administración Pública, 2005, p. 269. Un magnífico análisis del Derecho constitucional español desde la perspectiva de género realiza la misma autora en Las mujeres y la Constitución Española de 1978, Madrid, Instituto de la Mujer, 1999.

61. FerRAJOLI, Luigi: «Sobre la definición de «democracia». Una discusión con Michelangelo Bovero", Isonomía, 19 (2003), especialmente pp. 230 y ss.

62. Es lo que plantea Rosa Cobo cuando afirma que «La perspectiva de la igualdad reivindica la radicalización de la ciudadanía y de la democracia para las mujeres: tanta ciudadanía y tanta democracia como sean necesarias para que las mujeres se constituyan en sujetos». COBO, Rosa: «Sexo, democracia y poder político», Feminismo/s, 3 (2004), p. 25.

63. Me refiero a la nueva normativa de igualdad, en todos los ámbitos, desde el comunitario hasta el municipal. 
reconocer y visibilizar a las mujeres como sujetos constitucionales ${ }^{64}$. Sin embargo, ello se revela insuficiente.

Desde la perspectiva histórica podemos apreciar que la extensión de los derechos ya existentes a sujetos excluidos de ellos en el origen no alteran las esencias del pacto social. Esta afirmación se evidencia si se tiene en cuenta que las sucesivas ampliaciones del sujeto político a través de las periódicas extensiones del sufragio no se tradujeron en un inmediato reconocimiento de nuevos derechos, sino que su consecución fue un proceso gradual, susceptible de sufrir recortes o involuciones cuando se trata de fijar los términos o líneas esenciales del pacto de convivencia. Así se puso de manifiesto en las Constituciones del Estado social, en las que las exigencias de la parte de la clase trabajadora (de reciente incorporación al pacto) se incorporan al mismo con menor presencia, tanto cuantitativa como cualitativa ${ }^{65}$, respecto de la clase dominante.

Las mujeres sufrimos un proceso que guarda alguna similitud con éste: accedimos al ámbito de toma de decisiones con las Constituciones contemporáneas (del Estado social), pero nuestras reivindicaciones se han ido atendiendo gradualmente en diversos instrumentos normativos de carácter infraconstitucional desde una base sumamente frágil ${ }^{66}$, de tal forma que su afianzamiento y refuerzo requiere de su inclusión en la norma suprema que articula la convivencia ${ }^{67}$, pues sólo así se pueden evitar riesgos involucionistas ante nuevos desafíos ligados al

64. Fue Alemania la primera que modificó su Constitución en 1994 añadiendo en su artículo 3 un mandato expreso a los poderes públicos para la consecución de una igualdad real y efectiva entre mujeres y hombres. En julio de 1999 fue Francia la que reformó dos artículos (3 y 4) de la Constitución de 1958 a fin de introducir la posibilidad de que la ley electoral favorezca la igualdad de mujeres y hombres. La revisión de la Constitución portuguesa en 1999 se plasmó en la redacción del artículo 109, que enfatiza la igualdad en la perspectiva de la participación. Y en 2002, se reforma la Constitución belga, dando nueva redacción al art. 10 y añadiendo un nuevo artículo (11.bis) referido al igual goce de los derechos y libertades por hombres y mujeres, especialmente por lo que respecta al acceso a los órganos de toma de decisiones en todos los niveles. Por último, la Constitución italiana, reforma el primer apartado de su artículo 51 para reforzar la promoción de la igualdad de oportunidades entre mujeres y hombres respecto a la participación pública.

65. Como se desprende de los distintos sistemas de protección establecidos según el tipo de derechos sociales reconocidos.

66. En el caso español dicha base es la denominada igualdad material del art. 9.2 C.E.

67. Como propone la Red Feminista de Derecho Constitucional en «Bases para la incorporación de la perspectiva de género en las reformas de los Estatutos de Autonomía», en Teresa Freixes Sanjuán y Julia Sevilla Merino (coords.): Género, Constitución y Estatutos de Autonomía, Madrid, Instituto Nacional de Administración Pública, 2005. En idéntico sentido y en ese mismo volumen MARTINEZ SAMPERE, Eva: «Hacia la plena ciudadanía». Acertadamente apunta esta autora al respecto que «esta transformación fundamental es en nuestros días el punto de partida de la articulación de la sociedad democrática. Por eso, la paridad entre mujeres y hombres en el reparto del poder; el derecho de cada una y cada uno a combinar la vida personal, familiar y profesional; la educación en la igualdad para la eliminación psicológica de la mentalidad sexista contra mujeres y niñas, y el mínimo vital garantizado a cada individuo, deben estar en la Constitución y en los Estatutos de Autonomía y, mediante su fuerza normativa y con la colaboración de toda la sociedad, hacerse realidad», p. 66. También en el mismo volumen DURAN FEBRER, María: «La constitucionalización de los derechos de género", realiza propuestas concretas de inclusión de nuevos derechos y otras previsiones en nuestro texto constitucional, pp. 285-287. 


\section{fenómeno de la globalización, no sólo de carácter económico ${ }^{68}$, sino también ideológico ${ }^{69}$ y avanzar en la consecución de una verdadera democracia.}

68. Podríamos calificar como riesgos más evidentes las consecuencias del proceso de globalización. Con respecto a la globalización, se ha producido, en los últimos años, una literatura relativamente abundante que insiste en la feminización de la pobreza (los informes de la ONU al respecto son definitivos). Los procesos globalizadores han contribuido al desplazamiento y reemplazo de la categoría fordista del salario familiar por el trabajo de las mujeres y los inmigrantes, que aparecen como oferta de trabajo a la que se puede imponer bajos salarios y ausencia de derechos laborales. Pero, fundamentalmente, son los programas de ajuste estructural impuestos por los organismos financieros internacionales los que han producido perniciosas consecuencias para las mujeres. Como acertadamente señala Rosa Cobo, el crecimiento del trabajo gratuito de las mujeres en el hogar es uno «de los efectos más rotundos de los programas de ajuste estructural». Y ello debido a que los escasos recursos del Estado del bienestar se ven drásticamente recortados, por lo que las funciones que anteriormente eran (parcialmente) cubiertas por el sector público, revierten de nuevo al ámbito familiar. Además, las condiciones macroeconómicas que estos programas imponen, reflejadas sobre el sistema impositivo, las políticas monetarias y tipos de cambio, también provocan un impacto negativo sobre las mujeres que las colocan en una situación de desigualdad estructural con respecto de los varones. Para un análisis más detallado vid. Сово, Rosa: "Globalización... También SASSEN, Saskia: Contrageografías de la globalización. Género y ciudadanía en los circuitos transfronterizos, Madrid, Ed. Traficantes de sueños, 2003, especialmente pp. 74 y ss.

69. Me refiero aquí no precisamente al denominado "pensamiento único» con el que se identifican las tesis neoliberalistas que legitiman las trasformaciones impuestas por la globalización económica, sino al discurso que se erige en oposición a éste y que, simplificadamente, se representa por el denominado multiculturalismo. La permeabilidad de nuestras sociedades a pretensiones multiculturalistas impugnan el paradigma individualista y es obvio que ello comportaría consecuencias nefastas para las mujeres. Resulta especialmente preocupante que estas tesis se hayan importado ya al ámbito del Derecho constitucional bajo la apariencia de un «neoconstitucionalismo" superador de las contradicciones del modelo surgido en el contexto revolucionario de la Ilustración y sean contempladas con cierto entusiasmo como nuevos paradigmas desde los que «reconstruir una teoría del constitucionalismo», como propone CABO MARTín, Carlos de: Teoría Constitucional de la Solidaridad, Madrid, Marcial Pons, 2006. 



\section{LA IGUALDAD ENTRE MUJERES Y HOMBRES EN LA CONSTITUCIÓN ESPAÑ̃LA DE 1978}

Má ÁNGELES MORAGA GARCÍA Universidad de Alicante

La igualdad entre mujeres y hombres es un principio constitucionalmente reconocido en nuestro ordenamiento jurídico. Sin embargo la realidad viene a demostrar continuamente la persistencia de importantes escenarios de desigualdad por razón de género, que sitúan a las mujeres en una posición de desventaja, cuando no de clara inferioridad, frente a la de los hombres.

No es una afirmación tópica o gratuita, cualquiera puede verificarla con la simple observación de su entorno familiar, social, laboral, etc. A continuación, citaré algunos ejemplos que vienen a corroborar la situación de desigualdad que continua sufriendo la mujer en nuestro país actualmente:

- España es el cuarto país de la Unión Europea con menor proporción de mujeres que trabajan fuera de casa mientras tienen hijos menores de 12 años. Así lo demuestra un estudio de la oficina estadística comunitaria, EUROSTAT, elaborado el pasado año 2005. A tenor de ese trabajo, la tasa de empleo entre las españolas con niños pequeños alcanza el $51,2 \%$, frente al $60,4 \%$ de media comunitaria. Sólo sobrepasan este índice las madres de Italia, Hungría y Malta.

- En nuestro país, cerca de 400.000 mujeres abandonan su empleo cada año por razones personales o para asumir responsabilidades familiares, según el Instituto Nacional de Estadística. En concreto en el año 2004, dieron ese paso 379.500 trabajadoras, según revela la Encuesta de Población Activa. Mientras que entre los trabajadores varones sólo tomaron esa decisión un total de 14.500 .

- El salario medio de la mujer en España es un 34,7 \% inferior al del hombre, según el informe sobre el mercado laboral publicado por la empresa de trabajo temporal Manpower en el mes de enero de 2005. La menor desigualdad tiene lugar en aquellas compañías de 20 a 49 trabajadores en las que los hombre ganan de media un 13,8\% más que las mujeres, mientras que son las empresas de 100 a 499 trabajadores las que presen- 
$\tan$ las mayores diferencias salariales ente sexos (hasta un 50\%, siempre a favor del hombre).

Asimismo este estudio indica que en el año 2001 el sueldo medio de la mujer en el sector privado era sólo de 992 euros brutos al mes, un $50 \%$ menos que el del hombre, que ascendía a 1.489 euros. Estas diferencias salariales se reducen hasta el $44 \%$ en los niveles educativos más altos, mientras que en los niveles inferiores el salario de la mujer se sitúa un $56 \%$ por debajo. De igual manera, el estudio señala que la desigualdad se acrecienta a medida que aumentan los años de experiencia laboral. En este caso, mientras que las mujeres con experiencia de entre 5 y 29 años cobran entre un $12 \%$ y un $28 \%$ menos que el hombre, a partir de los 29 años de experiencia el salario del hombre llega a ser un $73 \%$ superior.

- He aquí un ejemplo paradigmático: nuestro país tiene, desde hace dos años, el primer Gobierno paritario de la historia, contando a su vez con la primera Vicepresidenta del Gobierno. Sin embargo, la paridad no se traslada a los sucesivos niveles del poder. Según datos del Instituto Nacional de Estadística correspondientes a 2004, sólo hay un $15 \%$ de Secretarias de Estado (3 entre 17) y un 23\% de Directoras Generales. Esta desigualdad se dispara en las Delegaciones del Gobierno, donde el desequilibrio crece sensiblemente: 2 mujeres Delegadas del Gobierno, frente a 17 hombres, lo que supone un $10 \%$.

- Si nos adentramos en la representación exterior del Estado y atendiendo a los datos del propio Ministerio de Asuntos Exteriores, en España hay una plantilla total de 800 Diplomáticos, de los cuales sólo 150 son mujeres.

Asimismo, de un total de 144 embajadores destinados en delegaciones diplomáticas o en misiones especiales, sólo 12 son embajadoras -un 7,7\%-. Ahondando en el ejemplo, en lo que llevamos del año 2006, sólo se ha nombrado una embajadora, mientras que se han designado seis embajadores, todos ellos con sede diplomática en distintos países, mientras que la embajadora lo es en misión especial.

- En la política local la realidad no es más esperanzadora: Tras las elecciones locales de 2003, en nuestro país se proclamaron 15.443 concejalas frente a 41.048 concejales -según datos del INE-. Eso supone que únicamente un $27 \%$ de los regidores municipales mujeres. Alcaldesas hay aún menos (un 12,48\%).

- Otra tanto podemos constatar en la Justicia. A la luz de los datos del INE de 2004, hay 4.451 jueces y magistrados en activo. De ellos, el 44,80\% son mujeres, pero la mayoría ejerce sus funciones en el escalón más bajo, el de jueces, donde son más que hombres (64,13\%). Sin embargo sólo hay un $10 \%$ de mujeres entre los vocales del Consejo General del Poder Judicial y un $23 \%$ en el Tribunal Constitucional.

- En los Consejos de Administración de las empresas que cotizan en bolsa incluidas en el IBEX 35 -según datos del Instituto Nacional de la Mujer, año 2005- no había ninguna presidenta, y sólo un 2,32\% de los puestos de consejero eran ocupados por mujeres. 
- Otro ejemplo, en este caso del mundo de la cultura y de la ciencia: De las diez Reales Academias Españolas, sólo la de Farmacia supera los dos dígitos en cuanto al porcentaje de representación femenina $(12 \%$ de mujeres), siendo que en dos de ellas no se sienta ninguna mujer en sus sillones: en la Real Academia de Ciencias Veterinarias y en la Real Academia de Ciencias Políticas y Morales. Al parecer no hay mujeres capaces de alcanzar tales responsabilidades en nuestro país.

- En el ámbito universitario, a pesar de que la población universitaria de mujeres supera a la de los hombres, (54\%) y cada año se gradúan más alumnas $(59,10 \%)$ que alumnos, según datos del Ministerio de Educación. A medida que avanza el escalafón académico, la presencia de las mujeres se va perdiendo, así de las 8.619 cátedras de universidad sólo el $13,7 \%$ tienen al frente a una mujer.

Todos los ejemplos expuestos no son anecdóticos, su persistencia en los inicios del siglo XXI viene a demostrar la pervivencia de patrones de desigualdad, que ponen en entredicho la tan proclamada igualdad entre mujeres y hombres. La igualdad sigue siendo un objetivo inalcanzado, que tiene una mayor presencia en los textos jurídicos que en la realidad social. Que esta realidad jurídica abra paso a una nueva realidad social, es un trabajo de todas y todos, por este motivo resulta necesario que continuemos insistiendo en esta trascendental reivindicación.

\section{ANTECEDENTES}

La consecución de la igualdad real o material es uno de los objetivos del Estado Social, reconocido en las Constituciones europeas de la segunda mitad del siglo XX. Sin embargo, como demuestran los ejemplos que anteceden, lo cierto es que la tan pretendida igualdad real entre mujeres y hombres queda bastante lejos aún.

Como muy bien destaca María Luisa Balaguer, haciendo referencia a características del constitucionalismo moderno señaladas por Carlos De Cabo, «el Estado social y democrático de Derecho es una conquista de la ciudadanía, cuya evolución en Europa se inicia en la segunda mitad del siglo XIX y no llega a implantarse hasta bien entrado el siglo XX. La positivación del derecho como garantía jurídica y su efectividad, junto al de la generalidad de la ley y la separación de poderes del Estado, son instrumentos que permiten el desarrollo de las democracias formales que se generan en ese periodo histórico. Pero todas estas instituciones y garantías no comprenden a las mujeres, que accederán formalmente a los derechos políticos con bastante retraso sobre los hombres, y que tendrán restringidos los derechos civiles hasta fechas relativamente recientes ${ }^{1}$.

El ordenamiento jurídico español, como el resto de los ordenamientos fruto del Estado Liberal, no fue una excepción, y privó a las mujeres de los derechos

1. BALAgUer, Ma Teresa: Mujer y Constitución. La construcción jurídica del género, Madrid, Feminismos, 2005, p. 81. 
alcanzados por este modelo de Estado. Resultando especialmente negativa la influencia del Código de Napoleón de 1805 en nuestro Código Civil, que dejó a la mujer una exigua capacidad jurídica, y además la supeditó al marido o al padre para la realización de cualquier tipo de negocio jurídico.

En esta línea, ninguno de los textos constitucionales españoles hasta 1931 hacía referencia alguna a la igualdad de trato sin discriminación por razón de sexo.

Fue precisamente la Constitución Republicana de 1931, tan avanzada en muchos aspectos, la que supuso también un importante avance para las mujeres, en la medida que por primera vez se reconoció la igualdad jurídica entre mujeres y hombres. En concreto, el artículo 25 de texto constitucional establecía expresamente que no podía "ser fundamento de privilegio jurídico la naturaleza, la filiación y el sexo».

Respecto a la participación política, su artículo 36 proclamaba que «los ciudadanos de uno y otro sexo, mayores de veintitrés años, tendrán los mismos derechos electorales conforme determinen las leyes», reconociendo con ello el derecho de voto para la mujer.

Asimismo, en su artículo 41 se reconocía el matrimonio civil, lo que a su vez permitió instaurar el divorcio a través de la Ley de 2 de marzo de 1932. Esta misma Ley reconoció, entre otros aspectos, la igualdad de los hijos, suprimiendo la distinción entre hijos legítimos e ilegítimos, además de incorporar el término "autoridad del padre y de la madre», frente a la clásica autoridad paterna, aceptándose también el mutuo consentimiento para obtener el divorcio.

Lamentablemente esta nueva situación constitucional tuvo una escasa vigencia, que tan solo alcanzó hasta el estallido de la Guerra Civil, en 1936. El triunfo del golpe militar encabezado por el general Franco supuso un retroceso de siglos en el camino de la ansiada igualdad.

Resulta evidente que la instauración de un régimen dictatorial y fascista necesariamente había de comportar la limitación y hasta la negación de derechos para todas las personas, hombres y mujeres, pero lo cierto es que el régimen franquista incidió de una manera significativa en la vuelta a la subordinación jurídica de estas últimas, aprobándose numerosas normas jurídicas que tenían por finalidad conseguir el sometimiento de las mujeres, a fin de devolver a la mujer a su posición tradicional.

En este sentido, se suprimiría la escuela mixta, se «liberaría» a la mujer casada del taller y del trabajo - una medida acompañada de primas por maternidad y prohibición del ejercicio de profesiones liberales-, se derogaría la ley del matrimonio civil y la ley del divorcio -con efectos retroactivos-, se penalizó el aborto, el adulterio y el concubinato. También se incrementó la mayoría de edad a los 25 años, obligando a la mujer joven a permanecer en el hogar paterno hasta el momento de casarse o entrar en el convento, etc.

En las leyes franquistas la familia se identificaba con el matrimonio católico, de tal manera que sólo aquellas familias legalizadas merecían protección jurídica. Este tratamiento repercutía directamente en los hijos, que según hubieran sido engendrados dentro o fuera del matrimonio, gozaban de más o menos derechos. Pero además, la familia no sólo era el lugar natural de las mujeres, 
sino que además ésta tenía un cabeza de familia, el marido, de tal forma que la mujer, cuando pasaba a formar parte de la familia, pasaba también a depender de la potestad del marido. El marido era quien tenía la potestad dentro del ámbito familiar y quien podía hacer y deshacer de acuerdo con lo que consideraba más oportuno. La ley le reconocía como el único interlocutor valido.

Por lo tanto, la desigualdad jurídica entre los cónyuges era evidente, existiendo la llamada licencia marital -que no fue derogada las la Ley 14/1975, de 2 de mayo- que obligaba a la mujer casada bajo régimen de gananciales -que era el que regia el derecho común- a que su marido firmara antes que ella autorizándole, por ejemplo, a abrir una cuenta corriente, solicitar un pasaporte, y firmar una escritura o cualquier contrato. Incluso con respecto a la disposición de sus bienes propios, la mujer casada necesitaba la autorización marital. Además el marido era el administrador único de la sociedad de gananciales atribuyéndole el Código Civil la facultad de enajenar, a titulo oneroso, los bienes de la sociedad de gananciales.

Asimismo el franquismo dedicó un especial énfasis a controlar todo lo relacionado con el comportamiento sexual de las personas, especialmente de las mujeres, lo que suponía tipificar en el Código Penal como delitos, situaciones que se calificaban de atentados al honor de las mujeres, y sobre todo, al de sus maridos. Se penalizaba el aborto, así como el uso de los anticonceptivos. También el Código Penal incluía un titulo especifico que se refería a los delitos contra la honestidad, donde se contemplaban las figuras jurídicas de la violación, los abusos deshonestos, el escándalo publico, el estupro, la corrupción de menores, el rapto y los delitos relativos a la prostitución.

Otro ámbito vedado a las mujeres era el mundo laboral, limitándose su acceso al trabajo remunerado. El trabajo de las mujeres se situaba en el ámbito doméstico y cuando realizaban trabajos remunerados o fuera del hogar, era un trabajo provisional y auxiliar con respecto al de los hombres.

Siendo lo cierto que durante los cuarenta años que duró la dictadura en España, prácticamente no se modificaron las leyes discriminatorias contra la mujer, a pesar de que tanto la normativa internacional como la de Comunidad Europea estaban dando pasos muy importantes en el reconocimiento de la igualdad de género.

Con este escenario, la aprobación de la actual Constitución de 1978 supuso un giro copernicano, un cambio radical, que respondía a las tendencias universales que reclamaban el reconocimiento de la igualdad de las mujeres y los hombres. Aunque lo cierto, como muy bien señala Asunción Ventura, es que el texto constitucional no contiene una mínima perspectiva de género, situando el derecho de la mujer a la igualdad en su artículo 14, junto con el resto de la interdicción de las desigualdades sociales².

2. VenturA, Asunción: Las Mujeres y la Constitución Española de 1978, Madrid, Instituto de la Mujer, 1999. 


\section{CONCEPTO DE IGUALDAD EN LA CONSTITUCIÓN}

La primera referencia a la igualdad en nuestra Constitución aparece, en el artículo 1.1 C., que se refiere a la igualdad como uno de los «valores superiores del ordenamiento jurídico", esto es, como una condición ideal, a la que los poderes públicos deben tender a alcanzar. Por lo tanto, dicho precepto sitúa a la igualdad como un valor superior que debe inspirar todo el ordenamiento jurídico.

De otra parte, en el artículo 9.2. del texto constitucional, aparece recogida la llamada "Igualdad Material», como un mandato dirigido a los poderes públicos que exige que se promuevan las condiciones para que la igualdad de los individuos y de los grupos en que se integran sean reales y efectivas. Con ello, se autoriza al legislador para desarrollar una acción igualizante, más allá de la mera igualdad formal.

Finalmente, el articulo 14 reconoce que los españoles son iguales ante la ley, sin que pueda prevalecer discriminación alguna, entre otras, por razón de sexo. Recogiéndose la llamada "Igualdad Formal», que se define en dos vertientes distintas: la igualdad ante la ley y la igualdad en la ley.

\subsection{La igualdad ante la Ley o en la aplicación de la Ley}

La igualdad ante la Ley puede definirse como la obligación que tienen los poderes públicos encargados de aplicar la ley, de aplicarla sin excepciones ni consideraciones personales. De esta forma el Tribunal Constitucional en su Sentencia 8/1981, de 30 de marzo señala que la igualdad en la aplicación de la ley impone que «un mismo órgano no puede modificar arbitrariamente el sentido de sus decisiones en casos sustancialmente iguales, y que cuando el órgano en cuestión considere que debe apartarse de sus precedentes tiene que ofrecer para ello una fundamentación suficiente y razonable».

Pero no obstante ello, el T.C. admite la diferencia de trato, en la aplicación de la Ley, cuando ésta no sea arbitraria por estar razonablemente justificada. De esta forma el propio Tribunal ha ido estableciendo una serie de requisitos que deben tenerse en cuenta para apreciar la existencia o no de desigualdad en la aplicación de la ley:

a) Que se trate de un mismo órgano judicial: Es doctrina reiterada del Tribunal Constitucional desde su inicio que «el principio de igualdad en la aplicación de la ley sólo puede ser invocado en caso de que las resoluciones aducidas procedan del mismo órgano judicial» (STC 2/1983, de 24 de enero, 105/87, de 22 de junio, 17/1988, de 20 de junio; 126/1988, de 24 de junio; 132/1988, de 4 de julio; 134/1991, de 17 de junio; 245/1994, de 15 de septiembre; 25/1999, de 8 de marzo; 32/1999, de 22 de abril; 59/2000, de 2 de marzo; 102/2000de 10 de abril; 122/2001, de 4 de junio y 140/2003, de 14 de julio, entre otras.

b) Que los supuestos de hecho sean idénticos, "pues sólo si los casos son iguales entre sí puede efectivamente pretenderse que la solución dada para uno 
sea igual a la del otro» (STC 140/2003, de 14 de julio, en la que se hace referencia numerosas sentencias anteriores que se pronuncian al respecto).

c) Que el cambio de criterio en la aplicación de la norma se base en una fundamentación suficiente y razonable: lo que no se permite es modificar el sentido de las decisiones de forma arbitraria, pero sí que se pueda variar el sentido de la resolución siempre y cuando se ofrezca una fundamentación suficiente y razonable en la que descasen dicho cambio de criterio. Así, la STC 142/1985, de 23 de octubre señala que será arbitraria aquella diferencia de trato que obedezca «a una deliberada modificación de los criterios de interpretación de la legalidad hasta entonces mantenidos, apreciable mediante cualquier elemento de juicio externo».

\subsection{La igualdad en la Ley o igualdad de trato}

La segunda vertiente de la igualdad formal que contempla el artículo 14, es la llamada Igualdad en la Ley o Igualdad de Trato, a fin de evitar situaciones de desigualdad entre los ciudadanos, lo que implica la prohibición de cualquier forma de arbitrariedad normativa.

Pero ese mandato de igualdad de trato, implica trato igual a situaciones iguales, lo que no impide diferencias de trato a situaciones diferentes. Tales diferencias de trato han de derivarse de diferencias de situación, que deben estar debidamente justificadas y ser razonables. En este sentido el Tribunal Constitucional ha establecido ciertos requisitos que sirven para determinar si una desigualdad de trato vulnera o no el mandato de igualdad formal del artículo 14 de la Constitución. Se trata del llamado «test o juicio de constitucionalidad»; que consiste en examinar, en cada caso concreto, si la diferencia de trato obedece a fines lícitos y relevantes, por un lado; y por otro, si esa diferencia de trato es proporcionada al fin perseguido.

Al legislador, por tanto, le está permitido establecer un trato distinto para los ciudadanos en aquellos casos en los que tenga que resolver situaciones de hecho diferentes, cuyo contenido exija una decisión distinta. En este sentido, el Tribunal Constitucional en su Sentencia 75/1983, de 3 de agosto, señala que "resulta indispensable que exista una justificación objetiva y razonable, de acuerdo con criterios y juicios de valor generalmente aceptados, cuya exigencia deba aplicarse en relación con la finalidad y efectos de la medida considerada, debiendo estar presente por ello una razonable relación de proporcionalidad entre los medios empleados y la finalidad perseguida, y dejando en definitiva al legislador con carácter general la apreciación de situaciones distintas que sea procedente diferenciar y tratar desigualmente, siempre que su acuerdo no vaya contra los derechos y libertades protegidos en los artículos 53.1 y 9.3 CE, ni sea irrazonada».

De esta forma, la jurisprudencia constitucional para determinar si una desigualdad de trato vulnera el mandato del articulo $14 \mathrm{C}$. ha basado su examen en el criterio de la razonabilidad; esto es, si la diferencia obedece a fines lícitos y relevantes, y si esa diferencia de trato es proporcionada al fin perseguido. Así lo establece la STC 155/1998, de 3 de agosto, en la que se afirma que «las 
diferencias normativas habrán de mostrar, en primer lugar, un fin discernible y legitimo; tendrán que articularse, además, en términos no inconsistentes con la finalidad y, deberán, por último, no incurrir en desproporciones manifiestas a la hora de atribuir a los diferentes grupos y categorías jurídicas, derechos y obligaciones o cualesquiera otras situaciones jurídicas subjetivas». En este mismo sentido se pronuncian las SSTC, de 3 de agosto; 222/1992, de 11 de diciembre; 158/1993, de 6 de mayo y 229/1999, de 28 de septiembre, entre otras.

\section{IGUALDAD Y DISCRIMINACIÓN}

El artículo 14 de nuestra Constitución, junto al principio de igualdad ante la ley, reconoce la prohibición de discriminación basada en determinadas causas especificadas en dicho precepto, entre las que se incluye el sexo.

Dicho mandato de no discriminación del articulo 14 debe interpretarse desde una doble vertiente que puede parecer paradójica, pero que resulta absolutamente complementaria: de un lado, como prohibición de trato desigual o principio general de igualdad; y de otro, desde una vertiente positiva que obliga a un trato desigual, en conexión con el art. 9.2, a fin de conseguir la igualdad real. Y ello con la finalidad de acabar con la histórica situación de marginación en la que social y jurídicamente se había situado a determinados grupos sociales.

De ahí, que haya ido apareciendo la llamada "Jurisprudencia Compensadora", que viene a aceptar y apoyar medidas que favorezcan a los grupos desfavorecidos, cuando éstas pretendan situar a dichos grupos en una posición efectivamente de igualdad, de forma tal que se justifican los tratos desiguales que traten de eliminar situaciones discriminatorias.

Respecto de las mujeres, tanto la realidad histórica como la realidad social de nuestros días, demuestran sin ningún género de duda que la discriminación se ha ejercido y se sigue ejerciendo contra el colectivo femenino, encontrándose profundamente arraigada en la sociedad.

Como muy bien señala Asunción Ventura, «el sexo ha sido, y sigue siendo, un factor de relevancia social que tiene implicaciones jurídicas desfavorables para las mujeres. Históricamente las mujeres han sido relegadas en la sociedad y esta marginación ha alcanzado la categoría de norma. Aunque actualmente no sucede de la misma manera, el sexo femenino sigue siendo un factor relevante que aparentemente no se tiene en cuenta, pero en la práctica resulta determinante para el desarrollo de las relaciones sociales y por tanto de las relaciones jurídicas. El sexo es un factor importante que sitúa a todas las mujeres en una categoría jurídica inferior en relación al hombre, por el simple hecho de pertenecer a ese grupo» ${ }^{3}$.

Por lo tanto, para avanzar en la igualdad, en primer lugar, resulta necesario que se considere a la mujer como un verdadero sujeto constitucional, lo que no ha venido ocurriendo. Ya que el derecho ha sido concebido desde su origen

3. VentuRA, Asunción: Op. cit., p. 159. 
por y para los hombres, habiendo creado un ordenamiento jurídico totalmente patriarcal, en el que las mujeres no han tenido cabida alguna.

Por ello, no es casual que la Constitución se limite, simplemente, a enumerar el sexo entre las categorías específicas citadas en el artículo 14 como causas prohibidas de discriminación, ilegitimando con ello toda diferenciación de trato basada en el sexo.

A este respecto, resulta preciso distinguir entre:

- Discriminación directa: que se produce cuando la diferencia de trato se vincula expresamente al sexo. El Tribunal Constitucional ha considerado discriminación directa el trato desfavorable dado a la mujer como consecuencia de una condición únicamente femenina, como por ejemplo, tratar de forma desfavorable el embarazo.

- Discriminación indirecta: en estos casos el trato desfavorable no aparece inmediatamente vinculado al sexo, pero en la práctica supone poner a la mujer en una posición desfavorable; como por ejemplo, que a efectos retributivos, se considere de menor valor aquel tipo de trabajo que es realizado por mujeres en forma casi totalmente exclusiva. Sirva como ejemplo la practica habitual de ofrecer una remuneración mayor a tareas realizadas por hombres, -como las de vigilancia y seguridad-, que las consideradas tradicionalmente femeninas, -limpieza-, aun cuando la duración, esfuerzo y atención de esas tareas fueran equivalentes.

Con ello, el Tribunal Constitucional viene a admitir que el principio de igualdad, ante determinadas situaciones, contiene un mandato de desigualdad; $y$, por tanto, es necesaria la desigualdad formal para alcanzar la igualdad real, señalando que dicha diferenciación ha de ser razonable y proporcional a la finalidad perseguida y a la desigualdad existente.

Reconociendo, con ello, el llamado "derecho desigual igualatorio» (tal y como lo define la STC 229/1992, de 14 de diciembre), con el fin de conseguir la igualdad real y efectiva -(art.9.2)- de los colectivos históricamente marginados siempre y cuando dicho tratamiento jurídico diferenciado igualatorio cumpla con los requisitos de razonabilidad o justificación razonable, temporalidad y proporcionalidad. Reconociendo expresamente la referida STC 229/1992, en su Fundamento Jurídico 2, que "la consecución del objetivo igualatorio entre hombres y mujeres permite el establecimiento de un derecho desigual igualatorio, es decir, la adopción de medidas reequilibradoras de situaciones sociales discriminatorias, preexistentes para lograr una sustancial y efectiva equiparación entre las mujeres, socialmente desfavorecidas, y los hombres para asegurar el goce efectivo del derecho a la igualdad por parte de la mujer».

Por lo tanto, para conseguir la igualdad es necesario tratar de forma diferente situaciones iguales. Aunque teniendo en cuenta que no existe reconocido constitucionalmente un derecho subjetivo de trato diferente, ni tan siquiera derivado del articulo 9.2, que no es susceptible de recurso de amparo. De esta forma se ha pronunciado el Tribunal Constitucional, entre otras, en las Sentencias 181/2000, 21/2001, de 29 de enero, 49/2002, de 25 de febrero y 156/2003, de 15 de septiembre, que «es doctrina constitucional reiterada que el derecho a 
la igualdad que consagra el artículo $14 \mathrm{CE}$ ni otorga un derecho a la desigualdad de trato, ni ampara la falta de distinción entre supuestos desiguales, ya que no existe ningún derecho subjetivo al trato normativo desigual, siendo ajeno al ámbito de este precepto la llamada discriminación por indiferenciación».

En consecuencia, podemos afirmar que aunque el art. 9.2 CE resulta vinculante para los poderes públicos, su cumplimiento por parte de los que tienen capacidad normativa obedecerá a criterios de oportunidad política, de tal forma que la adopción de medidas correctoras de situaciones de desigualdad de hecho nunca podrá ser de naturaleza judicial, como resultado del recurso a la jurisdicción ordinaria ni tampoco a la jurisdicción constitucional.

\section{TRATAMIENTO JURÍDICO DIFERENCIADO Y MEDIDAS DE ACCIÓN POSITIVA}

Por lo tanto, para la consecución de la igualdad material, es posible establecer tratamientos jurídicos formalmente desiguales, lo que conecta con las llamadas medidas de acción positiva, utilizadas para paliar situaciones de desigualdad arraigadas en la sociedad.

Aunque sin olvidar que no todos los tratamientos diferenciados orientados a la consecución de la igualdad real o material pueden catalogarse como acciones positivas, constituyendo éstas sólo una especie de aquéllos. A este respecto, Mar Esquembre afirma «que el tratamiento jurídico diferenciado consistente en las denominadas medidas de igualación positiva o prestaciones diferenciadas se corresponderían con el objetivo de la eliminación de la discriminación intragrupal (dentro de grupo, pero entre individuos), mientras que el tratamiento jurídico diferenciado consiste en medidas de acción positiva se corresponderían con el objetivo de la eliminación de la discriminación intergrupal (entre grupos)».

Lo cierto es que existe una gran confusión terminológica y conceptual sobre las llamadas acciones positivas, ya que cualquier medida tendente a la consecuencia de la igualdad, aunque sea entre individuos, es catalogada como acción positiva, obviando que las mismas tienen la finalidad de eliminar la discriminación intergrupal y no intragrupal.

Siguiendo a M.A. Martín Vida, las medidas de acción positiva pueden definirse como "todas aquellas medidas, diversas en sus manifestaciones, que tienen como destinatarios directos a personas que están o han estado discriminadas o que se hallan en una situación de desventaja estructural como consecuencia de su pertenencia a un cierto colectivo, pertenencia determinadas por la posesión de algún rasgo completamente inmutable e íntimamente ligado, en tanto que definitorio de su identidad, a su dignidad como seres humanos, y que persiguen poner fin a esa situación de desventaja estructural, reducir los niveles de des-

4. ESOUEMBRe VALDES, Mar: Fundamentos de la discriminación positiva en Europa y España. En especial, en la Administración Publica, Alicante, Agencia Local de Desarrollo Económico y Social de Alicante, 2004 , p. 61. 
igualdad entre dichos colectivos (y sus miembros) y el resto de la sociedad, y alcanzar mayores cuotas de igualdad real dentro de la comunidad $»^{5}$.

Por lo que se hace necesaria una clasificación de las medidas de acción positiva, a fin de determinar su admisibilidad en el ordenamiento jurídico. A este respecto, Mar Esquembre realiza la siguiente clasificación de las medidas de acción positiva ${ }^{6}$ :

- "Las medidas de concienciación: son generalmente medidas de formación o de carácter publicitario que pretender crear un estado de oposición o una sensibilización del problema. Por ejemplo: las campañas de publicidad para la igualdad sexual, el fomento de cursos de especialización, formación de agentes de igualdad de oportunidades, etc.

- Las medidas de retribución, recompensa o sanción positiva: se trata de medidas que se adoptan tras las realización de la acción querida, como por ejemplo: la asignación de un premio, como puede ser una mención distintiva a las empresas que adopten medidas tendentes a conseguir la igualdad real entre mujeres y hombre, o una exención fiscal, etc.

- Las medidas de facilitación, de impulso o de promoción: son las medidas previas tendentes a la consecución del fin pretendido, que no es otro que el de la eliminación de la discriminación estructural a fin de conseguir una efectiva igualdad real. Dentro de estas, se distingue:

a) Medidas de incentivación: para aumentar las oportunidades competitivas de las personas pertenecientes a colectivos tradicionalmente desfavorecidos; como por ejemplo: subvenciones, becas, etc.

b) Medidas de discriminación inversa o positiva en sentido amplio: se aplican en situaciones de particular escasez e indivisibilidad del bien que se pretende adjudicar. La determinación de la proporción de sujetos tradicionalmente marginados que van a beneficiarse de estas medidas puede hacerse por el sistema de cuotas o por el de objetivos numérico. Dichas medidas pueden, a su vez, revestir diferentes modalidades tales como la de asignar una puntuación extra junto al mérito, a los miembros del colectivo desfavorecido, las medidas de desempate, o finalmente las medidas de trato diferencial.

Nuestra actual Constitución no contiene una referencia específica a las medidas de acción positiva, a diferencia de lo que ocurre en otros textos constitucionales europeos. Así por ejemplo, en Alemania, tras la reforma de la Ley Fundamental de Bonn que se realizó en el año 1994, se añadió un inciso final al apartado 2 del articulo 3, disponiendo expresamente que: «hombres y mujeres gozan de los mismos derechos. El estado favorecerá la realización efectiva de la igualdad entre hombres y mujeres y actuará con el fin de eliminar las desigualdades existentes».

5. MARTÍN VIDA, Ma Ángeles: Fundamento y límites constitucionales de las medidas de acción positiva, Madrid, Civitas, 2003, pp. 39-40.

6. ESQuembre Valdés, Mar: Op. cit. 
También Austria modificó su Ley Constitucional Federal en el año 1998, estableciendo en el apartado 2 de su artículo 7 que «La Federación, las provincias y las comunidades locales asumen un compromiso a favor de la igualdad real entre hombres y mujeres. Se admiten las medidas orientadas a promover la igualdad de hecho de hombres y mujeres, en especial mediante la eliminación de las desigualdades facticas existentes».

En el mismo sentido, tanto la Constitución finlandesa de 1995, como la Ley Constitucional sueca de 1975 o la reforma de la Constitución de Bélgica realizada en febrero del 2002, hacen referencia a la admisiblidad de medidas orientadas a lograr la igualdad real de las mujeres.

Pero a pesar de no existir referencia alguna en nuestro texto constitucional a la admisibilidad de medidas de acción positiva a favor de colectivos desfavorecidos, lo cierto es que éstas si han sido reconocidas legalmente, aunque de momento únicamente destinadas a los discapacitados. En concreto, en la Ley $51 / 2.003$, de 2 de diciembre, de igualdad de oportunidades, no discriminación y accesibilidad universal de las personas con discapacidad, donde en el párrafo segundo de su articulo 1, en el que se concreta el objeto de la misma, se señala que "se entiende por igualdad de oportunidades la ausencia de discriminación, directa o indirecta, que tenga su causa en una discapacidad, así como la adopción de medidas de acción positiva orientadas a evitar o compensar las desventajas de una persona con discapacidad para participar plenamente en la vida política, económica, cultural y social».

Pero a pesar de ese escaso apoyo constitucional, el Tribunal Constitucional ha admitido la diferencia de trato a favor de la mujer, partiendo siempre de la cláusula de interdicción de la discriminación, por considerar que tal interdicción, para ser efectiva en la realidad, necesitaba la concesión de ventajas al sexo femenino, es decir, acciones positivas por parte de los poderes públicos.

Resoluciones de este tipo se pueden encontrar en la jurisprudencia constitucional a partir de 1987. En ellas, se ha venido admitiendo que el remedio de discriminaciones, históricamente arraigadas en la sociedad, de grupos concretos -específicamente, del sexo femenino- pueden justificar acciones positivas, esto es, medidas que tiendan a corregir situaciones desfavorables concediendo determinadas ventajas a los sectores desfavorecidos. Aceptando el Tribunal Constitucional que la discriminación de la mujer es un hecho histórico que ha situado a las mujeres en una posición de inferioridad social y jurídica.

En estos casos de discriminación, la acción positiva se legitima no en función de las características individuales de la persona beneficiaria, sino en función de su pertenencia a un colectivo discriminado: lo que persigue es suprimir aquellas circunstancias de carácter social general que llevan a que los componentes de un grupo determinado se encuentren, como regla general, sometidos a un trato social desfavorable.

Por ello, podemos afirmar que las acciones positivas se encuentran legitimadas en nuestro ordenamiento jurídico, de acuerdo con la interpretación que del concepto de igualdad ha desarrollado el Tribunal Constitucional, entre otras, en las siguientes sentencias: 
- S.T.C. 128/87, de 16 de julio: Reconoce como no discriminatorio para los varones, la percepción de cierta cantidad mensual en concepto de gastos de guardería limitado a las mujeres con responsabilidades familiares, admitiendo la discriminación indirecta, tendente a equilibrar el mercado laboral, eliminando los obstáculos que se han interpuesto históricamente en el acceso de las mujeres al trabajo. Destacando en su Fundamento Jurídico 10 que «La diferencia reside en que existe una innegable y mayor dificultad para la mujer con hijos de corta edad para incorporarse al trabajo o para permanecer en él, dificultad que tiene orígenes muy diversos, pero que coloca a esta categoría social en una situación de hecho claramente desventajosa respecto a los hombres en la misma situación. En tanto, pues, esta realidad perdure, no pueden considerarse discriminatorias las medidas tendentes a favorecer el acceso al trabajo de un grupo en situación de clara desigualdad social, y que traten de evitar, facilitando el empleo de guardería, que una práctica social discriminatoria se traduzca en un apartamiento del trabajo de la mujer con hijos pequeños».

- S.T.C. 19/89, de 31 de enero, en este supuesto el Tribunal Constitucional declara como no discriminatoria la diferenciación de porcentajes aplicables a las pensiones de jubilación anticipadas en el sector textil aplicables al caso enjuiciado, que establecían una sensible diferencia entre hombres y mujeres cuando la jubilación se producía entre los sesenta y los sesenta y cuatro años (la de la mujer podía llegar a un $80 \%$ del salario regulador y la del varón podía alcanzar como máximo el 70\%). Reconociendo en su Fundamento Jurídico 5 «que la diferencia de trato consagrada en los Estatutos de la Mutualidad Laboral del sector textil no tenía por objeto colocar al trabajador varón en peores condiciones al momento de su jubilación, sino más bien compensar de algún modo la situación de inferioridad que, laboral y socialmente, venía padeciendo el personal femenino".

- S.T.C. 28/1.992, de 9 de marzo: Asimismo en esta sentencia el Tribunal Constitucional considera no discriminatorio la compensación económica por el uso del transporte nocturno que el Convenio Colectivo de la Compañía Telefónica Nacional de España concedía al personal femenino. Destacando en su Fundamento Jurídico 3 que «este Tribunal ha entendido que la referencia al sexo en el art. 14 implica también la decisión constitucional de acabar con una histórica situación de inferioridad atribuida a la mujer también en el ámbito del empleo y las condiciones de trabajo, por lo que son constitucionalmente legitimas aquellas medidas que tienden a compensar una desigualdad real de partida, de modo que el precepto constitucional que prohíbe a discriminación por razón de sexo ha de ser interpretado sistemáticamente con otro preceptos constitucionales, en particular con el art. 9.2 C.E. que obliga a los poderes públicos a promover las condiciones para que la igualdad de las mujeres en relación con los hombres sea real y efectiva». Además, es en esta sentencia cuando, por primera vez, el Tribunal Constitucional utiliza el termino «acción positiva», al afirmar que «la prohibición de discriminación por razón de sexo 
admite la existencia de medias singulares a favor de la mujer, que traten de corregir una situación desigual de partida, como son las medidas de acción positiva o similares».

Pero en todos estos casos examinados, se trataban de "medidas de incentivación", cuyo objetivo consistía en incrementar las oportunidades a colectivos desfavorecidos en la participación del reparto de bienes considerados especialmente valiosos. Pretendiendo con dichas medidas, la igualdad de todas las personas en el punto de partida, lo que en principio no presenta un daño directo y concreto a quien no pertenezca al grupo desfavorecido.

El problema se presenta con otro tipo de medidas acción positiva, como son las "medidas de discriminación inversa", dado que no consisten en un simple reparto de bienes sociales valiosos que sitúen a los miembros del colectivo desfavorecido en un punto de partida similar al que se encuentran los excluidos de dicho colectivo, sino que por el contrario implica un perjuicio para el sujeto excluido del grupo, puesto que ya no se trata de que dicho sujeto no pueda obtener determinados beneficios sino que éste sufre una perdida, que de no haberse tenido en cuenta favorablemente el rasgo, no se hubiera producido.

Estas medidas pueden revestir diferentes modalidades, como:

- Asignar una puntuación extra junto al mérito, a los miembros de colectivo desfavorecido, por su simple pertenencia a dicho colectivo.

- Medidas de desempate o de discriminación inversa racionalizada, también llamadas de cuota flexible. Consisten en adjudicar el bien escaso al miembro del colectivo marginado, cuando concurran circunstancias iguales en los candidatos.

- Medidas de discriminación inversa en sentido estricto o también llamadas de cuota rígida; en las que se establece una preferencia automática para el miembro perteneciente al colectivo desfavorecido.

La determinación de los sujetos del colectivo desfavorecido que van a beneficiarse de los dos últimos tipos de medidas, se puede hacer mediante el "sistema de cuotas», por el que se reserva un número determinado de bienes o porcentaje de los mismos a los miembros del colectivo marginado; o por el de "objetivos numérico", por el que se fija un determinado porcentaje a alcanzar de miembros del colectivo discriminado por un periodo de tiempo determinado.

Un ejemplo de medidas de discriminación inversa lo encontramos en la S.T.C. 269/94, de 3 de octubre, referida a un concurso de acceso a la Administración canaria en el que se estableció una reserva porcentual de plazas para discapacitados, estableciéndose en la convocatoria una diferencia de trato basada en la condición de discapacidad de la persona que perjudicaba a aquellas otras que, obteniendo una puntuación superior, no formaban parte de este colectivo.

En este caso el TC no consideró que se tratase de un supuesto de prohibición de discriminación del art. 14 C., al considerarlo como una exigencia derivada del cumplimiento del mandato contenido en el art. 9.2 C., que reconoce la constitucionalidad de medidas equiparadoras de situaciones sociales de desventaja. Entendiendo, por tanto, que la medida adoptada respondía a una 
finalidad constitucional lo suficientemente deseable como para justificar un trato desigual: la lucha contra la discriminación de los discapacitados, habida cuenta de la dificultad de éstos para el acceso al empleo.

Ésta fue la primera (y, por el momento única) ocasión en la que el Tribunal Constitucional se ha pronunciado acerca de la constitucionalidad de las medidas de discriminación inversa.

La aplicación de medidas de discriminación inversa en el caso de las mujeres, supondría el establecimiento de criterios a favor de la mujer en situaciones de competición abierta entre individuos de ambos sexos. Pero lo cierto, es que el Tribunal Constitucional no se ha pronunciado sobre la admisibilidad de medidas de discriminación inversa a favor de las mujeres.

\section{LOS RECIENTES AVANCES LEGISLATIVOS EN MATERIA DE IGUALDAD}

En el año 2004, se aprobó una importantísima y muy necesaria norma de protección de la mujer victima de actos violentos. Se trata de la Ley de protección integral contra la violencia de genero, aprobada por la Ley Orgánica 1/2004, de 28 de diciembre.

La violencia contra las mujeres se produce en el núcleo familiar, pero ha dejado de ser una cuestión privada para pasar a ser un problema social inaceptable, que no debe quedar en ningún caso impune, lo que requiere la actuación efectiva de los poderes públicos. De esta forma, la propia Exposición de Motivos de la referida ley, comienza afirmando que "La violencia de género no es un problema que afecte al ámbito privado. Al contrario, se manifiesta como el símbolo más brutal de la desigualdad existente en nuestra sociedad. Se trata de una violencia que se dirige sobre las mujeres por el hecho mismo de serlo, por ser consideradas, por sus agresores, carentes de los derechos mínimos de libertad, respeto y capacidad de decisión».

En concreto el ámbito de la Ley abarca tanto los aspectos preventivos, educativos, sociales, asistenciales y de atención a las victimas, como toda la normativa civil que incide en el ámbito familiar, así como la respuesta punitiva que deben recibir todas las manifestaciones de violencia contra las mujeres. Destacando en su artículo 1, que la misma tiene por objeto «actuar contra la violencia que, como manifestación de la discriminación, la situación de desigualdad y las relaciones de poder de los hombres sobres las mujeres, se ejerce sobre éstas por parte de quienes sean o hayan sido sus cónyuges o de quienes estén o hayan estado ligados a ellas por relaciones similares de afectividad, aun sin convivencia».

Pero a pesar de la importancia de dicha Ley, y de las medidas que en ella se han aprobado, la violencia contra las mujeres continua, y según confirman los datos, todavía con mas virulencia. El principal problema radica en la consideración por parte del hombre de su superioridad sobre la mujer, y por tanto la sumisión de ésta, lo que a su entender le legitima a actuar de forma violenta hacia ella. Sin duda este drama es el fruto de un sistema patriarcal todavía arraigado en nuestra sociedad, que debe ser definitivamente extinguido. 
Además, de la referida Ley, a corto plazo, parece vislumbrarse un futuro prometedor en la lucha a favor de la igualdad, con la futura Ley Orgánica para la igualdad efectiva de mujeres y hombres, que se encuentra en fase de tramitación parlamentaria. Desde luego no va a ser la panacea universal, pero sí un paso importante en la lucha por conseguir la igualdad de todas las personas.

En la Exposición de Motivos de esta ley, se reconoce expresamente que «resulta necesaria una acción normativa dirigida a combatir todas las manifestaciones aún subsistentes de discriminación, directa o indirecta, por razón de sexo y a promover la igualdad real entre mujeres y hombres, con remoción de los obstáculos y estereotipos sociales que impiden alcanzarla».

Para ello la Ley tiene como principales ejes de actuación: la prevención de las conductas discriminatorias, la previsión de políticas activas para hacer efectivo el principio de igualdad, proyección general del principio de igualdad en los diferentes ámbitos normativos, la ordenación general de las políticas públicas bajo la óptica del principio de igualdad, la adopción de medidas positivas con el fin de alcanzar la igualdad efectiva de mujeres y hombres, establecimiento de medidas de promoción de la igualdad efectiva en las empresas privadas, la corrección de la desigualdad en el ámbito de las relaciones laborales, la promoción de medidas concretas a favor de la igualdad en las empresas, asegurar una representación equilibrada de mujeres y hombres en órganos y cargos de responsabilidad, etc.

En suma, lo que se pretende con dicha norma, es hacer efectiva la igualdad real de mujeres y hombres, mediante la eliminación de cualquier discriminación contra la mujer, en cumplimiento de lo previsto en los artículos 9.2 y 14 .

También está prevista la aprobación del Proyecto de Ley de promoción de la autonomía personal y atención a las personas en situación de dependencia, que tiene por objeto regular las condiciones básicas que garanticen el derecho a la promoción de la autonomía personal y atención a las personas en situación de dependencia, mediante la creación de un Sistema Nacional de Dependencia con la colaboración y participación de todas las Administraciones Publicas. Y ello, como se hace constar en la Exposición de Motivos, debido a que "La atención a este colectivo de población se convierte, pues, en un reto ineludible para los poderes públicos, que requiere una respuesta firme, sostenida y adaptada al actual modelo de nuestra sociedad. No hay que olvidar que, hasta ahora, han sido las familias, y en especial las mujeres, las que tradicionalmente han asumido el cuidado de las personas dependientes, constituyendo lo que ha dado en llamarse el «apoyo informal». Los cambios en el modelo de familia y la incorporación progresiva de las mujeres al mercado de trabajo introducen nuevos factores en esta situación que hacen imprescindible una revisión del sistema tradicional de atención para asegurar una adecuada capacidad de prestación de cuidados a aquellas personas que los necesitan.»

El desarrollo de toda esta normativa, sin duda nos hará avanzar en el camino de la igualdad, permitiéndonos alcanzar una igualdad real y efectiva de mujeres y hombres, eliminando cualquier tipo de discriminación contra la mujer y dando cumplimiento, con ello, al mandato de nuestra actual Constitución. 
Pero finalmente cabe preguntarse ¿qué ocurrirá en el ámbito privado?, ¿llegará algún día esa igualdad de mujeres y hombres también al ámbito familiar?, ¿las mujeres y los hombres compartirán por igual las tareas de cuidado familiar y de trabajo doméstico?, ¿seremos capaces de superar el modelo de familia paternalista, avanzando en la corresponsabilidad de mujeres y hombres?

Aunque el panorama jurídico nos invita al optimismo, creo que tardaremos bastante tiempo en cambiar muchas de estas conductas, que quedan fuera de la posibilidad de regulación legal. Sólo espero que la generación de mi hijo lea estas líneas con el mismo asombro que yo sentía cuando descubrí, por ejemplo, que las mujeres en España no tuvimos derecho a votar hasta 1931.

\section{REFERENCIAS BIBLIOGRÁFICAS}

BARRERE UNZUETA, $M^{a}$ Ángeles: Discriminación, derecho antidiscriminatorio y acción positiva a favor de las mujeres, Madrid, Civitas, 1997.

Balaguer, $\mathrm{M}^{a}$ Teresa: Mujer y Constitución. La construcción jurídica del género, Madrid, Feminismos, 2005.

ESQUEMBRE VALDES, Mar: Fundamentos de la discriminación positiva en Europa y España. En especial, en la Administración Publica, Alicante, Agencia Local de Desarrollo Económico y Social de Alicante, 2004.

GIMENEZ GLUCK, David: Una manifestación polémica del principio de igualdad: acciones positivas moderadas y medidas de discriminación inversa, Valencia, Tirant Lo Blanch, 1999.

LÓPEZ GUERRA, Luis: Igualdad, no discriminación y acción positiva en la Constitución de 1978, en Mujer y Constitución en España, Madrid, Centro de Estudios Políticos y Constitucionales, 2000.

MARTín VIDA, Ma Ángeles: Fundamento y limites constitucionales de las medidas de acción positiva, Madrid, Civitas, 2003.

- "Modelos de medidas de acción positiva en los países miembros de la Unión Europea», Teoría y Realidad Constitucional, $12-13$ (2 semestre 2003-1 semestre 2004), pp. 321-349.

Rodríguez PiñeIro, M. y Fernández López, M.F.: Igualdad y discriminación, Madrid, Tecnos, 1986.

VenturA, Asunción: Las Mujeres y la Constitución Española de 1978, Madrid, Instituto de la Mujer, 1999. 



\section{LA TRIBUTACIÓN FAMILIAR}

MARÍA TERESA SOLER ROCH

Universidad de Alicante

El deber de contribuir en nuestro ordenamiento jurídico tiene su fundamento en los principios proclamados en el artículo $31.1^{\circ}$ de la Constitución, según el cual: Todos contribuirán al sostenimiento de los gastos públicos:

- De acuerdo con su capacidad económica (principio de capacidad económica).

- Mediante un sistema tributario justo, inspirado en los principios de igualdad y progresividad que en ningún caso tendrá alcance confiscatorio (principios de justicia tributaria: igualdad y progresividad).

La aplicación de estos principios a la tributación familiar exige plantearse, previamente, dos cuestiones, a saber:

- ¿Es la familia una unidad económica? bros?

- ¿Incide la pertenencia a una familia en la posición económica de sus miem-

La respuesta a estas preguntas nos lleva a descubrir que, en el caso de la tributación familiar, la aplicación de aquellos principios se manifiesta a través de distintas paradojas que exponemos a continuación.

Primera, la paradoja de la capacidad económica ${ }^{1}$, en la medida en que la situación familiar, genera:

- Por un lado, una mayor capacidad económica, por el disfrute conjunto de rentas y patrimonios que genera economías de escala.

- Por otro lado, una menor capacidad económica. En general, por la existencia de cargas familiares; en particular, por los deberes económicos de la sociedad conyugal.

Segunda, la paradoja de la igualdad ${ }^{2}$, en la medida en que tener en cuenta la situación familiar, genera:

1. SOler Roch, María Teresa: «Subjetividad tributaria y capacidad económica de las personas integradas en unidades familiares», Civitas. Revista española de Derecho Financiero, 66 (1990), p. 203.

2. NúÑEZ GRAÑón, Mercedes: Las desigualdades tributarias por razones familiares y de residencia, Madrid, Instituto de Estudios Fiscales-Marcial Pons, 1998. 
- Por un lado, si la ley opta por una tributación exclusivamente individual, esta opción provoca una discriminación a favor / en contra de las unidades familiares.

- Por otro lado, si la ley opta por una tributación familiar (atendiendo sólo a familias legalmente constituidas), esta opción provoca una discriminación a favor / en contra de las uniones de hecho.

Tercera, la paradoja de la progresividad; en este caso, provocada por los efectos de la escala progresiva (aplicable en los impuestos directos que gravan la renta y el patrimonio de las personas físicas, así como en el impuesto sobre sucesiones y donaciones). Así:

- Por un lado, la aplicación de la escala a una base imponible conjunta implica una mayor cuota, mientras que su aplicación a bases imponibles separadas determina una cantidad menor resultante de la suma de las cuotas individuales.

- Por otro lado, en cuanto a las reducciones por cargas familiares: su aplicación sobre la base reduce la progresividad, mientras que su aplicación sobre la cuota mantiene la progresividad del gravamen.

Como no podía ser de otro modo, tratándose de la aplicación de principios constitucionales, la jurisprudencia constitucional, española y comparada, ha tenido ocasión de pronunciarse sobre estas cuestiones ${ }^{3}$; en concreto, en relación con la imposición sobre la renta de las personas físicas.

Dicha jurisprudencia se manifestó contraria a la tributación conjunta obligatoria en: Alemania (1957), Italia (1976), España (1989), siendo en todos los casos utilizados como principales argumentos:

- Los principios de igualdad y protección a la familia.

- La valoración de la capacidad económica individual.

- El perjuicio para el trabajo de la mujer casada.

Como consecuencia de esta doctrina jurisprudencial, la legislación comparada optó por diversas soluciones, así:

- Por un lado, distintas opciones de modelo único obligatorio, tales como: la tributación separada (total o parcial, sólo para determinadas rentas), el splitting (división de la renta entre ambos cónyuges) o el cociente familiar.

- Por otro lado, se produciría una eliminación del problema sustituyendo la tarifa progresiva por tipos proporcionales; pero ésta es una opción no elegida, por ahora, en ninguna jurisdicción fiscal (al menos por razones de tributación familiar $\left.{ }^{4}\right)$.

Los principales argumentos utilizados en su día por la jurisprudencia constitucional española se manifestaron en la sentencia 20/1989 del Tribunal Constitucional y fueron los siguientes:

3. Soler, María Teresa: Op. cit., p. 204.

4. La introducción del gravamen dual en el IRPF (2007) responde a la opción por una tributación más favorable del ahorro. 
- En relación con el principio de capacidad económica: la consideración de la individualidad del gravamen como un derecho fundamental.

- En relación con el principio de igualdad: los argumentos a favor de la tributación conjunta se dan en todo tipo de familia (legalmente constituida o de hecho).

- En relación con la protección a la familia: la aplicación de la tributación conjunta obligatoria sólo a las familias legales las discrimina frente a las uniones de hecho.

Las soluciones en Derecho español no se hicieron esperar; hubo una primera reforma de urgencia (1989) y un nuevo marco legal a partir de 1991, estableciendo un sistema de tributación familiar que se ha consolidado en reformas posteriores, incluyendo la proyectada reforma que entrará en vigor en 2007.

En relación con el IRPF, se regula un sistema dual consistente en:

- La tributación individual como regla general y,

- Una opción a la tributación conjunta para las unidades familiares conyugales y las unidades familiares monoparentales (con exclusión de las uniones de hecho).

En relación con la tributación individual, se establece la tributación individual obligatoria en cualquier caso (con independencia del hecho del matrimonio).

La exclusión de las meras uniones de hecho que no constituyan familia monoparental (parejas sin hijos) planteó, en un principio, nuevas dudas de constitucionalidad $^{5}$, que fueron solventadas a favor de la regulación legal, por el Tribunal Constitucional. En la sentencia 212/2001, argumentó el alto Tribunal que: «No basta con que, en situaciones puntuales, los sujetos puedan verse ocasionalmente beneficiados por no mantener una relación matrimonial».

En cuanto a la discriminación, entiende que se produce «sólo si la ley establece un régimen más gravoso en su conjunto para los sujetos casados que para quienes no lo están en atención, precisamente, a su situación patrimonial».

Mayores problemas se plantean en relación con el tratamiento de las uniones de hecho en el impuesto sucesorio. En este caso, se manifiesta, una vez más, la tensión dialéctica entre los principios de igualdad y seguridad jurídica ${ }^{6}$.

La legislación reguladora de este impuesto utiliza las expresiones "cónyuge» $\mathrm{y}$ «extraño» (esta última expresión en ausencia de parentesco), lo cual supone:

- Por un lado, que los beneficios fiscales (reducciones de la base imponible) se aplican sólo a los cónyuges.

- Por otro lado, que el incremento de la cuota en proporción al patrimonio preexistente del heredero, es menor en el caso de los cónyuges.

5. NúÑEz GraÑón, Mercedes: «Régimen tributario de las uniones de hecho», Revista Derecho privado y Constitución, Centro de Estudios Políticos y Constitucionales, 12 (1998), p. 197.

6. NúÑ̃E, Mercedes: Régimen tributario de las uniones..., op. cit., p. 209 y BAYONA JIMÉNEZ, J.J.: «Las uniones de hecho en el Impuesto sobre Sucesiones y Donaciones», Civitas. Revista española de Derecho Financiero, 93 (1997), p. 136. 
La combinación de estas dos circunstancias determina que la deuda tributaria de la pareja de hecho pueda llegar a ser muy superior a la que resultaría si tuviese la condición de cónyuge.

Aunque algunas Comunidades Autónomas han consagrado la equiparación de matrimonios y uniones de hecho, haciendo extensiva esta equiparación a la aplicación de las reducciones en el Impuesto de Sucesiones, no es ésta una solución generalizada que sólo podría venir a través de una modificación de la ley estatal reguladora del Impuesto sobre Sucesiones y Donaciones.

Mientras no se produzca esta reforma de la legislación estatal, habrá que tener en cuenta la doctrina jurisprudencial sobre la interpretación de la ley vigente, que ha rechazado la posibilidad de equiparar la pareja de hecho al cónyuge invocando la Ley General Tributaria que prohíbe la aplicación analógica de las normas sobre beneficios fiscales.

Volviendo a la tributación individual de los cónyuges en el impuesto sobre la renta, debe tenerse en cuenta la relación de las reglas de atribución de las distintas rentas en función de su origen con el régimen económico matrimonial, ya que las normas de titularidad civil van a afectar de forma distinta, de modo que:

- Las rentas del capital (mobiliario/inmobiliario), se atribuyen en función de la titularidad civil de los elementos patrimoniales que las producen.

- Las de trabajo y actividades económicas corresponden al cónyuge que realiza la actividad.

Esta diferencia de tratamiento ha sido objeto de consideraciones críticas desde la perspectiva del principio de igualdad, por considerar que favorece las rentas de capital y el régimen de gananciales.

También en este punto el Tribunal Constitucional ha considerado las citadas normas de atribución conformes con la Constitución. Así en relación con las rentas de trabajo en el régimen de gananciales, la sentencia 146/1994 estableció la siguiente doctrina:

«El problema constitucional de la imputación de rentas no reside en comprobar si las normas tributarias concuerdan con las civiles, sino en su conformidad con los principios constitucionales aplicables en la materia».

"Las rentas del capital compartido pueden imputarse por mitad, pero el hecho de que esta posibilidad no pueda hacerse con las rentas de trabajo, de condición estrictamente personal, no vulnera el principio de igualdad, pues ese diferente trato deriva de la distinta naturaleza de las fuentes productoras de ambas rentas».

La relación entre familia y capacidad económica en el IRPF es intrínseca a la propia naturaleza de este impuesto, como expresamente reconoce su Ley reguladora, cuando describe:

- Por un lado, su naturaleza: «impuesto personal que grava la renta de las personas físicas de acuerdo con sus circunstancias personales y familiares».

- Por otro lado, su objeto: «la capacidad económica del contribuyente, entendida ésta como su renta disponible, que será el resultado de disminuir la renta en la cuantía del mínimo personal y familiar». 
Esta relación se manifiesta, de modo más concreto, en el tratamiento legal de las cargas familiares, estableciendo al respecto una serie de medidas, tales como:

- El mínimo personal y por descendientes.

- Las reducciones en la base imponible por: edad, cuidado de hijos, asistencia y discapacitados.

- Un tratamiento específico para las madres trabajadoras, estableciendo una deducción específica por maternidad (hijos menores de tres años y alta en la Seguridad Social); deducción aplicable al padre en caso de fallecimiento de la madre o custodia exclusiva.

Por la misma razón, prevé la ley una serie de prestaciones familiares exentas del IRPF, tales como:

- Las prestaciones públicas por hijos (+ nacimiento, parto múltiple, adopción e hijos a cargo y orfandad) y por acogimiento (menores, minusválidos, mayores de 65 años).

- Las anualidades por alimentos y las percibidas de los padres en virtud de decisión judicial.

Una mención especial merece el tratamiento de las pensiones en el IRPF, debiendo distinguirse a este respecto entre:

- La pensión compensatoria al cónyuge, que se considera deducible para el cónyuge que la paga y renta de trabajo para el cónyuge que la recibe.

- La pensión a los hijos, que se considera no deducible para el padre o madre que la paga (aunque atenuando, en este caso, los efectos de la progresividad) y renta exenta para los hijos que la reciben.

En relación con este tratamiento de las pensiones, el Tribunal Constitucional, en sentencia de 15 enero 2001, estableció la siguiente doctrina:

"Aunque, desde luego, no existiría inconveniente constitucional alguno, el legislador tributario no ha previsto deducción alguna por la renta consumida en el deber de alimentos a los hijos».

"Con ello equipara la situación de estos padres a la de todos los que sufragan la manutención y educación de sus hijos sin que una decisión judicial lo imponga».

El tratamiento del patrimonio familiar en el Impuesto sobre el Patrimonio, se caracteriza, fundamentalmente por:

- El gravamen exclusivamente individual de todos y cada uno de los miembros de la familia.

- La atribución de los elementos patrimoniales según las reglas de titularidad civil (en el caso de los bienes comunes de los cónyuges, las que resulten aplicables en función del régimen económico o las capitulaciones matrimoniales).

- La exención de la vivienda habitual.

- Los beneficios fiscales aplicables a la empresa familiar (exención de los bienes y derechos afectos a la actividad o de las acciones y participaciones sociales correspondientes).

- Beneficios fiscales específicos para el patrimonio de los discapacitados. 
En cuanto a la responsabilidad patrimonial, la legislación aplicable considera obligados al pago de la deuda tributaria:

- En la tributación individual (IRPF, IP), la regla general es la asunción individual de la deuda correspondiente a cada miembro de la familia. Como regla especial, se establece el carácter ganancial de la deuda tributaria individual de cada cónyuge.

- En la tributación conjunta (IRPF), la ley establece la solidaridad de la deuda conjunta, sin perjuicio del prorrateo entre los contribuyentes de la unidad familiar.

La tributación de la disolución matrimonial afecta a supuestos de: separación legal, nulidad, divorcio o fallecimiento. En cuanto a sus efectos sobre la unidad familiar destaca:

- Por un lado, la opción a la tributación conjunta en la unidad monoparental resultante.

- Por otro lado, el tratamiento de las alteraciones patrimoniales que se producen como consecuencia de la disolución de la sociedad legal de gananciales y de las adjudicaciones resultantes en otros regímenes y cuya consecuencia más relevante, a efectos del IRPF es la no sujeción y el consiguiente diferimiento del gravamen.

Finalmente, en cuanto a la tributación de los no residentes, debe tenerse en cuenta que los impuestos que gravan la renta obtenida o el patrimonio situado en España por estos contribuyentes, al no imponer un gravamen sobre la renta o patrimonio mundial, se basan en el principio de tributación individual, siendo en principio, irrelevante, la situación familiar de estos contribuyentes.

Ello no obstante y teniendo en cuenta la doctrina establecida por el Tribunal de Justicia de la CE en punto al principio de no discriminación por razón de la residencia, la Ley española reguladora del Impuesto sobre la Renta de no Residentes prevé para los contribuyentes residentes en otro Estado miembro de la Unión Europea que obtenga en territorio español más del 75 de su renta procedente del trabajo o de actividades económicas, la opción a tributar por el IRPF pudiendo, además, en este caso, elegir entre las modalidades de tributación familiar (individual o conjunta) previstas en este impuesto7.

7. NÚÑEZ GRAÑóN, Mercedes: «Spanish Income Tax: option for residents of EU countries», EC Tax Review, 3 (1999). 


\title{
NOTAS SOBRE LA CONFIGURACIÓN DE LAS UNIONES DE HECHO EN ROMA
}

\author{
WALENKA ARÉVALO CABALLERO \\ Universidad de Alicante
}

Las uniones de hecho se caracterizan en la actualidad por ser uno de los temas más candentes que se plantea a los estudiosos del Derecho, porque si bien, hasta ahora y durante muchos siglos fue el matrimonio la institución en la que descansaba la seguridad de la familia y la estabilidad de la nación ${ }^{1}$, hoy día se están constituyendo nuevos tipos de convivencia familiar de los que se derivan innumerables problemas jurídicos a los que se debe procurar correcta solución.

Cuando se alude a parejas de hecho, tanto en Roma como en época actual, se hace referencia a uniones estables y no de mera relación sexual que deben cumplir determinados requisitos, recogidos por la jurisprudencia, en los que se evita la voluntad de los convivientes de contraer matrimonio conforme a las normas del Ordenamiento jurídico.

Ahora bien, antes de abordar el tema de las uniones de hecho en Roma o por citarlo en terminología latina -concubinatus-, se debe exponer, aunque sea sucintamente las líneas generales del matrimonio romano².

1. TORRENT, A.: "Uniones de hecho, nueva tipología de la familia», en Libro homenaje al profesor Manuel Albaladejo Garcia, Murcia, Universidad de Murcia, 2004, pp. 4783 ss.

2. Para conocer más sobre el tema vid. entre otros: BRINI, G.: Matrimonio e divorzio nel diritto romano, Bologna, Nicola Zanicchelli, 3 vols. 1886-1889; DI MARZO, S.: Lezioni sul matrimonio romano, reed. Palermo, L'Erma di Bretchneider, 1972; VOLTERRA, E.: La conception du mariage d'aprés les juristes romains, Padova, La Garangola, 1940; ORESTANO, R.: «La estruttura giuridica del matrimonio romano dal diritto clásico al diritto giustinianeo», BIDR, 55-56 (1952), pp. 185 ss.; LAURIA, M.: Matrimonio e dote, Napoli, L'Arte Tipográfica, 1952; Bonfante, P.: Corso di Diritto Romano, Diritto di Familia, vol. I., Milano, Giuffré, 1963, pp. 255 ss.; RoBledA, O.: El matrimonio en Derecho Romano, Roma, Università Gregoriana, 1970; DAZA, J.: Nuptiae et matrimonium, Estudios Álvarez Suárez, Madrid, 1978, pp. 57 ss.; VolterRA, E.: Instituciones de Derecho Privado Romano, Madrid, 1991 (trad. español por J. Daza), pp. 635 ss.; TorRent, A.: Manual de Derecho privado Romano, Zaragoza, Edisofer, 1995, pp. 525 ss.; PANERO, R.: Derecho Romano, Valencia, Tirant lo Blanc, 2000 , pp. 289 ss. 
Originariamente el matrimonio en Roma fue una institución que no presentaba vínculos jurídicos sino primordialmente connotaciones sociales, éticas y religiosas ${ }^{3}$. No obstante, desde época arcaica, se planteó la cuestión de establecer los requisitos necesarios para que la unión entre un hombre y una mujer, ciudadanos romanos, pudiera lograr determinadas consecuencias jurídicas. A este respecto, es necesario indicar que entre los efectos jurídicos más significativos que se establecieron para dar estabilidad a esta relación se encontraban, por una parte la determinación de la filiación de los hijos nacidos de esa unión y por otra la concesión a padres e hijos de derechos y deberes recíprocos; pero sobre todo y como efecto de mayor trascendencia, la atribución al hijo de la condición de ciudadano romano que ostentaban los padres ${ }^{4}$.

Con referencia al status civitatis de los hijos, se determinó que el nacido de iustum matrimonium ${ }^{5}$ adquiría la condición que ostentaba el padre en el momento de la concepción, por lo tanto, si el padre era ciudadano romano casado en iustas nupcias con ciudadana romana o con latina o peregrina con ius conubii ${ }^{6}$, el hijo nacía ciudadano romano, al establecerse que el filius siguiese la condición que ostentaba el padre ${ }^{7}$.

Ahora bien, si la madre era ciudadana romana y estaba casada con un latino o un peregrino con ius conubii, los hijos nacerían con el status de latinos o peregrinos, puesto que, como hemos señalado, debían seguir la condición del padre.

Sin embargo, hay que advertir que sobre el reconocimiento del status civitatis se establecía un derecho particular para las mujeres, aunque desgraciadamente no permaneció durante mucho tiempo, pues en principio, al nacido de una ciudadana romana y un latino o peregrino sin ius conubii que constituían un

3. Torrent, A.: Manual...,op. cit., p. 525.

4. Sobre el tema vid. POLO ARÉVALO, E.M.: «Influencia del matrimonio y condición ciudadana de los padres en el status civitatis y familiae de los hijos», en El Derecho de familia de Roma al Derecho actual, Huelva, Asociación Iberoamericana de Derecho Romano, 2004, pp. 585 ss.

5. Los requisitos del matrimonio iustum se establecen en los Tituli ex corpore Ulpiani. 5, 2 Iustum matrimonium est, si inter eos, qui nuptias contrahunt, conubium sit, et tam masculus pubes quam femina potens sit, et utrique consentiant, si sui iuris sunt, aut etiam parentes eorum, si in potestate sunt, esto es, existe justo matrimonio si entre los que contraen nupcias existe conubium, el varón es púber, la mujer núbil y ambos consienten si son sui iuris, o en el caso de que esten in potestate den su consentimiento también los padres.

6. El conubiun era la capacidad jurídica para contraer matrimonio. Sobre la materia, vid. entre otros: VolterRA, E.: «La nozione giuridica del conubium», Studi Albertario, II (1959), pp. 374 ss.; DE VISSCHER, F.: "Conubium et civitas», IURA, II (1951), pp. 140 ss.; GAUDEMET, J.: "Iustum matrimonium», RIDA, III (1956), pp. 227 ss.

7. Gayo expone que los concebidos en justas nupcias no solo entraban bajo la potestad del padre sino que adquirían la condición de ciudadanos romanos: GAI 1, 56. Iustas autem nuptias contraxisse liberosque iis procreatos in potestate habere cives Romani ita intelleguntur, si cives Romanas uxores duxerint vel etiam Latinas peregrinasve, cum quibus conubium habeant: Cum enim conubium id efficiat, ut liberi patris condicionem sequantur, evenit, ut non solum cives Romani fiant, sed et in potestate patris sint. 57. Unde et veteranis quibusdam concedi solet principalibus constitutionibus conubium cum his Latinis peregrinisve, quas primas post missionem uxores duxerint; et qui ex eo matrimonio nascuntur, et cives Romani et in potestatem parentum fiunt. 
matrimonium iniustum ${ }^{8}$, se le concedía la ciudadanía romana si la madre la poseía en el momento del nacimiento de su hijo, con independencia de que la hubiese ostentado o no con anterioridad.

Este privilegio fue modificado por una lex Minicia del año 90 a.C., estableciendo que los hijos de las uniones impropias siguieran el status civitatis del padre, por ello, a las mujeres que quisieran concebir hijos ciudadanos romanos, no les quedaba otra opción que casarse con cives romanos.

Analizando el matrimonio en Roma, se puede constatar que era una situación de hecho más que de derecho y por ello, no se encuentra en las fuentes ninguna definición jurídica del matrimonio; al respecto hay que señalar que los juristas romanos no plantearon una noción clara de la institución sino que establecieron meras aproximaciones que destacaban el hecho de la unidad de vida entre dos seres de distinto sexo, como se constata en las Instituciones de Justiniano 1,9,1, donde se establece que el matrimonio era la unión de un hombre y una mujer dirigida a una unidad de vida; concepto que perfila más una realidad sociológica que un instituto jurídico?.

I. 1,9,1 -Nuptiae autem sive matrimonium est viri et mulieris coniunctio, individuam consuetudinem vitae continens.

Se vuelve a acentuar el carácter de comunidad de vida en la célebre definición de Modestino, contenida en D. 23, 2, 1, en la que se destacan tres aspectos en el concepto de matrimonio, al manifestar que, eran nupcias la unión de un hombre y mujer, el consorcio de toda la vida y la comunicación de derecho divino y humano.

D. 23. 2. 1 -Modestinus 1 reg. -Nuptiae sunt coniunctio maris et feminae et consortium omnis vitae, divini et humani iuris communicatio.

El jurista, en ningún momento se refiere a las consecuencias jurídicas que pudiese llevar consigo esa unión, lo que pone de manifiesto, que el matrimonio en Roma era esencialmente, como ya se ha manifestado, una situación de hecho basado en la praxis de las relaciones sociales, sin tener en cuenta vínculos jurídicos.

No obstante, se podría establecer una noción del matrimonio en época clásica, siguiendo a Bonfante ${ }^{10}$ manifestando que existía matrimonio cuando se establecía la unión de un hombre y una mujer libres, que ostentaban conubium, tenían la edad prescrita por la ley -hombre púber y mujer núbil- y creaban una relación conyugal con la voluntad efectiva y continua de estar unidos en matrimonio.

8. VolterRA, E.: «Iniustum matrimonio», Scritti Giuridici, III (1991), pp. 441 ss. manifiesta que al matrimonio iniustum le faltaba el conubium, requisito esencial para poder contraer matrimonio conforme a las reglas del Ordenamiento jurídico romano, no obstante, no podía considerársele nulo sino que de él no se derivaban los efectos jurídicos propios del matrimonio legítimo.

9. TORRENT, A.: Manual..., op. cit., p. 525.

10. BONFANTE, P.: Corso...,op. cit., p. 258. 
Ahora bien, si el fundamento del matrimonio romano descansaba en el consensus o mero consentimiento de ambos cónyuges si eran sui iuris, expresado sin formalidad alguna y en el caso de que alguno de los esposos estuviera sometido a potestad también era necesario que prestara el consentimiento su pater; no era menos importante la coniunctio o convivencia conyugal de los contrayentes.

Por lo tanto, el matrimonio romano en época clásica comportaba dos elementos, primero el consensus, que se plasmaba en la affectio maritalis, o intención reciproca de los contrayentes de tenerse por marido y mujer; sin embargo, no bastaba con que se conviniera el consensus al inicio del matrimonio sino que debería estar presente todo el tiempo que durase el mismo, por ello, si se perdía la affectio maritalis, se disolvía el matrimonio sin más causa. El segundo se plasmaba en la coniunctio, que no comportaba la convivencia efectiva de los cónyuges sino que la mujer fuese conducida a la casa del marido -deductio in domus mariti- como expone Pomponio en D. 23, 2, $5^{11}$, y en el honor matrimonii por el que la mujer adquiría la misma condición social que el marido, además de ser considerada materfamilias.

Asimismo, para que el matrimonio se considerase iustum, y pudiese obtener los derechos que a tal unión le confería el Ordenamiento jurídico, requería unas condiciones de validez que pueden concretarse en los siguientes requisitos: en primer lugar, capacidad jurídica -conubium- esto es, la facultad conforme al ius civile de constituir entre ellos justo matrimonio; esta aptitud, que en principio fue reservada a los patricios, posteriormente, fue concedida a los plebeyos por la Lex Canuleia. Sin embargo, fuera de la esfera de los ciudadanos romanos, el ius conubi sólo pudo atribuirse a algunos latinos y peregrinos por concesión especial. En segundo lugar, capacidad natural, lo que implicaba que ambos fueran púberes, esto es, que fueran mayores de edad. En tercer lugar, hay que indicar que el matrimonio clásico era monogámico, lo que excluía de la institución a personas unidas por una relación conyugal anterior y exogámico -que no existiese entre los cónyuges parentela consanguínea, de adopción o afinidad-.

La concepción del matrimonio cambiará totalmente en época postclásica, puesto que la legislación imperial abolió la necesidad del ius conubii para contraer justo matrimonio y estableció una modificación en la forma de prestar el consentimiento matrimonial, ya que, si bien en época clásica debía ser continuado durante todo el tiempo que permaneciera la relación conyugal, se transformará en inicial por obra de los emperadores cristianos, esto es, que únicamente sería requerido al inicio de la relación; por tanto, el consensus debía interpretarse como la voluntad de los contrayentes de unirse en matrimonio, con independencia de que tal voluntad persistiese o cambiase.

La transformación de la prestación del consentimiento de continuada a inicial, tendrá como consecuencia que el matrimonio ya no se disolverá libremen-

11. D. 23, 2, 5-Pomponius 4 ad sab.-Mulierem absenti per litteras eius vel per nuntium posse nubere placet, si in domum eius deduceretur: eam vero quae abesset ex litteris vel nuntio suo duci a marito non posse: deductione enim opus esse in mariti, non in uxoris domum, quasi in domicilium matrimonii. 
te con la perdida de la affectio maritalis, sino que para poder divorciarse debían concurrir toda una serie de causas tipificadas en la legislación, cuyo efecto era el de mantener vivo el vínculo matrimonial.

Después de haber expuesto en líneas generales los requisitos del matrimonio romano, se analizará el concepto de concubinato o unión de hecho en Roma.

Considerando los requisitos necesarios para contraer matrimonio en época clásica, se puede determinar que las uniones entre personas de distinto sexo que no tuvieran conubium no podían constituir matrimonio iustum, por lo que su convivencia podría ser calificada en la actualidad como unión de hecho. Igualmente, si faltaba el consentimiento de las partes para formar matrimonio -affectio maritalis-, también sería consideraba esa unión concubinatus o unión de hecho.

Por tanto, la doctrina romanística ${ }^{12}$ es conforme al definir el concubinato -unión de hecho-, como la convivencia estable de un hombre y una mujer entre los que no existía conubium ${ }^{13}$, o bien, no tenían la voluntad continua y efectiva de ser recíprocamente marido y mujer.

El concubinato se configuró como una unión de hecho ${ }^{14}$ que se distinguía por su estabilidad de las uniones fugaces de mera relación sexual. Esta institución no fue en Roma ni ilegal ni socialmente reprochable y su fundamento y amplia difusión obedeció, primordialmente, a la legislación de Augusto en materia matrimonial que vino a restringir, notablemente, el número de mujeres con las que podía contraerse iutum matrimonio ${ }^{15}$.

Por un lado, la Lex Iulia et Papia Poppaea prohibía el matrimonio entre personas de distinto rango social para evitar la mezcla de la clase alta-senadores e hijos de senadores- con personas de baja o abyecta condición social, -libertas, artistas, hijas de artistas, meretrices, etc.- y estableció, asimismo, el impedimento para contraer matrimonio entre los gobernadores provinciales y las mujeres de la provincia en la que estaban destinados, prohibición que también se impuso a los militares ${ }^{16}$.

De igual manera, la Lex Iulia et Papia establecía impedimentos matrimoniales a los demás ingenuos, con mujeres libertas, adúlteras, alcahuetas o condenadas en juicio público, entre otras ${ }^{17}$.

12. Entre otros, Bonfante, P.: Corso..., op.cit., p. 315; GAUdemet, J.: «Union libre et marriage dans la Roma Imperiale», IURA, 40 (1989), pp. 1 ss.; VOLTERRA, E.: Instituciones..., op.cit., p. 666; ToRRENT, A.: Manual...,op. cit., p. 537; PANERO, R.: Derecho..., op. cit., p. 305.

13. PANERO ORIA, R.: "Algunas observaciones en torno al concubinato", en El Derecho de familia de Roma al Derecho actual, Huelva, Asociación Iberoamericana de Derecho Romano, 2004, pp. 527 ss., establece que cuando faltaba uno de los presupuestos exigidos para contraer matrimonio, existía affectio maritalis y honor matrimonii, sin embargo, al no poder constituir matrimonio la única posibilidad de mantener una relación estable era el concubinato.

14. PlaSSARD, M.J.: Concubinat romain sous le haut empire, Toulouse-Paris, Dalloz, 1921, p. 17

15. PANERO, R.: Derecho...,op. cit., p. 305.

16. Sobre los impedimentos vid. Astolfr: La lex Iulia et Papia, Padova, 1995.

17. D. 25, 7, 3, pr.-Marcianus 12 inst. -In concubinatu potest esse et aliena liberta et ingenua et maxime ea quae obscuro loco nata est vel quaestum corpore fecit. alioquin si honestae vitae et ingenuam mulierem in concubinatum habere maluerit, sine testatione hoc manifestum faciente non conceditur. sed necesse est ei vel uxorem eam habere vel hoc recusantem stuprum cum ea committere. El jurista se refiere a las mujeres 
Por lo que se refiere a la Lex Iulia de adulteriis, se debe señalar que sancionaba gravemente la unión extraconyugal con mujeres ingenuas y honestas, tipificando los delitos de adulterium y stuprum. Se cometía adulterium cuando la unión se realizaba con mujer casada y stuprum cuando la mujer, ingenua y honesta, era viuda o doncella. Ahora bien, las palabras adulterio y estupro, consignadas en la Lex Iulia, no tenían el significado moderno de violencia e infidelidad conyugal $^{18}$.

Por otra parte, las mujeres de alta condición social, se vieron condicionadas por las leyes augusteas, puesto que no podían casarse con libertos, gladiadores, hijos de gladiadores, etc.

Las prohibiciones de las Leges Iuliae originaron que las uniones constituidas al margen de sus disposiciones fueran consideradas ilegales o contra mandata ${ }^{19}$, puesto que en su virtud se privaba de conubium a los contrayentes, requisito esencial para poder contraer justo matrimonio.

Un punto discutido por la doctrina romanistíca ${ }^{20}$ fue la posibilidad de que las leyes promulgadas por Augusto hubiesen sido las determinantes de la elevación del concubinato de relación social a instituto jurídico, pero se llegó a la conclusión de que las leyes caducarias no establecieron normas que definiesen y regulasen el concubinato y sólo se hacía mención al mismo para declararlo exento de las penas que castigaban el delito de estupro de la Lex Iulia de adulteris y para distinguirlo del matrimonio regulado en la Lex Iulia et Papia ${ }^{21}$.

Sin embargo, hay que precisar que no se redujo el concubinato por el exceso de puritanismo marcado por Augusto sino que su legislación llevó a un resultado contrario, estimulando la propagación de las parejas de hecho al limitar tanto las mujeres como los hombres con los que los ciudadanos romanos podían contraer matrimonio.

El concubinato, expone Bonfante ${ }^{22}$ no era más que una institución de hecho, socialmente tolerada en Roma, pero absolutamente fuera del Derecho; no

con las que se podía vivir en concubinato, aludiendo a la liberta ajena y a la ingenua, no obstante, en caso de que fuera ingenua sólo se podía establecer concubinato con aquella nacida de oscuro linaje o con la que hizo ganancia con su cuerpo, porque si era honesta se cometía stuprum. CASTELLO, C.: In tema di matrimonio e concubinato nel mondo romano, Milano, Giuffré, 1940, p. 189, establece que la mención del concubinato con ingenua es una interpolación justinianea.

18. BONFANTE, P.: Corso..., op. cit., p. 315.

19. Las uniones contra mandata eran aquellas prohibidas por un senadoconsulto o por disposiciones imperiales.

20. Entre los autores que establecen que la elevación del concubinato de relación social a jurídica se debe al emperador Augusto se encuentran, entre otros: MOMMSEM, T.: Romisches Staatsrecht, III, Leipzig, S. Hirzel, 1887, p. 430, n. 2; MEYER, P.M.: Des römische Konkubinat nach den Rechtsquellen und den Inschriften, Leigzig, S. Hirzel, 1895, p. 25; GIDE, P.: Études susr la condition privée de la femme dans le droit ansien et moderne, Durant et Pedone-Lauriel, 1867; BRINI, G.: Matrimonio e divorzio, op.cit., pp. 193-194; COSTA, E.: "Il concubinato a Roma», BIDR, XI (1898), p. 293 ss.; entre los autores que sostienen una teoría contraria y establecen que el concubinato era una relación de hecho tolerada por el Derecho, vid.: CASTELLI: «Il concubinato e la legislazione augustea», BIDR, XVII (1915), pp. 55 ss; Bonfante, P.: Corso..., op. cit., p. 316.

21. BONFANTE, P.: Corso..., op. cit., p. 316.

22. Ibid., pp. 316-317. 
obstante, al propagarse en todas las clases sociales y especialmente en las más elevadas, determinó que asumiera, algunas veces, el aspecto de un verdadero matrimonio morganático, pues incluso emperadores de alta moralidad como Vespasiano y Marco Aurelio, después de la muerte de su mujer, vivieron en concubinato y la concubina se consideró también indispensable para los gobernadores provinciales.

Una posición particular, casi jurídica, tuvo el concubinato de la liberta con su patrono ${ }^{23}$. Unión que no fue, en ningún momento, deshonrosa para la mujer, puesto que la concubina tomaba el nombre de matrona o materfamilias, denominación que siempre se había reservado para las mujeres legítimas del paterfami$\operatorname{lias}^{24}$. En época clásica se dejaba a voluntad del patrono mantener a su liberta como esposa o como concubina, aunque Ulpiano en D. 25, 7, 1, pr. consideraba más honroso para el patrón que conviviese en concubinato con su liberta.

D. 25, 7, 1, pr. - Ulpianus 2 ad l. iul. et pap.-Quae in concubinatu est, ab invito patrono poterit discedere et alteri se aut in matrimonium aut in concubinatum dare? ego quidem probo in concubina adimendum ei conubium, si patronum invitum deserat, quippe cum honestius sit patrono libertam concubinam quam matrem familias habere.

Por otra parte, este régimen especial determinaba que la concubina podía ser sometida a la acusación pública de adulterio, acción impensable fuera del matrimonium iustum, puesto que, evidentemente, no se podía acusar como marido a quien nunca fue su legítima mujer; no obstante, la acusación publica podía entablarse por un extraño, como expone Ulpiano en su libro II de adulteriis -iure tamen extranei accusationem instituere non prohibebitur, si modo ea sit, quae in concubinatum se dando matronae nomen non amisit, ut puta quae patroni concubina fuit- siempre que la mujer, aún uniéndose en concubinato, no hubiese perdido el titulo de matrona, y en efecto, la liberta que se unía en concubinato con su patrono no perdía su honestidad.

D. 48, 5, 14, pr. - Ulpianus 2 de adult.-Si uxor non fuerit in adulterio, concubina tamen fuit, iure quidem mariti accusare eam non poterit, quae uxor non fuit, iure tamen extranei accusationem instituere non prohibebitur, si modo ea sit, quae in concubinatum se dando matronae nomen non amisit, ut puta quae patroni concubina fuit.

Además, si la mujer había sido manumitida matrimonii causa no podía separarse de su patrón por voluntad propia, ni podía unirse en concubinato ni desposarse con otro hombre ${ }^{25}$.

Desde el punto de vista jurídico, la elevación del concubinato de relación social a institución jurídica se debió, sobre todo, al esfuerzo de los emperadores cristianos por abolirlo; hasta el punto, que llegaron a combatir estas parejas de hecho desde dos frentes: por un lado desprestigiando la condición de la concu-

23. CAstello, C.: In tema..., op. cit., pp. 76 ss.

24. Bonfante, P.: "Nota sulla riforma giustinianea del concubinato», Separata de Studi in onore di Silvio Perozzi, Palermo, 1924, p. 285.

25. D. 24, 2, 11 pr.- Ulpianus 3 ad l. iul. et pap. 
bina y de sus hijos y por otro, favoreciendo directamente la transformación del concubinato en matrimonio ${ }^{26}$.

Ambas vías fueron abiertas por Constantino. El emperador dictó tres constituciones sobre el particular ${ }^{27}$ y entre otras cuestiones desfavorables, decidió que no podían realizarse donaciones ni a la concubina ni a sus hijos aunque fuera de forma encubierta; si esto se hubiera cumplido, se les obligaba a restituir los bienes recibidos a los parientes consanguíneos del hombre cuando éste muriese -hijos legítimos, padres, hermanos-; condenándosele a pagar el cuádruplo, previa indagación bajo tortura, si no hubieran sido devueltos dichos bienes ${ }^{28}$.

Los emperadores posteriores, con oscilaciones, mitigaron o volvieron a aplicar el duro régimen de Constantino en su intento de combatir el concubinato.

Ahora bien, será Justiniano el que modifique el concepto del instituto y atenúe su régimen. En primer lugar, declaró abolida la categoría de mujeres con las cuales no se cometía stuprum de las leyes augusteas, +todas aquellas que no fuesen ingenuas y honestas+ y en segundo lugar, estableció que era jurídicamente lícito, previa declaración de los dos convivientes, el concubinato con mujer honesta e ingenua.

Una vez reconocido el concubinato como relación jurídica, se configuró como una unión conyugal inferior al matrimonio legítimo ${ }^{29}$, por lo que exigió las mismas condiciones establecidas para el matrimonio, que siguiendo a Bonfante $^{30}$ pueden señalarse las siguientes:

$1^{\circ}$.- El concubinato era rigurosamente monogámico, prohibiéndose al hombre que tenía esposa mantener una concubina y al soltero poseer más de una.

$2^{\circ}$.- Se requería para el concubinato la misma edad que para el matrimonio, esto es, que los convivientes fueran púberes.

$3^{\circ}$.- Estaba sujeto a los impedimentos de parentela consanguínea, por adopción o afinidad vigentes para el matrimonio.

Por otra parte, para calificar jurídicamente una unión conyugal como matrimonio o como concubinato se atendía exclusivamente a la voluntad inicial de las partes, esto es, que se hubiese querido constituir una u otra relación. No obstante, permaneció sin reconocimiento, el derecho de la concubina a participar en el grado de dignidad de su pareja. Ahora bien, se declaró abrogada la prohibición de donaciones a la concubina y a sus hijos.

Por último, Justiniano reguló definitivamente la legitimación de los liberi naturales, denominación que tomaban los hijos fruto del concubinato. La legitimación podía llevarse a cabo de tres formas distintas, primero, por el matrimonio posterior de sus padres - per subsequens matrimonium-; segundo, por concesión imperial -per rescriptum principis; tercero, por inscripción de los hijos en la curia del lugar donde tuviesen el domicilio sus padres -per oblationum curiae-.

26. BONFANTE, P.: Corso..., op. cit., p. 318.

27. C. TH. 4, 6, 2 y 3.

28. BONFANTE, P.: Corso..., op. cit., p. 318.

29. VOLTERRA, E.: Instituciones..., op. cit., p. 666.

30. Bonfante, P.: Corso..., op. cit., p. 324. 
Con la regulación del concubinato y sobre todo con la eliminación de los impedimentos para contraer matrimonio de las leyes augusteas, Justiniano logró, quizás, lo que no habían alcanzado los emperadores precedentes con sus severas sanciones, pues al suprimir la imposibilidad para contraer matrimonio con determinadas mujeres, consiguió que se fuera extinguiendo el concubinato.

El concubinato en Roma amparó uniones entre parejas de distinto sexo, que o no podían o no querían contraer matrimonio, pero nunca contempló la unión entre parejas homosexuales.

La institución fue abolida definitivamente en Oriente en tiempos de León el Filósofo ${ }^{31}$, estando vigente en Occidente hasta el siglo XII.

Hasta aquí he expuesto las uniones de hecho en Roma, pero antes de finalizar este trabajo deseo manifestar, como apunte final, que tanto el concepto de pareja de hecho como los requisitos exigidos en Roma para la constitución de las mismas, están presentes en la Ley 1/2001 que regula las uniones de hecho en la Comunidad Valenciana. No obstante, como puede contemplarse en su artículo primero, esta Ley es mucho más amplia y permisiva que el Derecho Romano, puesto que incluye en su ámbito de aplicación a las parejas homosexuales.

La Ley 1/2001 en su articulo primero dispone que para considerar una unión como pareja de hecho, ésta debe ser, libre, consentida, publica y notoria, estable, al menos durante un periodo ininterrumpido de doce meses y que exista una relación de afectividad. Por lo tanto, de igual manera que en Roma se excluyen las uniones casuales o de mera relación sexual y será la voluntad de los convivientes la que determine que esa pareja se constituya en unión de hecho.

Además, incidiendo en el consentimiento de las partes la Ley 1/2001 establece que para la aplicación de la ley, los convivientes deben someterse a la inscripción de la unión en el Registro Administrativo de Uniones de Hecho de la Comunidad Valenciana.

En cuanto a los requisitos personales que se encuentran enumerados en el artículo segundo de la citada Ley, podemos llegar a la conclusión de que existe paralelismo con los exigidos en el Derecho romano justinianeo para el concubinato o unión de hecho, pues, en primer lugar, en ambas regulaciones está presente el requisito de la edad, esto es, que para constituir una unión de hecho según las normas de la Ley 1/2001 ambos constituyentes deben ser mayores de edad o si son menores deben estar emancipados; en segundo lugar, se prohíbe la constitución de parejas de hecho a las personas ligadas por el vínculo de matrimonio o que hayan constituido una unión de hecho anterior que no haya sido disuelta y como ha podido comprobarse anteriormente, también los romanos prohibieron que el ciudadano casado mantuviese una concubina y que el soltero pudiese tener más de una; en tercer lugar, no se permite uniones de hecho entre los parientes por consanguinidad o adopción en línea recta y en línea colateral hasta el tercer grado, por lo tanto, la Ley se perfila rigurosamente monogámica y exogámica, aunque no incluya a los parientes afines.

31. Año 866-912 - siglo VII-VIII d.C. 
En cuanto a la disolución de las uniones de hecho, se encuentra similitud con las causas por las que se disolvía el matrimonio romano clásico y posteriormente el concubinato, al establecerse en el artículo sexto de la Ley 1/2001, que las uniones de hecho instituidas conforme a los dictados de la misma, se disuelven, bien por común acuerdo entre las partes o bien por decisión unilateral, muerte o matrimonio de uno de sus miembros. 


\section{LA FILIACIÓN MATERNA Y PATERNA EN EL DERECHO ISLÁMICO. DERECHO SUSTANTIVO Y REFORMAS EN LOS SISTEMAS JURÍDICOS ACTUALES}

Ma MAGDALENA MARTÍNEZ ALMIRA

Universidad de Alicante

\section{CONSIDERACIONES GENERALES}

La presencia en España de un importante número de personas que profesan la religión islámica ha favorecido el interés por el Derecho islámico en sus diversas manifestaciones. En este sentido, son muchos los expertos en Derecho que han planteado cuestiones relativas a instituciones del ámbito privado respecto a matrimonios mixtos, como la familia, la filiación o la adopción respecto, y también por razón de las demandas presentadas ante tribunales españoles por matrimonios contraídos validamente entre musulmanes en sus países de origen $^{1}$.

Ahora bien, el asentamiento de los musulmanes en España, bien de forma temporal o bien definitiva, obliga al jurista interesado en este sistema jurídico a considerar la pluralidad de textos normativos propios de cada nacional. Se trata de un Derecho que ha experimentado un proceso de modernización en los últimos ciento cincuenta años, especialmente respecto al Derecho de familia, una materia que al menos conceptualmente presenta ciertas características en modo alguno comparables al derecho occidental ${ }^{2}$. En efecto, en el Derecho islámico

1. Remítase el lector a BORRAS, A., y MERNISSI, S.: El islam jurídico y Europa, Barcelona, Icaria, 1998. Y sobre la incorporación de estos sistemas jurídicos al mismo ámbito CASTRO, F. y ALLIEVI, S.: Islam and European Legal Sistems, Milan-Leicester, Oxford University Press, 2001, pp. 154 y ss.

2. Aluff BeCK-PeCCOZ, R.: La modernizazione del Diritto di Familia nei Paesi arabe, Milano, Giuffré, 1990, pp. 160-177. Pese a no contener muchas de las recientes reformas acontecidas en los países africanos, el lector interesado en estas cuestiones no puede dejar de remitirse a la obra de conjunto PRADER, J.: Il matrimonio nel mondo: celebracione-nullitá e scioglimiento del vincolo, $2^{\mathrm{a}} \mathrm{ed}$. aggiornata, Padova, CEDAM, 1986; el texto aproxima a una situación global respecto a la institución matrimonial en los países de tradición islámica y a los cambios acaecidos en los últimos cuarenta años respecto a los textos surgidos fruto de la codificación. 
el contrato de matrimonio (nika $\left.h^{3}\right)$-tanto lícito como ilícito, si se toma en consideración que la mut'a es una institución legal para los šiies duodecimanos ${ }^{4}$-, el repudio, la filiación y los efectos legales y patrimoniales derivados de estas instituciones jurídicas son instituciones que guardan su singularidad desde el punto de la sistemática del derecho, tartīb, y en modo alguno forman parte de un materia unitaria como así sucede en otros sistemas jurídicos.

Una de las instituciones que mayor interés suscita por las sucesivas cuestiones que se plantean ante los tribunales es la filiación y el reconocimiento de la paternidad, sobre todo en relación a los procesos de repudio y divorcio que se sustancian en nuestro territorio. Los problemas que surgen cuando las autoridades españolas deben identificar la autoridad competente en un Estado extranjero para conocer estas demandas son complejos, especialmente en lo que a los países islámicos se refiere, tanto del ámbito del Magreb como del Masriq, e incluso en áreas aún más alejadas. Nótese que son muchos los residentes en España procedentes de Nigeria, Níger, Malí, Sudán, Senegal, Somalia, Argelia, Túnez y Marruecos y, en menor cuantía, de Irán e Iraq; países cuya legislación en la materia que nos ocupa difícilmente es conocida en nuestro país ${ }^{5}$. La fluidez con la que se produce el intercambio de información sobre la legislación vigente en aquellos países depende en gran medida de las relaciones diplomáticas y de la expresa reglamentación sobre traspaso de información y competencias en estas materias 6 .

3. S.v. «nikāh», en Encycoplaedia of Islam (en adelante $E I^{2}$ ), vol. VIII, Leiden, Brill, 1995, pp. 26-35.

4. Un matrimonio cuya validez depende de la constatación de dos condiciones. La fijación del término de cohabitación, pudiendo ser un día, un mes, un año o un número determinado de años; y en segundo lugar la fijación de la dote. En este caso el divorcio no es factible y el contrato expira con el término del plazo establecido en el mismo. S.v. "muta'a», en $E I^{2}$, vol. VII, Leiden-Nueva York, Brill, 1993, pp. 757-759.

5. Aunque sería interesante abordar el derecho sustantivo de cada uno de estos países en relación a la filiación y las formas de reconocimiento de la paternidad, así como sus efectos, este planteamiento excede en cuanto a posibilidades materiales el objeto de este trabajo;así pues se ha optado por hacer un seguimiento de aquellos textos jurídicos de países del Magreb (Túnez, Argelia y Marruecos) y del Masriq -especialmente de Egipto y Sudán- sin olvidar aquellos otros de la zona más oriental en los que, si bien la mayoría de la población es musulmana oficialmente, no se aplica la šarì'a, y entre estos cabe citar Jordania, Siria, Iraq o Kuwait, sujetos a la influencia británica. Kuwait, por ejemplo, adoptó tras la independencia un modelo jurídico basado en las propuestas de al-Sanhuri y concluyó con la elaboración de un Estatuto Personal en 1984. Abd al-Razzaq Ahmad al-Sanhuri (1895-1971) fue discípulo de Lambert, y desarrollo un modelo normativo de amplia difusión en el mundo árabe, tanto en el Magreb, en Libia, Argelia y los países del desmembrado Imperio otomano, como Siria (1949), Iraq (1951) y Jordania (1976), conocido bajo el nombre de "modelo egipcio». El proyecto de código civil egipcio fué adoptado en Libano, Túnez, Argelia y Marruecos, habiéndose redactado otro para Siria, Transjordania, Iraq y Palestina. Véase CASTRO, F.: «La Codificazione del diritto privato negli stati arabi contemporanei», Rivista de Diritto Civile, 4 (1985), I, pp. 384-447. CIlARDO, A.: Il Diritto islamico e il sistema giuridico italiano: le bozze di intesa tra la Repubblica Italiana e le associazioni islamiche italiane, Nápoles, Edizioni Scientifiche Italiane, 2002, p. 267.

6. De hecho el punto de partida ante esta problematica es la determinación de la competencia por parte del Estado en el que se desarrolla el procedimiento en cuestión. Dos son los preceptos operativos: en primer lugar el art. 10 del Convenio de la Haya de 1996 respecto a la competencia del 
Los continuos flujos migratorios de personas procedentes de países en los que rige el Derecho islámico han dado lugar a que en los tribunales españoles se planteen situaciones que obligan a considerar y analizar la normativa de los países de origen, especialmente en relación a las cuestiones sustantivas surgidas sobre la filiación. Sin lugar a dudas la filiación es en el Derecho islámico una institución que presenta algunas divergencias respecto a otros sistemas jurídicos. La filiación define el derecho al parentesco correspondiente tanto al padre como al hijo. Un derecho que el ordenamiento musulmán reconoce al padre desde el momento en que el feto se encuentra en el útero materno. En este sentido, el primer derecho que adquiere el nasciturus es el mantenimiento por parte del padre y los cuidados necesarios respecto a la madre durante el periodo de su embarazo y hasta el alumbramiento. Desde ese momento, y hasta la mayoría de edad, el niño atraviesa por una serie de etapas vitales en las que se reconocen derechos concretos garantes de su crecimiento y desarrollo en condiciones determinadas ${ }^{7}$. Los derechos de reconocimiento paterno, custodia, mantenimiento y guarda del hijo están estrechamente relacionados con la institución del matrimonio, y por tanto estos dependen, en última instancia, de la legítima unión entre los cónyuges por razón del contrato que entre ellos hayan celebrado, y que en aquellos países de tradición malikí el criterio seguido es la guarda ejercida por los agnados ${ }^{8}$.

Es importante hacer una referencia a la diversidad de situaciones que se derivan de la normativa contenida sobre estas instituciones en los Códigos y Estatutos personales que rigen en los distintos países de tradición islámica. Hay que tener en cuenta también que la filiación en el Derecho islámico responde a un esquema propio y singular, circunstancia que permite una mejor compren-

juez español para conocer demandas de nulidad, separación o divorcio y responsabilidad parental ante demandas presentadas de mutuo acuerdo siemrpe que alguno de los cónyuges resida en España; en segundo lugar los arts. 8 y 9 del citado Convenio en los que se establece que respecto a los derechos del menor fruto de un matrimonio serán las autoridades del Estado en las que el menor tiene su residencia, las que cedan su competencia a las autoridades de otro Estado en el que se esté conociendo una demanda de nulidad, separación o divorcio de los padres del niño. Así pues, los procesos iniciados en España obligarán a los tribunales españoles a solicitar permiso para adoptar las medidas necesarias para la protección del menor y el respeto de sus derechos, ante los supuestos de divorcio o separación de los padres. Sobre las dificultades que día a dia se producen y las vías de solución véase ARENAS GARCÍA, R.: Crisis matrimoniales internacionales. Nulidad matrimonial, separación y divorcio en el nuevo derecho internacional, Santiago de Compostela, Universidad de Santiago, 2004, pp. 78-83. Y en relación a las distintas problemáticas surgidas por inadaptación e inadecuación de los textos normativos al Derecho español MotilLA, A. y LORENZO, P.: Derecho de familia islamico. Los problemas de adaptacion al derecho español, Madrid, Colex, 2002, $1^{\circ}$ ed. Remítase el lector al artículo de MENHOFER, B.: «Enfant et patrimoine dans la recontre des civilisations", en J. Carlier J. y Verwilghen (eds.): L'estatut personnel des musulmans: droit comparé et droit international privé, Bruxelles, Verwilghen, 1992, pp. 356-377.

7. NASIR, J.J.: The Islamic Law of Personal Status, London, Graham and Trotman, 1986, pp. 156-169.

8. NASIR, J.A.: The islamic law of personnal Statuts, $2^{\circ}$ ed., London-Dordrecht-Boston, Graham and Trotman, 1990, p. 50. En este sentido el orden seguido es el de descendientes, ascendientes, los hermanos y los hijos de éstos, y finalmente los tios agnados y sus hijos. 
sión del contenido de las demandas formuladas por los musulmanes residentes en territorio español, sobre todo a la luz del Derecho comparado?.

\section{EL MARCO JURÍDICO DE LAS RELACIONES FILIALES}

\subsection{Presunción de paternidad}

La relación filial de parentesco, nasab ${ }^{10}$, se establece en el Derecho islámico mediando matrimonio válido; la presunción de paternidad que tiene en las palabras de Mahoma su justificación última: «el hijo pertenece al lecho», al-walad lil-firas $\mathfrak{s}^{11}$. Ello no obsta para que la doctrina haya reconocido otras posibilidades con base en el citado ordenamiento jurídico, aún con desigual aceptación entre las distintas escuelas jurídicas, y así sucede con el reconocimiento de la paternidad $\left(i q r \bar{a} r^{12}\right)$ y la evidencia.

El parentesco es definido como un derecho del hijo y del padre. En efecto, la relación de parentesco confiere una serie de derechos y obligaciones entre ambas partes, pero de forma especial del progenitor masculino respecto al recién nacido; entre los derechos destacan el derecho a la herencia, a la guarda y a la custodia hada ${ }^{13} a^{13}$, del hijo durante su minoría de edad. Estos derechos son reconocidos al padre biológico y la madre respecto al hijo, por lo que el parentesco y la relación filial son instituciones de derecho que confieren al hijo el estatuto de legitimidad ${ }^{14}$.

La filiación (nasab) se inicia, pues, desde el momento en que el varón tiene conocimiento del embarazo de la mujer fruto de la relación conyugal, presumiendo la doctrina que la concepción se deriva de las relaciones conyugales dentro del matrimonio legítimo. El hombre asumirá desde ese momento los cuidados y el mantenimiento de la esposa, hasta el nacimiento del concebido. Una obligación que en el momento del alumbramiento abre otra serie de expectativas respecto al niño, y que tiene en el acto de la imposición del nombre

9. Calvé Corbalán, C.: "Filiación», cap. IV, Tratado de derecho de familia. Aspectos sustantivos y procesales adaptados a las leyes 13/2005 y 15/2005 (P. González Poveda, ed.), Pozuelo de Alarcón, Sepín ediciones, 2005.

10. s.v. «nasab» en $E I^{2}$, vol. VII, Leiden-Nueva York, Brill, 1993, pp. 967-968 y MAíllo SALGADO, F.: Diccionario de derecho islámico, Gijón, Trea, 2005, pp. 274-275.

11. Al-BuHĀễ: Les traditions islamiques, trad. Houdas et Martel, París, Maissoneuve, Vol. III, p. 100. La expresión ha sido justificada en la actualidad en alusión a la mujer con la que es lícito mantener relaciones sexuales, en virtud del contrato que legitima la relación conyugal. Sobre estas cuestiones Alluffi-BeCK-PeCCOZ, R.: La modernizzazione del diritto islamico..., op. cit., pp. 155-159.

12. Las condiciones de validez se refieren tanto al declarante (al-muqir) que debe ser púber y sano de mente, no pudiendo manifestar su declaración mediante fuerza o presión alguna; al beneficiario (al-muqar lahu), que debe existir o al menos haber sido ya concebido; y al objeto de reconocimiento (al-muqar bihi) y respecto a éste se ha de pronuniciar en un acto unilateral y debe existir, sin duda; s.v. «iqrār» en EI', vol.III, Leiden-London, Brill, 1986, pp. 1078-1080.

13. S.v. «hadāna» en $E I^{2}$, vol. III, Leiden, Brill, pp. 16-19.

14. Y así es revelado en el Corán, XXXIII, 4-5; las alusiones del texto coránico a este tema se refieren a la edición de Julio Cortés, Barcelona, Herder, 1986. La materia es objeto de estudio por NASIR, J.J.: The Islamic law..., op. cit., pp. 170-189. 
el momento más trascendental a nivel de reconocimiento público en el seno de la Comunidad islámica.

El hecho de que los hijos nacidos fuera de la relación matrimonial no sean reconocidos legítimos, y se les considere fruto de la fornicación, ha motivado que el embarazo sea la situación de hecho que mayores controversias suscite entre los juristas islámicos, al menos en cuanto a la determinación del periodo mínimo de gestación, considerado desde aquel en que tuvo lugar la celebración del contrato matrimonial. Ello se debe a que, si bien en la actualidad se ha determinado el período mínimo de gestación en seis meses, la tradición prolongaba el término máximo del embarazo entre dos y cuatro años, según las distintas escuelas jurídicas ${ }^{15}$. El plazo comienza a computarse desde el momento en que es factible la relación conyugal entre los esposos ${ }^{16}$, situación que favorece la presunción de paternidad a favor del marido. Este hecho recibe distinto tratamiento por parte de las escuelas; en concreto, en la escuela hanafi $i^{17}$ rige el criterio de que desde el momento mismo de la conclusión del contrato se presume la paternidad al marido siempre que éste sea considerado apto para la consumación, incluso si niega haber mantenido relación sexual alguna. De este modo, siempre cabe el reconocimiento de la paternidad cuando la relación entre los cónyuges sea, al menos, teóricamente posible; de forma que si no tiene lugar la consumación del matrimonio por causa del marido, éste estará obligado hacia la mujer por incumplimiento del acuerdo nupcial ${ }^{18}$.

En la actualidad los Códigos y Estatutos personales regulan y normalizan esta materia, y justifican las bases legales establecidas para poder acreditar y justificar de forma automática el nasab o relación filial paterna; para ello se considera el plazo comprendido desde el término mínimo de la gestación (seis meses) hasta el máximo (un año) como término viable en el que puedan haber tenido lugar relaciones sexuales ilegítimas que afecten al fruto de aquéllas. En estos casos el hijo nacido fuera del matrimonio tendrá la consideración en el

15. Los hanafies prolongaban este término hasta un máximo de dos años, los šaf'ies y hanbalies hasta cuatro años; y los malikíes hasta incluso siete años. Este tema es objeto de estudio y análisis conforme a la tradición por SANTILLANA, D.: Istituzioni di diritto musulmana, con riguardo al sistema malichita e sciafiita, Roma, Istituto per l'Oriente, 1929-1938, 2 vols; vol. I, p. 237.

16. En materia de matrimonio, la capacidad de las partes es uno de los requisitos para la válida celebración del contrato; así pues la intervención del walì se justificaba antaño por la incapacidad temporal de la hija; la patria potestad ejercida por el padre de la hija virgen, legitimaba su actuación pudiendo casar a la hija incluso antes de la pubertad. Los requisitos del contrato matrimonial son enunciados por la doctrina malekí a través de ${ }^{3}$ ALĪL IBN Iș̣̂̄Q: Il Muhtașar: Sommario del Diritto Malechita, 2 vols, Milan, 1919, trad. Por I. Guido-D. Santillana, Roma, Ulrico Hoepli, t. II, pp. 5 y 41.

17. SCHLEIFER, A.: "The Legal Aspects of Marriage According to hanafi Fiqh», Islam Quaterly, 29 (1985), pp. 193-219.

18. La escuela malekí se ha ocupado especialmente de los efectos derivados de la no consumación así como del desistimiento unilateral posterior al concierto entre las partes sobre la forma y modo en que se celebrará el matrimonio de la impúber; en estos casos en los que no hay consumación, el marido estará obligado a pagar la mitad de la dote en caso de repudio. IBN 'ĀṣıM: Op. cit., v. 356, p. 187. 
Derecho islámico de hijo fruto de la fornicación, situación que comporta serios efectos negativos en atención a sus derechos ${ }^{19}$.

Muchos países islámicos adaptaron en la primera mitad del siglo XX la legislación en materia de presunción de paternidad con el fin de legitimar la relación filial entre el niño, nacido antes del transcurso del plazo mínimo legal del embarazo, y el padre, siempre y cuando el parto tuviera lugar dentro del matrimonio. En este sentido, las reformas acometidas en Túnez han sido punto de referencia para otros países del mismo entorno, pero especialmente de aquellos seguidores de la escuela malikí; en efecto, la citada escuela estima que el hijo concebido antes de la celebración del contrato matrimonial, y por tanto previo al matrimonio válido es atribuido, mediante presunción automática, al marido. Y así es recogido por la legislación del marco magrebí ${ }^{20}$.

\subsection{El reconocimiento de la paternidad (iqrār)}

Es un acto jurídico voluntario y que supone la declaración por parte del padre natural de esa situación de hecho, es decir de la atribución de su paternidad. El reconocimiento por parte del padre tiene su momento más significativo tras el alumbramiento y la aceptación de las congratulaciones de sus convecinos. De manera que siguiendo estos presupuestos el hijo nacido fuera de la relación conyugal, y por tanto concebido por razón de la fornicación, no puede ser vinculado, en principio, al padre por presunción ni por reconocimiento expreso en el que se haga mención a esta irregularidad.

El acto jurídico por el que se reconoce la paternidad adquiere la consideración de confesión o declaración que afecta a derechos de terceros y expresamente del hijo. Es un instituto cuya validez depende de la concurrencia de una serie de elementos, definidos por los juristas $(f u q a h \bar{a})$, que confieren validez al acto. Las fórmulas de reconocimiento han de ser inequívocas, no pudiendo aludir al carácter ilícito de la relación entre el hombre y la mujer; se exige también una diferencia de edad mínima entre el padre y el hijo; conforme a la escuela

19. La duración máxima del embarazo se toma en consideración en base al cálculo de los períodos del ciclo menstrual, o bien desde el momento del alumbramiento, o bien desde el momento del fallecimiento del marido otrora de la ruptura de relaciones con motivo del repudio definitivo (talāq al-bā’in); sobre esta modalidad, véase voz «talaq» en $E I^{2}$, vol. X, Leiden, Brill, 2000, pp. 151-157. Y en cuanto al reconocimiento en los ordenamientos jurídicos actuales de los países islámicos: ALLUfFI-BECK-PECCOZ, R.: La modernizzazione..., op. cit., pp. 169-174.

20. Un argumento que se considera fundamental para la erradicación del llamado matrimonio consuetudinario o de costumbre (al-zawağ al-urfi); s.v. "zawağ» en $E I^{2}$ op.cit, vol. XI, Leiden, Brill, 2002). Esta modalidad ha sido objeto de reciente reforma en el código argelino conforme a art. 11. "Les conditions de fond relatives à la validité du mariage sont régies par la loi nationale de chacun des deux conjoints» y considerado también, a través del art. 1565, por las reformas de la Moudawwana marroquí recientemente, con el fin de evitar equívocos en cuanto a la determinación del periodo de embarazo de una mujer, en atención al reconocimiento de la paternidad. Sobre las analogías entre los distintos códigos o Estatutos Personales véase Ruíz DE Almodóvar, C.: "Estudio comparado de los Códigos Magrebíes del Estatuto Personal», en Gemma Martín Muñoz (ed.): Mujeres, democracia y desarrollo en el Magreb, Madrid, Martín Muñoz, 1995, p. 204. 
maliki es preceptivo que no se den circunstancias que contrasten con la razón, tales como la concepción de un hijo mientras uno de los cónyuges se encuentra alejado físicamente del otro por grandes distancias durante un tiempo prolongado, en el que se considere inviable la relación conyugal.

Comoquiera que la relación de filiación no surge sino en virtud del reconocimiento en caso de relaciones ilícitas, la legislación prevé que el marido pueda asumir su responsabilidad sobre el niño nacido en el matrimonio al sexto mes de la conclusión del contrato, incluso del concebido antes de la celebración de aquel; es más, atendiendo al interés del niño cabe incluso el reconocimiento de la paternidad respecto a la mujer con la que no ha mantenido relaciones íntimas. Un supuesto que se extiende a los casos en los que ha fallecido el marido, o el repudio impide reconocer la evidencia de las relaciones; así las cosas los herederos del hombre tendrán la obligación de reconocer al niño, atendiendo al término máximo de la gestación -un año-, y al principio de la necesaria legitimación de la filiación paterna, propia de la escuela malik ${ }^{21}$. Para evitar situaciones extremas se intenta erradicar la aplicación de la teoría del niño dormido, como queda expresamente enunciado en el Código Kuwaití, fijando el plazo de un año como máximo de embarazo 22 .

El código argelino, modificado recientemente en parte de su articulado $^{23}$, y en concreto en materia de filiación (art. 8), establece ahora en el art. 13 bis. que la filiación y el reconocimiento de la paternidad, así como su negación, se

21. En este supuesto se suscita la cuestión sobre la paternidad biológica del marido, ya que el nacimiento suele acontecer más allá del término máximo, y por tanto el niño será fruto de relaciones ilícitas. Al margen de esta consideración otras escuelas, y concretametne la escuela lanafi-vigente en Turquía, Siria, Iraq, Egipto, Asia central, Afaganistan, y los sunníes de Pakistan, India y China, así como en Turquía y Argelia, en convivencia con la escuela malikí-, impera el criterio de que el padre y la madre que aún no han contraído matrimonio puedan mantener relaciones lícitas al realizar el coito por error;puede suceder cuando el hombre, habiendo contraído matrimonio con una mujer yazca, con otra por confusión, o bien se une por error con una mujer extraña -como sostiene la escuela hanbalí-. En estos casos la causa del reconocimiento viene dado por las relaciones lícitas que justifican la relación paterna, incluso ante el supuesto de coito por error; mientras que el modo de hacer valer el nasab consistirá en la prueba o manifestación externa del mismo. Estos supuestos pueden darse también respecto a personas que procedentes de alguno de estos países y viviendo en España hagan remisión a su ley nacional, lo que obliga a analizar el derecho sustantivo propio de cada país. AlLufFI-BECK-PECCOZ, R.: La modernizzazione..., op. cit., p. 174. También con caracter monográfio aborda estas cuestiones NASIR, J.J.: The Status of Women under Islamic Law and under modern Islamic Legislation, London, Graham and Trotman, 1990, pp. 45-60. Texto legislativo del año 1984; véase Ruíz-Almodóvar, C.: «El código Kuwaití de Estatuto Personal», Miscelánea de Estudios Árabes y Hebraicos, (en adelante M.E.A.H.), 47 (1998), pp. 335-381.

22. En este sentido es preciso señalar que el período mínimo del embarazo es de seis meses lunares y el máximo es de trescientos sesenta y cinco días.

23. Concretamente en relación a la filiación regulada por el antiguo art. 8, la Ley núm 05-10 de 20 de junio 2005 modificó la Ordenanza núm. 75-58 de 26 septiembre 1975, modificada y completada en materia de Derecho civil, en Journal officiel (JO), 2005-06-26, n 44, pp. 14-20, Secrétariat général du gouvernement, Algérie (consultado el 22-08-2005). Esta materia es objeto de desarrollo en el Decreto ejecutivo núm 96-259 de 29 de julio de 1996 por el que se crea un Comité nacional para la preservación y promoción de la familia. 
someten a la ley nacional del padre en el momento del nacimiento del niño. De manera que si el padre fallece antes del nacimiento del niño la ley que se le aplique será la que le fuera aplicable en vigor en el momento del deceso.

El hijo legítimo es reconocido por el padre mediante distintos signos y actos que evidencian y dan publicidad a su paternidad; la imposición del nombre, tasmiy $a^{24}$, a los siete días del nacimiento es uno de los actos que se celebran con carácter festivo para todos los miembros de la familia y la Comunidad islámica y que, como tal, comporta no solo la imposición de aquél sino también la incorporación de un nuevo musulmán a la Comunidad. Prueba de todo ello es el hecho de que la tasmiya se efectúa sobre el recién nacido por el padre o alguna persona de autoridad ${ }^{25}$. La celebración de estos actos recibe el nombre de 'aquiqa siendo acto recomendable (mustahabb o sunna), y comporta además cortar un mechón de pelo - de ahí el término que designa el acto-y sacrificar una víctima.

En realidad se trata de un ritual que comienza con el bi-'smi llāh o invocación del nombre de Alà que se pronuncia al oído del recién nacido para luego hacer la llamada a la oración -el adān ${ }^{26}$-, o cualquier otra fórmula pía aceptada por la costumbre, y tras una breve alocución se impone el nombre. Un nombre propio, ism 'alam, que viene acompañado de una serie de partes principales impuestas al tiempo de la tasmiya del neonato ${ }^{27}$. La kunya -en español alcurnia-indica la relación de paternidad y se expresa con Umm para la madre y $A b \bar{u}$ para el padre; kunya que alude al honor que da entre los musulmanes la paternidad, y que puede ser ficticia u honorífica. Otro elemento principal del nombre, en esta fase inicial de reconocimiento de la paternidad, es el nasab ${ }^{28}$, o relación de

24. S.v. «Basmala» en $E I^{2}$, t.I, Leiden, Brill, 1986, pp. 1084-1085; la frase es una invocación a Allāh «bism llāh 1-rahmāni 1-rahịmm», que significa "En nombre de Dios el Clemente el Misericordioso», conforme a la alocución de Corán, XXVII, 30. MAílLo SALGADO, F.: Diccionario de derecho islámico, op. cit., pp. 162-163.

25. La imposición del nombre y los apellidos es un ritual ajeno al carácter civil dispuesto en otros sistemas jurídicos, como es el caso del español, tal y conforme se deduce de lo contendio en la Ley 40/1999, de 5 de noviembre, sobre nombre, apellidos y orden de los mismos, que modificaba el art. 109 del C.C.

26. Cabe también cualquier otra fórmula pía, conforme a la costumbre del lugar. Antigua costumbre es la 'aqìqa consistente en el corte de un mechón de pelo del recién nacido y el sacrificio de alguna víctima. Como es costumbre también se suelen hacer regalos, convite y fiesta familiar. PAREJA, F.: Islamología, Madrid, Razón y Fe, 1952-1954, vol. II, pp. 547-548.

27. Entre las muchas posibilidades cabe hacer alusión mediante el nombre a situaciones, hechos y características que se desean reconocer en el neófito. Nombres que en la antigüedad hacían referencia a cosas duras, ásperas, fuertes, o de buen augurio contra los enemigos. A los esclavos se les imponían nombres de cosas agradables. Incluso se asignaron nombres bíblicos citados en el Corán o nombres teóforos o asimilados, caso de 'Abd Allah que significa siervo de Alá, siervo del Misericordioso.

28. El nasab designa el principio fundamental de organización de la sociedad árabe, y alude a la genealogía y relación entre los individuos; s.v. «nasab», $E I^{2}$, vol. VII, Leiden-Nueva York, Brill, 1993, pp. 967-968. 
filiación que se expresa con los términos ibn-o bin-y bint; en ocasiones con sentido metafórico ${ }^{29}$.

Entre las partes secundarias del nombre destacan: el lacab o epíteto de origen popular y descriptivo, mediante el que se pueden exponer características físicas del neonato y morales, e incluso anomalías; la nisba, que como extensión de la idea de filiación alude a las relaciones genealógicas, étnicas o geográficas del recién nacido. Y finalmente, nombres de profesión u oficio, ism mansab, del padre o antecesores por vía masculina.

Cabe también la posibilidad de determinar la filiación judicialmente, al igual que sucede en otros sistemas jurídicos ${ }^{30}$, aún en contra o con la oposición del padre, pudiendo el hijo ostentar el apellido el progenitor si lo solicita el mismo o su representante legal. Tal situación además, no afecta al derecho de velar por los hijos y prestarles alimentos, cumpliendo así con los deberes inherentes a la citada institución $\mathrm{Y}$ del mismo modo la privación de la patria potestad puede ser adoptada mediando decisión judicial, y la devolución de este derecho se efectuará por la misma vía, es decir previa sentencia por pronunciamiento judicial.

\section{LAS OBLIGACIONES INHERENTES A LA PATERNIDAD: VELAR POR LOS HIJOS Y PROCURAR SU SUSTENTO}

Conforme a lo dispuesto en otros sistemas jurídicos ${ }^{31}$ los deberes de velar y alimentar a los hijos son inherentes a la propia filiación, y como tales son exigibles ante los tribunales en situaciones de ruptura y divorcio de matrimonios mixtos $^{32}$.

Las obligaciones son enumeradas en los Codigos de Estatuto personal de forma unánime, si bien con las matizaciones y peculiaridades de los distintos textos vigentes, y a tenor del modelo codificador que los inspira. Así por eljemplo, el Derecho marroquí expresamente a través de su artículo 52 bis de la Mudawwana ${ }^{33}$ establece que la guarda del niño forma parte de las obligaciones sometidas a la carga del padre y de la madre mientras que se encuentren unidos

29. Así sucede con términos impuestos como ibn ul-sapì, que significa hijo del camino, viandante o peregrino. Es de uso corriente la abreviación de Ibn con una sola b. PAREJA, F.: Islamología, op. cit., p. 547.

30. Según lo dispuesto en el art. 111 C.C.

31. SEOANE PRADO, J.: «Prestaciones económicas: Derecho de alimentos y pensión compensatoria» en Tratado de Derecho de Familia, op. cit., cap. VI, pp. 365-442.

32. El art. 110 C.C. reconoce estos deberes y ha de ser considerado en atención a los supuestos de ruptura familiar en matrimonios o parejas no matrimoniales con hijos menores; los alimentos corrspondientes a los hijos ante tales procesos se exigirán desde la fecha de la demanda, conforme a lo dispuesto en el art. 148 C.C.; el juez estará a lo dipuesto en el art. 768 de la Ley de Enjuiciamiento Civil sobre la adopción de medidas cautelares. Sobre la materia reguladora de estos supuestos y la jurisprudencia véase CALVÉ CORBALÁN, C.: "Filiación», en Tratado de derecho de familia, op. cit., cap. IV, pp. 235-236.

33. Dahir $n^{\circ} 1-04-22$ du 3 février 2004 portant promulgation de la loi $n^{\circ} 70-03$ portant Code de la Famille. Bulletin officiel, 2005-10-06, n 5358, pp. 667-701. Con especial mención a las disposiciones sobre matrimonio, divorcio, nacimiento y sus efectos, la representación legal, el testamento 
por los lazos del matrimonio; la guarda del niño se confía prioritariamente a la madre y después al padre y a la parentela materna y paterna conforme a reglas determinadas ${ }^{34}$. No en vano, la madre es quien debe proveer de alimento al niño desde el momento de su nacimiento, conforme al texto coránico ${ }^{35}$, al margen de la pervivencia del contrato matrimonial entre los cónyuges, o de la rescisión del mismo en virtud del divorcio consensual ${ }^{36}$.

En este mismo sentido, los cambios que se han producido en la legislación maroquí sobre la materia prevén -debido según algunos autores a la influencia de la escuela hanafi- que la mujer que ejerce la hadăana pueda reclarmar una remuneración distinta a la de la nafaqa -a la que está obligado el padre hacia el hijo (arts. 103-104)- incluso en caso de separación del esposo. La institución de la guarda del menor ha sido objeto de sucesivas reformas, ya que si bien en los textos originarios se supeditaba hasta la mayoría de edad o la emancipación, en la actualidad la guarda se extiende en el caso de los niños hasta la edad de 12 años y hasta los 15 años para las niñas, conforme a lo dispuesto en el art. 102 de la Mudawwana ${ }^{37}$. Si bien, más allá de este período el niño puede elegir entre residir en casa de la persona a su elección que puede ser su padre, su madre u otro pariente mencionado en el artículo 99 del mencionado texto. Este artículo hace referencia a la capacidad de elección por parte de los niños; un supuesto que por ser ajeno a los valores de la sociedad musulmana se ha puesto en tela de juicio por parte de la doctrina ${ }^{38}$.

y la sucesión. Prevé, también, la determinación de la responsabilidad conjunta de los esposos respecto a los hijos habidos de su unión y confirma la igualdad entre hombre y mujer en cuanto a la edad para contraer matrimonio.

34. Mudawwana, Lib.III. De la filiación y sus efectos. Cap. III La custodia del niño (hadāna), art. 99. Al padre, a la abuela materna del niño, a la madre de su abuela materna, a su tía materna germana, a su tía materna cosanguínea, a su tía materna uterina, en a su abuela paterna, a la bisabuela paterna del niño, en una u otra línea donde el padre es probado, y en defecto, hasta el infinito en esta mismas líneas; a la hermana del niño, a su tía paterna, a su tía paterna del padre del niño, a la tía materna del padre del niño, a su sobrina por parte de hermano, a su sobrina por una hermana, a su hermano, a su abuelo paterno, a su sobrino carnal por un hermano, a su tío paterno. En todos estos casos, el padre hermano tiene prioridad sobre el uterino y este último sobre el cosanguíneo.

35. Cor. II,233.

36. Esta circunstancia es analizada conforme a la propuesta de las distintas escuelas jurídicas por NASIR, J.J.: The Islamic Law, op. cit., pp. 170 y ss.

37. Desde el punto de vista histórico la fijación de esta edad para la mujer venía condicionada a aquella en la que se considera hábil para consumar el matrimonio; parece ser que los andalusíes respetaban por tradición los nueve años en las féminas, como queda constatado en las Leyes de moros. A partir de ese momento el padre está obligado a la nafaga de la hija, por un plazo máximo de siete años después de la consumación -que por regla general podía tener lugar a los nueve años-. La tutela voluntaria del padre durante ese periodo está justificada en base a la tradición, ya que esta fue la edad a la que el Profeta casó con 'Aicha, según las tradiciones de Al-Buhââî (AL-BuHĀRĪ: Op.cit, t. II, p. 568). Sobre este supuesto véase Leyes de moros, op. cit., tit. CCCVIII, cap. XXXVII, p. 337. En relación al ejercicio de la tutela por el padre una vez consumado el matrimonio véase IBN ‘ĀṣıM: Op. cit., v. 1339, p. 721

38. Idem, art. 102. 
Esta situación se hace compatible con aquella otra que prevé que, planteado el caso de la elección al joven, será preferible la permanencia bajo tutela hasta su emancipación o la mayoría de edad (art. 165) siempre y cuando el tutor, explícitamente, justifique que es apto para ser liberado de la tutela y se hayan cumplido las formalidades legales establecidas a tal fin. Cualquier desacuerdo en relación al reconocimiento de la capacidad entre el menor y el tutor se someterá al juez, como así mismo se prevé en otros ordenamientos jurídicos del mismo ámbito geográfico.

El derecho argelino, a través de su art. 65 prevé el ejercicio de la guarda por parte de la madre, si bien reserva la formación religiosa del niño a favor del padre, al menos hasta que cumpla diez años, en el caso de los niños, y hasta la edad del matrimonio, para el caso de las féminas, salvo que se den circunstancias especiales que precisen la intervención judicial. Así por ejemplo, la reciente reforma del Código de Estatuto personal argelino en materia de guarda por parte de los padres regula la intervención del juez para determinar la competencia del padre, la madre y en defecto de estos de los abuelos sobre el menor ${ }^{39}$. La legislación argelina prevé, también en su legislación sobre familia, a través del art. 20 que son los padres los titulares del deber de cuidar y alimentar a los hijos $^{40}$, estando obligados a esta tarea por el Estado y los entes públicos. Un deber que, en el caso de abandono del menor, comporta la consideración de delito y atentado contra los derechos elementales de aqué $1^{41}$.

En algunos países magrebíes, caso de Túnez y Marruecos, los supuestos de ruptura matrimonial son abordados en base a la doctrina de la escuela maliki, incorporando algunas modificaciones inspiradas en la doctrina de la escuela hanafi. En este sentido el código tunecino (art. 67) limita la duración de la custodia por las mujeres a los siete años para el caso de los chicos y de los nueves años para las chicas, cuando muchos de los países seguidores de la escuela citada han abandonado ya esta regla, como es el caso de Túnez mediante reciente reforma ${ }^{42}$.

En este sentido el Código tunecino en materia de custodia del menor, mediante el art. 67 (Modificado por la ley n. 49 de 3/6/1996 y por la ley n.74 de 12/7/1993) establecía que cuando el matrimonio se rompe por muerte, la custodia se confía al cónyuge superviviente. Por otro lado, si el matrimonio se rompe y ambos cónyuges están vivos, la custodia se confía bien a uno de los dos, bien

39. Véase art. 65 Loi n. 84-11 du 9 juin 1984 portant Code de famille, Journal officiel de la Republique Algerienne democratique et Popolaire, y respecto a la guarda art. 66 bis de Loi n $2006-10$ du 6 mars 2006 complétant les dispositions du Code du statut personnel. Journal officiel, 2006-03-10, n²0, p. 532., respecto Code du statut personnel du 13 août 1956, al (TUN-1956-L-73374).

40. BenmelHa, G.: «L'obligation alimentaire en droit interne», Revue Algériene des Sciences Juridiques (en adelante RASJP), 21 (1984), pp. 799-831.

41. AsLAOUI, L: "Le statu juridique de l'enfant au Magreb», RASJP, 28 (1990), pp. 241-257. Y sobre la guarda del niño, BENCHEIKH Hocine DeNNOUNI, H.: "La garde: un attribut de la maternité en droit Algérien", Revue International du Droit Comparé, 38 (1986), pp. 897-917.

42. Sobre protección menor en Túnez reciente reforma Code de la protection de l'enfant - Y desarrollado por Loi nº 2006-35 du 12 juin 2006. 
a otra persona. En estos casos el juez, al adoptar la decisión, tiene que considerar el interés del custodiado; y la madre, en el caso de que se le haya confiado la custodia, goza de las atribuciones de la tutela (wilāya) en lo que concierne a los viajes, estudios y administración de las cuentas financieras del custodiado.

Regula también dicho Códigola contribución y participación de la esposa en los gastos del hogar. Así en virtud del art. 23 -modificado por el mismo texto legal anteriormente citado-, cada uno de los cónyuges debe tratar al otro con benevolencia, tener buenas relaciones con él y evitarle sufrir perjuicio. Ambos colaborarán en la marcha de los asuntos de la familia, la buena educación de los hijos y la gestión de los asuntos de estos últimos que comprende la enseñanza, los viajes y las transacciones financieras. Y el esposo, en su condición de jefe de la familia, deberá asumir los gastos de la esposa y de sus hijos, según su situación y la situación de ellos, en el marco de las obligaciones propias de la manutención (nafaqa). La esposa, por el contrario, solo participará en los gastos familiares si posee bienes ${ }^{43}$.

La manutención de los hijos se prolonga hasta que alcancen la mayoría de edad o, después de ésta, hasta que finalicen sus estudios, a condición de que no sobrepasen los veinticinco años. Un derecho que en el caso de las féminas continúa mientras no disponga de recursos para mantenerse o su manutención no sea obligación de su esposo. Así mismo subsiste el derecho de manutención de los hijos impedidos o incapaces de mantenerse sin tener en cuenta su edad. En ambos casos obligan al padre, al tutor y a la madre, en la medida que establezca la ley (art. 60).

El código marroquí adopta análogos criterios ${ }^{44}$ y prevé la situación de indigencia del padre que, conocida por el juez, supondrá la prohibición de la alienación de los pocos bienes que conserve, especialmente de los inmuebles.

Estos criterios se han extendido a otros países bajo la influencia de la escuela malikí, como es el caso de Senegal que se rige por idénticos principios, tal y conforme queda reflejado en la legislación promulgada sobre la materia ${ }^{45}$. La edad sobre la que se ejerce la guarda y custodia dentro del matrimonio es la de los 21 años, sin que ello sea inconveniente para que los chicos puedan contraer matrimonio a los 20 años y las chicas a los 16; e incluso por debajo de esa edad, en la que el padre o tutor ejerce la custodia y previa autorización judicial ${ }^{46}$. En

43. En el caso del código argelino conforme al art. 12. los efectos personales y matrimoniales del matrimonio se someten a la ley nacional del marido al momento de la conclusión del contrato matrimonial; de esta manera la disolución y separación de los cuerpos se someterá a la ley nacional de los esposos, en el momento del acto de presentación de la instancia.

44. En concreto a través del Libro IV. De la capacidad y de la representación. Capítulo IV. De la representación legal. Art. 148 y ss del texto primigenio.

45. Senegal a partir del año 1961 inició un proceso de reforma del Estatuto Personal, que concluyó en 1972 mediante la publicación el 1 de enero de 1973 del Family Code que regula las instituciones del matrimonio, divorcio, sucesión y custodia, con una sección dedicada al Derecho sucesorio islámico. http://www.gouv.sn/textes/const_detail.cfm?numero=TITREII

46. En cualquier caso, el matrimonio contraído por un menor, sin consentimiento, previo será nulo. 
materia de guarda y custodia se garantizan esos mismos derechos a favor del niño y en caso de separación de los cónyuges mediando sentencia judicial; en cualquier caso, será el padre quien ejerza esta obligación, salvo que sea declarado incapaz para tal ejercicio.

La escuela malikí en Kuwait reconoce el derecho a las madres de mantener la custodia de los hijos e hijas hasta la pubertad, para los varones, y hasta el casamiento para las féminas. Cabe también la posibilidad de que tal derecho lo ejerza una mujer no musulmana pero en ningún caso le estará permitido al custodiado permanecer con ella después de haber cumplido los siete años. La custodia por las mujeres finaliza para el joven con la pubertad -en concreto hasta que el niño adquiera la capacidad de razonar $\left(r u s ̌ d^{47}\right)$ y sea capaz de comprender los principios del Islam-, y para la joven con su matrimonio y la consumación del mismo ${ }^{48}$.

En realidad todos estos supuestos y derechos reconocidos a favor del menor forman parte de una institución clásica en el Derecho islámico: la hadāna o el derecho de custodia de un niño, extensión de la guarda que como regla ejerce la madre o cualquier otra persona de sexo femenino por línea materna, y que solo en determinadas circunstancias revierte a favor del padre o de otra persona de sexo masculino dentro de la línea paterna ${ }^{49}$. Tal derecho comienza en el momento del nacimiento del bebé, indistintamente macho o hembra y mientras los padres vivan juntos, constituyendo una prerrogativa de la mujer, incluso antes de la disolución del matrimonio. Tan solo bajo dos supuestos cabe que el padre asuma ese derecho sobre la mujer: cuando el marido permite a la mujer viajar lejos de domicilio conyugal para visitar a sus parientes -como así prevé la escuela hanafi, mientras que las escuelas maliki y hanbali solo reconocen esta posibilidad para los casos previstos en las cláusulas matrimoniales-, o bien cuando el marido decide, de forma temporal, llevar al niño consigo a un viaje sin que le acompañe su esposa.

De ello se deduce que el marido no puede viajar o separar al hijo de su madre sin su autorización, salvo en situaciones en las que se ponga en peligro su persona o su condición de musulmán, como se ha puesto de relieve a lo largo de la historia ${ }^{50}$. Si la mujer que tiene la custodia no es musulmana, tiene derecho a

47. S.v. «rušd» en MAíllo SAlGADO, F.: Diccionario de derecho islámico, op. cit., p. 328.

48. En relación a este supuesto existe una tradición recogida por Al-Buhânî, en la que se hace alusión al matrimonio de `Aicha con el Profeta, cuando la primera contaba tan sólo seis años; al respecto véase EL-BoKHĀRİ: Les traditions islamiques, t. III, chap. XXXIX, p. 568. En relación a la licitud del matrimonio de la mujer antes de la pubertad véase Corán, LXV, 4. Sobre este mismo asunto véase voz «nikāh» en $E I^{2}$, vol VIII, Leiden, Brill, 1995, p. 29.

49. El término técnico en el lenguaje de los fuqahā' es hiḍana con el significado explicado en el texto.

50. Una situación análoga fue presentada por un padre que residente en Tlemencen en época andalusí reclamó la separación de su hija de siete años de la madre, pues estaba en peligro su condición de musulman, ante la presión ejercida por los cristianos en época nasri; véase MARIN, M. y EL-Hour, R.: "Captives, Children and conversion: a case from late nașri Granada», Journal of the Economic and Social History of the Orient, 41:4 (1998), pp. 453-473. 
ejercer la custodia del niño musulmán hasta que éste pueda comprender la religión o se tema que corra peligro su formación fuera del Islam ${ }^{51}$. Y aún a pesar de estos supuestos, los países en los que rige la escuela šaf'ii y hanbali reconocen la posibilidad al adolescente de que, llegada la pubertad, pueda expresar su deseo de independizarse de su padre o madre, si bien lo recomendable (makrūh) es que permanezca con sus padres.

Una cuestión controvertida es la ponderación de la naturaleza de la hadāna en cuanto derecho del padre o derecho del niño. En este sentido la doctrina determina que, si bien es un derecho que debe ejercer la madre o el padre, es ante todo un derecho del niño, y solo en atención de su interés se definen las condiciones en las que debe ejercerse ${ }^{52}$. El ejercicio de la hadāna por parte del marido solo es factible en supuestos determinados, ante la ausencia de la madre o si ella es declarada incapaz para asumirla o se le ha denegado este derecho; en estos casos la custodia la ejercerá las hermanas de la madre las hermanas uterinas, antes que la consanguíneas; seguidamente las sobrinas -a excepción de las consanguíneas que están relacionadas con el niño por vínculo solo del padre-y las tías maternas con preferencia a las paternas. De igual modo, las escuelas hanafi y mäliki reconocen al padre ese mismo derecho solo en defecto de todas las féminas relacionadas con los grados prohibidos para contraer matrimonio. El hombre es ante todo el 'ạsabat o parientes de línea masculina que concurren

51. En estos casos conceptos como hadāna, tafrīq-derecho del padre a separar al hijo de la madre-y $i t h q \bar{a} r-$ periodo en el que se ejerce la guarda sobre las niñas, pasada la primera infancia- son objeto de análisis por la doctrina, que en el caso de la escuela malikí permiten la permanencia con mujeres de religión no islámica. El Derecho islámico a lo largo de la historia ha observado circunstancias especiales, tales como la celebración de esponsales con hijas impúberes o menores de edad; esta posibilidad comportaba aplazar el perfeccionamiento del contrato hasta el momento en que la prometida pueda consumar el matrimonio Existe divergencia de opiniones sobre el valor de la consumación del matrimonio en atención a la perfección del contrato, ya que para muchos autores el contrato matrimonial es perfecto desde que se produce el intercambio de consentimiento. Sobre el matrimonio en la etapa andalusí. En relación con las fuentes y el tratamiento de esta institución véase VILA, S.: "Formulario notarial de Abenmoguit», A.H.D.E., 8 (1931), p.16 y del mismo autor «Un contrato de matrimonio entre musulmanes», A.H.D.E., 10 (1933), p. 187; en este último artículo se abordan cuestiones relativas a la dote y derechos de la mujer en relación al cumplimiento de la misma por el marido; de un momento posterior pero de gran utilidad es el estudio y presentación de unos contratos matrimoniales en los que inicialmente se hace alusión a su condición de "contratos de esponsales» y que han sido presentados por LABARTA, A.: "Contratos matrimoniales entre moriscos valencianos», AL-Qantara, 4, fasc.1 (1983), pp. 64-65; asimismo es destacable el estudio de LONGAS, P.: Vida religiosa de los moriscos, ed. facs., Granada, Universidad de Granada, 1990, pp. 273-283 y del mismo modo IDRIS, H.R.: "Le mariage en Occident musulman. D'après un choix de fatwâs médiévales extraites du Mi'yâr d'Al-Wanšarî̌ŝ̀̀, Studia Islamica, 32 (1979), pp. 157-167; remítase el lector a los estudios de CARMONA GONZÁLEZ, A. en "Aportación al estudio del contrato matrimonial en el Occidente islámico medieval», Miscellanea Arabica et Islamica. Dissertationes in Academia Ultrajectina prolatae, anno 1990, 52 (1993), pp. 53-66; y finalmente con carácter general véase GAUDEFROY-DEMONBINES, M.: Les institutions musulmanes, Paris, 1921, p. 122. El tratamiento de la institución conforme a los presupuestos de la escuela malekí y šaf'ii en SANTILLANA: op. cit., t. II, p. 226. Véase también la opinión de juristas malikíes, y en concreto las referencias de Ibn Sahl, en MARIN, EL-HouR: "Captives, Chindren and conversión", op. cit., pp. 464-465.

52. s.v. «hadāna», en $E I^{2}$, vol. III, op. cit., p. 17. 
en el mismo orden que en materia de sucesión: primeramente, el padre; en ausencia de cualquier 'ạșib, la escuela hanafi hace un llamamiento a los hombres por línea femenina pero solo a aquéllos respecto a los que está prohibido el matrimonio, si se trata de la custodia sobre una hembra; finalmente se llama a hombres y mujeres con los que no hay impedimento de grado para contraer matrimonio, ejerciendo los hombres la custodia sobre los chicos y las mujeres sobre las chicas. Para el caso de ausencia total de parientes que puedan ejercerla será el qā dì quien determina la persona de confianza-.

Estos presupuestos son regulados en la escuela šaf'i $i$ hanbalī, aunque prevén el ejercicio por parte de la mujer en menor medida pudiendo el varón asumir la custodia, incluso si existen mujeres de grado próximo al menor. En estos supuestos, ante la ausencia de la madre y de ascendientes femeninas-e incluso si estas son apartadas o consideradas incapaces para ejercer este derecho-, la lä̈...na la asumirá el padre y seguidamente sus ascendientes femeninas. También estas escuelas presentan como particularidad el que la hermana consanguínea sea preferida a la uterina y la tía paterna a la materna.

Los Estatutos y Códigos personales han introducido ciertas reformas respecto al Derecho islámico tradicional. Así por ejemplo, los países de tradición hanafi se han ocupado de extender el periodo de custodia y guarda del menor más allá de los límites establecidos por el Derecho islámico tradicional. Egipto es uno de los países en los que prima la escuela hanafi y sobre esta materia las reformas acaecidas en 1929 reglamentaron la posibilidad de que el juez, por razón del interés del niño, extendiera este periodo de custodia más allá de los nueve años para el niño y de los once para las niñas, si bien las últimas reformas acaecidas en este país prolongan este periodo de custodia y guarda hasta los diez años para el caso de los chicos y a los doce para las chicas, respecto al ejercicio de la misma por parte de la madre divorciada. Ello no obsta para que el juez extienda esos derechos hasta los quince años para los jóvenes y la edad del matrimonio en el caso de las féminas, cuando las circunstancias así lo requieran ${ }^{53}$. Igual criterio se siguió en el caso de Jordania ${ }^{54}$ (1951, art. 123) y Siria ${ }^{55}$ (1953, art. 147), países seguidores de la misma escuela jurídica. En el caso de Jordania el matrimonio contraído por mujeres menores de dieciocho años con

53. Nótese que la edad mínima para el matrimonio se sitúa en los 18 años para el caso de los chicos, y en los dieciseis para las chicas. En cualquier, el juez es competente para autorizar el matrimonio en aquellos casos en los que el wali rechace esta posibilidad, conforme a las últimas reformas del Personal Status (Amendment) Law, núm.. 100/1985, reformado el 27 de enero 2000; véase http://www.law.emory.edu/IFL/legal/egypt.htm. Y sobre la institución del matrimonio y sus efectos en Egipto, conforme a las nuevas reformas véase: EL ALAMI, M.: «Law no. 100 of 1985 Amending Certain Provisions of Egypt's Personal Status Laws», Islamic Law and Society, 1:1 (1994), pp. 116-136; NAJJAR, F.: "Egypt's Laws of Personal Status», Arab Studies Quarterly, 10:3 (1988), pp. 319-345.

54. El texto del año 1976 en Ruíz Almodovar, C.: «El Código Jordano de Estatuo Personal», M.E.A.H., 46 (1997), pp. 3-418.

55. Véase Ruíz Almodóvar, C.: «El Código Sirio de Estatuto Personal», Miscelánea de Estudios Árabes y Hebraicos, 45 (1996), pp. 3-378. 
varones que superen los 20 requerirán autorización especial, como también se precisa el consentimiento de quien ejerza la custodia en los supuestos de matrimonio entre chicas menores de dieciocho años, salvo en el supuesto de las féminas que superen esa edad y sean divorciadas o viudas; y ello considerando que es hasta esa edad en la que se ha de ejercer la custodia pero sin eliminar la posibilidad de que el juez, ante circunstancias especiales, autorice el matrimonio de chicas menores de esa edad ${ }^{56}$.

El Código sirio en su legislación sobre estas cuestiones considera que el periodo de custodia finaliza al cumplir el joven nueve años de edad y la niña a los once años ${ }^{57}$. Si el tutor no es el padre, el juez puede entregar al hijo, niño o niña, al que sea más apto entre la madre, el tutor o quien ocupe el puesto de ambos hasta que la niña se case o llegue a la pubertad y hasta que el niño alcance la mayoría de edad. Determina las obligaciones del padre respecto al hijo en caso de repudio ${ }^{58}$. Si en el repudio por compensación se exige como condición que el esposo no pague la remuneración de la lactancia del niño o que su madre lo conserve con ella, manteniéndolo durante un tiempo determinado, y la esposa se vuelve a casar o abandona al niño, el esposo recupera de la esposa lo que equivalga a la remuneración de la lactancia o de la manutención del niño durante el tiempo restante. En otro orden de cosas, si la madre es indigente en el momento del repudio por compensación o llega a ser indigente después, el padre está obligado a pagar la manutención del niño y la madre contrae una deuda con él.

Asimismo, el citado código reconoce el derecho de la mujer a la custodia de sus hijos, que no prescribe a causa de su trabajo siempre y cuando garantice la protección y el cuidado de ellos de modo válido. En el supuesto de separación o divorcio, la persona que ejerza la custodia, bien sea la madre o la abuela materna, podrá solicitar ante el juez la entrega del menor, siendo el juez quien decida esta cuestión tras cerciorarse del parentesco por medio de documento acreditativo expedido por la Secretaría del registro civil; en este mismo sentido deberá decidir quien asumirá la manutención temporal del menor.

No obstante ello, la madre tiene una serie de limitaciones, y entre ellas el no poder viajar con su hijo durante la vida conyugal, salvo con autorización de su padre. Asimismo la madre que tiene la custodia, al finalizar su'idda puede viajar con el custodiado sin la autorización del tutor a la población en la que tuvo lugar su contrato matrimonial. Y de igual modo podrá viajar con él por el

56. The Civil Status Law No 9 of 2001. Al-Jarida Al-Rasmiya, 2001, No 4470 y http://www.fidh. org/lettres/130-2.htm.

57. Lib. III, Del nacimiento y sus efectos. Cap. $2^{\circ}$ De la custodia. Art. 139.2. La ejecución de la decisión del juez tendrá lugar por parte del departamento competente para dicha ejecución y quien se oponga a la entrega o a la manutención necesario potencialmente, tiene que presentar en el juzgado competente la demanda de agravio por esta decisión y la demanda se someterá a los procedimientos y medios de la impugnación de las sentencias legales, la presentación de esta demanda no tendrá efecto sobre la ejecución de la decisión mencionada, salvo cuando exista una sentencia firme.

58. Lib. II, De la disolución del matrimonio. Capítulo $2^{\circ}$ Del repudio por compensación. Art. 102. 1. 
interior del país a la población en la que resida o en la que trabaje, cualquiera que sea, a condición de que uno de sus parientes ('aṣaba) en grado prohibido para el matrimonio resida en ella. Derechos reconocidos también a la abuela materna. Y entre las causas para impedir la custodia baste citar la oposición y negligencia de la mujer que tiene la custodia.

En la órbita de los países de tradición hanafi, Iraq en 1959 se ocupó de la materia (art. 57, 5) determinando que la custodia sería ejercida por la madre, en el caso de divorcio de los cónyuges, hasta los diez años, tanto para los chicos como para las chicas. Cabe la posibilidad de extender la hadāna en principio hasta los quince años, pero sin que ello suponga la consideración de un plazo máximo: desde ese momento el chico podrá decidir con quien de sus padres convivir ${ }^{59}$.

En Sudán las reformas se realizaron por vía de la Circular núm 34 (1932, art. 1) en virtud de la cual, y siguiendo la escuela malikí los niños permanecerán bajo la custodia de las mujeres hasta la pubertad, y las niñas hasta la consumación del matrimonio. Además, la citada legislación sudanesa prevé la custodia por una mujer de diferente religión, concluyendo este derecho cuando el niño alcanza los cinco años, con el fin de evitar que éste se instruya en una religión distinta a la del Islam ${ }^{60}$.

\section{LA NEGACIÓN DE LA PATERNIDAD}

Al margen de los supuestos legalmente establecidos para atribuir y reconocer la paternidad, caben otros supuestos, también legales, que han sido objeto de revisión en las últimas décadas, por la indefensión que para la madre y el niño puedan ocasionar. La negación de paternidad, li'ān, es, además de motivo de repudio, una modalidad tradicional en el Derecho islámico que sin duda genera no pocos perjuicios respecto a los derechos de la mujer y el niño en los países en los que durante siglos se ha ejercido ${ }^{61}$.

El li'ān se pronuncia ante el juez, quien de inmediato ordenará la separación de los cónyuges. Se trata de una anulación tiene carácter irrevocable y, en modo alguno tiene carácter de divorcio. El marido mediante este supuesto se reserva el derecho a negar la paternidad sobre el niño nacido de su esposa, existiendo constancia por su parte de no ser fruto de la unión con aquella. Este supuesto precisa del testimonio de cuatro testigos requeridos para acusar de adulterio a

59. Aspectos regulados en la Ley sobre Cuidados del menor núm. 78/1980 y Ley sobre el derecho de custodia de la madre núm. 106/1987; http://www.law.emory.edu/IFL/legal/iraq.htm.

60. La custodia del menor en Sudán, a la luz de la tradición islámica y su pervivencia pese a movimientos posteriores de reconocimiento de los derechos de la mujer, fue abordada por FLUEHRLobBan, C.: "Issues in the Shari'a Child Custody Law in the Sudan", Northeast African Studies, 4 (1984), pp. 1-9.

61. Se trata de una de las modalidades del talak, s.v. en $E I^{2}$, vol. X, Leiden, Brill, 2000, pp. 151-158. Un análisis sobre la evolución del Derecho privdo sudanés en GUADAGNI, M.: «La riforma del diritto privato nel Sudan: uno studio sui modelli normativi nel diritto africano", en Raccolta di scritti per il cinquantesimo anniversario dell'Università di Trieste (1924-1974), Trieste, EUT, 1976, pp. 183-198. 
su mujer; si tiene constancia de que no es padre de lo que pueda venir, tiene como único medio de eximirse de la presunción de paternidad el indicado en el Cor. 24/6-9 de jurar cuatro veces su veracidad y de imprecar luego el castigo divino sobre sí si ha acusado en falso. Cuando el padre niega la paternidad mediante juramento, la mujer puede defenderse respecto a la condición del hijo parido como propio con juramento análogo y en tal caso se anulan ambos juramentos.

El Corán no hace referencia a los efectos jurídicos de este acto, a diferencia de la tradición y la doctrina, que prevé el caso en que el marido, hecha la acusación, no quiera confirmarla con el juramento. En este supuesto hay que constreñirle a que jure, con la alternativa de 80 azotes, pena del calumniador. También se ha de castigar a la mujer que no defienda su inocencia. En todo caso quedará disuelto el matrimonio.

El Derecho islámico determina dos categorías de hijos ilegítimos: la primera corresponde al llamado walad al-mulā'ana, es decir, hijo negado -hipótesis que es considerada meramente teórica-, y la segunda hace referencia al hijo fruto de relaciones extramatrimoniales o walad az-zin $\bar{a}$, anteriormente citado. En ambas circunstancias estos hijos no generan lazos de parentesco con el padre ni con la familia de éste, pues la irregularidad de su nacimiento -o mejor de su concepción- le hace ser considerado fruto de la fornicación.

Los efectos inmediatos de la negación de paternidad son la negación del derecho a heredar, la negación del derecho a su mantenimiento y la determinación de nuevos grados de prohibición a nivel de relación entre el hombre y el niño. Sin embargo, respecto a la cuota hereditaria correspondiente al hijo ilegítimo, este heredará de su madre y de todos los parientes de ella, de sus hermanos y hermanas uterinas, como si fuera legítimo ${ }^{62}$.

Desde el punto de vista conceptual interviene en esta materia otro término cual es el de hijo natural, y que conforme al Derecho islámico se da en aquello supuestos en los que el niño no se atribuye automaticante al padre si este reconoce que es fruto de relaciones extramatrimoniales, por parte de la mujer. En el caso en que el padre reconozca a aquél como hijo, no podrá, en modo alguno, manifestar que es fruto de la fornicación o el adulterio. La madre, por el contrario, asumirá por derecho su condición, y desde el punto de los derechos concernientes al niño competerán no solo a ella sino a toda su familia ${ }^{63}$. En definitiva, y según las escuelas ortodoxas, el hijo considerado natural, tiene una familia uterina, que no se limita tan solo a la madre, sino que comprende a todos los parientes ('asaba) de aquélla, sus hermanos y hermanas uterinas. Entre todos ellos existe vocación sucesoria recíproca. De manera que en caso de fallecimiento del llamado hijo ilégitimo sin descendencia masculina, la cuota fija correspondiente herditaria (farḍ) se adjudicará, si los hubiera, a la hija, ma-

62. AIt ZAI, N.: "L'enfant illégitime dans la societé musulmane», Peuples Méditerranéens, 48-49 (1989), pp. 113-122.

63. Véase al respecto CHALABI, E.H., y MEKABECH, C.: "L'enfant conçu et né hors mariage», RASJEP, 25 (1997), pp. 295-312. 
dre, hermanos, hermanas uterinas y ascendientes maternales, con exclusión de cualquier pariente del padre que en su momento negó tal condición.

Es importante aludir a la filiación materna, una posibilidad que no suele plantear controversia, a diferencia de lo que sucede en el caso del reconocimiento de la filiación paterna ${ }^{64}$. No en vano, cabe la posibilidad de que la mujer emprenda acciones para obtener, mediante sentencia firme, la filiación desconocida sobre el hijo habido con un hombre que niega su paternidad, ajustándose la nueva situación a la realidad registral.

Cuando el padre niega la paternidad mediante juramento, la mujer puede defenderse respecto a la condición del hijo parido como propio con juramento análogo y en tal caso se eliden ambos juramentos.

Desde el momento del nacimiento la madre está obligada a los cuidados hacia su hijo, si bien pudiera darse el caso de que la madre no pueda alimentar a su hijo o rechace hacerlo, debiendo en estos casos -así como en caso de fallecimiento de ésta - procurar lo necesario para su alimentación; esta postura, defendida por las escuelas sunnies, no es compartida por los šiies para quienes si la madre rechaza o niega el alimento al niño perderá la custodia sobre el; derecho de custodia que se extiende al niño (hadāna), durante los primeros años de su vida, que comprende también el derecho a ser educado, y a la administración de sus bienes-tanto por el padre como por la madre ${ }^{65}$.

La presunción de paternidad (después de la celebración del matrimonio y antes del plazo legalmente establecido siguiente a la disolución del mismo) es una posibilidad que, al igual que en otros ordenamientos jurídicos ${ }^{66}$, prevé el Derecho islámico. Una de las medidas legales más eficaces para evitar la denegación de paternidad no ajustada a los requerimientos legales es la supresión de la práctica del niño dormido; así se evidencia a través de los distintos códigos de Estatuto personal.

El Código tunecino fija el plazo máximo de embarazo, que para malikíes y šaf'iiss supone para el marido la presunción de la filiación iuris tantum y para los hanafíes iuris et de iure ${ }^{67}$, del hijo nacido durante el matrimonio, siguiendo el principio del al-walad lil-firaš; si bien el período máximo de gravidez materna es de diez meses. Sin embargo la escuela malikí ha defendido durante décadas

64. NASIR, J.J.: The Islamic Law, op. cit., pp. 162-164; y AllufFI-BECK-PECCOZ, R.: La modernizzazione, op. cit., pp. 162-164.

65. NASIR, J.J.: The islamic personal Status, op. cit., p. 173.

66. En este caso el ordenamiento español, a través del art. 116 del C.C. determina que ese plazo es de trescientos días siguientes a la disolución o la separación legal o de hecho de los cónyuges. Por otro lado es medio de prueba suficiente de la filiación presumida la mera presunción de paternidad, conforme al art. 113 C.C. Los cónyuges estarán exentos de probar el hecho presunto, según el art. 385 de la ley de Enjuiciamiento Civil si están de acuerdo con la filiación; mientras que si no es así el cónyuge que la niegue deberá negar la presunción mediante prueba en contrario, y atendiendo a la presunción de separación de convivencia, deal art. 69 del C.C. Véase Calvé Corbalán, C.: Tratado de derecho de Familia, op. cit., cap. IV, «Filiación», pp 236 y ss.

67. CASTRO, F.: "Diritto musulmano e dei paesi musulmani», en Encilopedia Giuridica Treccani, vol. XI, pp. 7-11. 
incluso un período de gestación de tres o cuatro años, mediante la teoría del niño dormido ${ }^{68}$. Un supuesto que ha sido erradicado por un lado mediante la fijación de los periodos de pureza legal 'idda, que se prolonga durante tres meses completos para la divorciada; mientras que en el caso de la viuda ésta deberá observar una 'idda de cuatro meses y diez días completos y la mujer embarazada verá prolongada su idda dura hasta el parto; y por otro mediante la fijación de la duración máxima del embarazo es de un año desde la fecha del repudio o muerte del esposo.

El Código marroquí también aborda esta cuestión en su última reforma ${ }^{69}$. En relación al término del embarazo regula el periodo de 'idda de la mujer embarazada, a efectos de la disolución del matrimonio, y al objeto de evitar la negación de paternidad por parte del marido. Según tal reforma en la que la mujer se someterá a la opinión de expertos para determinar si se encuentra embarazada, y así fijar el plazo máximo de su gestación, que en todo casos será de un año y se efectuará con la mayor precisión posible a fin de evitar cualquier interpretación errónea que pudiera perjudicarla a ella y al hijo que espera ${ }^{70}$.

Entre los textos de inspiración malikí el código jordano puso también fin a la práctica del niño dormido, fijando el plazo máximo del embarazo en un año ${ }^{71}$. El hijo de la esposa de un matrimonio válido o anulable después de la consumación o de la cohabitación válida, si naciera después de seis meses, o más, desde la fecha de la consumación o de la cohabitación válida, su filiación pertenece al esposo; mientras que si naciera después de la separación, su filiación no se establece, salvo que tenga lugar durante el año siguiente a la fecha de la separación.

68. En este sentido el plazo mínimo admitido por sunnies y ši'ies es de seis meses en base a los preceptos coránicos-Cor. XLVI, 15 y Cor. XXXI, 14-, que permiten por deducción establecer ese término mínimo. De manera que si el hijo nace en perfectas condiciones después de seis meses de embarazo el hijo se atribuye al marido y si nace antes de ese término respecto al momento de celebración del contrato matrimonial será considerado ilegítimo. El padre podrá reconocer el hijo nacido antes del término de seis meses, con la condición de que no haga mención a la concepción ilegítima, y tendrá el hijo reservados los mismos derechos que el legítimo. Ahora bien en caso de disolución del matrimonio y para el supuesto que nazca un hijo antes de tal circunstancia, el periodo máximo -no fijado en el Corán- sino en base a tradiciones y declaraciones de la esposa del Profeta, 'Aiša, se barajan dos años, e incluso según Ibn Qudāma, (Mugini, VII, 477), hasta tres y seis años. Sobre el término máximo del embarazo, LINANT DE BELLEFONDS, Y.: Traité de Droit musulmán comparé, Paris-La Haya, Mouton\&Co, 1973, pp. 36-37.

69. A partir de lo dispuesto en el Libro III, «De la filiación y sus efectos». Capítulo III La guarda del niño (hadāna) se justifican los cambios de la reforma de 1992. Reformado por "Ley promulgada por el dahir n 1-04-22 de 3 de febrero de 2004" y publicada en Bulletin officiel, 2005-10-06, $\mathrm{n}^{\circ}$ 5358, pp. 667-701.

70. Véanse los art. 143 y 156 de la Mudawana, op. cit.. El tema ha sido abordado con anterioridad a las recientes reformas, como así queda justificado en la exposición de motivos de la misma; en este sentido véase el punto de vista de la doctrina, y así por ejemplo CHAFI, M.: "L'enfant né hors mariage au Maroc», Revue marocaine de Droit et d'Économie du Développement, 19 (1989), pp. 133-152.

71. Cap. 14. De la filiación (al-nasab). Art. 148. 
El Estatuto Personal Sirio, introdujo en la redacción de 1953 una serie de reformas que afectaban, entre otros, al tema controvertido de la teoría del niño dormido ${ }^{72}$, fijando en un año el plazo máximo de embarazo (art. 128), y determinando las circunstancias en las que la tutela del menor es una obligación para los cónyuges en todo momento, y de forma más cuidadosa en caso de separación (art. 146.2). En 1975 se acometen una serie de modificaciones, consideradas también insuficientes respecto a mayores logros en el campo del derecho de la mujer y de la familia, y concretamente referidas a los hijos habidos fruto de la relación conyugal. Modificaciones que, en la misma línea, se han efectuado en Egipto-mediante textos legales redactados al efecto- o en Sudán -en este caso por medio de circulares judiciales, caso de la Circular núm. 41 de 1935 por la que se regula el plazo máximo del embarazo-.

El código kuwaití determinó el plazo de un año -trescientos sesenta y cinco días- como máximo de embarazo, y el período mínimo es de seis meses lunares. Y como corolario de esta cuestión tan controvertida se ha reglamentado el modo de ejercer la acción de impugnación de la paternidad matrimonial, estando legitimados para ello la madre, el hijo o el Ministerio Fiscal en previsión de la protección de los derechos del menor.

Todas estas reformas se han prolongado durante las últimas décadas del siglo pasado, debiendo señalar entre las últimas reformas la acontecida en Yemen del Norte, país fiel a la tradición en el que en 1978 se promulgó la ley sobre la familia, Qanun al-usrah, conforme a los principios de la escuela zaid $\imath^{3}$, seguida por la mayor parte de la población yemeni ${ }^{74}$ y objeto de reforma recientemente ${ }^{75}$. El anterior texto, de corte más conservador, fijaba la duración máxima del embarazo en tres o cuatro años, siendo el médico la persona competente para determinar la filiación del niño por razón del tiempo de gestación. Tal normativa que fue sustituida en la reciente reforma de 1992 al fijar el período mínimo del embarazo en seis meses lunares y el máximo en trescientos sesenta y cinco días (art. 166).

72. Art. Lib. III, Del nacimiento y sus efectos. Cap. $2^{\circ}$ De la custodia. Art. 139.2.

73. Movimiento šiís moderado surgido a mediados del siglo XI, y que en materia de derecho matrimonial no acepta el de carácter temporal (mut'a); MAílLo SALGADO, F.: Diccionario de derecho islámico, op. cit., p. 473-474.

74. Se trata de una forma moderada del shi'ismo; cuyo fundador fue Zaid ibn 'Ali, o quinto imam del Islam. Sobre su obra véase AL-WASITI, Halid: Magmu al-figh, Milán, Griffini, Corpus Iuris di Zaid ibn 'Ali, 1919; Bousouet, G.M. y Beroues, J. (trads.): Recueil de la Loi Musulmane de Zaid ben 'Ali, Argel, La maison des livres, 1941.

75. En este sentido destaca el estatuto personal para Yemen del sur del año 1974 que fue sustituido por el Código otorgado en 1992 con validez en todo el Yemen. 


\section{LA ADOPCIÓN (TABANNI ${ }^{6}$ ) Y EL ACOGIMIENTO (KAFALA ${ }^{77}$ ) EN EL DERECHO ISLÁMICO: LA ADAPTACIÓN A LOS SISTEMAS JURÍDICOS ACTUALES ${ }^{78}$}

\subsection{Aspectos generales según el Derecho islámico tradicional}

El lector interesado en estos temas debe partir del hecho de que en el Derecho musulmán la filiación es una materia prácticamente inmutable respecto a la legislación que la regula de hecho, las pocas reformas acaecidas se refieren a la presunción de paternidad. Por otro lado la adopción, tabannī, esta prohibida por el Derecho islámico ${ }^{79}$, si bien durante la etapa preislámica se ejercía bajo los mismos presupuestos que se conocen en la actualidad ${ }^{80}$.

A tenor de los planteamientos generales expuestos en la mayoría de los Estatutos y Códigos de los diversos países mencionados se explica la ausencia de esta institución. Una vez más las exigencias del orden internacional conllevan a la búsqueda de soluciones en el plano jurídico que permitan dar carta de naturaleza a situaciones controvertidas.

La legislación contemporánea, a través de los Códigos y Estatutos personales, apenas aborda la cuestión, a diferencia de lo que sucede respecto al reconocimiento de la paternidad, materia objeto de profusa reglamentación. Las modificaciones introducidas en materia de adopción se evidencian en la legislación tunecina -por influencia de la presencia francesa y de su legislación en este país-, que se introdujo mediante un anexo a la ley (n. 58-27 de 4 de marzo de 1958) y que solo se prevé respecto a los menores (art. 12). En este sentido, y ante las situaciones de indefensión que se están dando en España en los últimos años, el Ministerio de Trabajo y Asuntos sociales, a través de la Secretaría de Asuntos sociales y la Dirección General de Acción Social del Menor y la Familia aborda la tutela dativa, respecto a menores marroquíes en territorio español, y ha generado un procedimiento que a continuación se expone y que responde a la modalidad kafăla ${ }^{81}$. En realidad la kafâla es la acción de hacerse cargo de un niño abandonado y atender a las necesidades de quienes por distintas circunstancias, tienen necesidad de ser atendidos por una familia sustituta, una acción de carácter humanitaria que como tal supone el «acogimiento en una familia de un menor indigente, con el fin de educarlo y de ocuparse de él material y

76. NAQVI, A.R.: "Adoption in Muslim Law», Islamic Studies, 19 (1980), pp. 283-302.

77. s.v. «kafala» en $E I^{2}$, op. cit., vol. IV, Leiden, Brill, 1990, pp. 404-405. Y en el marco del derecho islámico clásico SCHACHT, J.: Islamic law, Oxford, Oxford University Press, 1964, pp. 158-159.

78. UtRera GutiéRReZ, J.L.: "Protección de menores: Acogimiento, adopción y tutela» en Tratado de Derecho de Familia, cap. V, op. cit., pp. 291-364; CILARDO, A.: Il Diritto islamico e il sistema giuridico italiano, op. cit., pp. 270-271. GOVERNMENT OF TUNISIA y MAHMOOD, T.: «Tunisia: Law of Guardianship and Adoption (Law núm. 58-67 of 4 march, 1958 as amended by Law núm. 59-69 of 19 June, 1959)", Islamic and Comparative Law Quaterly, 1 (1981), pp. 226-231. El lector interesado encontrará abundantes referencias al respecto en http://www.afada.org/docus/africa000fichatec.htm.

79. Cor. XXXIII, 4-5.

80. LinANT DE BELLEFOndS, Y. : Traité, op. cit., pp. 22-25.

81. s.v. «kafăla» en $E I^{2}$, vol. IV, Leiden, Brill, 1990, pp. 404-405. 
moralmente como si fuera su propio hijo, sin que ello produzca efectos sobre su filiación.

La característica principal de la institución de la kafāla es la de no producir efectos de filiación entre el menor y la persona que lo toma a cargo, por lo que aquél, nunca rompe sus vínculos con su familia de origen ${ }^{82}$. El hecho de que la kafâla no produzca ningún efecto jurídico sobre la filiación es la razón por la cual es necesario que para que una familia española se pueda hacer cargo de un niño de origen marroquí debe, una vez instituida la kafāla de un niño declarado abandonado, solicitar del juez de menores, tutor por ley de todos los niños abandonados, la tutela dativa del mismo. En este caso la tutela confiere el ejercicio de la patria potestad y, como consecuencia, la representación legal del niño tutelado.

\subsection{Sobre el procedimiento administrativo en materia de acogimiento: la adaptación del ordenamiento islámico a las exigencias internacionales}

La proliferación de matrimonios mixtos y los cambios de residencia por razones de trabajo o causas análogas obligaron también a modificar el texto anterior, concretamente en lo dispuesto en los artículos 15, 16 et 17 de la Ordenanza $\mathrm{n}^{\circ} 75-58$ de 26 de septiembre de 1975; en este sentido se reglamenta que las condiciones de fondo en materia de tutela testamentaria, curatela y otras instituciones de protección de menores, de incapaces y de ausentes, serán determinadas por la ley nacional de la persona a proteger. En todo caso, cuando de medidas de urgencia se trate sobre menores, incapaces y ausentes encontrados en Argelia, se adoptaran estas medidas, así como si sus bienes se encuentran en territorio argelino.

La protección del menor recibe especial atención por el Derecho islámico, que regula desde tiempo inmemorial instituciones acordes con el principio de protección y defensa de los intereses del menor. En este sentido el papel relevante que desde antaño desempeña el padre en la acción tutelar es un hecho innegable, y sujeto a la adaptación de las exigencias del derecho actual. Desde tiempo inmemorial el padre ejercía un papel fundamental en la celebración del matrimonio de la hija; esta intervención quedaba justificada por el hecho de que el padre es quien ejerce la patria potestad sobre los hijos hasta que éstos llegan a la pubertad, y sobre las hijas hasta el momento de la consumación del matri-

82. Una situación que dista mucho del supuesto contemplado en la legislación española de filiación por naturaleza no matrimonial; regulado por el art. 120 del C.C. contempla cuatro supuestos: reconocimiento formal, resolución recaída en el expediente tramitado con arreglo a la legislación del Registro Civil y por sentencia firme; estos supuestos se refieren al padre. Para el caso de la madre la filiación en restos casos se atribuirá cuando se haga constar en la inscripción del nacimiento. En todos estos supuestos los efectos vendrán determinados por el cumplimeitno de los requisitos establecidos en el art. 121 y ss del C.C.. Calvé Corbalán, C.: Tratado de derecho de familia, op. cit., cap. IV, «Filiación», p. 241. 
monio ${ }^{83}$. De ahí que sea el padre a quien competa en primer lugar el ejercicio de la tutela, wilāya $a^{84}$, hasta el momento en que por razón del matrimonio la hija es entregada a su futuro esposo. Esta autoridad que es reconocida al padre tanto en la esfera temporal como espiritual, e incluso en ambas y que supone también la potestad de representar a una persona que por razones diversas, ve reducida su capacidad para actuar.

El poder de representación sobre el tutelado permite distinguir dos categorías: la custodia de menores (hadāna al-ṣagìr) y la custodia de una persona (wil.ayat al-nafs) que superada la edad de la infancia se encuentra en situación de incapacidad por razones diversas ${ }^{85}$. Incluso es el padre quien, en su condición de walì de la hija virgen y púber, debe administrar aquéllos bienes de la dote que le han sido transmitidos por razón del casamiento ${ }^{86}$. Situación que, a tenor de los tiempos modernos, es considerada anacrónica y alejada de los presupuestos de la normativa vigente en la mayoría de los países islámicos, experimentando un proceso de revisión y adaptación a las circunstancias de la sociedad actual.

La protección del menor por entidades públicas, en el marco jurídico de la adopción internacional, ha favorecido el reconocimiento de instituciones particulares que permitan ajustar la realidad vivida por los menores abandonados a las necesidades planteadas ante los organismos competentes en esta materia ${ }^{87}$. La figura del tutor del menor y los organismos tutelares, el defensor o juez de adopciones adquieren razón de ser en una sociedad que se enfrenta a problemas constantes de inmigración de menores y abandono de los mismos en países ajenos a su cultura y a la legislación que le es reconocida en sus países de origen.

Los sistemas jurídicos inspirados en el Corán, como ocurre con el Código del Estatuto Personal marroquí, Mudawana, no contemplan la institución de la adopción. Argelia es otro de los países del ámbito magrebí que se ha ocupado de esta institución, concretamente a través del art. 13 de su reciente reforma del Estatuto personal ${ }^{88}$. Reconoce la validez de acogida legal, kafäla, y se somete

83. Véase al respecto la voz «saghîr» en $E I^{2}$, vol. III, Leiden, Brill, 1995, pp. 821-825. En este mismo sentido se pronuncian BELLEFONDS, Y.L.: Traité..., op. cit., p. 179 y SANTILLANA, D.: Istitutioni di Diritto musulmano, con riguardo anche al Sistema Sciafiita, op. cit., t. I, p. 295 y t.II, pp. 197-199.

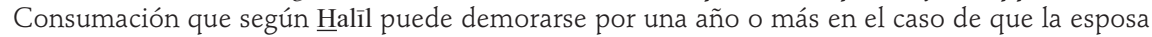
sea «demasiado joven", legitimando así la celebración de esponsales cuando la mujer es de corta edad (HALİl IBN IsḤ̂AQ: "Il Muhtașar» Sommario del Diritto Malechita, op. cit., vol. II, p. 41).

84. Sobre el término véase voz "wil...ya» en $E I^{2}$, vol. XI, Leiden, Brill, 2002, pp. 208-209.

85. S.v. «wālaya» en $E I^{2}$, vol. XI, Leiden, Brill, 2002, p. 208.

86. Chalmeta Gendrón, P., y Corriente, F.: Formulario notarial de Ibn Al-'Attêr, Madrid, Academia Matritense del Notariado, 1983, pp. 339-340; y en el mismo sentido véase CHALMETA GENDRON, P.: «Acerca del 'amal en Al-Andalus: algunos casos concretos», A.H.D.E., 57 (1987), p. 358. Sobre la potestad del representante legal de la mujer véase "walī» en $E I^{2}$, vol. XI, Leiden, Brill, 2002, pp. 109-125.

87. Enfance et Familles d'Adoption (EFA): para más información: http://www.adoptionefa.org/accueil.php y http://www.efa78.org.

88. Art. 13 ter. - La validité du recueil légal (Kafala) est soumis simultanément à la loi nationale du titulaire du droit de recueil (Kafil) et à celle de l'enfant recueilli (Makfoul) au moment de son établissement. Les effets du recueil légal (Kafala) sont soumis à la loi nationale du titulaire du droit de recueil (Kafil). L'adoption est soumise aux mêmes dispositions». Remítase el lector a 
simultáneamente a la ley nacional del titular del derecho de acogida, $k a \overline{f i l l}$, y a la del niño sobre la que se ejerce, makful, en el momento de su establecimiento. Y apostilla el mismo texto que la adopción (tabannī) se regirá por las mismas disposiciones.

De manera que la kafâla consiste en el hecho de acoger (recoger) legalmente, a un menor suministrándole los medios necesarios para su mantenimiento, educación, y protección. De la misma manera que lo haría un padre con su hijo. Está establecida por un acto auténtico y sincero.

El acogimiento legal es acordado ante un juez «kafăla judicial», o ante notario «kafăla notarial» y requiere el consentimiento del niño si éste tuviese padre o madre. El titular del derecho de acogimiento legal (käfil) debe ser musulmán, estar en su sano juicio, ser íntegro, poder mantener al niño acogido (makful) y capaz de protegerlo. El niño acogido puede ser de filiación conocida o desconocida, ateniéndose en todo caso la acogida a los acuerdos bilaterales entre España y los distintos países, conforme a lo dispuesto en su ordenamiento jurídico y la normativa internacional ${ }^{89}$.

En Marruecos, el sistema judicial autoriza el tanzil, o gratificación testamentaria que permite al niño (makful), percibir una cierta parte de la herencia. En Argelia (tras el Decreto n 92-24 del 13 de enero de 1992 que completa la decreto $\mathrm{n}^{\circ}$ 71-157 del 3 de junio de 1971 relativo al cambio de nombre), el makful, del menor recogido, si es de padre desconocido, puede cambiar de nombre haciéndolo coincidir con el nombre patronímico. Incluso en ocasiones la citada institución, kafāla judicial, ha sido interpretada como adopción, especialmente cuando no existía una filiación establecida o los padres biológicos habían consentido con esta modalidad ${ }^{90}$.

El procedimiento para la constitución de una kafāla se atiene a lo dispuesto en la legislación específica sobre esta institución ${ }^{91}$. Si el solicitante de la kafâla del menor abandonado es un extranjero deberá, en primer lugar, convertirse al

«Loi n 05-10 du 13 Joumada El Oula 1426 correspondant au 20 juin 2005 modifiant et complétant l'ordonnance $n^{\circ} 75-58$ du 26 septembre 1975, modifiée et complétée, portent code civil», en Journal Officiel De La Republique Algerienne, $\mathrm{n}^{\circ}$ 44, pp. 14-15.

89. Por razón del objeto y finalidad de este trabajo no ha lugar la exposición detallada de estas normas, ni siquiera en el marco del derecho comparado, por lo que el lector interesado debe remitirse a lo dispuesto en la normativa legal, que puede ser consultada en la página web de la Secretaría General de Asuntos Sociales del Ministerio detrabajo y Asuntos Sociales, Dirección General de Acción Social, del Menor y de la Familia, Subdirección General de Infancia y Familia.

90. Supuesto que se hizo patente antes de la Circular del 16 de febrero de 1999 relativa a la adopción internacional. En este sentido, el Derecho marroquí establece que el niño tomado a cargo y protegido como legítimo no podrá beneficiarse de una nueva filiación. Ley francesa ${ }^{\circ}$ 2001-111 de 6 de febrero 2001-relativa a los conflictos legales en la adopción internacional. Y un tratamiento análogo se da en la legislación argelina. La pluralidad de situaciones sobre estos casos ha dado lugar a un movimiento asociacionista de importancia en algunos países europeos, siendo Francia ejemplo al respecto. Fuente: Zaynab Alkaraz http://www.afada.org/docus/africa000fichatec.htm.

91. Ley 165/93, la Circular del Ministerio del Interior de 1983 y el Código del Estatuto Personal (Mudawana). 
Islam, en un acto ante dos adultos (notarios) y dos testigos ${ }^{92}$; este requisito se debe a que la kafála sólo puede constituirse a favor de los musulmanes, siendo preceptiva el Acta de conversión o profesión de la fe islámica, junto con otros documentos debidamente legalizados ${ }^{93}$.

Una vez completado el expediente se hará llegar al máximo órgano de representación local, wilāya ${ }^{94}$, o a la Prefectura; desde ese momento una asistente social y un qaíd acometerán cuantas acciones sean precisar para conocer a la familia aspirante al acogimiento. El matrimonio debe mantener un encuentro con las citadas personas y tras la conclusión de las encuestas se remitirán, con toda la documentación, al Ministerio del Interior, que es el organismo competente para aprobar o denegar el expediente. Si el Ministerio del Interior decide la autorización del expediente, éste se enviará de nuevo a la wilāya o Prefectura, donde se vuelve a convocar a los padres y en un plazo aproximado de 24 horas, el wầli -en su condición de persona de autoridad y gobierno que esta a cargo de alguna otra persona $a^{95}$-autoriza la entrega del menor y la constitución de la kafäla.

Constituida la kafăla deberá solicitarse la tutela dativa que confiere la representación legal sobre el menor. La legislación marroquí establece que la tutela del menor abandonado corresponde al Juez encargado de Menores en el Tribunal de Primera Instancia ${ }^{96}$. No obstante, el art. 152 de la Mudawana permite la constitución de una tutela dativa, al señalar que será tutor dativo de un menor la persona que designe el juez. Por ello, junto a la solicitud de autorización de salida del territorio nacional, debe solicitarse al Juez de menores que nombre tutor del menor al kafil. Tras la decisión del juez de menores, el matrimonio deberá acudir al Tribunal de Primera Instancia para que confirme la autorización del juez de menores.

Una vez obtenida la confirmación del Tribunal de Primera Instancia, el matrimonio debe volver a la wilàya para que ésta proceda a expedir un pasaporte marroquí al menor. Tras obtenerlo deben dirigirse al Consulado español correspondiente, con todo el expediente traducido, para solicitar el correspondiente visado de entrada en España.

Así pues, la tramitación en España de un expediente de tutela dativa de un menor de origen marroquí debe tener en cuenta las características especiales de

92. Requisitos exigidos en la Circular de 1983 y en el art. 7 de la Ley 165/93.

93. Certificado de nacimiento, el certificado de matrimonio, con un mínimo de dos años de matrimonio; certificado de solvencia económica.; certificado de trabajo; certificado médico; encuesta psico-social; certificado de antecedentes penales; certificado de residencia y certificado de idoneidad. Todos estos documentos traducidos al francés o al árabe. Además, una solicitud de un certificado de alojamiento, en el que se establece que dicho matrimonio tiene domicilio en Marruecos, ya que la Circular de 1983 exige este requisito a los ciudadanos extranjeros que quieran constituir una kafăla.

94. S.v. «wilaya» en $E I^{2}$, op. cit., vol. XI, Leiden, Brill, 2002, pp. 208-209.

95. Institución que tiene su orgien en el texto coránico, XIII, 12; sobre sus funciones y competencias véase $E I^{2}$, vol. XI, Leiden, Brill, 2002, pp. 109-116.

96. Art.6 de la Ley $165 / 93$ y art. 147 y ss. de la Mudawana. 
esta tramitación, con el fin de asegurar a los interesados que el trámite que inician en Marruecos está configurado para el supuesto de niños abandonados ${ }^{97}$. Este es el único supuesto previsible, y exige el cumplimiento de una serie de requisitos ante el Consulado español correspondiente ${ }^{98}$.

97. Recogidos en una serie de Centros como el Hospital Asan de Nador, el Lalla Meriem de Rabat, el Centro Hospitalario al- Ghassani de Fez y la Ligue Marrocaine pour la Protection de I'Enfance, Bureau de Marrakech en Marraquech.

98. El envío del certificado de idoneidad e informes psico-sociales, junto con un escrito de constatación del Centro en el que han iniciado el trámite, en el cual conste la identidad de los adoptantes (nombre y apellidos); los informes psico-sociales y el certificado de idoneidad deben hacer referencia siempre a una tutela dativa y no a la adopción -la razón: por ser la adopción una figura no reconocida en la legislación islámica y, como consecuencia, considerar la tutela dativa la única figura que permite, por sus garantías jurídicas, la entrada con visado del niño en España. Los interesados tramitan directamente su documentación personal - de manera que los informes psico-sociales y certificado de idoneidad remitidos por las Comunidades Autónomas se envían, desde este Ministerio, por valija diplomática, al Consulado español correspondiente de Marruecos para su remisión al Centro correspondiente. La documentación, junto a la autorización del juez encargado de asuntos notariales y de menores para que el menor viaje fuera del territorio nacional y conviva o resida habitualmente con la familia que le acoge en el extranjero, deberá ser remitida ante el Consulado General de España en Rabat, para el caso de Marruecos. 



\section{LA POSICIÓN JURÍDICA DE LA MUJER A TRAVÉS DE LAS REFORMAS DEL DERECHO DE FAMILIA}

MARÍA LUISA VALLÉS AMORES

Universidad de Alicante

\section{INTRODUCCIÓN}

Durante los días 17, 18 y 19 de noviembre de 2004, el Seminario Universitario sobre los Derechos de las Mujeres, del Área de Derecho Constitucional de la Facultad de Derecho de la Universidad de Alicante, organizó un Curso, "Mujeres y Derecho", cuya finalidad consistió en poner de manifiesto que, a pesar de los cambios legislativos producidos desde la aprobación de la Constitución de 1978, para llegar a la igualdad legal entre hombres y mujeres, la realidad nos muestra que las diferencias de género producen desvíos significativos en la creación, interpretación y aplicación del Derecho.

Agradeciendo muy sinceramente mi participación en dicho curso mediante la ponencia, "La posición jurídica de la mujer a través de las reformas del Derecho de familia», mi colaboración consistió en una exposición, dentro del contexto del Derecho Civil y concretamente en el ámbito del Derecho de Familia, del desarrollo evolutivo de la situación jurídica de la mujer, con independencia de su situación matrimonial, en el Derecho de Familia desde la redacción originaria del Código civil1.

Antes de comenzar con la exposición quisiera puntualizar dos cuestiones. En primer lugar debo advertir que la ponencia no tiene la finalidad de analizar la problemática planteada como consecuencia de la situación jurídica en la que se encontraba la mujer según la legalidad vigente en cada momento histórico; su objetivo radica en una mera exposición de la normativa reguladora en cada época en la que se ha llevado a cabo una reforma del Código civil en esta temá-

1. Para obtener una visión de los antecedentes prelegislativos, precedentes legales así como de la posición de la jurisprudencia de la época, vid. SCAEVola, Q. M.: Código Civil, tomos correspondientes, $5^{\mathrm{a}}$ ed. coment. por ORTEGA LORCA, F.: Madrid, Instituto Editorial Reus, 1942.

Feminismo/s, 8, diciembre 2006, pp. 115-129 
tica ${ }^{2}$. Por otra parte, quiero hacer constar que si bien de la exposición pudiera deducirse mi rechazo hacia nuestra legislación anterior, inspirada en los principios dominantes en cada momento, no es esa mi pretensión, al menos en este momento, más bien quiero poner de manifiesto mi satisfacción hacia una evolución en la posición jurídica de la mujer, demandada por nuestra sociedad.

De los diversos sectores del Derecho Civil, es el Derecho de familia el que se ha visto sometido en las últimas décadas a reformas más profundas. El fenómeno es particularmente ostensible en nuestro país como consecuencia de dos factores fundamentales desde el punto de vista técnico. En primer lugar, la redacción originaria del Código civil de 1889, inspirado en criterios propios del momento codificador, que pueden sintetizarse en el carácter patriarcal de la familia, la sumisión de la mujer a la autoridad del marido y la radical discriminación entre los hijos legítimos e ilegítimos. El segundo factor, a que aludía, se refiere a la aprobación y promulgación de la Constitución de 1978, consagrando principios relativos a la dinámica familiar, absolutamente contradictorios con los inspiradores del Código civil.

En este sentido, y en relación a la posición jurídica de la mujer, la Constitución establece la absoluta igualdad jurídica de todos los españoles ante la Ley sin que pueda prevalecer discriminación, entre otras causas, por razón de sexo (artículo 14.1) así como entre el marido y la mujer respecto al matrimonio (artículo 32.1).

Tales principios han sido plasmados fundamentalmente mediante las reformas del Código civil operadas por una legislación que ha supuesto de facto la construcción o instauración de un nuevo Derecho de familia, asentado, en numerosísimos aspectos, en presupuestos contrarios de lo establecido en la redacción originaria del Código civil.

\section{REFERENCIA A LA SINGULAR POSICIÓN JURÍDICA DE LA MUJER RESPECTO A LA DEL VARÓN EN RELACIÓN A LA EDAD Y AL MATRIMONIO}

En el Código civil, el sexo ha sido considerado tradicionalmente como una de las causas modificativas de la capacidad de obrar, en el sentido de que las diferencias existentes entre el hombre y la mujer hacían aconsejable restringir la libre iniciativa de esta última. En cambio, el sexo masculino nunca ha supuesto históricamente restricción alguna de las posibles actividades del hombre. La consecuencia de ello se tradujo en que la redacción originaria del Código civil de 1889, reflejaba algo tan evidente como que durante siglos, la mujer ha

2. La problemática jurídica planteada como consecuencia de la distinta posición jurídica de la mujer respecto al varón, resulta tan diferente y diversa en cada uno de los ámbitos en los que se producía, que excede de nuestras pretensiones en este momento. En cualquier caso, respecto a los comentarios a las diferentes reformas en esta temática, vid. ALVADALEJO, M. (dir.): Comentarios al Código Civil y Compilaciones forales, (arts. corresp.), Madrid, ediciones de 1978, 1982 y 2000 y BerCovitz, R. (coord..): Comentarios a las reformas del Código Civil (arts. corresp.), Madrid, Edersa, 1977 y 1993. 
desempañado un papel secundario en la sociedad y que dicha realidad ha sido siempre objeto de diverso tratamiento por las normas jurídicas.

En base a esta consideración de la mujer, por la normativa reguladora, la mayoría de edad, que se adquiría a los 23 años para ambos, quedaba limitada en su ejercicio para la mujer, puesto que hasta el cumplimiento de los 25 años, las hijas de familia mayores de edad, no podían dejar la casa paterna sin licencia del padre o de la madre en cuya compañía vivían, salvo para ingresar en convento, contraer matrimonio o cuando cualquiera de los padres hubieran contraído ulteriores nupcias ${ }^{3}$. La Ley de 13 de diciembre de 1943, si bien rebajó la mayoría de edad a 21 años, mantuvo la misma situación. Fue la Ley 31/1972, de 22 de julio la que suprimió la restricción de la mujer no casada, respecto a su autonomía como persona, para poder abandonar voluntariamente el domicilio paterno si deseaba vivir fuera del hogar familiar.

En relación a la apuntada restricción en la mujer, curiosamente hasta el año 1981-reforma del Código civil de suma importancia para la mujer y a la que me referiré posteriormente -, el artículo 46 del Código establecía que "corresponde otorgar la licencia para el matrimonio de los hijos legítimos al padre, faltando éste o hallándose impedido, en orden sucesivo, a la madre, al abuelo paterno, al materno, a las abuelas paterna, materna, y en su defecto al Consejo de familia». El precepto en cuestión pone de manifiesto la autoridad patriarcal hasta tiempos muy recientes, puesto que puede observarse la forma en que la mujer (madre, abuela) era relegada al último lugar. No sólo necesitaba autorización, siendo mayor de edad, para abandonar el domicilio paterno; también la licencia se otorgaba con una prioridad por parte del varón.

En cualquier caso, más desolador resultaba el panorama de la mujer casa$\mathrm{da}$, puesto que estaba sometida a la autoridad marital (artículo 57 C.c.) ${ }^{4}$. En consecuencia, no solo le pesaba el deber unilateral de obediencia a su marido; también estaba obligada a seguir el domicilio y la nacionalidad de su cónyuge (artículos 58 y 21 del Código civil) $)^{5}$. Esta posición de sumisión producía que en caso de infidelidad conyugal, la conducta de la mujer, independientemente de su consideración penal, a tenor del artículo 105 del Código civil, fuera discriminatoria respecto a la infidelidad del varón, puesto que el precepto reseñado disponía que «Las causas legítimas del divorcio son: $1^{\circ} \mathrm{El}$ adulterio de la mujer, en todo caso, y el del marido cuando resulte escándalo público o menosprecio de la mujer». En virtud de esta normativa, el varón que no cometiese escándalo público o no causara menosprecio a su mujer, como consecuencia del incumpli-

3. Artículo 321 del Código civil en su redacción originaria.

4. Artículo 57 del Código civil en su redacción originaria: «El marido debe proteger a la mujer y ésta obedecer al marido».

5. Artículo 58 del Código civil en su redacción originaria: «La mujer está obligada a seguir a su marido donde quiera que fije su residencia. Los Tribunales, sin embargo, podrán con justa causa eximirla de esta obligación cuando el marido traslade su residencia a ultramar o a país extranjero». Desaparece esta restricción por Ley 14/1975, de 2 de mayo. 
miento de su deber de fidelidad, no tenía el temor de ver disuelto el matrimonio en contra de su voluntad.

En base a las consideraciones apuntadas, la propia normativa imponía como conducta socialmente aceptable «la relación extramatrimonial discreta del varón", sin embargo, la locución, "en todo caso», referida a la mujer, la hacía merecedora de culpabilidad sin ninguna duda.

Otra consecuencia práctica, derivada de la autoridad marital, se traducía en la ineludible necesidad de licencia de su marido para la realización de diversos actos. Baste como ejemplo que para aceptar una herencia que a ella le hubiera correspondido necesitaba la anuencia de su esposo, puesto que el artículo 1263.3 del Código civil prohibía a las mujeres casadas prestar su consentimiento en los casos expresados en la Ley, siendo uno de ellos la aceptación de la herencia a su favor con su sola declaración de voluntad. Tampoco podía, a tenor de los artículos 6 a 9 del Código de comercio, ejercer el comercio sin licencia marital.

En síntesis, el marido era el representante de la mujer a tenor de lo dispuesto en el artículo 60 del Código civil ${ }^{6}$.

Con semejantes planteamientos legales, la mujer que conservara su soltería, una vez que cumplía la edad de 25 años, de alguna manera se colocaba en una posición de cierta autonomía personal; ahora bien, con el reproche social por conservar su soltería, puesto que no había logrado un marido. Si la mujer soltera no había cumplido los 25 años, su estado jurídico quedaba reservado a la sumisión patriarcal; situación que no se producía en el caso del varón ${ }^{7}$. Si bien, al cumplir la referida edad, podía considerarse que su posición jurídica no distaba demasiado de la del varón, salvo en determinadas cuestiones a las que más adelante haré referencia, en el supuesto de que optara por contraer matrimonio, se le negaba su capacidad y autonomía como persona, puesto que debía obediencia y sumisión a su marido.

Ley de 2 de mayo de 1975, adelantándose, aunque no fuera este su propósito, a nuestro Texto Constitucional, tuvo a bien suprimir estos deberes unilaterales, sustituyéndolos por derechos y deberes recíprocos de respeto y protección.

La referida Ley suprimió asimismo la marginación que pesaba sobre la mujer casada respecto a la administración y disposición de los bienes matrimoniales,

6. Artículo 60 del Código civil en su redacción originaria: «El marido es el representante de su mujer. Ésta no puede, sin su licencia, comparecer en juicio por sí o por medio de Procurador». Desaparece esta restricción por Ley 14/1975, de 2 de mayo.

7. Debe observarse un dato curioso, constatado popularmente, en los supuestos de separación y posteriormente- a partir de la Ley 30/1981, de 7 de julio- de divorcio. Las mujeres reconocen haber contraído matrimonio, en numerosísimas ocasiones, impulsadas por la necesidad de salir del sometimiento paterno; sin embargo, la Ley les obligaba, entonces, al sometimiento a la autoridad marital mientras duraba el matrimonio. 
puesto que dicha esfera quedaba, hasta ese momento, reservada a la iniciativa del marido a tenor de lo dispuesto en el artículo 62 del Código civil ${ }^{8}$

\section{POSICIÓN JURÍDICA DE LA MUJER EN CUANTO A LA PATRIA POTESTAD Y TUTELA}

Si bien, como ha quedado constatado hasta el momento, la situación marginal de la mujer casada respecto a sus bienes privativos y matrimoniales producía una considerable limitación en su autonomía personal, todavía, más grave resultaba que la titularidad de la patria potestad correspondiera al marido, y sólo en su defecto a la mujer según disponía el artículo 154 del Código civil. En este contexto de limitación de la autonomía de la mujer, el artículo 237 del mismo Texto legal la imposibilitaba para ser tutora; situación que persiste hasta su supresión por la Ley 14/1975, de 2 de mayo.

Curiosamente, entre las personas que la Ley consideraba no aptas para desempeñar la tutela, además de las mujeres, se encontraban una serie de personas cuya conducta o modo de vivir era perjudicial para el pupilo, o bien en razón a su situación les impediría atender a las necesidades del tutelado9.

La circunstancia de que la patria potestad la ostentase el marido, producía consecuencias gravísimas no sólo para la mujer, también para los hijos menores de edad, puesto que el Código civil disponía que si la esposa enviudaba y contraía nuevo matrimonio, perdía la patria potestad sobre sus hijos, salvo que el difunto marido (padre de los hijos) hubiera previsto expresamente en testamento que su viuda contrajera matrimonio, habiendo ordenado, en tal caso, que conservase y ejerciese la patria potestad sobre sus hijos a tenor de lo dispuesto en el artículo 168 del Código. Sólo si volvía a enviudar de este segundo matrimonio, recuperaba la patria potestad sobre todos los hijos no emancipados según disponía el artículo 172 del mismo Texto lega ${ }^{10}$.

8. Artículo 62 del Código civil en su redacción originaria: «Son nulos los actos ejecutados por la mujer contra lo dispuesto en los artículos anteriores, salvo cuando se trate de cosas que por su naturaleza estén destinadas al consumo ordinario de la familia, en cuyo caso, las compras hechas por la mujer serán válidas. Las compras de joyas, muebles y objetos preciosos, hechas, sin licencia del marido, sólo se convalidarán cuando éste hubiere consentido a su mujer el uso y disfrute de tales objetos».

9. El artículo $237.7^{\circ}$ C.c., en su redacción originaria, disponía que «no pueden ser tutores ni protutores, las mujeres, salvo los casos en que la ley las llama expresamente». El mismo precepto y número se modificó por Ley de 24 de abril de 1958 con objeto de permitir que la mujer pudiera ser tutora, salvo si estaba casada y no había obtenido licencia de su marido. El artículo 237, en los 12 números que imposibilitaba la tutela a las personas reseñadas, incluía además de a las mujeres a los penados por delitos de robo, hurto, corrupción de menores, escándalo público; los condenados a cualquier pena privativa de libertad, mientras estuvieran sufriendo condena; personas de mala conducta o que no tuvieran manera de vivir conocida. La imposibilidad para ser tutores se extendía, asimismo, a otras personas a las que se presumía no poder ocuparse del tutelado: religiosos profesos, extranjeros no residentes en España.

10. Fue la Ley de 24 de abril de 1958 la que suprimió esta injusta normativa para la mujer que le impedía libremente volver a contraer matrimonio, puesto que el precio que debía pagar era la pérdida de la patria potestad, salvo que su difunto marido le hubiera otorgado el pertinente permiso. 
La normativa patriarcal sobre atribución de la patria potestad producía la grave consecuencia, en numerosas ocasiones, de que en los supuestos de separación de los cónyuges, la mujer perdía incluso el derecho de visita respecto de sus hijos $y$, por consiguiente, los menores también quedaban sin poder relacionarse con su madre con las consecuencias perjudiciales para su desarrollo emocional y afectivo. En este sentido, resulta muy significativa la Sentencia del Tribunal Supremo de 9 de junio de 1909 que parte de unas argumentaciones totalmente concordantes con la normativa vigente en la época. En cualquier caso, el Tribunal Supremo parece justificar su decisión en los preceptos reguladores, aunque reconociendo el derecho que por naturaleza la madre debería tener a relacionarse con sus hijos; sin embargo, hace una aplicación de la normativa vigente sin tener en consideración otras circunstancias, imposibilitando con ello el derecho de la madre y sus hijos a poder relacionarse.

En síntesis, los argumentos del Tribunal Supremo son los siguientes:

El Auto de la Audiencia Territoria ${ }^{11}$ atenta en realidad y en el fondo a los derechos y deberes de la patria potestad del marido, obligándolo a separarlos y educarlos contra su voluntad, para lo cual no hay precepto alguno que así lo autorice, ni mucho menos puede fundarse en la razón alegada por su madre, ya que "aun cuando ésta tuviera el derecho de verlos y manifestarle su cariño, eso habría de hacerse y realizarse en cuanto la situación de los cónyuges legalmente reconocida así lo consienta». El Tribunal Supremo sigue considerando: «Es manifiesto el error cometido por el Tribunal sentenciador. Si las decisiones de instancia se inspiran, a lo que parece, en razones humanitarias (madre que probablemente no ejerce ninguna profesión y no puede sufragar el desplazamiento para ver a sus hijos y padre, en cambio, notario, que le permite tener una economía desahogada)".

El Tribunal Supremo, ante el conflicto entre los deseos y propósitos de los progenitores respecto de sus hijos, se inclina a favor de aquel que cuenta con el estricto apoyo legal, a la sazón el artículo 154 del Código civil, estableciendo que "El padre y en su defecto la madre tienen potestad sobre sus hijos legítimos no emancipados». En cualquier caso, como habíamos señalado, el Supremo, no obstante, parece reconocer el derecho de la madre a relacionarse con sus hijos, aunque la dura aplicación de la legalidad vigente le impida, siquiera, poder visitarlos en un colegio elegido por el cabeza de familia.

Debe tenerse en cuenta que en la época en que nos situamos, la mujer, además de la sumisión respecto a su marido, la legalidad vigente la imposibilitaba

11. Los hechos brevemente resumidos son los siguientes: en una separación, la esposa solicita el traslado, a Madrid, de sus hijos a fin de poder visitarlos, puesto que su marido y padre de los menores los había internado en Badajoz con expresa prohibición de que recibieran visitas y correspondencia de su madre. El juzgado requirió al marido (que ejercía de notario en esa localidad y había sido nombrado para Navarra) al objeto de que situara a los hijos en poder de persona o colegio de confianza en Madrid para que pudieran ser visitados por su madre los días festivos; acuerdo confirmado por la Audiencia Territorial de Madrid en auto que recurrió y que fue casado por la citada sentencia del Tribunal Supremo. 
para presentarse, entre otras, a oposiciones al Cuerpo de Notarios y Registradores de la Propiedad, profesión que desempeñaba el marido de la Sentencia comentada en líneas precedentes ${ }^{12}$.

\subsection{La Constitución de la Segunda República}

En la posición jurídica de la mujer se abre un periodo más alentador para ella en la década de los años treinta, puesto que la Constitución de la Segunda República de 9 de diciembre de 1931, sienta como principio a desarrollar la igualdad entre ambos sexos, siendo objeto de consideración expresa en diversos artículos. En concreto, el artículo 25 señalaba que el sexo no podía ser fundamento de ningún privilegio jurídico. Por su parte, el artículo 43 establecía que el matrimonio se fundaba en la igualdad de sexos. En consonancia con tal declaración, la Ley de divorcio de 2 de marzo de 1932, de la Segunda República, suprimió esta drástica situación de atribución de la patria potestad, puesto que dispuso, en el artículo 20/II, que «El cónyuge que no tenga a los hijos menores en su poder, conserva el derecho de comunicar con ellos y vigilar su educación en la forma que determine el Juez, quien adoptará las medidas necesarias para el ejercicio de este derecho".

El artículo 40 de la Constitución Republicana sirvió de punto de partida para establecer, a través de diversos Decretos, algunas conquistas parciales para la mujer, entre las que pueden citarse: poder presentarse a oposiciones al Cuerpo de Notarios y Registradores de la Propiedad (Decreto de 29 de abril de 1931); Cuerpos Técnicos de Prisiones (Decreto 29 octubre de 1931); Secretaría de los Tribunales de Justicia (19 de mayo de 1932); ejercer la profesión de Procurador de los Tribunales.

Con la caída de la República, el Estado se sitúa en una actitud patriarcal y paternalista, ocupando la mujer un papel claramente doméstico, puesto que se consideraba como natural y conveniente para el sexo femenino.

\subsection{La Ley de $\mathbf{2 4}$ de abril de 1958}

Durante el régimen del general Franco, poco a poco, las circunstancias sociológicas -desaparición de prejuicios sociales, entrada masiva de turismo, despegue económico- van determinando nueva legislación tendente a abolir las discriminaciones más evidentes entre el hombre y la mujer; disposiciones legales que tiene por objeto sentar las bases de una equiparación entre varón y mujer de una parte y, de otra, en el ámbito familiar, entre el marido y la mujer.

La reforma llevada a cabo por la Ley de 24 de abril de 1958 tiende a ampliar la capacidad de la mujer ${ }^{13}$. En este sentido y con referencia al derecho de

12. También recaía sobre la mujer la prohibición de poder presentarse a oposiciones a la Secretaría de los Tribunales de Justicia así como, entre otras profesiones, ejercer de Procuradora de los Tribunales.

13. Vid. Batlle Vázouez, M: Observaciones sobre la reforma del Código civil lla Ley de 24 de abril de 1958), Madrid, Instituto Editorial Reus, 1958. 
comunicación de la madre separada respecto a sus hijos -que señalábamos anteriormente- aunque la patria potestad la sigue teniendo el padre y sólo en defecto la madre, el Código civil establece que «El Juez determinará el tiempo, modo y lugar que el cónyuge apartado de los hijos podrá visitarlos y comunicar con ellos».

Se suprime la pérdida de la patria potestad por contraer nuevo matrimonio la mujer (artículo 168 del Código civil); permitiéndosele, a partir de este momento, ser testigo en los testamentos (artículo 681).

Respecto a la tutela, si la mujer conserva su soltería, a partir de este momento, ya no tiene imposibilidad para su ejercicio; sin embargo, si ha contraído matrimonio, necesita, para desempeñar este cargo, autorización marital a tenor de lo dispuesto en el número 7 del artículo 237 del Código civil. En cualquier caso, para el llamamiento al ejercicio de este cargo, todavía, el varón se encuentra en una posición preferente, puesto que el artículo 211 del Código establecía el llamamiento de los varones, para el ejercicio del cargo tutelar, con preferencia al de las mujeres; otorgando, incluso entre los varones, prioridad a los ascendientes de este último y prefiriendo a los hermanos de vínculo sencillo antes que a las hermanas, a las que situaba en el mismo orden con independencia de su vínculo ${ }^{14}$. En cualquier caso, al menos, la reforma, llevada a cabo por la Ley de 24 de abril de 1958, en el ámbito de permisión limitada de la tutela para las mujeres, suprimió el requisito de viudedad en las ascendientes maternas del tutelado que exigía la redacción originaria del Código civil ${ }^{15}$.

Si bien las reformas operadas en el Código civil, por la Ley de 1958 supusieron un considerable avance en la consideración de la autonomía personal de la mujer, la modificación más importante es la que atañe al artículo 1413 del Código civil, que hasta este momento permitía al marido no sólo administrar los bienes comunes de ambos cónyuges (sigue siendo así hasta 1981, puesto que el artículo 1441 permitía no solo que la mujer administrase los bienes comunes cuando fuera tutora de su marido, se hubiera pedido la declaración de ausencia, hubiese sido declarado prófugo por la autoridad militar o rebelde en causa criminal. La misma regla se aplicaba si el marido hubiese abandonado a la familia), también gravarlos o enajenarlos sin consentimiento de la mujer. A partir de esta reforma necesitará su consentimiento.

14. Artículo 211 del Código civil según redacción por Ley de 24 de abril de 1958: «La tutela legítima de los menores no emancipados corresponde únicamente: Primero. Al abuelo paterno y, en su defecto, al materno. Segundo. A las abuelas por el mismo orden. Tercero. Al mayor de los hermanos de doble vínculo, y a falta de éstos, de los consanguíneos o uterinos. Cuarto. A las hermanas por el mismo orden. La tutela de que trata este artículo no tiene lugar respecto de los hijos ilegítimos».

15. Artículo 211 del Código civil en su redacción originaria: La tutela legítima de los menores no emancipados corresponde únicamente: $1^{\circ} \mathrm{Al}$ abuelo paterno. $2^{\circ} \mathrm{Al}$ abuelo materno. $3^{\circ} \mathrm{A}$ las abuelas paterna y materna, por el mismo orden, mientras se conserven viudas. $4^{\mathrm{a}} \mathrm{Al}$ mayor de los hermanos varones de doble vínculo y, a falta de éstos, al mayor de los hermanos consanguíneos o uterinos. La tutela de que trata este artículo no tiene lugar respecto de los hijos ilegítimos». 


\section{EVOLUCIÓN LEGAL EN CUANTO A UNA POSICIÓN MÁS IGUALITARIA DE LA MUJER RESPECTO A LA SITUACIÓN DEL VARÓN EN EL MATRIMONIO}

La evolución hacia una consideración más igualitaria entre la mujer y el varón parece iniciarse en la década de los años setenta. Como consecuencia de esta nueva situación, la Ley 31/ 1972, según señalábamos anteriormente, estableció la mayoría de edad en 21 años para ambos. A partir de este momento, la mujer puede abandonar la casa paterna sin necesidad de contraer matrimonio o ingresar en convento; en consecuencia, siempre que conserve su soltería o se encuentre en estado de viudedad, gozará prácticamente de una posición jurídica equiparable a la del varón en el ámbito del Derecho de Familia, con las salvedades de preferencia del varón en todos los llamamientos que hace el Código civil. En cualquier caso, la mujer casada tardará unos años más en alcanzar esta posición.

\subsection{Ley de 2 de mayo de 1975}

La primera Ley que puede encuadrarse en esta línea evolutiva es, sin duda, la Ley de 2 de mayo de 1975, aunque, tal como se desprende de la presentación del Proyecto de Ley a las Cortes, no tuviera un propósito tan reformista, no obstante, introdujo sustanciales reformas en el Código civil y en el Código de Comercio. Al realizar una nueva regulación del domicilio ${ }^{16}$, la nacionalidad y los derechos y deberes recíprocos de los cónyuges, la mujer, deja de ser considerada como un mero satélite del marido. Como consecuencia de esta reforma, deja de estar supeditada a la eterna licencia marital con las subsiguientes consecuencias que la supresión de la licencia del marido conlleva en el ámbito familiar.

La redacción del originario artículo 64 del Código civil, disponiendo que «la mujer gozará de los honores de su marido, excepto los que fueran estrictamente y exclusivamente personales, y los conservará mientras no contraiga matrimonio", se sustituye por una nueva fórmula acorde con esta nueva concepción más progresista. El novedoso precepto establece el disfrute recíproco para ambos cónyuges de los honores de su consorte.

La mencionada Ley de 1975 produce la ruptura del principio de unidad jurídico familiar en materia de nacionalidad. No ocurrió de la misma forma en materia de vecindad civil. Tuvo que ser la Ley de 15 de octubre de 1990, sobre reforma del Código civil, en aplicación del principio de no discriminación por razón de sexo, la que llevara a cabo la ruptura del principio jurídico familiar en sede de vecindad civil. En este sentido, la Exposición de Motivos de la Ley de 1990 señala que el fundamento de esta Ley consiste en «eliminar las discriminaciones que por razón de sexo aún perduran en la legislación civil y perfeccionar el desarrollo normativo del principio constitucional de igualdad».

16. Artículo 58 del C.c. en su redacción originaria: «La mujer está obligada a seguir a su marido donde quiera que fije su residencia. Los Tribunales, sin embargo, podrán con justa causa eximirla de esta obligación cuando el marido traslade su residencia a ultramar o país extranjero». 
De gran trascendencia resultó la reforma introducida, por la Ley de 2 de mayo de 1975, en el artículo 1387 del Código civil. Hasta este momento, la mujer no podía, sin licencia de su marido, disponer de los bienes parafernales, ni siquiera comparecer en juicio para litigar sobre ellos ${ }^{17}$. La nueva redacción del precepto la habilita para disponer por sí sola de sus bienes propios, salvo que fuera menor de edad, en cuyo supuesto, a tenor de lo dispuesto en el artículo 61, necesitaba el consentimiento de su padre, en su defecto el de su madre y, a falta de ambos, el de su tutor. En este mismo contexto, a tenor de la nueva redacción dada al artículo 1388 del Código civil, la mujer podía comparecer en juicio y litigar sobre los bienes parafernales, suprimiéndose, con esta nueva redacción del precepto, el poder del marido sobre los bienes propios de la mujer ${ }^{18}$.

Un avance considerable y, a la vez, muy significativo de la Ley de 2 de mayo de 1975, consistió en la sustitución de los preceptos, referentes a los derechos y obligaciones entre marido y mujer, por normas que establecían derechos y deberes recíprocos en consonancia con el principio de que el matrimonio no restringe la capacidad de obrar de los cónyuges. En este sentido, se sustituye la redacción del artículo 57 del Código disponiendo que «el marido debe proteger a la mujer, y ésta obedecer al marido", por una nueva redacción en consonancia con principios más igualitarios que constituyen el presupuesto legal. De esta forma, el reseñado precepto se incardina en las nuevas directrices, disponiendo que «el marido y la mujer se deben respeto y protección recíprocos, y actuarán siempre en interés de la familia».

Con independencia de estas modificaciones que supusieron un avance considerable en la posición jurídica de la mujer, dentro del ámbito del Derecho de Familia, todavía, no se llega a una total equiparación, puesto que el Código civil, sigue atribuyendo, al marido, tanto la patria potestad con preferencia sobre la mujer así como la administración de los bienes matrimoniales.

De la misma suerte, sigue vigente con esta normativa la obligación de constituir dote para la mujer. El artículo 1336 del Código civil dispone que «la dote se compone de los bienes y derechos que en este concepto la mujer aporta al matrimonio al tiempo de contraerlo y de los que durante él adquiera por donación, herencia o legado con el carácter dotal». En perfecta concordancia con esta obligación, el Código civil, en el artículo $1340^{19}$, obligaba a los padres a dotar a

17. Artículo 1387 del Código civil en su redacción originaria: «La mujer no puede, sin licencia, de su marido, enajenar, gravar ni hipotecar los bienes parafernales, ni comparecer en juicio para litigar sobre ellos, a menos que sea judicialmente habilitada al efecto».

18. El artículo 1388 del C.c. en su redacción originaria disponía que «cuando los parafernales, cuya administración se reserva la mujer, consistan en metálico o efectos públicos o muebles preciosos, el marido tendrá derecho a exigir que sean depositados o invertidos en términos que hagan imposible la enajenación o pignoración sin su consentimiento».

19. Artículo 1340 del C.c. según redacción por Ley de 24 de abril de 1958: «el padre o la madre, o el que de ellos viviese, están obligados a dotar a sus hijas legítima, fuera del caso en que necesitando éstas la licencia de aquéllos para contraer matrimonio con arreglo a la ley, se casen sin obtenerla ni obtener tampoco la autorización equivalente, conforme al artículo 49 de este Código". 
sus hijas legítimas cuando contraían matrimonio. El marido, por supuesto, era el administrador y usufructuario de la dote.

La situación de la mujer respecto a la tutela persistió en cuanto a una ostensible discriminación en relación al varón; correspondiendo su ejercicio, en primer lugar al abuelo paterno y en su defecto al materno, ocupan el segundo puesto, las abuelas, en tercer lugar corresponde su ejercicio a los hermanos de doble vínculo, a continuación los de vínculo sencillo, situándose en último lugar las hermanas todas por igual. En este contexto, debo hacer constar que a pesar de la existencia de un tratamiento discriminatorio respecto a la mujer en el ámbito familiar, se producía una contradicción legal, puesto que la Ley de adopción de 4 de julio de 1970, posibilitaba, en el párrafo primero del artículo 178 del Código civil, que además de los cónyuges, procediendo conjuntamente, pudiera adoptar plenamente cualquier persona en estado de viudedad o soltería, por lo que no existía imposibilidad de que la mujer que hubiera enviudado o no hubiera contraído matrimonio, pudiera convertirse en madre adoptiva.

Otras preferencias, en el tratamiento que el Código civil realiza en diversos preceptos, otorgan una situación de prevalencia al varón sobre la mujer ${ }^{20}$.

\subsection{Ley $11 / 1981$, de 13 de mayo y Ley $30 / 1981$, de 7 de julio}

Con la proclamación constitucional de que el hombre y la mujer tienen derecho a contraer matrimonio con plena igualdad jurídica (artículo. 32.1) se promulgaron dos leyes de gran importancia para la equiparación efectiva de marido y mujer dentro del matrimonio:

- Ley 11/1981, de 13 de mayo, sobre filiación, patria potestad y régimen económico del matrimonio.

- Ley 30/1981, de 7 de julio, reguladora del sistema matrimonial, popularmente conocida como Ley del divorcio.

La promulgación de las citadas normativas supuso la instauración de un nuevo Derecho de Familia que- según hemos expuesto en esta breve evolución histórica desde la redacción originaria del Código civil- comenzó a perfilarse a mediados de la década de los años setenta. Esta nueva consideración en la posición jurídica de la mujer en el Derecho de Familia se tradujo, en una total equiparación entre la mujer y el varón con independencia de su estado de soltería, viudedad o matrimonial.

20. En este sentido, a título de ejemplo, citaré el párrafo primero del artículo 1066 del Código civil que, en relación a los títulos de adquisición o pertenencia de una finca existiendo varios coherederos, dispone: "Cuando el mismo título comprenda varias fincas adjudicadas a diversos coherederos, o una sola que se haya dividido entre dos o más, el título quedará en poder del mayor interesado en la finca o fincas, y se facilitarán a los otros copias fehacientes, a costa del caudal hereditario. Si el interés fuere igual, el título se entregará la varón, y, habiendo más de uno, al de mayor edad». En el mismo sentido, el artículo 1060 del Código civil, disponiendo la representación de los hijos menores de edad, en la partición de la herencia, por el padre y en su caso por la madre. 
En consecuencia, en líneas generales, se procede a la sustitución de la «expresiones marido y mujer» por la de "cónyuges", salvo en aquellos preceptos que hacen referencia a la igualdad conyugal. En la nueva sistematización del Título cuarto del Libro primero del Código civil, como resultado de la novedosa normativa, se reserva el Capítulo quinto ${ }^{21}$ a los derechos y deberes de los cónyuges; estableciéndose la igualdad entre ambos, el respeto y la ayuda mutua, la obligación de vivir juntos, guardarse fidelidad y socorrerse mutuamente; asimismo fijarán de común acuerdo el domicilio conyugal. Siguiendo esta tendencia, el artículo 71 del Código civil dispone que ninguno de los cónyuges puede atribuirse la representación del otro sin que le hubiese sido conferida.

En base a estos presupuestos, además de la supresión de la dote y atribución conjunta a los padres, con independencia de su estado matrimonial ${ }^{22}$, de la patria potestad sobre sus hijos menores de edad no emancipados ${ }^{23}$, los cónyuges, a tenor de lo dispuesto en el artículo 1315 del Código civil, tendrán libertad para configurar su régimen económico matrimonial; siendo nula, a tenor del artículo 1328, cualquier estipulación limitativa de la igualdad de derechos que corresponda a cada cónyuge. En base a este planteamiento, cualquiera de los consortes queda facultado para atender a las necesidades ordinarias de la familia según dispone el artículo 1319.1 del Código civil; quedando, de esta forma, cualquiera de ellos facultado para el ejercicio de la "potestad doméstica»que tradicionalmente con bastantes limitaciones le había sido concedido a la mujer ${ }^{24}$.

La última parte del artículo 1438 del Código civil - precepto referido al régimen matrimonial de separación de bienes - es también una novedad de la reforma de 1981, puesto que, hasta ese momento, el Código civil había guardado silencio sobre las labores domésticas, a las que en muchísimos casos se dedicaba exclusivamente la mujer. Quizás, el legislador, pensando que las tareas y labores domésticas, todavía en 1981, las seguía realizando, en la mayoría de los casos, la mujer, introduce que en este régimen matrimonial sea valorado el trabajo doméstico de cualquiera de los cónyuges, disponiendo que «el trabajo para la casa será computado como contribución a las cargas y dará derecho a obtener una compensación que el Juez señalará, a falta de acuerdo, a la extin-

21. El capítulo quinto del título cuarto del libro primero del Código civil lo componen los artículos 66 al 72 inclusive; quedando este último precepto sin contenido.

22. Artículo 108/II según redacción por Ley 11/1981, de 13 de mayo: «La filiación matrimonial y la no matrimonial, así como la adoptiva, surten los mismos efectos, conforme a las disposiciones de este Código".

23. Artículo 154 párrafo primero del Código civil: «Los hijos no emancipados están bajo la potestad del padre y de la madre».

Artículo 156 párrafo primero del Código civil: «La patria potestad se ejercerá conjuntamente por ambos progenitores o por uno solo con el consentimiento expreso o tácito del otro...».

24. Artículo 62 del C.c. en su redacción originaria: «Son nulos los actos ejecutados por la mujer contra lo dispuesto en los anteriores artículos (relativos a la administración de los bienes de la sociedad conyugal), salvo cuando se trate de cosas que por su naturaleza estén destinadas al consumo ordinario de la familia, en cuyo caso las compras hechas por la mujer serán válidas. Las compras de joyas, muebles y objetos preciosos, hechas sin licencia del marido, sólo se convalidarán cuando éste hubiese consentido a su mujer el uso y disfrute de tales objetos». 
ción del régimen de separación». El resultado de esta novedosa valoración de las tareas del hogar es verdaderamente satisfactorio, puesto que no sólo se computa como contribución a las cargas matrimoniales; también como compensación a la extinción del citado régimen de separación.

A mi entender parece que el legislador quiso "premiar» tantos años de dedicación de la mujer a la ardua tarea del hogar, resultando doblemente considerado este trabajo. En cualquier caso, si bien actualmente, cualquiera de los cónyuges, en virtud de la planificación del hogar conyugal, puede elegir su dedicación a la organización del hogar familiar, no resultaría oportuno ni correcto presumir que se haya intentado que el varón, en el supuesto de encargarse de esta función, pudiese resultar en una situación discriminatoria, similar a la que en épocas pasadas aconteció con la mujer.

Siguiendo esta tendencia, la novedosa Ley 15/2005, de 8 de julio, sobre divorcio rápido y custodia compartida, introduce unos ligeros retoques en el artículo 97 del Código civil que posibilita que, cualquiera de los cónyuges que con ocasión de la separación o divorcio sufra un desequilibrio económico en relación a su consorte, tenga derecho a una compensación económica. Entre las circunstancias enumeradas en el mencionado precepto, introduce una nueva, referida a cualquier otra circunstancia relevante, lo que a mi entender puede interpretarse como un logro para la mujer en determinadas circunstancias que superen a las enunciadas en los números tercero y cuarto ${ }^{25}$.

En otro orden de cosas, por constituir un logro considerable en la evolución de la posición jurídica de la mujer en el ámbito del Derecho de familia, debe hacerse constar el avance que supuso la Ley 35/1988, de 22 de noviembre, sobre técnicas de reproducción asistida ${ }^{26}$, posibilitando su acceso como usuaria de las técnicas establecidas en la Ley con independencia de su estado civil ${ }^{27}$.

Para concluir con esta exposición que no ha tenido otra pretensión que recordar o exponer, de manera somera, la evolución de la posición jurídica de

25. Artículo. 97 del Código civil: «el cónyuge al que la separación o el divorcio produzca un desequilibrio económico en relación con la posición del otro, que implique un empeoramiento en su situación anterior en el matrimonio, tendrá derecho a una compensación que podrá consistir en una pensión temporal o por tiempo indefinido, o en una prestación única, según se determine en el convenio regulador o en la sentencia.

A falta de acuerdo de los cónyuges, el Juez, en sentencia, determinará su importe teniendo en cuenta las siguientes circunstancias:

$n^{\circ} 3$ La cualificación profesional y las probabilidades de acceso a un empleo.

$\mathrm{n}^{\circ} 4$ La dedicación pasada y futura a la familia.

$n^{\circ} 9$ Cualquier otra circunstancia relevante.»

26. Esta Ley ha sido recientemente modificada por la Ley 14/2006, de técnicas de reproducción asistida (BOE, de 27 de mayo de 2006). En cualquier caso, respecto a la temática que nos ocupa no se ha producido ningún cambio en este sentido, salvo la inclusión expresa de que para ser receptora resulta independiente el estado civil y la orientación sexual de la mujer.

27. El artículo 6 de la Ley sobre técnicas de reproducción asistida dispone en su número 1 que «toda mujer podrá ser receptora o usuaria de las técnicas reguladas en la presente Ley, siempre que haya prestado su consentimiento a la utilización de aquellas de manera libre, consciente, expresa y por escrito. Deberá tener dieciocho años al menos y plena capacidad de obrar». Si la mujer está casada, el n 3 impone el consentimiento de su marido: «Si estuviere casada, se precisará 
la mujer en el ámbito del Derecho de Familia, señalaré que salvo pequeños retoques, introducidos por la Ley 11/1990, de 15 de octubre, sobre reforma del Código civil en aplicación del principio de no discriminación por razón de sexo, con objeto de borrar discriminaciones terminológicas, es a partir de este momento -1981- cuando desaparece cualquier tipo de discriminación en la posición jurídica de la mujer en el ámbito reseñado. Haciendo constar, en cualquier caso, que tanto socialmente como en otros ámbitos legales, todavía falta la real consolidación de esa igualdad o, en sentido más correcto, equiparación ${ }^{28}$. Si bien la novedosa Ley de divorcio rápido y custodia compartida- a la que hemos hecho referencia en líneas precedentes-introduce en el artículo 68 del Código civil ${ }^{29}$, junto a la obligación de los cónyuges de vivir juntos, guardarse fidelidad y socorrerse mutuamente, la responsabilidad de ambos consortes en el ámbito doméstico y en el cuidado y atención de descendientes, ascendientes y otras personas dependientes a su cargo, la realidad nos muestra que todavía queda camino por recorrer para su asunción en el ámbito social. La misma afirmación, creo sinceramente, debe hacerse respecto a la guarda y custodia de los hijos menores de edad en los supuestos de separación o divorcio de sus progenitores ${ }^{30}$.

además el consentimiento del marido, con las características expresadas en el apartado anterior, a menos que estuvieren separados por sentencia firme de divorcio o separación, o de hecho o por mutuo acuerdo que conste fehacientemente».

28. Respecto a los progresos que en esta sede se vienen realizando, señalaré que con fecha de 19 de mayo de 2006, el Consejo General del Poder Judicial ha emitido un informe sobre el Anteproyecto de Ley Orgánica de igualdad entre mujeres y hombres. En el referido se pone de manifiesto, entre otras cuestiones, que efectivamente «la lucha por la igualdad está en la base de la construcción del Estado moderno........]Nuestra Constitución no se limitó a recoger el principio de igualdad formal (artículo. 14), propio de esa tradición constitucionalista, ni le bastó configurarlo como derecho fundamental especialmente tutelable (artículo. 53.2). Dio un paso más con el artículo 9.2. Este precepto, tomado del artículo 3.2 de la Constitución italiana, confiere un dinamismo especial al fijar, en lo que aquí interesa, el argumento de los Poderes Públicos en nuestro Estado Social y democrático de Derecho: promoción de la igualdad, remoción de los obstáculos que esa igualdad sea real y efectiva». Puede consultarse el informe al que hacemos referencia en Iustel.com de 22 de mayo de 2006.

Resulta, también, significativo en este ámbito de la consolidación a que hacíamos referencia la reciente legislación autónoma sobre mediación familiar. En este sentido, por hacer referencia, en el momento de redactar estas líneas, a la última normativa en esta temática, la Ley 1/2006, de 6 de abril, de mediación familiar de Castilla y León, (BOE de 3 de mayo), en su Exposición de Motivos pone de manifiesto que "El Estatuto de Autonomía de Castilla y León establece en su artículo 8.2 que corresponde a los poderes públicos de la Comunidad promover las condiciones para que la libertad y la igualdad del individuo y de los grupos en que se integra sean reales y efectivas, remover los obstáculos que impidan o dificulten su plenitud».

29. Artículo 68 del Código civil: «los cónyuges están obligados a vivir juntos, guardarse fidelidad y socorrerse mutuamente. Deberán, además, compartir las responsabilidades domésticas y el cuidado y atención de ascendientes y descendientes y otras personas dependientes a su cargo».

30. Resulta un dato constatable que aquellas mujeres que consienten, en los supuestos de separación o divorcio, que la custodia sobre sus hijos menores la ostente el otro progenitor, son censuradas familiar y socialmente. 
En este ámbito, por lo que respecta a nuestra Comunidad Autónoma, la reciente Ley Orgánica $1 / 2006$, de 10 de abril ${ }^{31}$ de reforma de la Ley Orgánica 5/1982, de 1 de julio, de Estatuto de Autonomía de la Comunidad Valenciana, entre otros preceptos importantes que modifica, hace una nueva redacción del artículo 11 en los siguientes términos: "La Generalitat, conforme a la Carta de los Derechos Sociales, velará en todo caso para que las mujeres y los hombres puedan participar plenamente en la vida laboral, social, familiar y política sin discriminaciones de ningún tipo y garantizarán que lo hagan en igualdad de condiciones. A estos efectos se garantizará la compatibilidad de la vida familiar y laboral». 



\title{
CONCILIACIÓN DE LA VIDA FAMILIAR Y LABORAL ${ }^{1}$
}

\author{
SOL RUIZ DE LA CUESTA FERNÁNDEZ \\ IRENE BAJO GARCÍA \\ Universidad de Alicante
}

\section{PRESENTACIÓN}

A la hora de abordar una materia como ésta, en el contexto de un Curso organizado por y para juristas, era dudoso qué enfoque resultaría el más adecuado, pues, como se ha dicho, la naturaleza principalmente jurídica de este encuentro invitaba a optar por un tratamiento puramente jurídico de la conciliación entre la vida familiar y laboral. Sin embargo, una perspectiva jurídica pura del tema resulta excesivamente descriptiva y mucho menos apasionada que la que se desprende de la combinación de factores jurídicos y sociales. Por ello, hemos decidido abordar la materia desde la dimensión sociolaboral del trabajo de la mujer, considerando "trabajo» tan sólo a aquel que se realiza por cuenta ajena, es decir, según los parámetros previstos por el Estatuto de los Trabajadores $^{2}$ (ET, en adelante), sin atender, por lo tanto, a las particularidades derivadas de una prestación de servicios en régimen autónomo.

1. El presente estudio, articulado y revisado conjuntamente, corresponde por lo que se refiere a su elaboración escrita a la Profesora Sol Ruiz de la Cuesta los epígrafes 1, 3 y 4, y a la Profesora Irene Bajo los epígrafes 2 y 5. Queremos también dejar constancia de que la conciliación entre la vida familiar y laboral está pendiente de sufrir un -se espera que importante-cambio a nivel legislativo, pues en estos momentos existen dos proyectos de ley de obligada referencia. Por un lado, el de Promoción de la Autonomía Personal y Atención a las Personas en situación de Dependencia, que superó su primer trámite en el Congreso el pasado 23 de junio de 2006, con los votos favorables de PSOE, ERC e IU-ICV. Por otro lado, el Consejo de Ministros aprobó el 26 de junio de 2006 la remisión a las Cortes Generales del Proyecto de Ley Orgánica de Igualdad entre Hombres y Mujeres.

2. Real Decreto Legislativo 1/1995, de 24 de marzo, por el que se aprueba el Texto Refundido de la Ley del Estatuto de los Trabajadores (BOE de 29 de marzo). El artículo $1.1 \mathrm{ET}$, al delimitar el ámbito de aplicación de la Ley, establece los presupuestos sustantivos del contrato de trabajo, a saber: voluntariedad, dependencia, ajenidad y retribución, cuando indica que "La presente Ley será de aplicación a los trabajadores que voluntariamente presten sus servicios retribuidos por cuenta ajena y dentro del ámbito de organización y dirección de otra persona, física o jurídica, denominada empleador o empresario». 
Con la exposición que ahora iniciamos se persiguen diversos objetivos. En primer lugar, el de dejar constancia, siquiera brevemente, de cuál ha sido el proceso de incorporación de la mujer al mundo del trabajo, en función de qué factores y bajo qué concretas condiciones. A continuación, se analizarán las medidas con las que el ordenamiento jurídico laboral pretende garantizar la conciliación entre familia y trabajo. Seguidamente, se valorará la eficacia real de estas medidas, intentando identificar las razones por las que, en su caso, puedan resultar insuficientes o inoperantes a la hora de conseguir el objetivo que persiguen. Finalmente, se intentarán identificar los retos y los cambios a los que debe hacerse frente si se quiere hablar en el futuro de una plena conciliación entre vida familiar y vida laboral.

\section{LA PROGRESIVA INCORPORACIÓN DE LA MUJER AL TRABAJO}

Comenzando por el proceso de incorporación de la mujer al mundo del trabajo éste se inicia en nuestro país recientemente, aunque debe señalarse que con una progresión notable. En un estadio previo la sociedad española se muestra como una sociedad eminentemente patriarcal, caracterizada por una división sexual del trabajo y por contemplar roles claramente diferenciados para hombre y mujer. En esta sociedad las mujeres quedan relegadas al ámbito de lo doméstico y privado, en tanto el hombre ocupa el rol de proveedor, inserto en el ámbito de lo público. Es evidente que, en este contexto, resulta innecesario totalmente plantear siquiera una política de conciliación de la vida familiar y laboral.

Este modelo ha funcionado durante un largo período de tiempo, y no es hasta prácticamente las dos últimas décadas cuando la mujer comienza a introducirse de una manera paulatina pero constante e irreversible en el mercado de trabajo. Los factores que han contribuido a dicha incorporación son múltiples. Así, la prosperidad económica que ha caracterizado la evolución de nuestro país en las últimas décadas multiplica la necesidad de mano de obra de las empresas $y$, al mismo tiempo, permite a las familias una ampliación del número de sus miembros que acceden a una formación académica. Junto a ello ha de situarse la aprobación de la Ley del divorcio, que amplía la capacidad de decisión de la mujer y genera para ésta una necesidad de estabilidad económica que el matrimonio ya no garantiza ${ }^{3}$. Por otra parte, los ingresos en la familia que proporciona el trabajo de la mujer permiten elevar el nivel de vida y consumo de la misma, situación a la que ya no se renuncia. Así mismo, la propia llegada de la democracia propicia una lenta pero pacífica aceptación social de la autonomía económica y sentimental de la mujer. En ello ha influido definitivamente la propia actitud de la mujer, que ha mostrado su autonomía personal y su inquietud laboral a través de su incorporación al mercado de trabajo con independencia

3. La mayor igualdad real entre hombre y mujer genera nuevos modelos conyugales en los que el amor y no la necesidad determinan tanto la celebración como la conservación del matrimonio. 
del grado de necesidad de los ingresos con ello obtenidos para su sustento o el de su familia.

Propiciada por los factores descritos, la incorporación de la mujer al trabajo se produce de manera no traumática ni conflictiva, hecho que probablemente determine que la misma no haya venido acompañada de un paralelo cambio en el modelo social heredado y anteriormente descrito. En este sentido, tanto desde las iniciativas privadas como desde las públicas se ha enfatizado en la incorporación de la mujer a la vida laboral, quedando absolutamente postergada la imprescindible y paralela democratización de la vida doméstica, esto es, que los varones asuman la parte de responsabilidad que les corresponde en el reparto igualitario de tareas domésticas. La corresponsabilidad familiar y el nuevo papel que el hombre ha de desempeñar en el seno de la misma no ha sido asumida ni por los varones ni por la sociedad en general ${ }^{4}$. La inadaptación al nuevo modelo de relaciones familiares, en casos extremos, da lugar a graves conflictos en el seno de las familias, como es el caso de la violencia doméstica, los menores conflictivos, etc., cuyo estudio corresponde a la sociología.

A ello ha de sumarse la incidencia de políticas neoliberales, con la consecuente reducción del estado de bienestar y cuyo resultado es el llamado modelo familista, propio de los países mediterráneos (España, Grecia e Italia), en el que el Estado da por supuesto y pone énfasis en que los hogares asuman la obligación de garantizar el bienestar de sus miembros, que no depende del estado ni del trabajo y que se estructura en torno a la tradicional división de roles.

La suma de estos elementos ofrece como resultado una incorporación efectiva de la mujer al mundo laboral que no ha venido acompañada de una reducción de sus tareas familiares, consistente fundamentalmente en el cuidado de los hijos y otros familiares, junto a la gobernación del hogar familiar, asumiendo todas aquellas funciones familiares que no ejecuta el hombre y todas aquellas asistenciales que no proporciona el Estado (centros de atención de menores y niños, y de personas mayores, fundamentalmente).

Desde la perspectiva jurídico-laboral, la situación descrita desemboca en tres grandes problemas. En primer lugar, la mujer trabajadora se encuentra sometida a una doble jornada laboral, esto es, la que desarrolla en su trabajo por cuenta ajena, sumada a la que desarrolla en su casa, al cuidado de su familia. Con el desequilibrio añadido de que ese trabajo doméstico, que no es remunerado ni tiene atribuido un valor económico, está, sin embargo, subsidiando el crecimiento, pues es la mujer quien, al hacerse cargo de esas responsabilidades gratuitamente, permite que se genere riqueza que no es necesario invertir en el cuidado y atención de la familia. En segundo lugar, y consecuencia directa de la doble jornada de la mujer trabajadora, se produce una feminización del desempleo. En tercer lugar, se generan y perpetúan situaciones de discriminación en

4. Ciertamente, en la última década se ha percibido un aumento de la participación de los hombres en las tareas domésticas; sin embargo, ello no permite eliminar su carácter marginal y minoritario. 
el trabajo, tanto salarial como ocupacional, reflejada esta última en la dificultad para acceder a puestos de responsabilidad en las empresas.

Frente a la situación descrita, resulta positivo constatar la existencia de una conciencia social respecto a las dificultades del acceso a la vida laboral de la mujer, conciencia que, desde la perspectiva jurídico-laboral se traduce en iniciativas legislativas destinadas a promover condiciones de igualdad. Su análisis es objeto del siguiente apartado.

\section{MARCO LEGISLATIVO}

No existe en nuestro ordenamiento jurídico una legislación integral en torno a la conciliación de la vida familiar y laboral, sino que el contenido que integra ésta se encuentra regulado en diversas normas. Sin duda, la Ley 39/99 de conciliación de la vida laboral y familiar constituye el texto que más directa y exclusivamente afronta la materia. No obstante, junto a esta norma deben citarse otras, como es la Constitución, el Estatuto de los Trabajadores o la Ley de Prevención de Riesgos Laborales ${ }^{6}$.

Dada la estrecha vinculación de la conciliación de vida laboral y familiar con la igualdad de oportunidades y la protección de la familia, son varios los preceptos constitucionales cuyo contenido regulador afecta a aquella materia. Así, el art. 9.2 CE dirige un mandato a los poderes públicos para la promoción de condiciones efectivas de igualdad. La protección social, jurídica y económica de la familia se consagra en el art. $39.1 \mathrm{CE}$, precepto cuyo contenido debe compatibilizarse con el derecho al trabajo, a una promoción en el mismo y a una remuneración suficiente sin discriminación (entre otras) por razones de sexo, contemplado en el art. 35.1 CE. Con una vinculación de carácter indirecto, también cabe citar la obligación de los poderes públicos del mantenimiento de un régimen público de seguridad social, especialmente en lo relativo a la protección por desempleo (art. $41 \mathrm{CE}$ ).

El ET reitera el mandato constitucional de no discriminación en las relaciones laborales, entre otras causas, por razones de sexo. Junto a esta genérica proclamación del derecho a la igualdad, son varias las previsiones que pueden contemplarse en la norma estatutaria dirigidas a la conciliación de la vida laboral y familiar? ${ }^{7}$. El conjunto de previsiones abarca al permiso por lactancia de hijo menos de nueve meses, de una hora de duración (o reducción de la jornada en media hora) (art. 37.4 ET); el permiso por hospitalización de hijo prematuro,

5. Vid., en el mismo sentido, ARGÜElles Blanco, Ana Rosa: «La igualdad de oportunidades mediante la conciliación de la vida laboral y familiar», en AAVV: Igualdad de oportunidades y responsabilidades familiares", Madrid, CES, 2004, p. 21.

6. No es éste el marco apropiado para realizar un análisis exhaustivo del marco legislativo en materia de conciliación. Al respecto, se remite a GIL SUÁREZ, Luis: «La conciliación de la vida familiar y laboral de las personas trabajadoras. Puntos críticos», en AAVV: Nueva sociedad y derecho del trabajo, Madrid, Ministerio de Trabajo y Asuntos Sociales/La Ley, 2004, pp. 553 y ss.

7. Para un análisis minucioso de cada una de las previsiones estatutarias al respecto, consultar la obra colectiva Igualdad de oportunidades y responsabilidades familiares, Madrid, CES, 2004. 
de duración idéntica al anterior pero sujeto a reducción de salario (art. 37.4 bis); la reducción de jornada entre $1 / 3$ y $1 / 2$, con equivalente reducción de salario, por guarda legal de un menor de seis años; el derecho a la movilidad geográfica en base a la reagrupación familiar (art. 40.3 ET) ${ }^{8}$; la suspensión del contrato de trabajo por maternidad, riesgo durante el embarazo o adopción (art. 45.1.d); la excedencia para el cuidado hijos menores de tres años, que conlleva reserva del puesto de trabajo durante el primer año y, los siguientes, un derecho preferente al reingreso (art. $46.3 \mathrm{ET}$ ); la licencia por maternidad de 16 semanas, a distribuir según voluntad de la madre, que puede optar por ceder parte del permiso al padre, a excepción de las seis semanas posteriores al parto (art. 48.4 ET); la suspensión del contrato de trabajo por riesgo durante el embarazo (art. $48.5 \mathrm{ET}$ ), y la declaración de nulidad del despido cuando el mismo se produzca durante y con causa en el embarazo o durante la suspensión del contrato de trabajo por alguna de las causas expuestas y relacionadas con la maternidad?.

Contribuye al acervo normativo en la materia la Ley de Prevención de Riesgos Laborales, cuando en su art. 26 impone al empresario la obligación de llevar a cabo una evaluación específica de los riesgos que puedan afectar a la mujer embarazada o puérpera, y, junto a ello, la obligación de adaptar las condiciones y jornada de trabajo a esta circunstancia, o bien al traslado a la mujer a un puesto de trabajo compatible con su estado.

Por su parte, la Ley 39/99 de conciliación de la vida laboral y familiar, ha cumplido la importante tarea de hacer aflorar la problemática que dicha conciliación plantea e incorporarla al debate social. Sin embargo, su contenido regulador ha sido absorbido por los textos anteriormente enumerados, cuando, probablemente, el legislador debía haber convertido dicha Ley en la norma de referencia en materia de conciliación ${ }^{10}$.

En cualquier caso, resulta fundamental conocer que la totalidad de las medidas previstas en los preceptos legales enumerados tienen atribuido por el ordenamiento jurídico el carácter de mínimos, esto es, regulaciones que pueden ser mejoradas tanto a través de los convenios colectivos como de los contratos

8. Rabanal Carbajo menciona ésta como ejemplo de medida de conciliación escasamente explorada. (RABANAl CARBAjo, Pedro: «Familia y trabajo. Algunas reflexiones sobre el ordenamiento laboral y la conciliación de la vida laboral y familiar», en AAVV: Nueva sociedad y derecho del trabajo, op.cit., p. 57.)

9. Es escasa la aportación jurisprudencial respecto al análisis de los aspectos conflictivos que pueda plantear esta regulación. Sea como fuere, para una relación y análisis de las principales cuestiones polémicas planteadas y resueltas a nivel jurisprudencial, vid. AGUILERA IZOUIERDO, Raquel; CRISTÓbal Roncero, Rosario y GaRcía PiñeIRO, Nuria: "La conciliación de la vida familiar y laboral: cuestiones polémicas en la reciente doctrina jurisprudencial», en AAVV.: Nueva sociedad y derecho del trabajo, op. cit., pp. 583 y ss.

10. Como indica el profesor De La Villa, al constituirse en una ley de reforma de otras anteriores ha renunciado a un planteamiento de conjunto sobre el fenómeno de la conciliación. Sin embargo, no existe en el derecho español una filosofía de la conciliación de la vida familiar y laboral. DE LA VILla GIL, Luis Enrique: «El marco normativo jurídico laboral vigente sobre conciliación trabajo/familia. Presente y futuro", en AAVV: La conciliación entre el trabajo y la familia, op. cit., p. 70 . 
de trabajo. Posibilidad que, como se verá más adelante, no ha sido convenientemente aprovechada por los agentes sociales.

\section{LA EFICACIA DE LAS MEDIDAS DESTINADAS A LA CONCILIACIÓN DE LA VIDA FAMILIAR Y LABORAL}

Acaban de exponerse las diferentes medidas que el ordenamiento jurídico laboral arbitra con el objetivo de conciliar la vida familiar y laboral. Cabe preguntarse, sin embargo, hasta qué punto son realmente eficaces y cuáles son, en su caso, los obstáculos con los se encuentra la aplicación práctica de las mismas.

Los datos con los que se cuenta en este momento ${ }^{11}$ arrojan cifras que, a priori, hacen pensar que la batería de medidas descrita no alcanza el objetivo que persigue. Si, como se desprende de las cifras, las mujeres con hijos menores de 15 años trabajan en menor número que las que no los tienen o las que los tienen de más edad, no es difícil concluir que a la mujer española no le resulta sencillo conciliar familia y trabajo. Por otro lado, se constata que los permisos de maternidad los solicitan y disfrutan, en un $98 ' 46 \%$, las mujeres, frente al escasísimo 1'54\% de hombres que lo hacen, con una evolución del disfrute por parte de los padres de tan sólo el 0'17\% en los últimos cuatro años ${ }^{12}$. Del mismo modo, las excedencias por cuidado de hijos/as las solicitan mayoritariamente las madres (96'38\%, frente a un 3'98\% de padres) y en los últimos cuatro años sólo ha aumentado en un $0^{\prime} 76 \%$ el número de padres que las disfrutan.

Desde luego, la propia configuración de las medidas explica por sí misma alguno de los datos transcritos. El hecho de que su disfrute, las más de las veces, implique reducción o pérdida de salario en un momento en el que, precisamente, aumenta el nivel de gastos por la llegada del hijo, hace poco atractivas algunas de las medidas previstas, fundamentalmente las reducciones de jornada y las excedencias ${ }^{13}$. Por otro lado, la inexistencia de permisos dirigidos únicamente a los padres hace que el disfrute acabe recayendo, de forma mayoritaria, en la madre. La situación en la empresa de la mujer trabajadora tampoco facilita la combinación de familia y trabajo. El 29\% de las mujeres trabajadoras de entre

11. Los últimos datos, en las estadísticas que presenta regularmente el Instituto de la Mujer y que pueden consultarse en http://www.mtas.es/mujer/mujeres/cifras/index.htm

12. Pueden consultarse las Estadísticas e Informes que publica el Instituto Nacional de Seguridad Social en http://www.seg-social.es

13. RABANAL CARBAjo, Pedro, escribe que «No se trata de trabajar menos si ello conlleva reducción salarial, pues tal circunstancia conduce necesariamente a variar el estatus socioeconómico familiar. En efecto (...) una norma que permite trabajar menos, pero que conlleva cobrar menos, modifica la situación socioeconómica y por tanto no atiende al fin propuesto, sino que lo altera, pues altera los presupuestos sobre los que se conforma» (Vid. «Familia y trabajo...», op. cit., pág. 56). Lo expresa muy nítidamente De LA VILLA GIL, Luis Enrique: "Usted lo que puede hacer es cambiar su jornada completa por una jornada a tiempo parcial, en el bien entendido que yo le voy a pagar sólo la jornada a tiempo parcial, no la jornada a tiempo completo que usted realizaba antes. Evidentemente, usted tendrá más tiempo para la familia, pero se lo paga usted. (...) Evidentemente, ahí es el propio trabajador el que se está pagando ese esfuerzo de conciliación entre vida laboral y familiar» (Vid. "El marco normativo...", op. cit., p. 73). 
30 y 39 años -franja de edad en la que se vienen teniendo los hijos ${ }^{14}$ - están ligadas a la empresa con contratos temporales ${ }^{15}$, lo que supone, sin duda, un freno a la hora de hacer valer sus derechos ante el empresario. Las que están contratadas indefinidamente se arriesgan a la segura frenada de su carrera profesional ${ }^{16}$, frente a la promoción sin obstáculos del trabajador varón o de la trabajadora sin responsabilidades familiares ${ }^{17}$.

El contexto sociolaboral español tampoco juega a favor de la conciliación entre trabajo y familia. La jornada partida está implantada en muchos sectores de producción, lo que significa un ritmo de trabajo de lunes a viernes, con entre ocho y nueve horas de trabajo diario y una larga pausa para comer, horario totalmente incompatible con las necesidades familiares ${ }^{18}$, máxime si se tiene en cuenta la escasez de centros de atención y cuidado de niños y adultos dependientes. Por otro lado, parece que en España existe todavía la cultura -desterrada ya en países europeos y en EEUU- de la prolongación voluntaria de la jornada, con la conciencia de que salir del trabajo a la hora que correspondería es sinónimo de falta de motivación y, por el contrario, trabajar más horas de las pactadas lo es de dedicación a la empresa, lo que parece premiarse con ascensos y rápida promoción en determinados sectores ${ }^{19}$. Sin embargo, somos el país europeo con menor productividad.

14. Pueden consultarse los datos que presenta GómEz López-EGEA, Sandalio, en su ponencia «La incorporación de la mujer al mercado laboral: implicaciones personales, familiares y profesionales y medidas estructurales de conciliación", en AAVV: La conciliación entre el trabajo y la familia..., op. cit., pp. 110 y 111.

15. Consúltense las estadísticas al respecto disponibles en la web del Instituto de la Mujer (http:// www.mtas.es/mujer/mujeres/cifras/index.htm).

16. Polaino Lorente, Aquilino ofrece el dato de que el $47 \%$ de las mujeres españolas que trabajan consideran que ser madre afecta de forma negativa a su carrera profesional ("La conciliación trabajo/familia y sus implicaciones en la sociedad civil: transformaciones sociales y tendencias de futuro", en AAVV: La conciliación entre el trabajo y la familia.., op. cit., p. 87).

17. Escribe RABANAL CARBAJO, Pedro («Familia y trabajo...», cit., p. 60) que «la existencia de responsabilidades familiares constituye un elemento perjudicial para todo aquél que las asume, pues aunque en el sexo masculino no exista una ostensible discriminación para la contratación, el hombre que asume responsabilidades familiares deja de dedicar a la empresa el 100 por 100 de su tiempo de actividad, con la consecuencia ineluctable de su postergación en el derecho de promoción profesional».

18. Para García ECHeVArRía, Santiago, el del tiempo de trabajo «...es uno de los grandes temas de la economía empresarial actual. En lo que aquí nos concierne, aparte de ser uno de los problemas clave de la configuración de nuestra Sociedad, empuja a la empresa a buscar nuevas formas instrumentales de la organización que sean altamente innovadoras para que puedan devolver a las personas, como tales, una mayor autonomía en la disposición del tiempo.» (Vid. "Exigencias corporativas y estratégicas de la empresa en la conciliación de la vida laboral y familiar», en AAVV: La conciliación entre el trabajo y la familia.... op. cit., p. 50).

19. Vid. CHInChILla Albiol, Nuria, que, como contra-ejemplo, describe el siguiente: «Hace un año SONY quería promocionar a un buenísimo MBA del IESE. El tipo estaba haciéndolo genial, pero se marchaba cada día a las nueve y media de la noche a casa. Entonces le dijeron: "Te queremos promocionar, pero si tú no cambias de actitud y no te marchas antes de las ocho, no podemos promocionarte, porque el mensaje que vamos a dar es que aquí sólo se promociona a la gente que no tiene tiempo para nada más; y eso no nos interesa, así que, por favor, hazlo bien». Le 
Que éste sea el contexto en el que se desarrolla, mayoritariamente, el trabajo por cuenta ajena en nuestro país produce, de forma inevitable, una serie de consecuencias. En primer lugar, para la propia familia. A los trabajadores madres y padres, el desfase entre el horario laboral y el demandado por las necesidades familiares les ocasiona problemas en el trabajo y en el seno familiar, derivados de la falta de tiempo y de la mala calidad del tiempo destinado a atender a la familia, lo que genera estrés, mala calidad de vida y problemas conyugales. Consecuencias también para los hijos, pues se pone de manifiesto cada vez más la ausencia de modelos familiares que reviertan positivamente en la educación de los niños ${ }^{20}$. Y para las empresas, aunque no acaben de interiorizarlo como costo de producción ${ }^{21}$, ya que el estrés que supone para los trabajadores la precaria atención dispensada a la familia, junto con los eventuales retrasos y ausencias derivados del cuidado de los hijos ${ }^{22}$, supone indudablemente un menor rendimiento de los trabajadores ${ }^{23}$. El conjunto de la sociedad también padece las consecuencias derivadas de la dificultad de conciliar empleo y familia. Tenemos uno de los índices más bajos de natalidad mundial, y uno de los más elevados de esperanza de vida ${ }^{24}$ : el envejecimiento de la población activa y su

dejaron tres meses, y cuando hubo cambiado de hábito, le promocionaron» ("Empresa, familia y sociedad, un triángulo en constante evolución", en AAVV: La conciliación entre el trabajo y la familia..., op. cit., p. 129).

20. «Ocho de cada diez mujeres españolas que trabajan están muy contentas con su trabajo, pero la mitad de ellas sostiene que eso influye negativamente en la educación de sus hijos y en las personas que tienen a su cargo.» (Vid. POLAINO LORENTE, Aquilino: Op.cit., p. 87). Datos porcentuales ofrece GÓmeZ LóPEZ-EGEA, Sandalio (Op.cit., p. 115): el 15\% de las mujeres trabajadoras españolas considera que comparte muy poco tiempo con sus hijos; el $46 \%$ cree que es poco tiempo; entiende que comparte un tiempo suficiente el $37 \%$; frente a un $2 \%$ que NS/NC.

21. Más optimista es Polaino Lorente, Aquilino, cuando escribe que «En el ámbito de las empresas se ha despertado una nueva sensibilidad sobre estos problemas. El 90\% de los directores de recursos humanos está de acuerdo en que mejorar la conciliación entre familia y trabajo mejora el rendimiento de los empleados» (Op.cit., p. 85).

22. Los retrasos de la mujer, por motivos familiares, en la hora de entrar al trabajo son del $27 \%$ y en los hombres del $22 \%$. Las salidas anticipadas, por motivos familiares, llegan en las mujeres al $33 \%$ y en los hombres al 22\%, según expone POLAINO LORENTE, Aquilino: Op.cit., p. 87.

23. "Aquellas empresas, y hay mucho ejemplos, que tengan éxito en la innovación del manejo del factor tiempo, vía organización y desarrollo de los recursos humanos, en la integración de los potenciales de mujeres y hombres en el contexto de su actividad, tendrán, sin duda, grandes ventajas competitivas y contribuirán a su propia existencia empresarial»: GARCÍA ECHEVARRÍA, Sandalio: Op.cit., p. 50. El mismo autor escribe que los trabajos en redes, frente a las estructuras jerárquicas y matriciales, «son las únicas formas organizativas que generan los espacios flexibles y los tiempos abiertos para que pueda diseñarse la realización de aportaciones, resultados dentro de equipos de altas prestaciones, que se responsabilizan, tanto por la vía de la organización de proyectos como de procesos. Ésta es, sin duda, la clave del diseño organizativo inmediato que puede acometer la ruptura organizativa tradicional» (ibídem, p. 63).

24. «El incremento vegetativo que experimentó nuestro país hasta hace tres años era deplorable. Se entiende por crecimiento vegetativo el resultado que se obtiene de restar a la suma total de defunciones el número de los nacidos cada año. En el año 1998 el crecimiento vegetativo de nuestro país fue de 4.005; en 1999 de 7.300; y en el año 2000 se elevó a 36.300. Sin embargo, de todos los nacidos, sólo el 3'8\% procedían de padre y madre españolas». Por ello sigue escri- 
escasez son problemas que nos afectan a todos, por su incidencia en el sistema de Seguridad Social ${ }^{25}$.

\section{CONCLUSIONES Y PROPUESTAS}

De lo dicho hasta ahora queda constancia de las siguientes realidades:

1) En las últimas décadas se ha producido una progresiva y pacífica incorporación de la mujer al mundo laboral.

2) Esta incorporación, sin embargo, no ha ido acompañada de una simultánea incorporación del hombre a las tareas domésticas ni de una reacción firme del Estado que facilite de hecho tal incorporación.

3) Las medidas jurídicas que se arbitran en el ámbito de la conciliación trabajo/ familia no son eficaces, ya que, por una parte, restan poder adquisitivo en un momento en el que aumentan los gastos; $y$, por otra parte, porque la empresa se encuentra, con carácter mayoritario, anclada en viejas estructuras y sistemas productivos y de distribución del tiempo de trabajo.

Ante la situación descrita, se hace patente la necesidad de un cambio, tanto legislativo como socio-cultural, que deberá observarse en la totalidad de los agentes implicados, esto es, en primer lugar el legislador, pero junto a él también los agentes sociales (asociaciones de empresarios y sindicatos de trabajadores), la empresa como organización productiva, los varones, las propias mujeres y la sociedad en su conjunto.

Por lo que se refiere al legislador, debe mostrarse más ambicioso en sus objetivos, no limitándose a crear medidas estancas, sino abordando el problema de manera integral, tal y como se ha hecho con la violencia de género. En este sentido debe hacerse especial mención a las normas comunitarias. Así, la Directiva 2002/73/CE contiene el mandato a los Estados Miembros de aplicar el principio de transversalidad en el momento de elaborar las leyes y aplicar las políticas y las actividades de cualquier índole que puedan tener trascendencia sobre la conciliación de la vida laboral y familiar. También constituye responsabilidad del Estado (entendido en sentido amplio, incluyendo a las Comunidades Autónomas que hayan asumido competencias en la materia) la creación de centros de atención y cuidado de mayores y, especialmente, de niños menores de 3 años, aspecto en el que nos encontramos a la cola de Europa y que los textos europeos consideran como instrumento fundamental para la incorporación en condiciones de igualdad de la mujer al trabajo.

Junto a las anteriores, otras medidas que fomentarían la igualdad y, con ello, la conciliación de la vida laboral y familiar, consistirían en premiar o ayudar a través de incentivos fiscales o bonificaciones en la cotización a la Seguridad

biendo POLAINO LORENTE que en el año 2003 se produjo también un incremento significativo del 1'5\% de la población (41.110.000 de españoles), y que ello se explica desde la misma óptica: por la llegada de los inmigrantes y su tasa de natalidad (Op.cit., pp. 94-95).

25. Vid. Rabanal Carbajo, Pedro: "Familia y trabajo...», Op.cit., p. 58. Igualmente, en relación a la crisis del estado del bienestar, centrando el análisis en el contexto de la familia como elemento integrador de aquél, Vid. GARCÍA ECHEVARRÍA, Sandalio: Op.cit., pp. 37-41. 
Social a las empresas que demuestren ser familiarmente responsables, categoría que merecería un reconocimiento público por parte de las autoridades; incentivar la gestión de recursos humanos en las empresas, tanto a través de servicios internos como externos subvencionados; $y$, de manera complementaria a las medidas anteriores, sancionar de forma suficiente los incumplimientos por parte de las empresas en esta materia.

Por otra parte, la Directiva anteriormente mencionada exige también que los Estados Miembros fomenten la participación de los interlocutores sociales en la elaboración y aplicación de medidas al respecto. Este segundo mandato hace obligado preguntarse cómo afronta actualmente la negociación colectiva esta materia.

Pues bien, por lo que se refiere al tratamiento que recibe la materia de conciliación trabajo/familia en los convenios colectivos, la Dirección General de la Mujer de la Comunidad de Madrid ha publicado un riguroso estudio de 100 convenios colectivos, del que se extraen las siguientes conclusiones ${ }^{26}:$ a) los convenios colectivos aplicables institucionalizan el trato desigual, asignando las medidas conciliadoras sólo a las mujeres; b) el lenguaje empleado en las cláusulas relativas a la conciliación confirma esta institucionalización. Es muy frecuente el empleo de términos como «maternidad» y expresiones como «mujer trabajadora» frente a las de «conciliación de la vida familiar y laboral» o "maternidad /paternidad ${ }^{27}$; c) se pone de manifiesto en determinados complementos saláriales una minusvaloración del trabajo realizado por la mujer, por el sólo hecho de serlo; d) prácticamente son inexistentes los complementos que tienden a lograr el $100 \%$ del salario en las situaciones de baja por riesgo durante el embarazo.

Los resultados de este análisis ponen de manifiesto una clara falta de asunción por parte de empresarios y sindicatos de su responsabilidad en esta materia, que queda prácticamente limitada a la demanda y exigencia de medidas a

26. Guía de Criterios y Cláusulas para la Negociación de los convenios, en materia de Conciliación de la Vida Familiar y Profesional, Madrid, Comunidad de Madrid, 2003.

27. Como indica Menéndez Sebastián «...es preciso que los interlocutores (...) formulen en general los derechos sin distinción por razón de sexo, evitando que la trabajadora reciba un trato más beneficioso o perjudicial cimentado únicamente en su condición femenina...» La autora propone, en este sentido, que el derecho a la ausencia por lactancia (art. 37.4 ET) se reconozca en los convenios como exclusivo de la madre sólo si la alimentación se va a producir de forma natural. De esta manera, el empresario no tiene porqué presumir que será la mujer quien disfrute de la reducción salvo en el supuesto señalado (la autora reseña un listado de convenios que así lo recogen, si bien reconociendo su carácter excepcional). Otro ejemplo de la infrautilización de la negociación colectiva como vía de igualdad puede apreciarse al observar que los convenios colectivos no corrigen la tendencia a presuponer que el derecho a permisos para preparación al parto son titularidad de la mujer, lo que resulta disuasorio para la contratación de éstas. (MENÉNDEZ SEBASTIÁN, Paz: "Principio de igualdad y configuración convencional de las reducciones de jornada y los permisos específicos para la conciliación de la vida familiar y laboral», en AAVV, Nueva sociedad $y$ derecho del trabajo, op.cit., pp. 632 y ss). 
la propia administración ${ }^{28}$. No obstante, se observan, paralelamente, cláusulas en convenios colectivos que sí pueden ser objeto de una valoración positiva. Así ocurre con aquellas que, en igualdad de condiciones de idoneidad, declaran la preferencia por las personas del género menos representado en el grupo profesional (vid., al respecto, Convenio Colectivo de la Industria Química y Convenio de las industrias transformadoras de plásticos de la COM. Aut. De Madrid).

Por otro lado, la empresa, no ya a través de sus representantes colectivos, sino como entidad individualmente considerada, es el lugar en el que las medidas previstas legal y convencionalmente deben ser aplicadas. Una aplicación eficaz de las mismas requiere una adecuada organización del trabajo. Al respecto, resulta extraordinariamente significativo el hecho de que nuestro país sea el menor índice de productividad de Europa. Cada empresario ha de asumir que un trabajador satisfecho con su vida personal porque dispone de un horario de trabajo que le permite atender cualitativa y cuantitativamente a su familia es un trabajador que incrementa su productividad, reduciendo errores y padeciendo un menor número de accidentes/incidentes; en definitiva, es más rentable. Un cambio en la política legislativa que no venga acompañado de otro en la cultura empresarial estará abocado al fracaso, ya que ningún trabajador hará uso de las medidas que el Estado pone a su disposición por temor a represalias que afecten a sus posibilidades de promoción o incluso de conservación de su empleo. En consecuencia, debe generalizarse la implantación de planes internos de conciliación de vida familiar y laboral -los llamados Programas de Trabajo/Familia-, a través, fundamentalmente, de la flexibilidad laboral. Los horarios estrictos y el control de horas presenciales deben ser sustituido por horarios flexibles, autocontrol y una evaluación del rendimiento basada en objetivos, no en horas de trabajo ${ }^{29}$. Las empresas también deben empezar por sí mismas a facilitar la vida familiar de sus trabajadores, desde la perspectiva de que, así, rendirán más ${ }^{30}$.

Aunque desde este estudio se insiste en que la conciliación de vida laboral y familiar no es un problema específico de las mujeres, lo cierto es que, de hecho, la incorporación de mujeres a órganos directivos de las empresas constituye importante baza a tener en cuenta, ya que una mujer directiva (o empresaria) tiende, hoy por hoy, a mostrar una mayor sensibilidad respecto de estos problemas.

28. Tras constatar esta realidad, De La Villa Gil propone la creación de fondos de cofinanciación de acciones a favor de la conciliación familiar-laboral sufragada por empresas y trabajadores por medio de la negociación colectiva, sin que ello desmerezca el hecho de que el gran coste de la conciliación deba grabar a los poderes públicos (DE LA VILLA GIL, Luis Enrique: «El marco normativo...", op.cit., pp. 79 y ss).

29. En este sentido, IBM España constituye un ejemplo a seguir de empresa con horarios flexibles y gestión por objetivos.

30. Airtel, por ejemplo, fue de las primeras empresas que ofrecieron en España la opción de una baja por maternidad más larga de la que la ley ofrece; también ofrece a los padres cinco días -en vez de los dos legales- para atender a un hijo recién nacido. 
No obstante, ni las medidas legislativas ni el cambio en la organización del trabajo en las empresas serán efectivos si no van acompañados de un cambio profundo en la mentalidad de los varones españoles, que deben incrementar su grado de implicación tanto en el cuidado de los hijos y/o familiares como en el cumplimiento de las tareas domésticas. Este cambio concreto en la mentalidad de los hombres presenta importantes dificultades para su promoción desde las medidas legislativas (aunque sí sería posible, por ejemplo, establecer como medida permisos de los que pudiera disfrutar sólo el padre) y constituye sin duda un pilar fundamental para la efectiva conciliación de la vida familiar y laboral

Ahora bien, en ocasiones, el obstáculo se encuentra en la propia concepción que determinadas mujeres tienen respecto del rol que deben asumir en la sociedad, en el trabajo y en su familia. En este sentido, no sólo la mujer de ámbito rural, escasamente formada, sino también -aunque parezca sorprendente- la mujer urbana, con formación académica y profesional, acepta e institucionaliza en su propia familia su doble rol de trabajadora y madre, asumiendo casi en exclusiva las tareas domésticas. El peligro no es sólo actual, sino también de futuro, dado que ello supone educar a los hijos de hoy-adultos de mañana- en la perpetuación de la división sexual del trabajo. Por este motivo son tan importantes los movimientos asociativos dirigidos a exponer, analizar y cambiar la situación laboral y familiar de la mujer, por la capacidad que los foros sociales tienen para llegar hasta el individuo.

Para finalizar, se debe hacer una llamada a toda la sociedad, en cuanto sociedad consumista. Cada uno de sus miembros tenemos no sólo la responsabilidad sino también el poder de premiar con nuestro consumo a aquellas empresas con certificado de EFR (Empresa Familiarmente Responsable) y, simultáneamente, retirar nuestro apoyo a las que no lo son y, especialmente, a las incumplidoras u obstaculizadoras. Esta es una forma de denuncia pública altamente eficaz.

Conseguir, en fin, que la vida familiar y laboral resulten compatibles es -aunque suene a tópico- una tarea de todos, no sólo del legislador. 


\title{
ALGUNOS ASPECTOS PROCESALES DE LA LEY ORGÁNICA DE MEDIDAS DE PROTECCIÓN INTEGRAL CONTRA LA VIOLENCIA DE GÉNERO ${ }^{1}$
}

\author{
CARMEN CUADRADO SALINAS \\ MERCEDES FERNÁNDEZ LÓPEZ \\ Universidad de Alicante
}

\section{INTRODUCCIÓN}

La Ley Orgánica 1/2004, de 28 de diciembre, de Medidas de Protección Integral contra la Violencia de Género (en adelante, Ley Integral) aborda por primera vez la problemática de la violencia y discriminación sexista desde todos los puntos de vista necesarios: educativo, sanitario, laboral, publicitario, penal y judicial, estableciendo una serie de medidas que van desde la prevención (como es la obligación de los centros docentes de educar a los menores en valores y en el respeto a la igualdad entre hombres y mujeres), pasando por medidas paliativas o asistenciales que minimicen los efectos de la violencia sexista hasta medidas de carácter penal y procesal a través de las cuales se realiza un endurecimiento de las penas a los maltratadores y se garantiza una mayor protección de la víctima. En efecto, aunque una primera lectura de la Ley Integral permitir concluir que es un texto mejorable en algunos de sus aspectos, lo cierto es que se trata de un instrumento esencial para la lucha contra la violencia de género.

Por lo que respecta a los aspectos procesales de la Ley Integral, destacan fundamentalmente dos medidas: en primer lugar, la creación de los Juzgados de Violencia sobre la Mujer (en adelante, JVM) y, en segundo lugar, el reforzamiento de la orden de protección, una herramienta básica para salvaguardar a

1. Este trabajo se ha realizado en el marco del proyecto de investigación «La reforma de la Justicia Penal», concedido por el Ministerio de Ciencia y Tecnología al Área de Derecho Procesal de la Universidad de Alicante. Se trata de una versión actualizada de la ponencia presentada en el curso "Mujeres y Derecho" el 19 de noviembre de 2004 en la Universidad de Alicante bajo el título "Aspectos procesales de la ley integral contra la violencia de género». Mercedes Fernández es responsable de la parte relativa a los Juzgados de Violencia sobre la Mujer (apartados 2 y 3) y Carmen Cuadrado Salinas de la parte relativa a la orden de protección (apartado 4). 
la víctima frente a nuevos actos de violencia de género. En este trabajo se analizan los aspectos más relevantes, tanto de los nuevos JVM como de la orden de protección, con el fin de dar una visión general de la actual situación procesal creada para luchar de una forma más eficaz contra la violencia de género.

\section{ENFOQUE CONSTITUCIONAL DE LOS JUZGADOS DE VIOLENCIA CONTRA LA MUJER}

La ley Integral, dentro de las medidas jurídicas de protección de la mujer contra la violencia de género, ha creado los Juzgados de Violencia contra la Mujer, juzgados de Instrucción especializados con competencia en materia penal y, en determinadas circunstancias, también civil, como luego veremos, cuya finalidad es dar una respuesta rápida, eficaz, coordinada e integral a la víctima de un acto de violencia de género.

Sin embargo, lejos de la unanimidad que cabría encontrar acerca de la conveniencia del tratamiento especializado de estos delitos, su puesta en marcha no ha estado exenta de duras críticas, formuladas fundamentalmente por la mayoría conservadora del CGPJ en el Informe al Anteproyecto de Ley Integral $y$ todas ellas dirigidas a poner en entredicho el encaje constitucional de los nuevos JVM²:

En primer lugar, el CGPJ señaló que los JVM constituyen una jurisdicción especial por razón del sexo de la víctima, quedando fuera, por tanto, del organigrama de los órganos jurisdiccionales que integran la Jurisdicción ordinaria. No obstante, no sólo los JVM no constituyen una Jurisdicción especial, sino que ni siquiera son órganos jurisdiccionales especiales. En efecto, se trata de órganos jurisdiccionales especializados pertenecientes al orden penal aunque con competencia para conocer de determinados asuntos civiles en presencia de ciertas circunstancias ${ }^{3}$, tal y como ocurre con otros muchos órganos jurisdiccionales acerca de los cuales nunca se han planteado problemas de legitimidad. Es el caso, por ejemplo, de los Juzgados de Menores y de los Juzgados de Vigilancia Penitenciaria en el orden penal o de los Juzgados de Familia y de lo Mercantil en el orden civil. En todos estos casos, se trata de órganos especializados por razón de la materia, creados con la finalidad de dar un tratamiento específico a unos determinados asuntos que requieren especiales conocimientos, ya sea por su complejidad, ya sea por el número de asuntos o por una decisión del Poder Ejecutivo basada en la prioridad que se pretende dar a un determinado tipo de casos.

En segundo lugar, el CGPJ señaló también que los JVM atentaban contra la apariencia de imparcialidad que debe presidir la actuación de todo órgano

2. Al respecto puede verse Asencio Mellado, J. Ma: «La competencia civil de los juzgados de violencia frente a la mujer», Práctica de Tribunales. Revista de Derecho Procesal Civil y Mercantil, 19 (2005), pp. 6-7. El citado informe del CGPJ está disponible en www.poderjudicial.es.

3. FUENTES SORIANO, O.: «Los nuevos juzgados contra la violencia sobre la mujer», en AA VV: La Administración de Justicia en la Ley Integral contra la violencia de género, Madrid, Ministerio de Justicia, 2005, p. 107. 
jurisdiccional, pues su única finalidad es la protección de la mujer. No obstante, lejos de ello, los JVM persiguen las mismas finalidades que cualquier Juzgado de Instrucción (investigación de delitos, enjuiciamiento de faltas, adopción de medidas cautelares, etc.), de modo tal que se encuentran vinculados por las garantías penales y procesales que asisten al imputado, sin que en ningún caso puedan adoptar medidas de protección de las víctimas de actos de violencia de género sin que se den los presupuestos para ello. En definitiva, su finalidad no es la protección de la mujer frente al hombre en cualquier circunstancia, sino -además de las antes señaladas-, la adopción de medidas de protección de las víctimas de violencia de género, competencia ésta que, en caso de no existir los JVM, deberían realizar igualmente los Juzgados de Instrucción.

En tercer y último lugar, el CGPJ se opuso a la creación de estos juzgados alegando que comprometen el derecho al juez legal predeterminado por la ley previsto en el art. $24.2 \mathrm{CE}$, pues se trata de órganos jurisdiccionales a medio camino entre el orden civil y el orden penal. Sin embargo, la Ley Integral es escrupulosa con este derecho, tal y como lo demuestra el hecho de que los JVM reúnen todos los requisitos que impone a los órganos jurisdiccionales el cumplimiento de este derecho:

a) Los órganos jurisdiccionales han de ser creados mediante Ley Orgánica, pero no mediante cualquier Ley Orgánica, sino por la LOPJ. La Ley Integral crea estos juzgados introduciendo el art. 87 bis en la LOPJ, por lo que ninguna duda plantea el cumplimiento de esta condición.

b) El régimen orgánico y procesal de los órganos jurisdiccionales ha de ser el ordinario. Este requisito también se observa, puesto que la Ley Integral no prevé especialidad alguna en este ámbito, de tal modo que los JVM están sometidos al régimen ordinario previsto en la LOPJ y en las demás normas procesales.

c) La competencia de los órganos jurisdiccionales ha de estar determinada por ley antes de la comisión del hecho y, además, ha de tener alcance general. Los JVM, en consonancia con ello, tienen su competencia perfectamente delimitada y, en todo caso, la Ley Integral no hace distinciones en cuanto al sujeto activo del delito: la finalidad de los JVM es la investigación de actos de violencia de género y de los demás hechos delictivos conexos cuya comisión tenga lugar con posterioridad a su creación ${ }^{4}$.

Además de cumplir estos requisitos, hay que tener en cuenta que el hecho de que los JVM asuman competencias para el conocimiento de asuntos civiles no los convierte en órganos jurisdiccionales especiales; antes al contrario, contamos con un precedente en este sentido, que son los Juzgados mixtos de Primera Instancia e Instrucción, cuya legitimidad constitucional no se pone en duda. Pero, además, no debe extrañar que los JVM conozcan de asuntos civiles, pues en nuestro sistema es tradicional que, salvo que se produzca una reserva de

4. En este sentido, Fuentes SORIAno, O.: «Los nuevos juzgados...», op. cit., pp. 107-108. De la misma autora, "La constitucionalidad de la Ley Orgánica de medidas de protección integral contra la violencia de género", La Ley, 6362 (18 de noviembre de 2005), apdo. VI (disponible en www.laley.es). 
acciones, el juez penal tenga que pronunciarse también sobre la responsabilidad civil derivada del delito ${ }^{5}$. Y lo mismo sucede con los Juzgados de lo Mercantil, que además de conocer de asuntos civiles, conocen también de causas laborales en situación de concurso, sin que por ello se haya cuestionado su carácter de órganos jurisdiccionales ordinarios 6 .

Salvados, como se ha visto, todos los pretendidos obstáculos a la creación de los JVM, lo cierto es que su encaje constitucional es indiscutible. Pero, además, no sólo se trata de órganos jurisdiccionales legítimos desde este punto de vista, sino que su creación es ciertamente oportuna si se tienen en cuenta los beneficios que reporta para la eficacia de la Administración de Justicia contar con órganos jurisdiccionales especializados y con competencias penales y civiles:

a) Su creación permite luchar contra la victimización secundaria, puesto que se evita que la víctima de actos de violencia de género tenga que declarar en distintas ocasiones ante distintos órganos jurisdiccionales.

b) Su creación supone también una optimización de recursos, pues los operadores jurídicos que van a intervenir en el proceso penal intervendrán también en el proceso civil cuando proceda la acumulación de los mismos según las reglas que luego veremos.

c) Precisamente, la intervención de los mismos operadores jurídicos en el proceso penal y en el proceso civil permite superar problemas de descoordinación que hasta su creación se venían produciendo cuando se planteaba una demanda matrimonial $y$, al mismo tiempo, se solicitaba al Juzgado de Instrucción la adopción de medidas de protección. Puesto que éste es uno de los momentos en los que existe un mayor riesgo de agresión, la necesidad de obtener una respuesta rápida y coordinada es también mayor.

\section{CONFIGURACIÓN LEGAL DE LOS JVM}

\subsection{La competencia objetiva y funcional}

Los JVM, que vienen funcionando desde el 29 de junio de 2005, fueron creados por el art. 43 de la Ley integral, que incorporó el art. 87 bis a la LOPJ, según el cual los JVM extienden su jurisdicción al partido judicial y tienen su sede en la capital del mismo (aunque excepcionalmente pueden tener competencia sobre varios partidos judiciales dentro de la misma provincia) ${ }^{7}$. Sus competencias son muy amplias y abarcan materias penales y civiles siempre que concurra un acto

5. Asencio Mellado, J. Ma: Op. cit., p. 7.

6. Para salvar la crítica a la especialidad que supone que los JVM conozcan simultáneamente de asuntos penales y civiles se propuso la posibilidad de crear un quinto orden jurisdiccional cuya misión fuera conocer de todos los asuntos relativos a la convivencia familiar, concurriera o no un acto de violencia de género. En este sentido, MOREno CATENA, V. (con Cortés Domínguez, V.): Derecho Procesal Penal, Valencia, Tirant lo Blanch, $2^{\text {a }}$ ed., 2005, p. 517.

7. Actualmente existen $18 \mathrm{JVM}$ con competencias exclusivas. El resto de los previstos en el Anexo XIII de la Ley Integral (421) son Juzgados de Instrucción que, además de conocer de los asuntos ordinarios, asumen también las competencias de los JVM. 
de violencia de género, tal y como dispone el nuevo art. 87 ter LOPJ, introducido por el art. 44 de la Ley Integral.

\subsubsection{Competencias penales}

En el ámbito penal, los JVM asumen la competencia para el conocimiento de tres materias:

1. Instrucción de delitos en dos supuestos delimitados objetiva y subjetivamente en atención a los delitos de los que se trate y a la víctima de los mismos. Han de darse, pues, dos condiciones de forma cumulativa: que se cometa alguno de los delitos enunciados en el art. 87.1 ter LOPJ y que la víctima sea una de las señalados en ese mismo precepto. De este modo, los JVM conocerán de la instrucción:

a) De los delitos de homicidio, aborto, lesiones, lesiones al feto o cualquier otro cometido con violencia o intimidación ${ }^{8}$ contra:

- Quien sea o haya sido esposa, cónyuge o mujer con quien el autor haya mantenido o mantenga análoga relación de afectividad, incluso sin convivencia?.

- Descendientes - propios o de la esposa o conviviente- o sobre menores o incapaces que convivan con el autor o estén sometidos a la potestad, tutela, curatela, acogimiento o guarda de hecho de la mujer o conviviente, siempre que se haya producido también un acto de violencia de género ${ }^{10}$. La Ley Integral considera violencia de género «la violencia que, como manifestación de la discriminación, la situación de desigualdad y las relaciones de poder de los hombres sobre las mujeres, se ejerce sobre éstas por parte de quienes sean o hayan sido

8. Quedan fuera de la enumeración legal delitos que, sin duda, constituyen violencia sexista, tal y como son la ablación del clítoris y el acoso sexual. En este sentido, PlanCHADELl GARGallo, A.: "La competencia de los Juzgados de Violencia sobre la Mujer», en J. Boix Reig y E. Martínez García (coords.): La nueva Ley contra la violencia de género (LO 1/2004, de 28 de diciembre), Madrid, Iustel, 2005, p. 285.

9. La Ley Integral amplía considerablemente el ámbito subjetivo del delito de malos tratos respecto de la regulación anterior, puesto que se incluyen las relaciones de afectividad sin convivencia que hasta ahora estaban excluidas y debían subsumirse en otros delitos. Otra de las cuestiones que suscita esta enumeración es que en caso de denuncias cruzadas entre cónyuges por malos tratos, la denuncia del hombre contra la mujer, en principio, sería competencia del Juzgado de Instrucción, pero sería conveniente que fuera el JVM quien asumiera la competencia sobre la misma dada la conexión entre ambas y la importancia de evitar investigaciones paralelas. En este sentido, CRUZ MORATONES, C.: "La Ley Integral de medidas de protección contra la violencia de género. Reflexiones sobre algunas cuestiones procesales», disponible en el Portal del Observatorio contra la Violencia Doméstica y de Género (www.poderjudicial.es), p. 4.

10. Muerza Esparza considera, por el contrario, que no es necesario que además de la comisión de un delito cuya víctima sea una de las señaladas, se produzca un acto de violencia de género (Muerza Esparza, J., en Muerza Esparza, J. (coord.), Sempere NaVarro, A. V. e Íñigo CoRROZA, E.: Comentario a la Ley Orgánica de Protección Integral contra la Violencia de Género. Aspectos Jurídico Penales, Procesales y Laborales, Pamplona, Thomson Aranzadi, 2005, p. 54). Para PLANCHADELL GARGALLO el precepto ha de interpretarse en el sentido de que el delito que se cometa constituya un acto de violencia de género (Op. cit., p. 287). 
sus cónyuges o de quienes estén o hayan estado ligados a ellas por relaciones similares de afectividad, aun sin convivencia» (art. 1).

b) De los delitos contra los derechos y deberes familiares (quebrantamiento de los deberes de custodia, inducción de menores al abandono del domicilio, sustracción de menores y abandono de familia, menores e incapaces) cuando la víctima sea alguna de las anteriores, siempre que se produzca también un acto de violencia de género.

2. Adopción de órdenes de protección a las víctimas, sin perjuicio de las competencias que pueda tener al respecto el Juez de Guardia en el marco de las diligencias urgentes de los juicios rápidos.

3. Enjuiciamiento y fallo de las faltas contra las personas y contra el patrimonio cuando la víctima sea alguna de las señaladas en el apartado primero del art. 87 ter LOPJ.

\subsubsection{Competencias civiles}

En materia civil, de acuerdo con el art. 87.2 ter LOPJ, los JVM podrán conocer con carácter facultativo de los procesos de filiación, maternidad y paternidad, nulidad matrimonial, separación y divorcio, relaciones paterno filiales; procesos que versen sobre la adopción o modificación de medidas de trascendencia familiar, sobre la guarda y custodia de los hijos o sobre prestación de alimentos; procesos sobre la necesidad de asentimiento en la adopción y sobre la oposición a medidas administrativas relativas a la protección de menores ${ }^{11}$.

Esta competencia deja de ser facultativa y pasa a ser exclusiva y excluyente cuando, tratándose de las materias que se acaban de enumerar, concurran simultáneamente las siguientes circunstancias (art. 87.3 ter LOPJ):

a) Que una de las partes en el proceso civil sea la víctima de un acto de violencia de género en los términos previstos en el art. 87.1 ter LOPJ.

b) Que una de las partes en el proceso civil esté imputada por la comisión de un acto de violencia de género como autor, inductor o cooperador necesario.

c) Que se hayan iniciado diligencias ante el JVM por delito o falta de violencia de género o se haya adoptado una orden de protección a una víctima de violencia de género.

Sólo cuando de forma notoria los hechos penales no constituyan un acto de violencia de género, el JVM podrá inadmitir la pretensión civil, remitiéndola al órgano jurisdiccional competente (es decir, cuando no se dé el último de los requisitos enunciados o, habiéndose iniciado las diligencias, se ponga de manifiesto dicha circunstancia).

Es importante destacar que la Ley Integral prevé una serie de reglas para solucionar aquellas situaciones en las que un juez civil está conociendo de un asunto que es competencia del JVM al haberse cometido un acto de violencia de género. En efecto, se prevén dos situaciones: Por un lado, puede suceder que

11. Competencia que, siendo facultativa, provocará, sin duda, importantes conflictos de competencia. Planchadell Gargallo, A.: Op. cit., p. 296. 
el juez civil que se encuentre conociendo de un proceso civil tenga noticia de la comisión de un acto de violencia de género cuando se den los requisitos para que el JVM asuma la competencia. En este caso, si ya se ha iniciado el proceso penal o se ha dictado una orden de protección, el juez civil remitirá las actuaciones al JVM, salvo que en el proceso penal ya se haya iniciado la fase de juicio oral ${ }^{12}$, en cuyo caso seguirá conociendo del proceso civil hasta el final ${ }^{13}$. Pero si no se ha iniciado el proceso penal ni todavía se ha dictado la orden de protección, el juez civil citará a las partes y al Ministerio Fiscal ${ }^{14}$ a una comparecencia $y$, en las veinticuatro horas siguientes, el Ministerio Fiscal decidirá si denuncia o pide la orden de protección al JVM. Si se inicia el proceso penal o se dicta la orden de protección, entonces será el JVM quien requerirá de inhibición al juez civil. Por otro lado, si el JVM se encuentra conociendo de una causa penal por violencia de género y tiene conocimiento de un proceso civil en marcha sobre el que tiene competencia, debe requerir de inhibición al juez civil y éste debe remitirle los autos inmediatamente ${ }^{15}$.

\subsection{La competencia territorial}

La Ley Integral incorpora un nuevo artículo 15 bis a la LECrim según el cual la competencia territorial para conocer de actos de violencia de género la tiene el JVM del domicilio de la víctima ${ }^{16}$. Se sustituye, pues, el fuero principal del

12. Se considera iniciado el juicio oral cuando el órgano jurisdiccional competente en función del proceso de que se trate decrete la apertura del mismo. En este sentido, MUERZA ESPARZA, J.: Op. cit., pp. 63-64.

13. La figura de la inhibición es extraña, pues lo más habitual es que sea el juez penal quien requiera al órgano civil para que se inhiba. Si el juez penal se declara incompetente, nos encontraríamos ante un conflicto negativo de competencia que tendría que resolver el tribunal de conflictos, lo que supondría un retardo importante de las actuaciones. Planchadell Gargallo, A.: Op. cit., p. 303.

14. La Ley Integral, en su art. 70, introduce un art. 18 quáter en el Estatuto Orgánico del Ministerio Fiscal por el que se crea el Fiscal contra la Violencia sobre la Mujer. Asimismo, el art. 71 de la Ley Integral modifica el art. 18.1 del citado Estatuto y crea una sección especializada en esta materia en las fiscalías de la Audiencia Nacional, de los Tribunales Superiores de Justicia y de las Audiencias Provinciales. Acerca de estas novedades véase GuIRALT MARTínEZ, R. Ma: «El Ministerio Fiscal y los Juzgados de Violencia contra la Mujer», en J. Boix Reig y E. Martínez García (coords.): La nueva Ley..., op.cit., pp. 399 y ss.

15. La Ley Integral no resuelve lo que debe suceder si, una vez asumida la competencia sobre un asunto civil, el JVM dicta un auto de sobreseimiento o una sentencia absolutoria en el asunto penal, por lo que dejaría de concurrir uno de los presupuestos para que el JVM asuma la competencia en materia civil. Teniendo en cuenta los principios de economía procesal y seguridad jurídica, cabe considerar que ha de mantener la competencia en materia civil aunque en el asunto penal por violencia de género se haya dictado alguna de las resoluciones mencionadas. Como señala Asencio Mellado, para que en este caso hubiese una pérdida de competencia sería necesaria una norma que así lo estableciera expresamente. Ante la falta de ésta, es de aplicación el art. 411 LEC, según el cual las alteraciones relativas al domicilio de las partes, a la situación de la cosa litigiosa o al objeto del juicio que se produzcan a lo largo del proceso no modificarán la competencia. Asencio Mellado, J. Mã: Op. cit., p. 13.

16. Domicilio de la víctima que, a tenor del Auto del Tribunal Supremo de 17 de enero de 2006, ha de ser el que posea al tiempo de la comisión del hecho. 
lugar de comisión del hecho (art. 15 LECrim) por el del domicilio de la víctima, lo que tiene todo el sentido si se piensa que, en muchos casos, el propio acto de violencia de género ha podido obligar a la víctima a cambiar de domicilio ${ }^{17}$, y no hay que perder de vista que la Ley Integral hace primar la protección de la víctima sobre un criterio de estricta eficacia de la investigación ${ }^{18}$. No obstante, si se han de adoptar medidas urgentes señaladas en el art. 13 LECrim o la orden de protección del art. 544 ter LECrim, así como si se ha de regularizar la situación personal del detenido, podrá hacerlo el Juzgado de Instrucción de Guardia del lugar de comisión del hecho ${ }^{19}$.

Ésta es, a grandes rasgos, la configuración legal de los JVM. Su puesta en marcha, sin embargo, no ha estado exenta de problemas, entre los que cabe destacar la sobrecarga de trabajo y la falta de especialización del personal a su servicio $^{20}$. No obstante, se trata en todo caso de problemas que se están tratando de solventar y que en ningún momento ponen en duda la conveniencia de estos juzgados. En efecto, a pesar de todas las medidas jurídicas adoptadas, como puede comprobarse tras un año desde la entrada en vigor de la Ley Integral, la violencia de género sigue siendo un problema de similares características e idéntica entidad que antes de la aprobación de la Ley. Como era de imaginar, los efectos de la nueva Ley no se dejarían ver a tan corto plazo. Sin embargo, se trata de medidas cuya eficacia no sólo ha de medirse en términos de disminución de los delitos de estas características, sino también en términos de mejoría del trato a la víctima del delito y de evitación de la victimización secundaria que hasta ahora suponía denunciar actos de maltrato. En este sentido, sin duda, apuntaba Comas d'Argemir cuando señalaba que

«ninguna ley, tampoco ésta, modifica de la noche a la mañana una realidad social tan sangrante y a la vez tan compleja de resolver, al estar anclada en hondas raíces culturales. Sin embargo, sí se puede afirmar que con ella se han abierto nuevas vías y nuevos instrumentos para poder intervenir en ella con el objetivo de poder modificarla. No es una utopía creer que un día será posible construir un modelo de sociedad con igualdad y sin violencia. Para ello hace falta una revolución cultural que ponga en cuestión la pervivencia de los patrones culturales machistas, de discriminación y dominio de las mujeres. Es una tarea de toda la sociedad. Es una tarea de todos: de hombres y de mujeres. Es además una lucha de largo alcance $\aleph^{21}$.

17. Fuentes SORIANO, O.: "Los nuevos juzgados...», op. cit., p. 104, quien aboga por una lectura amplia del concepto de "domicilio", no circunscrita al concepto civil. En el mismo sentido se manifiesta la Fiscalía General del Estado en la Circular 4/2005, de 18 de julio (apdo. VI-A.5).

18. En este sentido, Asencio Mellado, J. Ma: Op. cit., p. 7 y Muerza Esparza, J.: Op. cit., p. 66.

19. Delgado Martín, J.: "Los juzgados de violencia sobre la mujer», La Ley, 6279 (22 de junio de 2005), epígrafe II.2 (disponible en www.laley.es).

20. ComAs D’ARgemir Cendra, M.: «La aplicación de la Ley Orgánica de Medidas de Protección Integral contra la Violencia de Género», disponible en el Portal del Observatorio contra la Violencia Doméstica y de Género (www.poderjudicial.es), p. 22.

21. Ibid., p. 23. 


\section{LA ORDEN DE PROTECCIÓN DE LAS VÍCTIMAS DE LA VIOLENCIA DE GÉNERO}

A principios de los 90, el fenómeno delictivo tristemente conocido como "violencia doméstica» o "de género», como la Ley Orgánica 1/2004, de 28 de diciembre de Medidas de Protección Integral prefiere denominarla, comienza a convertirse en un alarmante problema social necesitado de una regulación jurídica eficaz dirigida a la protección de las mujeres que -de manera sistemática- son agredidas por quien está, o ha estado unido a ella, por una relación sentimental. Los esfuerzos que a nivel normativo se realizaron en un primer momento, a través de la LO 3/1989 de 21 de julio -que modificó el artículo 425 del ya derogado Código Penal-, supusieron una primera toma de contacto con la realidad al incluir el maltrato físico habitual como nueva figura delictiva. A esta primera toma de contacto le sucedieron nuevas reformas que, si bien de forma parcial y fragmentaria, trataban de alcanzar soluciones puntuales a los brotes de violencia que, año tras año, crecían de forma incontrolada. Baste recordar que mientras el número de mujeres maltratadas con resultado de muerte alcanzó la cifra de 54 en 1999, entre los años 2003-2004 se alcanzaría la más que escalofriante cifra de 143. Ello permitió constatar que la violencia contra la mujer, tal y como expresa la propia Exposición de Motivos de la Ley 1/2004, había dejado de ser un problema que afectaba al ámbito privado para convertirse en un asunto de interés público.

Pues bien, a pesar de las reformas que a nivel sustantivo se produjeron con la introducción en el Nuevo Código Penal de 1995 de nuevos tipos delictivos, y las correspondientes agravaciones de la pena que fueron modificándose con posteriores reformas en $1999^{22}$ y $2003^{23}$, lo tristemente cierto es que el elevado número de víctimas mantuvo un fuerte crecimiento ${ }^{24}$. Ello puso de manifiesto que la vía penal, si bien necesaria, no era suficiente para proteger adecuadamen-

22. La Ley $14 / 1999$ de 9 de junio, introduce tanto un nuevo tipo de delito al castigar la violencia psíquica habitual como los criterios para apreciar dicha habitualidad. Estos criterios se concretan en los siguientes: el número de actos acreditados, la conexión temporal de los mismos, la no exigencia de que los actos se lleven a cabo sobre la misma o diferentes víctimas y, por último, la no exigencia de que los actos violentos hayan sido o no objeto de enjuiciamiento en procesos anteriores.. Sobre el tema puede verse CAMPOS CRISTOBAL, R.: «Tratamiento penal de la violencia de género", en J. Boix Reig y E. Martínez García (coords.): La nueva Ley..., op.cit., pp. 253 y ss.

23. Destacan, por un lado, la Ley $11 / 2003$ de 29 de septiembre, de medidas concretas en materia de seguridad ciudadana, violencia doméstica e integración social de los extranjeros que agrava las penas y crea un nuevo delito de maltrato consistente en la realización de una sola falta de malos tratos, de lesiones, menoscabo psíquico o de amenaza leve con armas; y, por otro lado, la Ley 27/2003 de 31 de julio, que regula la Orden de Protección -que se analizará más adelante-, y la Ley Orgánica 13/2003 de 24 de octubre de reforma de la prisión provisional. Sobre el alcance de tales reformas, vid. ANADÓN JiMÉNEZ, M.A.: "Análisis de la protección penal y procesal contra la violencia doméstica desde el Código Penal de 1995 hasta la Ley Orgánica 1/2004», La Ley, 6457(6 de abril de 2006), disponible en www.laley.es.

24. Según datos aportados por el Instituto de la Mujer, en 1999 se produjeron 54 muertes; 63 en el año 2000; 71 en 2003; 72 en 2004; 60 en 2005, y hasta el 31 de mayo del presente 2006, la cifra ya alcanza a 32 mujeres muertas por violencia de género a manos de su pareja o ex -pareja. 
te a la víctima de malos tratos. Como acertadamente señala Fuentes Soriano, los poderes públicos comienzan a ser conscientes de que «la agilidad en la tramitación de los procesos judiciales resulta esencial para lo más básico e importante: la propia supervivencia de la víctima» ${ }^{25}$.

Esta sentida necesidad de agilización en la tramitación de los procesos judiciales derivó en la creación legislativa de uno de los instrumentos procesales que, técnicamente, aparece como el más útil y eficaz para proteger a la víctima de malos tratos: la Orden de Protección de las Víctimas de Violencia Doméstica. La virtual eficacia de dicho instrumento se traduce en la posibilidad para el juez de ordenar de forma conjunta y coordinada una medida cautelar de naturaleza penal contra el agresor -tendente a evitar el acercamiento de éste a su víctima, $\mathrm{y}$, por tanto, protegiendo a la víctima de un posible y reiterado daño futuro-, y otra medida cautelar de naturaleza civil -tendente a garantizar la estabilidad económica y familiar de la víctima de malos tratos de los posibles perjuicios que, con seguridad, se producirían tras la denuncia de los hechos que la originan- a través de una única resolución, y sin necesidad de acudir al trámite de separación o divorcio que, con anterioridad a la Orden de protección, era el único posible para que el juez adoptase las medidas oportunas acerca de la custodia de los hijos o de la regulación del régimen de prestación de alimentos, entre otras.

La Orden de Protección se introduce en nuestro ordenamiento procesal por la Ley Orgánica 27/2003 de 31 de julio que incorpora a la LECrim un nuevo artículo 544 ter, el cual es acogido en su totalidad por la Ley Integral de Medidas de Protección a través de la norma de remisión de su artículo 62. De este modo, el estudio que se realiza a continuación, y que tiene por objeto el análisis de algunos de los aspectos procesales de la orden, tendrá por referencia a la comentada LECrim, y en concreto, a su artículo 544 ter que regula dicho instrumento de protección.

\subsection{Aspectos generales de la orden}

La Orden de Protección nace, como se ha tenido ocasión de comentar, de la consciente necesidad de una rápida respuesta global y coordinada por parte de todos los poderes públicos. Resulta indudable que los actos de violencia ejercida dentro del ámbito familiar deben ser resueltos de forma inmediata, de modo que se otorgue una rápida y debida protección a aquellas personas que deciden presentar denuncia por maltrato. Es esencial, por tanto, que exista la posibilidad, para quien sufre violencia de esta naturaleza, de obtener una resolución que, en su caso, adopte aquellas medidas cautelares, tanto de carácter penal como civil necesarias para ordenar una relación que sitúa a la víctima en una situación objetiva de riesgo. El elemento más innovador y característico de la Orden de Protección es, pues, su función de instrumento de coordinación y

25. Fuentes SORIANO, O.: «Violencia de género. La respuesta de la Ley Orgánica de Medidas de Protección Integral», RGDPR, 5 (diciembre 2004), p. 9. 
de otorgamiento, a través de un único pronunciamiento judicial, de las diversas medidas cautelares que recoge nuestro ordenamiento, y que puede solicitar la víctima- o su entorno familiar más inmediato-, cuando se den los presupuestos que la Ley establece para ello.

Con el fin de hacer real y efectiva la protección a la víctima a través de las medidas que pueden incorporarse a la Orden, el legislador diseñó un procedimiento de tramitación sencilla, rápida (se permite al juez dictarla en un plazo máximo de 72 horas), y accesible a todas las víctimas de violencia doméstica, de modo que, tanto éstas como sus representantes legales o las personas de su entorno familiar más inmediato puedan solicitarla sin necesidad de formalismos técnicos ${ }^{26}$. Pero, al otorgarse a este tipo de delitos carta de naturaleza pública, además de legitimar a los sujetos pertenecientes al ámbito familiar de la víctima, también podrá solicitarlo el Ministerio Fiscal, y el propio juez de guardia al cual se le otorga la facultad de acordar una orden de protección de oficio (art. 544 ter.4), y, por tanto, sin necesidad de que la víctima u otras personas la soliciten en casos, por ejemplo, de temor o miedo a las consecuencias que dicho acto pudiese producir.

Del amplio abanico de posibilidades a través de las cuales puede canalizarse la solicitud de una orden de protección, y entre las que se encuentran como receptor cualquier organismo público, destaca, por sus especiales consecuencias procesales, la comisaría de policía ${ }^{27}$. En efecto, la celeridad que la orden pretende otorgar a la protección de la víctima, encuentra su máxima expresión en los conocidos como juicios rápidos, y a tenor de la exigencia del artículo 795.1 de la LECrim, éstos sólo se tramitan mediante el atestado resultante de una mínima investigación tras la correspondiente presentación de una denuncia ante la policía. El propio Protocolo General de aplicación de la orden entiende razonable que la solicitud llegue al juzgado acompañada del correspondiente atestado, y ello porque a través de éste-que normalmente contendrá el resultado de una mínima actividad investigadora- se otorgará al juez una mínima base para fundamentar su decisión resolutoria. Y de acuerdo con el artículo 544 ter de la LECrim, dicha resolución, en caso de ser estimatoria, exige la concurrencia de dos presupuestos: la de indicios de la comisión de un delito o falta de violencia doméstica, y la existencia de una situación objetiva de riesgo para la víctima.

26. La orden de protección puede solicitarse a través de un formulario normalizado y de fácil cumplementación. En cuanto al contenido, según el Protocolo General para la implantación de la orden de protección «deberá en todo caso incluir una descripción de los hechos constitutivos de la infracción penal (delito o falta) en que se fundamenta la petición». El principio general es, pues, el de facilitar a la víctima tanto la solicitud de la orden como la información relativa a la misma. En este último aspecto, y no obstante, el Protocolo General aconseja que la víctima esté acompañada de abogado en el momento de cumplimentar la solicitud y en el de denuncia ante la policía.

27. Circular 3/2003 de 30 de diciembre de la Fiscalía General del Estado. 


\subsection{Medidas cautelares penales y presupuestos para su adopción: indicios de la comisión de un delito de violencia doméstica y situación objetiva de riesgo para la víctima}

Cuando las medidas cautelares de protección que se solicitan al juez son de carácter penal, y por tanto, restrictivas de derechos como sucede, por ejemplo, cuando se solicita una orden de alejamiento que conlleva una restricción de movimientos, o una medida de prohibición de comunicación, que normalmente se otorgan en el ámbito de los delitos de violencia doméstica, el juez está sometido, por exigencias de nuestra Constitución y de la ley ordinaria, a la obligación de determinar y valorar la existencia de dos presupuestos: el fumus boni iuris que no es otra cosa que la imputación delictiva que se fundamenta a través de los indicios fundados de la comisión de un hecho delictivo, y el periculum in mora que, en el ámbito de violencia doméstica, se traduce en la situación objetiva de riesgo para la víctima, es decir, que de no ordenarse una medida cautelar, el hecho delictivo se repetiría y la víctima seguiría sufriendo el daño. Además de ello, el juez debe resolver sobre la solicitud con máximo respeto a los principios de proporcionalidad -entre el hecho y la medida restrictiva- y de necesidad, puesto que si bien el objetivo primordial es el de proteger a la víctima, las medidas que se ordenen deben ser respetuosas con los derechos fundamentales que, también, deben protegerse por exigencias de la constitución y de los principios básicos de un Estado de Derecho. De esta forma, el juez deberá adoptar la medida más idónea para garantizar la protección de la víctima pero que, al mismo tiempo, suponga - de la opción entre el abanico de medidas existentes y aplicables-, aquella que resulte la menos invasiva o restrictiva de los derechos del agresor; por ejemplo, si se trata de evitar el contacto con la víctima será más adecuado una orden de alejamiento que una de prisión provisional, mucho más restrictiva y desproporcionada al fin que se quiere conseguir.

El juez deberá, así, valorar las medidas concretas y necesarias que deban adoptarse para evitar la comisión de hechos aún más graves (SAP de Guadalajara 110/2003 de 10 de octubre). Y, en este sentido, ha de señalarse que la medida más solicitada suele ser la orden de alejamiento ${ }^{28}$ en virtud de la cual se prohíbe al agresor acercarse a la víctima a menos de una distancia que suele concretarse generalmente entre 300 y 500 metros $-y$, por tanto, limitando la libertad de movimientos del sujeto, y el contacto visual entre agresor y víctima que evita una situación amenazante para la última-; junto a la de prohibición de comunicación con la víctima por alguno de los medios existentes al efecto (teléfono, mensajes de móvil, carta, etc.)

El artículo 544 ter 1 exige, pues, que el juez dicte una orden de protección en los casos en los que existan «indicios fundados de la comisión de un delito o fal-

28. Según los datos aportados por el Consejo General del Poder Judicial correspondientes al primer semestre de 2005, de un total de 27. 445 medidas de naturaleza penal solicitadas a través de una orden de protección a instancias de la víctima, 12.326 eran de alejamiento frente a las 9.592 de prohibición de comunicación. 
ta contra la vida, integridad física o moral o seguridad de alguna de las personas mencionadas en el art. 173.2 del Código Penal». Pues bien, por «indicios fundados de la comisión de un delito» debe entenderse la existencia de un mínimo sustento indiciario o probatorio que permita su constatación por la autoridad judicial; es decir, que el juez pueda comprobar y fundamentar su decisión en la existencia de datos externos, señas o indicaciones que le permitan descubrir la responsabilidad criminal de una persona, sin la seguridad de la plenitud probatoria, pero con la firmeza de proporcionar una sospecha fundada ${ }^{29}$.

La constatación de tales indicios puede provenir por distintas vías, entre las que cabe mencionar bien un informe médico, bien la declaración de algún testigo, o bien la propia declaración de la víctima. En este último aspecto, y especialmente dentro del ámbito de los delitos de violencia doméstica, se entiende que uno de los indicios más importantes lo constituye la propia declaración de la víctima (SAP de Alicante 5/2004 de 3 de marzo, y AAP de Barcelona 77/2006 de 18 de enero). En efecto, la importancia que se otorga a la declaración de la víctima, y su valor para en un juicio posterior desvirtuar el principio de presunción de inocencia ${ }^{30}$ reside, fundamentalmente, en que, en muchos de los casos, el acto de violencia se produce en la intimidad, y, por tanto, sin posibilidad de que la versión de la víctima pueda corroborarse por la declaración de testigos, o por la ausencia de partes médicos; piénsese, por ejemplo, en los casos en los que el agresor haya amenazado de muerte a la víctima, proferido insultos, o le haya propinado empujones que no hubieren dejado lesión. Resulta indudable que, en estos casos, la ausencia de otros medios que permitan confirmar la versión de la víctima contenida en la denuncia no puede suponer la impunidad del acto. En este sentido, y en relación con este primer momento de solicitud por parte de la víctima de una orden de protección, la Instrucción 4/2004 de la Fiscalía General del Estado, reconoce, en efecto, que «el Ministerio Fiscal habrá de contemplar esa primera declaración de la víctima como la privilegiada fuente de conocimiento para postular las medidas de protección necesarias».

El siguiente presupuesto que exige el artículo 544 ter 1 y que va a determinar de forma concluyente la adopción judicial de la orden de protección es el de la existencia de "una situación objetiva de riesgo para la víctima». Es evidente que si la finalidad es la de proteger a la víctima el elemento fundamental que deba valorarse sea la posibilidad de que la situación de riesgo pueda repetirse en un futuro. Así, este requisito se erige en el elemento nuclear que el juez debe tener en cuenta a la hora de valorar la oportuna aplicación de alguna de las medidas

29. Tal y como ha declarado reiteradamente la jurisprudencia. Vid. entre otras las Sentencias del Tribunal Europeo de Derechos Humanos de 6 de septiembre de 1978 (caso Klas) y de 15 de junio de 1992, Auto del Tribunal Supremo de 18 de junio de 1992 y Sentencias del Tribunal Constitucional 174/1985 y 175/1985.

30. Es jurisprudencia consolidada del Tribunal Constitucional que la declaración de la víctima es suficiente para desvirtuar la presunción de inocencia siempre que no existan razones de resentimiento, odio, venganza, deseo de beneficio económico, o contradicciones en la incriminación, que hagan dudar de su veracidad (SSTC de 28 de diciembre de 1994, de 3 de octubre de 1994 y de 27 de febrero de 1997). 
cautelares que contempla la Ley. La objetivación de la situación de riesgo se concreta, pues, en un pronóstico de peligrosidad del denunciado para lo cual se tendrá en cuenta, entre otras circunstancias, la situación personal de la víctima y las circunstancias del hecho y del imputado que puedan ser susceptibles de producir una reiteración en la conducta agresiva (AAP de Barcelona, sección $10^{a}, N^{\circ} 36 / 2006$ de 20 de enero, y AP de Barcelona, sección $1^{\text {a }}$, No 35/2006 de 27 de enero).

Pero, a pesar de que, como se indicaba al comienzo de este trabajo, la orden de protección y las medidas susceptibles de adoptarse en la misma aparece «técnicamente» como un instrumento útil y eficaz en la lucha contra la violencia doméstica, por su accesibilidad, facilidad de tramitación y rapidez en cuanto a la producción de sus efectos protectores, lo cierto es que, desde su vigencia en el 2003, el número de mujeres muertas por sus parejas o ex-parejas sometidas a órdenes de protección, no ha descendido en el grado esperado ${ }^{31}$. Las razones de su «ineficacia» se encuentran en la dificultad y en el carácter sensible del ámbito dentro del que se mueven: las relaciones de pareja y la dependencia emocional que la misma genera. En definitiva, como se podrá comprobar, la eficacia de las medidas va a depender de la voluntad de ambas partes, y no sólo del agresor, sino también de cierta responsabilidad de la víctima que, a pesar de su situación de vulnerabilidad, debe ser consciente del peligro que puede encerrar su voluntad de acercarse a quien la ha maltratado.

\subsection{Eficacia de la medida de alejamiento contenida en la Orden de protección}

Resulta indudable que, tal y como se mencionaba con anterioridad, la medida de alejamiento y, por tanto, la de distanciamiento entre agresor y víctima es la que resulta más útil, proporcionada y conveniente para obtener la pretendida evitación del riesgo de reiteración de los actos delictivos y, de ahí, que la eficacia de esta medida, así como, junto a ella, la de prohibición de comunicación con la víctima, va a depender de su efectivo cumplimiento no sólo por el sometido a la medida sino, también, por la persona a quien se pretende proteger con ella.

Tan importante resulta ser esta medida que la Circular 2/2004 de la Fiscalía General del Estado recomienda a los Fiscales que la soliciten independientemente de la voluntad de la víctima. Y, como podrá comprobarse, en la circunstancia que rodea la indisponibilidad de la medida recae, al mismo tiempo, la solución y el problema de su eficacia. En efecto, desde el momento en que el Ministerio Fiscal o, más aún, el juez de oficio puede acordar una orden de protección, y dentro de ella, una orden de alejamiento, se está dejando a la mujer sin voluntad para proteger su propio interés, así como sin voluntad de decisión del momento

31. En una nota aparecida en El País de 1 de mayo de 2005, se confirma que el número de mujeres asesinadas en los cuatro primeros meses del 2004 quedaba muy cerca de las registradas en el mismo periodo de 2003, cuando todavía no había entrado en vigor la Orden de Protección. 
en que la misma debe ser revocada o, lo que es lo mismo, la valoración de la desaparición de la situación de riesgo para su vida, integridad física o moral.

El quebrantamiento de una medida de alejamiento en vigor, y con ello la pérdida de eficacia protectora de la misma, puede producirse, pues, a través de dos vías: el acercamiento del agresor sin voluntad de la víctima y el consentido por ella. En el primero de los supuestos, y en la mayoría de casos, la vulneración de la orden sólo puede ser conocida por la autoridad previa denuncia de la víctima. Puesto que, en muchos de estos casos, y de forma desgraciada, la integridad física de la víctima puede correr un grave riesgo antes de poder denunciar el hecho, la solución legislativa para estos supuestos proviene del apartado $4^{\circ}$ del art. 48 CP-introducido por la reforma 15/2003 de 25 de noviembre-, y se traduce en la posibilidad de someter a vigilancia electrónica a quien deba cumplir una orden de alejamiento. Ésta es, también, la opción acogida por la Ley Integral, que en su art. 64 la recoge como una de las posibilidades susceptibles de ser acordadas por el juez, y que permite a la autoridad policial una actuación más eficaz para proteger a la víctima. Pero, en lo que respecta al acercamiento del agresor consentido por la víctima, apuntado anteriormente, no existe previsión legal alguna, lo que ha llevado al Tribunal Supremo a dar una solución no sólo de compromiso, sino de equidad ante la tesitura en que la estricta aplicación de la ley ponía a los jueces y fiscales cuando la víctima decide por voluntad propia reanudar una convivencia o realizar un acercamiento con su agresor: la de ser condenada por cooperación necesaria o, al menos, por inducción ya que su voluntad resulta relevante de cara al delito de quebrantamiento de la medida del artículo 468 del Código Penal.

En la sentencia 1156/2005 de 19 de septiembre, entiende el Tribunal Supremo que

"la efectividad de la medida depende de la necesaria e imprescindible voluntad de la víctima (...)», pero, por otra parte, añade que "la vigencia o anulación de la medida no puede quedar al arbitrio de la persona en cuya protección se otorga, porque ello la convierte en árbitro de una decisión que no le afecta sólo a ella, sino también a la persona de quien se debe proteger. Ello produciría una falta absoluta de seguridad jurídica para el autor del quebrantamiento, que puede aparecer como autor del mismo según la exclusiva voluntad de la protegida, al tiempo que supondría dejar la efectividad del pronunciamiento judicial a la decisión de un particular, lo que no le consiente la naturaleza pública de la medida» (FJ $5^{\circ}$ ).

Sin embargo, y aunque el Tribunal Supremo implícitamente reconoce con ello que la valoración de la situación objetiva de riesgo no es función de la víctima sino del juez, tanto de su existencia -en el momento de ordenar el cumplimiento de la medida- cuanto de su extinción -en el momento de que se solicite dejar sin efectividad a la misma-, entiende y resuelve que la reanudación de la convivencia por voluntad de la víctima acredita la desaparición de las circunstancias que justificaron la medida de alejamiento, por lo que la misma desaparece y queda extinguida, sin perjuicio de que ante una nueva secuencia de violencia se pueda solicitar y, en su caso, obtener, otra medida de alejamien- 
to; es decir, que la eficacia de la medida sí depende de la voluntad-y, por tanto, de la responsabilidad-de la víctima.

\section{BIBLIOGRAFÍA}

ANADÓn JimeneZ, M.A.: "Análisis de la protección penal y procesal contra la violencia doméstica desde el Código Penal de 1995 hasta la Ley Orgánica 1/2004», La Ley, 6457 (6 de abril de 2006), disponible en www.laley.es.

ASENCIO MELlado, J. Ma : "La competencia civil de los juzgados de violencia frente a la mujer", Práctica de Tribunales. Revista de Derecho Procesal Civil y Mercantil, 19 (septiembre 2005), pp.5-8.

CAMPOS CRISTOBAL, R.: "Tratamiento penal de la violencia de género», en J. Boix Reig y E. Martínez García (coords.): La nueva Ley contra la violencia de género (LO 1/2004, de 28 de diciembre), Madrid, Iustel, 2005.

Comas D’Argemir Cendra, M.: «La aplicación de la Ley Orgánica de Medidas de Protección Integral contra la Violencia de Género", disponible en el Portal del Observatorio contra la Violencia Doméstica y de Género (www.poderjudicial.es).

Cruz MORATONES, C.: "La Ley Integral de medidas de protección contra la violencia de género. Reflexiones sobre algunas cuestiones procesales», disponible en el Portal del Observatorio contra la Violencia Doméstica y de Género (www.poderjudicial.es).

Delgado MARTín, J.: «Los juzgados de violencia sobre la mujer», La Ley, 6279 (22 de junio de 2005), disponible en www.laley.es.

FUENTES SORIANO, O.: "La constitucionalidad de la Ley Orgánica de medidas de protección integral contra la violencia de género", La Ley, 6362 (18 de noviembre de 2005), disponible en www.laley.es.

—: "Los nuevos juzgados contra la violencia sobre la mujer», en AA VV: La Administración de Justicia en la Ley Integral contra la violencia de género, Madrid, Ministerio de Justicia, 2005.

—: «Violencia de género. La respuesta de la Ley Orgánica de Medidas de Protección Integral», RGDP, 5 (diciembre de 2004), disponible en el portal www.iustel.com.

Guiralt Martínez, R. Ma: «El Ministerio Fiscal y los Juzgados de Violencia contra la Mujer», en J. Boix Reig y E. Martínez García (coords.): La nueva Ley contra la violencia de género (LO 1/2004, de 28 de diciembre), Madrid, Iustel, 2005, pp. 399-421.

Moreno Catena, V. (con Cortés Domínguez, V.): Derecho Procesal Penal, Valencia, Tirant lo Blanch, $2^{\text {a }}$ ed., 2005.

Muerza esparza, J., en Muerza Esparza, J. (coord.), Sempere Navarro, A. V. e Íñigo CorrozA, E.: Comentario a la Ley Orgánica de Protección Integral contra la Violencia de Género. Aspectos Jurídico Penales, Procesales y Laborales, Pamplona, Thomson Aranzadi, 2005, pp. 47-86.

Planchadell Gargalio, A.: "La competencia de los Juzgados de Violencia sobre la Mujer», en J. Boix Reig y E. Martínez García (coords.): La nueva Ley contra la violencia de género (LO 1/2004, de 28 de diciembre), Madrid, Iustel, 2005, pp. 277-317. 


\title{
MATRIMONIO Y HOMOSEXUALIDAD
}

NIEVES MONTESINOS SÁNCHEZ

Universidad de Alicante

\begin{abstract}
«Nacisteis juntos, y juntos permaneceréis para siempre [...]. Y manteneos unidos pero no demasiado unidos: porque las columnas del templo se encuentran separadas. Y ni el roble crece bajo la sombra del ciprés ni el ciprés bajo la del roble»*
\end{abstract}

El Congreso de los Diputados aprobó el 21 de abril de 2005, con 183 votos a favor, 136 en contra, y 3 abstenciones la reforma del Código Civil que permite el matrimonio entre personas del mismo sexo ${ }^{1}$. Posteriormente al pasar la reforma al Senado, tal y como es preceptivo, éste vetó el proyecto, merced a una propuesta que presentaron el Partido Popular, y Unió Democrática de Catalunya. La propuesta fue aprobada, lo que supuso la vuelta de la reforma al Congreso. Aprobándose finalmente el 30 de junio de $2005^{2}$, la Ley se publicó en el Boletín Oficial del Estado el día 2 de julio, y entró en vigor al día siguiente.

Con ella, España entra a formar parte de los pocos países en los que se admite el matrimonio entre personas del mismo $\mathrm{sexo}^{3}$, con una nueva redacción del artículo 44 Código Civil donde se establece: «1. El hombre y la mujer tienen derecho a contraer matrimonio conforme a las disposiciones de este Código. 2. El matrimonio tendrá los mismos requisitos y efectos cuando ambos contrayentes sean del mismo o de diferente sexo" ${ }^{4}$.

* Gibrán Kalhil Gibrán, El Profeta, ("El matrimonio»).

1. El 18 de junio, bajo el lema «la familia sí importa», se convocó en Madrid por El Foro Español de la Familia una manifestación a la que acudieron multitud de personas contra la proyectada Ley. La manifestación, de la que se hicieron eco todos los medios de comunicación, contó con el apoyo de la Iglesia Católica española y del Partido Popular.

2. Contó con 187 votos a favor: PSOE, ERC, Izquierda Unida, PNV, BNG, CC, CHA, dos diputados de CIU y una diputada del PP; 147 en contra: PP y Uniò; y cuatro abstenciones.

3. Con reconocimiento nacional en Países Bajos (2001), Bélgica (2003) y Canadá (2005).

4. Ap. 2 introducido por la L. 13/2005 de 1 de julio, art. uno (BOE de 2 de julio).

Feminismo/s, 8, diciembre 2006, pp. 159-180 
Tal modificación estaba ya prevista en el programa electoral del PSOE en las últimas elecciones generales ${ }^{5}$. A partir de aquí se desencadena una nueva problemática y polémica a la que haré referencia más adelante, y de la que dan cuenta, en mayor o menor medida los diferentes estudios de reciente publicación.

\section{ANTECEDENTES: LA REGULACIÓN DE LAS UNIONES DE HECHO}

El matrimonio entre personas del mismo sexo ha sido el resultado final de un largo recorrido, que se inicia con la problemática y posible regulación, a raíz, entre otras, de las diferentes demandas sociales y jurídicas, de las uniones de hecho (UDH).

Sobre él he tenido ocasión de trabajar en otros momentos ${ }^{6}$, razón por la cual considero interesante, partiendo de la premisa inicial de que el tema en su conjunto debe enmarcarse en el Estado social y democrático de Derecho que dibuja y define nuestro texto constitucional, y atendiendo a la normativa internacional y europea, poner sobre el tapete cuál ha sido la postura que comparto, para poder conocer el estado de la cuestión.

Si son al menos dos las instituciones que se podían sentir afectadas en el tema de la regulación de las UDH y que comprometen directamente las relaciones entre Derecho y Género: el matrimonio y la familia, la cuestión sería ir más allá del matrimonio. Y manteniendo la supervivencia de la construcción jurídica matrimonial y el derecho personal de acogerse o no a ella, debiera abandonase la concepción tradicional. Se trataría pues, de realizar una configuración de la familia y por ende del derecho de familia desde la institución susceptible de protección.

Ello supondría en consecuencia la no juridificación o formalización de las $\mathrm{UDH}$, excepción hecha de las uniones homosexuales, dependiendo de que se considere o no oportuno su acceso al matrimonio; y las limitaciones serían fru-

5. La propuesta presentada por el PSOE, que contaba con el visto bueno de la Federación Estatal de Lesbianas, Gays y Transexuales (FELGT), suponía el cambio de tres artículos del Código Civil: art. 44: «El hombre y la mujer tienen derecho a contraer matrimonio conforme a las disposiciones de este Código». Se cambia el sujeto por 'cualquier persona'. Art. 66: «El marido y la mujer son iguales en derechos y deberes». Se cambia el sujeto por 'los cónyuges'. Art. 67: «El marido y la mujer deben respetarse y ayudarse mutuamente y actuar en interés de la familia». Se hace lo mismo que en el art. 66. Estas propuestas permiten también la adopción por ambos cónyuges. Puede verse: El País (Sociedad), de 25 de marzo de 2004.

6. Pueden verse mis estudios: «Familia y Derecho: aproximación a la configuración jurídica y social del modelo familiar», en Martinell, J. $\mathrm{M}^{a}$ y Areces, $\mathrm{M}^{\mathrm{a}} \mathrm{T}$. (eds.): Uniones de hecho, Lleida, Universitat de Lleida, 1998, pp. 359-368; «La iniciativa legislativa y las uniones de hecho", en Estudios Jurídicos en homenaje al profesor Vidal Guitarte, Valencia, Serv. Pub. Diputación de Castellón, 1999, pp. 653-663; «La conflictividad jurídica de las uniones homosexuales», en Santos Díez, J. L. (ed.): XVIII Jornadas de la Asociación Española de Canonistas, Salamanca, Universidad Pontificia de Salamanca, 1999, pp. 353-369; «Demandas sociales y respuestas jurídicas a propósito de las uniones de hecho», en Castán Vázquez, J. Mª , Guzmán Pérez, C., Pérez-Agua López, T. y Sánchez García, J. Ma. (coords.): Hominum causa omne ius constitutum est. Escritos sobre el matrimonio en homenaje al Prof. José Ma Díaz Moreno, Madrid, Universidad Pontificia Comillas, 2000, pp. 1433-1458. 
to de una decisión de política legislativa acorde con los principios y derechos constitucionales. Pero no cabría esconder la regulación de las uniones homosexuales en la globalidad de las UDH, ya que no responden a unas mismas necesidades.

Entre las razones por las que se defiende esta vía de solución, cabe destacar que tiene perfectamente cabida dentro de un Estado social y democrático de Derecho, personalista como el nuestro y a mayor abundamiento desde la perspectiva que ofrece el artículo 39 del texto constitucional ${ }^{7}$. Además, se está hablando de la familia proteiforme, pero no sería conveniente la clasificación de modelos familiares o la juridificación de familias de distinta categoría ya que podría ser atentatorio de los principios que recoge nuestro propio sistema. En este contexto la asimilación al modelo matrimonial podría estar fuera de lugar para personas que pueden voluntariamente adherirse o no al mismo, excepción hecha de aquellos efectos que se unen al matrimonio pero que no corresponden necesariamente al mismo por su naturaleza ${ }^{8}$.

Desde el conocimiento del marco jurídico de formación de la institución matrimonial y de la familiar, es necesario que la construcción estatal, civil, se realice por tanto no ignorando, pero sí al margen de componentes y connotaciones morales y religiosas, y teniendo presente y sobre la base de las repercusiones jurídicas que llevan consigo los procesos de transformación social. Es por ello que en un Estado de Derecho que proclama entre los principios rectores de la política social y económica la protección a la familia, habrá que estar atentos a la realidad social que nos sirve de referencia puesto que tiene una construcción jurídica. Es decir, es básica la interrelación con la construcción jurídica matrimonial y por ende con la familiar en el análisis de la problemática de las UDH, y del acceso, o no, al matrimonio de personas del mismo sexo. Pero, al mismo tiempo, hay que destacar que no siempre cuando se habla de UDH se incluyen tanto las heterosexuales como las homosexuales. Sobre todo porque la referencia generalizada es a las uniones extramatrimoniales. Quizá ello ha llevado a que a la hora de plantear una propuesta legislativa, se incluyan ambas de manera indistinta. Lo cual puede inducir a error a la hora de dar una respuesta clara a los conflictos que se plantean en uno u otro caso, ya que aunque en ocasiones puedan ser coincidentes, no son siempre necesariamente idénticos.

Ahora bien, analizar el debate producido requiere pasar revista a una serie de cuestiones básicas que han colaborado a la conformación y configuración de lo que ha sido y es el eje del debate jurídico, político y social. Obviamente desde esta aportación no pueden ser todas ellas analizadas, pero sí enunciadas con un mayor o menor desarrollo.

7. En particular conviene recordar el punto $1 \mathrm{del}$ art. 39: «Los poderes públicos aseguran la protección social, económica y jurídica de la familia».

8. Puede verse: VAlPUESTA FernándeZ, $M^{a}$ R.: «La institucionalización jurídica de la pareja. Registro de parejas de hecho", en Las Uniones de Hecho, Cádiz, Servicio de Publicaciones de la Universidad de Cádiz y Departamento de la Mujer del Excmo. Ayuntamiento de Jerez de la Frontera, 1995, pp. 47-66. 
Es sabido que las investigaciones sobre las UDH en España son relativamente recientes en el tiempo, aunque son conocidos estudios históricos sobre distintas situaciones familiares. A partir de aquí un primer punto de atención lo constituye el análisis tanto de la evolución doctrinal como jurisprudencial y legislativa en la materia ${ }^{10}$.

En un segundo punto habría que tener en cuenta la Constitución, el Tribunal Constitucional y las resoluciones europeas. En la Constitución especialmente los artículos 10, 14, 18 y 3911. Por lo que se refiere al Tribunal Constitucional aunque son numerosas y variadas sus resoluciones y no todas están en la misma línea, considero interesante resaltar que para el más alto Tribunal «Nuestra constitución no ha identificado la familia que manda proteger con la que tiene su origen en el matrimonio, conclusión que se impone no sólo por la regulación bien diferenciada de una institución y otra (artículos 32 y 39), sino también, junto a ello, por el mismo sentido amparador o tuitivo con el que la norma fundamental considera siempre a la familia, y en especial en el repetido art. 39, protección que responde a imperativos ligados al carácter 'social' de nuestro Estado (artículos 1,1 y 9,2) y a la atención, por consiguiente, de la realidad efectiva de los modos de convivencia» ${ }^{12}$, y aunque reiteradamente expresa que el matrimonio y la convivencia matrimonial no son realidades equivalentes, recuerda que «la Constitución no sólo protege a la familia que se constituye mediante el matrimonio -aunque a ésta la proteja especialmente- sino también a la familia como realidad social, entendida por tal la que se constituye voluntariamente mediante la unión de hecho, afectiva y estable de una pareja» ${ }^{13}$. En cuanto a las parejas homosexuales, no es una institución regulada jurídicamente, y no existe-como ocurre con el matrimonio al que se refiere el artículo 32- derecho

9. Especial atención merece la institución de la barraganía, véase: FOSAR BENLLOCH, E.: «Las uniones no matrimoniales en el derecho histórico español. La sucesión mortis causa a favor de los hijos extramatrimoniales en el derecho Civil aragonés", Revista Crítica de Derecho Inmobiliario, 59 (1983), pp. 133-176.

10. En la doctrina tanto civilistas como canonistas se han ocupado del tema, y éste ha sido objeto de discusión tanto en foros nacionales como europeos. Entre los civilistas, mención especial merece por ser de los primeros, el estudio monográfico de ESTRADA ALONSO, E.: Las uniones extramatrimoniales en el Derecho Civil español, Madrid, Civitas, 1986; entre los canonistas y por la importancia de la construcción del modelo matrimonial, NAVARRO VALLS, R.: Matrimonio y Derecho, Madrid, Tecnos, 1995; también, REINA, V. y MARTINELL, J.: Las uniones matrimoniales de hecho, Madrid, Marcial Pons, 1996. En la jurisprudencia, diferentes pronunciamientos se han decantado por la imposibilidad de la aplicación analógica de la normativa matrimonial a las UDH, entre ellos: SsTS de 18-5-82, 21-10-92, 22-7-93, 27-5-94. Y por lo que respecta a la legislación bastaría recordar aquellas normas en las que se ha ido produciendo una asimilación de efectos entre las uniones matrimoniales y las UDH: Ley de Arrendamientos urbanos, Código penal, etc.

11. Sobre la oportunidad de tomar en consideración el artículo 18 del texto constitucional, y la escasa atención que se le ha prestado al mismo en conexión con la Jurisprudencia europea y el CEDH, véase: MONTESINOS SÁNCHEZ, N.: «Familia y Derecho: aproximación...», op.cit., p. 364.

12. Véase STC 222/1992.

13. Véase STC $47 / 93$. 
constitucional a su establecimiento ${ }^{14}$. Y por último, no se pueden dejar de lado ni las diferentes resoluciones europeas en materia de no discriminación: Resolución del Consejo de Europa de 1 de octubre de 1981, Resolución del Parlamento Europeo de 13 de marzo de 1984, Resolución del Parlamento Europeo de 8 de febrero de 1994, ni la Jurisprudencia TEDH.

El tercer bloque para fijar el estado de la cuestión lo integran las proposiciones de los grupos parlamentarios. De ellas se sigue que la decisión de nuestros legisladores fue inicialmente -porque en la actualidad parece que esté todo aparcado- la del establecimiento de una normativa general que contemple a las UDH, y, partiendo de una definición de lo que se considera unión de hecho o contrato de unión civil, extender la aplicación normativa tanto a las uniones heterosexuales como a las homosexuales sin diferenciación entre ambas.

Si bien se presentaron diferentes proposiciones y proyectos, la toma en consideración inicialmente de la proposición de Coalición Canaria permitía utilizarla como instrumento base para el análisis de las posturas mantenidas por los grupos políticos. Todos parecían defender la regulación legislativa de las $\mathrm{UDH}$, sin ser coincidentes las modificaciones legislativas propuestas $\mathrm{y}$, desde una línea argumental y con justificaciones no siempre idénticas.

Para Coalición Canaria la necesidad de la regulación se apoya en el hecho de que "la aceptación social de las uniones de hecho libres es creciente en nuestra sociedad», y de que "no debe permanecer al margen del derecho positivo aquella convivencia de pareja estable e independientemente, o no, de la sexualidad de quienes la constituyan", con lo cual el legislador debe "eliminar las discriminaciones que afectan a estas uniones y a sus miembros, adoptando al tiempo medidas de protección efectivas». Siendo su finalidad la de "conectar los efectos de la unión matrimonial a las parejas estables de hecho mediante la elaboración de una ley modificativa sobre los preceptos afectados» en diferentes leyes ${ }^{15}$. Tan sólo el Grupo Parlamentario Federal de Izquierda Unida-Iniciativa per Catalunya introduce alguna innovación en su argumentación, ya que en vez de partir de la asimilación de determinados beneficios de la unión matrimonial a la UDH,

14. Véanse: SsTC 184/90 y 66/94. La admisión o no del matrimonio para los homosexuales genera una viva polémica cuya discusión se centra a nivel normativo en la necesidad de reforma del artículo 32 de la Constitución, o simplemente de los artículos 44, 66 y 67 del Código civil. Véase: IBARRA ROBLES, J.L.: «El reconocimiento de efectos jurídicos a las uniones de hecho en el ordenamiento español: su evolución y aspectos a considerar en la actual iniciativa legislativa", El Derecho Europeo ante la Pareja de Hecho, Barcelona, Cedecs Derecho, 1996, pp. 31-40.

15. Véase la Exposición de Motivos que antecede a la proposición, altamente ilustrativa y necesaria por imperativo del artículo 124 del reglamento del Congreso de los Diputados (Boletín Oficial de las Cortes Generales. Congreso de los Diputados. VI Legislatura, Serie B, n 90, p. 2). Por lo que se refiere al Partido Socialista, éste había partido de pronunciamientos muy similares, por ello la regulación debía ir encaminada a «identificar en las diferentes legislaciones sectoriales los supuestos en que serían extensivos los efectos de las uniones matrimoniales a las de hecho y elaborar una ley 'modificativa' que de nueva redacción a los correspondientes preceptos de aquellas al tiempo que establezca los requisitos que han de cumplir las uniones de hecho y la forma de acreditar los mismos» (Boletin Oficial de las Cortes Generales. Congreso de los Diputados. VI Legislatura, Serie B, n 87, pp. 1-2). 
su razonamiento gira en torno a la interpretación y aplicación del artículo 39 del texto constitucional, entendiendo que en él «no existe una referencia a un modelo de familia predeterminado ni predominante, lo que hace necesario una interpretación amplia de lo que debe entenderse por familia, consecuente con la realidad social actual y con el resto del articulado constitucional referido a la persona» ${ }^{16}$. Por su parte, en la última proposición que planteó el PP el objetivo era que "quienes lo deseen puedan formalizar una unión civil por medio de un contrato para garantizar la certeza exigida por el principio de seguridad jurídica, sin menoscabo del derecho fundamental a la intimidad ${ }^{17}$. Con ello se entiende que se respetan y amparan tanto las situaciones de quienes quieren formalizar una unión civil, como la de aquellos que quieren relacionarse más allá del Derecho.

Existe una diferencia básica entre ambas proposiciones ya que el grupo popular no habla ni de UDH, ni de familia; diferencia que se convierte en evidencia con la simple lectura de las definiciones o requisitos que se proponen en consonancia con la decisión de formalizar estas uniones.

La definición que en cada caso se plantea encierra su trascendencia, Coalición Canaria entiende que son parejas de hecho estables "las uniones de los mayores de edad o menores emancipados, sin vínculos de parentesco en primer o segundos grados de consanguinidad, que convivan en pareja con independencia de su sexualidad, al menos durante un año, libre, pública y notoriamente» ${ }^{18}$. El Grupo Popular introdujo una figura alternativa, el contrato de unión civil, que considera como tal aquel por el cual «dos personas físicas mayores de edad acuerdan convivir y prestarse ayuda mutua»19.

Casi todos los grupos habían manifestado ya su postura en momentos anteriores, e incluso algunos esperaban el dictamen o el proyecto que pudiera salir de la subcomisión encargada de estudiar el tema ${ }^{20}$. El dictamen de dicha subcomisión que retrasa, para unos sí y para otros no, la tramitación de la ley y que

16. Véase: Exposición de Motivos de la Proposición del Grupo Parlamentario Federal de Izquierda Unida-Iniciativa per Catalunya (Boletín Oficial de las Cortes Generales. Congreso de los Diputados, VI Legislatura, Serie B, $n^{\circ} 88$, pp. 1-2).

17. Véase: Exposición de Motivos de la Proposición de Ley Orgánica presentada por el Grupo Parlamentario Popular en el Congreso (Boletín Oficial de las Cortes Generales. Congreso de los Diputados, VI Legislatura, Serie B, n 117, pp. 1-2).

18. Véase artículo 1. En la proposición del PSOE, el tiempo requerido de convivencia era de dos años (art. 1). Y en la de Izquierda Unida, que era aproximadamente idéntica, se partía de una declaración de principios en su art. 1 del siguiente tenor: «Nadie puede ser discriminado por razón del grupo familiar del que forme parte, tenga éste su origen en la filiación, en el matrimonio o en la unión de dos personas que convivan por análoga relación de afectividad, con independencia de su orientación sexual. Se entiende nula, y sin efecto, cualquier norma legal o convencional que vulnere o contradiga este principio».

19. Véase art. 1 puntos 1,2 y 3. Debe llamarse la atención sobre el hecho de la imposibilidad de que sean parte del mismo los menores emancipados, a los que sí se referían las otras proposiciones.

20. Remito a las opiniones mantenidas por los diferentes grupos con ocasión de la toma en consideración de las proposiciones de ley del Grupo Socialista del Congreso, del Grupo Parlamentario Federal de Izquierda Unida-Iniciativa per Catalunya y del Grupo Parlamentario de Coalición 
incluye las conclusiones separadas de cada grupo parlamentario fue aprobado por unanimidad de todos los grupos. No obstante, el debate se reabrió entre los diferentes grupos con ocasión de la toma en consideración de la Proposición del Partido Popular ${ }^{21}$.

En relación con la problemática homosexual -parejas homosexuales a las que en absoluto se alude en la proposición, pero a las que tampoco se excluye ya que tienen cabida en el tenor literal del precepto anteriormente trascrito-, los populares se formulan una serie de interrogantes: «iEs posible con arreglo a nuestro ordenamiento constitucional la regulación del denominado matrimonio homosexual? ¿Es posible, en cualquier caso, la regulación de una unión homosexual similar a la del matrimonio, pero que no se llame matrimonio y que sea, en cambio, considerada como una unión familiar? Por último, la no equiparación de las parejas homosexuales a la situación matrimonial o familiar de heterosexuales, aunque sí se equiparen sus efectos ¿supone acaso una discriminación?». Y la respuesta que encuentran es «no es posible». No es posible con arreglo a nuestras leyes esa regulación o esa equiparación de situaciones, aunque sí lo sería equiparar los efectos, tomando también en consideración las decisiones del Tribunal Constitucional. Entienden, en consecuencia, que «no puede hablarse de discriminación si hablamos con objetividad de la realidad jurídica española». Es más, para los populares -pese a manifestar la legitimidad de la petición, el respeto y apoyo a las parejas homosexuales- nuestra Constitución no admite una reforma legislativa "encaminada a un pleno reconocimiento como si sus uniones fuesen un matrimonio o una unidad familiar", ya que para ello tendría que haberse propuesto la reforma de la Constitución. Y porque la concepción de la familia que emana de la Constitución es el «modelo de unión entre un hombre y una mujer y de los hijos que con ellos convivan. Con arreglo a su texto no solamente son posibles familias matrimoniales, sino también las no matrimoniales heterosexuales. Por ello la Constitución española se refiere a la protección de los hijos, cualquiera que sea su filiación, y a la protección a las madres, cualquiera que sea su estado civil ${ }^{22}$. Estas son algunas de las razones que justifican una ley que está en la frontera de lo posible, a pesar de no satisfacer a determinados grupos ${ }^{23}$.

Los restantes grupos parlamentarios, mayoritariamente contrarios a la proposición, también argumentan de modo muy directo sus posiciones. El Bloque Nacionalista Galego se opone por una serie de criterios que considera básicos:

Canaria, Diario de Sesiones. Congreso, n 86 de 27 de mayo. Además a las posturas mantenidas por los grupos parlamentarios ya hice referencia en MONTESINOS SÁNCHEZ, N.: «La iniciativa legislativa y las uniones de hecho", op.cit., passim.

21. Véase: Diario de Sesiones. Congreso, n 120 , de 25 de noviembre de 1997.

22. Para el discurso del señor Trías, por el Grupo Popular, véase: Diario de Sesiones. Congreso, $\mathrm{n}^{\circ} 120$, de 25 de noviembre, pp. 6282-6284.

23. Entre estos grupos, los populares citan expresamente a la Iglesia [Católica], de la que dicen ve la ley como «algo peligroso para su concepción del matrimonio y de la familia». Ibíd., p. 6284. Puede verse también TRÍAS SAGNIER, J.: «El contrato de unión civil y modificaciones legislativas que introduce», Actualidad Jurídica Aranzadi, 315 (1997), pp. 1-5. 
la interpretación constitucional que hace el PP es sesgada y va destinada a que no se pueda aceptar la equiparación con el matrimonio y la familia, pese a que existen sentencias y leyes ya efectivas en el Estado español que apoyándose en la Constitución, tienden a esta equiparación; las alusiones a interpretaciones trascendentes, con las que se intenta proteger el matrimonio y la familia tradicional; la subordinación de este tema al matrimonio en vez de considerar su propia especificidad ${ }^{24}$.

Para la señora Rahola i Martínez, con esta propuesta el Partido Popular pretende desvirtuar el debate de las parejas de hecho, y con él, «el derecho de toda persona a crear modelos de familia diferentes al tradicional, pero basados en el amor y el compromiso"; y deja muy lejos en la historia la reclamación de la regulación de las parejas de hecho. Coincidente en algunos extremos es la posición del Partido Democrático de la Nueva Izquierda, entiende que es un parche para no reconocer algo a lo que ha aludido el señor Trías, que es la libertad y la constitucionalidad de las diferentes opciones sexuales que pueda haber. Ya que «lejos de ser un derecho anticonstitucional, como lo ha querido plantear, es un derecho de pura constitucionalidad y libertad. Las personas tienen derecho a amarse, sean o no del mismo sexo, tienen derecho a ese compromiso ante la sociedad y tienen derecho a plantear que su unión tenga los efectos que ellos quieran darle y que la ley les permita». Iniciativa per Catalunya-Els Verds también se pronuncia en términos similares. "Entendemos que esto más allá del debate político, esto es una burla, es como una pesadilla para un colectivo que desde hace años viene solicitando una ley de parejas de hecho» ${ }^{25}$.

El señor Mardones Sevilla defiende, frente a la nueva, la proposición que presentada por su Grupo fue tomada en consideración. Y votarían en contra por ser «un planteamiento conceptual política y jurídicamente diferente». Lo que en su día se presentó supone dar derechos en un Estado democrático de Derecho a los efectos jurídicos de las parejas de hecho estables, no una unión civil que recuerda una fórmula de legislación mercantil. "A mí me parece una ofensa que, en el espíritu del tipo de parejas heterosexuales u homosexuales que nosotros planteábamos y que querían estar en el Estado de Derecho, se diga aquí que se trata de respetar la libertad de quienes quieren relacionarse más allá del Derecho ${ }^{26}$. Convergència i Uniò, socio del partido en el gobierno, mantiene una postura particular. Comienza afirmando que el Grupo Parlamentario Catalán desde el inicio en esta legislatura del planteamiento de la cuestión que nos ocupa, ha tenido claros tres aspectos fundamentales: la necesidad de regulación de esta materia; la regulación con consenso, ya que por las características propias del tema, al afectar directamente a la libertad y a la dignidad de las personas era absolutamente fundamental intentarlo, y así evitar que pudiera cambiarse en cada legislatura; y el contenido de la regulación específica. Por lo que se refiere

24. Véase: Diario de Sesiones. Congreso, n 120, de 25 de noviembre, p. 6285.

25. Ibíd., p. 6287.

26. Ibíd., pp. 6287-6288. 
al contenido específico de la regulación que debe tener esta materia, remiten a su propio proyecto ${ }^{27}$. La posición no es coincidente con la del Grupo Popular ni con la de Coalición Canaria. Con el PP porque el proyecto no efectúa un reconocimiento expreso de eso que ya está reconocido perfectamente en la realidad social: las parejas integradas por personas del mismo sexo, porque atribuye efectos idénticos a realidades sociales que son diferentes: como puede ser la pareja heterosexual, la pareja homosexual y otras unidades de convivencia, y además, por el coste económico.

Y, ni el Grupo parlamentario Federal de Izquierda Unida, ni el Grupo socialista, están de acuerdo con la proposición de contrato de unión civil. Para la señora Urán González, lo que se consigue es una regresión respecto a textos legislativos ya aprobados en ésta Cámara y una regulación que no contempla la protección a la familia y la protección a las unidades familiares que a tenor de nuestra Constitución deben ser atendidas por los poderes públicos ${ }^{28}$. Y por el PSOE, el señor Pedret i Grenzner pedirá la retirada de la proposición por suponer casi un fraude de Reglamento. Califican la proposición de «auténtico dislate jurídico, económico, social y político». Y en lo que nos parece más relevante, el grupo socialista argumenta que están introduciendo una disolución del concepto de familia, al confundir interesadamente matrimonio y familia, pese a la existencia de otras familias no basadas en el matrimonio; e intentar la existencia de una legislación en la que por una parte esté el matrimonio al que atribuyen carácter familiar, y por otra, mezclados en la misma ley, cosas que son familia, con situaciones que no tienen nada de familiares ${ }^{29}$.

Por último, para concluir este apartado y completar así el debate y el marco normativo, hay que decir que, paralelamente a lo que sucede en las Cortes Generales, los parlamentos de las comunidades autónomas debaten la regulación de las UDH y paulatinamente, aunque con diferente alcance y contenido -también en función de sus propias competencias tal como se establece en el texto constitucional-, van aprobando leyes sobre UDH. La primera de ellas fue la catalana, en la que se diferenció en cuanto a su regulación, entre UDH heterosexuales y homosexuales ${ }^{30}$.

27. En la sesión del Gobierno de la Generalitat de Catalunya, celebrada el 25 de noviembre de 1997 se toman entre otras las siguientes medidas: «A proposta de la Consellera de Justicia s'aprova l'avantproyecte de Llei sobre relacions de convivència diferents del matrimoni i s'autoriza l'esmentada consellera perquè el presenti al Parlament», véase: Butlletí Oficial del Parlament de Catalunya, n² 242, de 30 de desembre de 1997, pp. 18555-18562.

28. Véase: Diario de Sesiones. Congreso, n 120 , de 25 de noviembre, pp. 6290-6291.

29. Id., pp. 6291-6293.

30. Pueden consultarse, entre otros: AmUnÁTegui Rodríguez, C.: Uniones de Hecho. Una nueva visión después de la publicación de las Leyes sobre parejas de hecho, Valencia, Tirant lo Blanch, 2002; MEIL LANDWerlin, G.: Las uniones de hecho en España, Madrid, CIS, 2003; MESA MARrero, C.: Las uniones de hecho, Navarra, Aranzadi, 2006. 


\section{LOS COLECTIVOS HOMOSEXUALES: DEMANDAS Y PROPUESTAS}

Los colectivos homosexuales reaccionaron ante la proposición del PP. La Comisión de Derechos de la Coordinadora gay-lesbiana (GLV), redactó un manifiesto que el 25 de noviembre de 1997 entrega a los grupos parlamentarios, en contestación a la proposición del partido popular. Del manifiesto, encabezado por un título reivindicativo: Familias diversas, iguales derechos, entresacamos algunas cuestiones por su significación: «[...] En consecuencia creemos oportuno que se continúe discutiendo, enmendando y mejorando el Proyecto de Ley de Parejas de Hecho presentado por Coalición Canaria y admitido a trámite por el Congreso de los Diputados el pasado 27 de mayo. Y, sin perjuicio a que puedan regularse otras formas de relación o compañía, nos oponemos al Proyecto de Ley Orgánica de Uniones Civiles presentado por el Partido Popular que elimina la equiparación de las parejas de hecho al matrimonio tal como ya figura en las anteriores leyes referidas y que sería un retroceso en el reconocimiento e igualdad de derechos de las parejas de hecho respecto del matrimonio ${ }^{31}$.

31. El escrito nos ha sido facilitado por la GLV, y está firmado por el Colectivo de Lesbianas y Gays de Madrid (COGAM), el Col.lectiu Lambda de València, la Coordinadora Gai-Lesbiana. Su contenido íntegro es el siguiente:

«La situación de discriminación y desigualdad que sufren las parejas de hecho en nuestro país respecto de las parejas matrimoniales no puede continuar perdurando por más tiempo.

Problemas derivados de los derechos de sucesión, pensiones, seguridad social, residencia de pareja extranjera, etc. exigen respuesta inmediata. Especialmente se ven discriminadas las parejas de gays y de lesbianas afectadas por el VIH/SIDA cuyos problemas requieren una urgente y solidaria solución.

Ante esta situación las entidades, ONG's y personas firmantes desean manifestar ante la opinión pública, grupos parlamentarios del Congreso de los Diputados y Gobierno del Estado que:

Consideramos básicos para la ordenación de nuestra convivencia el respeto a los principios constitucionales de no discriminación e igualdad de todas las personas, libre desarrollo de la personalidad y protección de la familia.

Entendemos que el matrimonio no es la única forma de organizar la libre relación afectiva entre las personas. Asistimos en la actualidad al desarrollo de diversas formas de familia en nuestra sociedad. En este sentido las relaciones de pareja estables no matrimoniales no tienen por qué sufrir pérdida de derechos.

Ciudadanas y ciudadanos somos iguales en deberes y derechos, luego no debe conculcarse por más tiempo la igualdad de derechos por causa de la forma de relación amorosa libremente adoptada.

Nos felicitamos por los avances legislativos que ya en nuestro país han comenzado a equiparar las parejas de hecho al matrimonio como análoga relación de afectividad con independencia de la orientación sexual así reza la LAU, la Ley de Indemnizaciones a Víctimas de la Violencia y varios artículos del Código Penal, en su día promulgado con pleno consenso del arco parlamentario por lo que respecta a las parejas de hecho.

Así pues, atendiendo a esta fórmula de equiparación que coincide además con numerosas sentencias de nuestra jurisprudencia y con las recomendaciones del Parlamento Europeo de febrero de 1994, que igualan los derechos de las parejas homosexuales al matrimonio, instamos al poder legislativo a continuar por esta vía de equiparación de derechos.

En consecuencia creemos oportuno que se continúe discutiendo, enmendando y mejorando el Proyecto de Ley de Parejas de Hecho presentado por Coalición Canaria y admitido a trámite por el Congreso de los Diputados el pasado 27 de mayo. Y, sin perjuicio a que puedan regularse 
En enero de 1998 Miguel Ángel Sánchez Rodríguez presidente de la Fundación Triángulo por la igualdad social de gays y lesbianas, critica en un artículo las trabas puestas por el Partido Popular a la ley de parejas ${ }^{32}$. En su opinión el PP ante la puesta en marcha del trámite parlamentario de una ley que reconocía a las parejas homosexuales como unidades familiares, se vio obligado a presentar su propio texto. Texto en el que tienen cabida situaciones distintas a fin de no reconocer que las parejas de hecho son familia, opinión que fue expresada de manera clara por el señor Trías.

La prensa, atenta a este tema desde el principio, también recogió las diferentes posturas que se suscitaron con ocasión tanto de la presentación de la proposición del PP como de la toma en consideración ${ }^{33}$.

Ante la posibilidad de que se eternizara la tramitación parlamentaria, los colectivos homosexuales convocaron a una macro manifestación en Madrid para el 28 de marzo bajo el lema: «ley de parejas, ya» ${ }^{34}$.

Ahora bien, si importantes son las actuaciones realizadas ante determinadas propuestas, mayor trascendencia revisten las actuaciones generales. A este respecto hay que decir que, los colectivos homosexuales han mantenido, aunque con diferente intensidad, una actitud activa en demanda de lo que consideran sus reivindicaciones básicas ${ }^{35}$. Y en lo referente a la problemática de las UDH parece que la intención ha sido la de englobar las cuestiones controvertidas sin diferenciación entre uniones homosexuales y heterosexuales, quizá para que se admitieran mejor éstas últimas. De modo que podría afirmarse que han

otras formas de relación o compañía, nos oponemos al Proyecto de Ley Orgánica de Uniones Civiles presentado por el Partido Popular que elimina la equiparación de las parejas de hecho al matrimonio tal como ya figura en las anteriores leyes referidas y que sería un retroceso en el reconocimiento e igualdad de derechos de las parejas de hecho respecto del matrimonio».

32. Véase SÁnchez Rodríguez, M. A.: "La Ley de Parejas y las zancadillas del PP», Temas para el Debate, 38 (1998), pp. 44-47. Miguel Ángel Sánchez Rodríguez es presidente de la Federación estatal de gays y lesbianas y miembro del colectivo gay de Madrid.

33. Entre los titulares más significativos: «Los 'gay' contra la idea del PP de enmendar la ley de parejas de hecho", "El PP presenta oficialmente su propuesta de ley de uniones civiles. La fórmula popular evita hablar de parejas de hecho», «El PSOE llama 'filibustero' al PP en relación con las parejas de hecho", "La ley del PP que admite todo tipo de uniones civiles dispara las pensiones de viudedad", "El Congreso acepta tramitar la proposición de ley sobre uniones civiles del PP. El PSOE describe el proyecto como 'incitación al fraude fiscal'", El País, 3 de septiembre de 1997, 20 de septiembre de 1997, 24 de septiembre de 1997, 10 de noviembre de 1997, 26 de noviembre de 1997, respectivamente.

34. Véase: «El movimiento Gay decide en Valencia una manifestación por la ley de parejas de hecho", El País, 19 de enero de 1998. Se da noticia del acuerdo de las organizaciones españolas de gays y lesbianas reunidas en su quinto encuentro estatal, por el que se convoca la manifestación. La protesta se organiza para «reclamar la Ley de Parejas de hecho [...] actualmente parada en el parlamento», y manifestar que están «rotundamente en contra» de la proposición del Partido Popular.

35. La documentación y el material al que a continuación se hará referencia nos ha fue facilitado por el CRECUL y el COGAM, a los que agradezco su colaboración, y muy especialmente a $\mathrm{M}^{\mathrm{a}}$ Elena de León y Mili Hernández, así como a todas aquellas personas que con su participación han hecho factible mi acercamiento y comprensión de la problemática homosexual. Para documentación general resulta de interés consultar las páginas webs de los diferentes colectivos. 
colaborado de manera significativa a crear el clima de opinión sobre el que se elaboraron los primeros borradores y proyectos.

No se puede afirmar que existiera una unanimidad absoluta ni en los planteamientos iniciales, ni en las diferentes cuestiones que han ido surgiendo al hilo de, lo que podrían llamarse, las negociaciones con los partidos políticos. Las variables en un primer momento consistían en apoyar lo que se denominó: una 'ley de máximos' o una 'ley de mínimos'. La distinción era importante ya que implicaba que, o se pedía la eliminación de las trabas que impedían contraer matrimonio a los homosexuales, o se era favorable a admitir proyectos diferentes, menos ambiciosos, aunque no alcanzaran el techo reivindicativo. De la documentación consultada se deduce la opción por la segunda posibilidad, que, ello no obstante no supone renuncia a los planteamientos propios sino un primer paso en la lucha por la igualdad. Un escollo posterior, venía dado por el tema de la adopción y la problemática generada en torno a la misma.

A partir de aquí, considero necesario hacer un breve apunte de cómo y cuál ha sido la actividad realizada por los colectivos homosexuales, o lo que es lo mismo, las demandas y propuestas por ellos planteadas.

En 1990 se crea el Comité reivindicativo y cultural de lesbianas (CRECUL) de Alcorcón (Madrid) ${ }^{36}$, y se inscribe por Resolución de la Secretaría General Técnica del Ministerio del Interior el 23 de enero de 199137. Al tiempo también se constituye la Federación de Gays y lesbianas (FEGL), cuya acta viene sellada por el Ministerio del Interior y el Ministerio de Asuntos Sociales.

Los trabajos realizados por los diferentes colectivos suponen la elaboración de distintos proyectos para regular las parejas de hecho que ven la luz durante el año $93^{38}$. Así, por ejemplo, el 20 de septiembre la FEGL remite una carta circular en la que se informa que el 18 de septiembre se realizó la presentación de la propuesta para regular las parejas no casadas con la que se viene a cubrir el vacío legislativo existente ${ }^{39}$.

36. El acta fundacional está firmada en Madrid a 16 de noviembre de 1990.

37. Con el número Nacional 97.216.

38. Véase SÁnCHEZ Rodríguez, MA.: "La Ley de Parejas y las zancadillas del PP», op.cit., p. 44.

39. La carta circular, firmada por $\mathrm{M}^{a}$ Elena de León y Miguel Ángel Sánchez, secretaria y secretario general respectivamente, es del siguiente tenor: «El pasado sábado, 18 de septiembre, se realizó la presentación de la propuesta para regular las parejas no casadas elaborada por la federación estatal de Gays y Lesbianas y que está siendo presentada a los diversos grupos políticos y sociales para su discusión y posterior aprobación.

La propuesta cubre el vacío legislativo existente y la desprotección que en este momento tienen tanto las parejas de gays y lesbianas como las de heterosexuales no casados.

El texto no trata, por tanto, exclusivamente las relaciones de pareja entre personas del mismo sexo, sino que es global para todas las parejas, mencionando expresamente ambas posibilidades.

La FEGL, está enviando este proyecto a múltiples grupos sociales tanto de gays y lesbianas como otros movimientos sociales, iniciando de este modo un debate que concluirá con la aprobación de una ley que ha sido el eje básico de las demandas de gays y lesbianas desde la transición: el reconocimiento de las parejas de hecho y su regulación jurídica. Una realidad social que aún no ha sido recogida por el legislador. 
Uno de los primeros a los que he tenido acceso, contempla la regulación para las Parejas de Hecho, entendiendo por tales: «La unión estable entre dos personas, sean o no del mismo sexo, sin vínculo matrimonial previo subsistente, que comporte una comunidad de afecto y de bienes análoga a la del matrimonio» (art. 1) $)^{40}$.

Se apunta lo que se considera como fundamental o básico a la hora de realizar una regulación de las UDH: la definición o concepto, el modo de acreditar la relación, la equiparación al matrimonio en cuanto a determinados efectos

Esperamos que el proyecto os parezca interesante, en caso de que así sea y queráis apoyarlo, os rogamos nos lo hagáis saber lo más pronto posible, de forma que podamos analizar posibles campañas. Para cualquier información adicional poneos en contacto con la dirección que encabeza la carta».

40. El resto del proyecto era del siguiente tenor:

"Artículo segundo. Esta relación afectiva y de bienes análoga a la del matrimonio, producirá sus mismos efectos contractuales y jurídicos cuando: a) Los convivientes se inscriban en el Registro Municipal de la ciudad donde residan y que a tal efecto deberá ser aperturado por las Entidades Locales en virtud de la autonomía administrativa que la Constitución española les otorga, tras la presentación del documento de empadronamiento en un mismo domicilio particular, expedido por el propio ayuntamiento a efectos censales. B) Mediante acta notarial en la que los convivientes, en acto consentido y libre de su voluntad, ante el fedatario público, haga constar su situación de convivencia como pareja de hecho ante la imposibilidad, en el caso de parejas del mismo sexo, de contraer matrimonio bajo el ordenamiento jurídico español. C) Por cualquier otra prueba de las admitidas en Derecho y tras seis meses de convivencia demostrada en un mismo domicilio particular. D) En el caso de que en las mencionadas parejas de hecho, concurran hijos biológicos de los mismos ambos convivientes, las previas disposiciones les serán de aplicación con independencia de la duración de su convivencia.

Artículo tercero. El régimen económico al que quedará sometida la Pareja de Hecho, será el Régimen de Separación de Bienes.

Artículo cuarto. La Pareja de Hecho, fundada y formada por los convivientes, se considerará disuelta: a) Por muerte, Declaración de Fallecimiento o expedición del Certificado de Defunción, una vez cumplidos los plazos y efectos de la Ausencia. B) Por voluntad unilateral declarada de forma expresa por cualquiera de los convivientes, dejando sin efecto la comunidad afectiva y de bienes, análoga a la del matrimonio y obtenida previamente por cualquiera de los medios expuestos en el Artículo Segundo manifestada ante el Registro Municipal donde estuviera inscrita la relación, ante el Notario que expidió el Acta de Convivencia o cargando con prueba contraria a la presentada como cualquiera de las admitidas en Derecho.

Artículo quinto. Una vez disuelta la Pareja de Hecho, cesarán todos los efectos contractuales y jurídicos análogos a los del matrimonio. Las partes acordarán un régimen económico disolutorio en el que intervenga la autonomía de la voluntad y en el que, en caso de desacuerdo, dirima la figura de un juez de Familia aplicando la analogía respecto de las normas del Régimen económico Matrimonial y del Régimen de Separación de Bienes.

Artículo sexto. Los efectos jurídicos, análogos a los del matrimonio, comprenderán los relacionados con todo el derecho de familia y sucesiones: nacionalidad, filiación, patria potestad, tutela, curatela, adopción, herencias testadas y ab-intestato, derecho laboral, seguridad social y pensiones, derecho tributario, derechos arrendaticios, etc.; Instando a las Cortes Generales y al Gobierno del Estado español la exigencia de desarrollar, por mandato del artículo 9.2 de la Constitución Española, el contenido de la Recomendación del Parlamento Europeo sobre la Igualdad de Derechos de los Homosexuales y Lesbianas en la Unión Europea de febrero de 1994, removiendo todos los obstáculos formales y jurídicos que los Códigos y Leyes Especiales, Orgánicas u Ordinarias, presenten, de acuerdo también con los artículos 10.1 y 14 sobre Derechos y Libertades Fundamentales como valores superiores del ordenamiento jurídico español por el artículo 1.1 de la misma norma fundamental». 
jurídicos; la remoción de los obstáculos formales y jurídicos que impidan la igualdad. Hay que advertir que los borradores más apoyados fueron los que contenían propuestas de mínimos.

Borradores como éste fueron tomados en consideración en la elaboración del texto realizado por el Ministerio de Asuntos Sociales y presentado por la Ministra Cristina Alberdi a los medios de comunicación a finales del año $94^{41}$. Se dijo que, "el proyecto de ley sobre familias de hecho (sin vínculo matrimonial) no discriminará a los homosexuales ni lesbianas, ya que en esta futura normativa legal no se tiene en cuenta la condición sexual de los integrantes de estos núcleos familiares» ${ }^{42}$.

El CRECUL no sólo plantea sus reivindicaciones en el ámbito nacional. En enero de 1995 ejercen el derecho de petición ante el Parlamento Europeo a fin de que desaparezcan las discriminaciones para las relaciones entre personas del mismo sexo. El objetivo era conseguir que por el Parlamento se emitiera una directiva, no una recomendación. El documento estaba dirigido al Presidente de la Comisión de Peticiones del Parlamento Europeo ${ }^{43}$. La Comisión de Peticiones admitió la solicitud al considerar que las cuestiones planteadas tienen cabida en el ámbito de actividades de las Comunidades Europeas ${ }^{44}$.

41. En la Navidad de 1994 en una carta de felicitación de la Ministra de Asuntos Sociales a Ma Elena de León (CRECUL), se puede leer: «[...] a la vez que agradeceros el apoyo firme de todos vosotros para realizar las difíciles y gratificantes tareas de gobierno. [...] Sé que se han conseguido logros importantes, pero también sé que no podría haberlo hecho sin vuestra colaboración y apoyo".

42. Véase: El País, 15 de diciembre de 1994: «La ley de uniones de hecho no discrimina a los homosexuales, según Alberdi». Según la información que se contiene en la noticia, la Ministra indicó que esta ley igualará los derechos de las familias de hecho con las tradicionales, tanto en los aspectos administrativos, como laborales y civiles. El texto que estaba «bastante avanzado» no llegó a presentarse por el Gobierno dada la disolución anticipada de las Cortes.

43. Está fechado en Madrid a 27 de enero de 1995. "Ante la sensibilidad mostrada por el Parlamento europeo hacia la mejora legal y social de los homosexuales y lesbianas de la Europa actual, manifestada a través de recomendaciones como la emitida el pasado 8 de febrero de 1994 sobre la IGUALDAD DE LOS DERECHOS de los homosexuales y lesbianas en la Comunidad Europea (A3-0028/94), así como propuestas de resolución presentadas por los diputados: LOMAS, sobre los derechos civiles de los homosexuales y lesbianas (B3-1186/92), BETTINI y otros, sobre reconocimiento de las uniones civiles de parejas formadas por individuos del mismo sexo (B31079/92), conocedores, así mismo, del proyecto de directiva para luchar contra la discriminación por razones de orientación sexual en el ámbito laboral y otros ámbitos jurídicos, elaborado por la federación de homosexuales de Alemania (Schwunleuverband, SVD) de conformidad con el artículo 8D del Tratado de la Unión Europea de Maastricht, VENIMOS A EJERCER EL DERECHO DE PETICIÓN, en los siguientes términos:

Que por el Parlamento europeo se emita una directiva encaminada a la supresión de todas las disposiciones jurídicas existentes en los países de la comunidad Europea que discriminen las relaciones sexuales entre personas del mismo sexo así como la correspondiente adaptación de los derechos de los diferentes países hacia una equiparación de los derechos de gays y lesbianas a la del matrimonio".

44. En escrito de 22 de noviembre de 1995 se contestó a la solicitud en los siguientes términos: «Me complace comunicarle que la Comisión de Peticiones examinó su solicitud el 29 de mayo de 1995 y consideró que las cuestiones planteadas son admisibles en virtud del Tratado de la Unión Europea, es decir que su objeto incide en el ámbito de actividades de las Comunidades 
Las actividades del CRECUL siguen su andadura en lo concerniente a la regulación de las UDH por el parlamento español. De modo que continúan sus contactos con los grupos parlamentarios, presionan al PSOE una vez registrada su proposición y durante su tramitación. Y como Comité reivindicativo presentan su propio borrador al Grupo Parlamentario de Izquierda Unida en 1996, borrador que entienden se acerca más a los máximos que deberían contemplarse.

Del borrador -«Proposición de ley para la igualdad jurídica de las parejas de hecho con independencia de su orientación sexual»-, que fue tomado en consideración por IU para presentar su propuesta, vale la pena destacar que en la Exposición de Motivos se contempla como justificación los argumentos que utilizara la izquierda ${ }^{45}$.

Europeas. La Comisión consideró oportuno que las observaciones formuladas en la petición sean trasladadas a la Comisión de Libertades Públicas y de Asuntos interiores del Parlamento Europeo.

La Comisión de Peticiones me ha encargado informarle que sobre esta base se ha concluido el examen de su petición». Del tema se hizo eco la prensa, así por ejemplo en El Mundo, de 19 de abril de 1997, se puede leer el siguiente titular: «Los 'gays' apremian a la Eurocámara a aprobar sus derechos".

45. "La existencia real de las uniones de hecho independientemente de su orientación sexual en nuestro Estado Español es patente desde siempre, lo cual debe considerarse como una realidad cotidiana. Hay amplia jurisprudencia que lo demuestra y se han llegado a recoger y regular legislativamente algunos derechos, véase Ley 21/1987 de 11 de Noviembre que reconoce a las parejas unidas de forma permanente por relación de afectividad análoga a la conyugal, la posibilidad de adoptar hijos conjuntamente, véase la última Ley de Arrendamientos Urbanos, la Ley reguladora del derecho al Asilo y Ley Orgánica del Poder Judicial.

Diversos países de la CE han regulado ya diversos derechos de las uniones de hecho con independencia de su orientación sexual.

Nuestra Constitución Española en el Art. 14 de Capítulo II. Derechos y Libertades. Dice «Los españoles son iguales ante la ley, sin que pueda prevalecer discriminación alguna por razón de nacimiento, sexo, religión, opinión o cualquier otra condición o circunstancia personal o social». Entendemos, pues, tal condición o circunstancia personal o social aplicable a la orientación sexual de cada individuo. Así mismo, nuestra Constitución en su artículo 32. sección segunda. De los derechos y deberes de los ciudadanos. Dice: «El hombre y la mujer tienen derecho a contraer matrimonio con plena igualdad jurídica» de ninguna forma interpreta la unión matrimonial como un deber, si bien es así, las personas que no hayan hecho uso de este derecho y hayan decidido unirse en análoga relación de afectividad no han de ser excluidas de su derechos de pareja estable en plena igualdad con respecto a las uniones matrimoniales, e independientemente de la orientación sexual, en coherencia con el artículo 14 de nuestra Constitución. En definitiva el Artículo 39 de nuestra Constitución indican la obligación de los poderes públicos de asegurar la protección social, económica y jurídica de la familia.

Por otra parte, la Resolución del Parlamento Europeo de 8 de febrero de 1994 sobre la igualdad de derechos de los homosexuales y lesbianas en la CE, pide expresamente a los Estados Miembros, punto 7. Que se ponga fin al trato desigual de las personas de orientación homosexual en las disposiciones jurídicas y administrativas, así mismo pide expresamente a la Comisión de la Comunidad Europea. Punto 14. que la recomendación debería poner fin entre otros a la prohibición de contraer matrimonio o acceder a regímenes jurídicos equivalentes a las parejas de lesbianas o de homosexuales; la recomendación debería garantizar los plenos derechos y beneficios del matrimonio permitiendo la inscripción de la convivencia, y a toda restricción de los derechos de las lesbianas y de los homosexuales a ser padres, a adoptar o criar niños. 
Una vez tomada en consideración la proposición canaria, también los colectivos siguen estando presentes en el iter de la tramitación parlamentaria. Así, tenemos noticia de que fueron convocados por la Subcomisión que se crea en la Comisión de Justicia del Congreso para el estudio de la regulación de las situaciones y efectos jurídicos derivados de las uniones de hecho ${ }^{46}$, y también de la elaboración de enmiendas que presentan a los grupos parlamentarios.

El Colectivo de Gays y Lesbianas de Madrid (COGAM) elabora unas enmiendas parciales a la Proposición de ley sobre reconocimiento de efectos jurídicos a las parejas de hecho estables y modificación de determinados efectos aspectos del Código civil, estatuto de los Trabajadores, Ley General de la Seguridad Social, Medidas para la Reforma de la Función Pública, Clases Pasivas del Estado y de la Ley del Impuesto sobre Sucesiones y Donaciones, para consensuar por los grupos de gays y lesbianas, y que fueron presentadas al PSOE dentro del plazo de presentación de enmiendas a la proposición canaria ${ }^{47}$.

De entre las modificaciones alternativas que se proponen considero relevante entresacar y reproducir las siguientes:

Con todo ello se pretende con el presente proyecto de ley la equiparación jurídica de las personas que convivan en análoga relación de afectividad con independencia de su orientación sexual, considerándose unión de hecho a la unión libre, pública y notoria de dos personas independientemente de su orientación sexual, mayores de edad, sin vínculos de parentesco en primer y segundo grado de consanguinidad. Ninguno de los miembros de la unión de hecho podrá estar unido por un vinculo matrimonial en vigor, a otra persona, salvo en los supuestos en que la ruptura de dicho vinculo sea imposible por causas ajenas a las voluntades de las partes.

La unión de hecho podrá acreditarse a través de la inscripción en los registros específicos existentes en las Comunidades Autónomas o Ayuntamientos, a través del padrón municipal o mediante documento público. Cuando se extinga la unión de hecho ambos miembros o un solo miembro de la misma instará la cancelación de la inscripción en los registros correspondientes y/o anulación de los documentos».

Tiene fecha de 4 de noviembre de 1996. Por lo que respecta a las modificaciones legislativas que propone estas afectan al: Código Civil, Estatuto de los Trabajadores, Ley General de Seguridad Social y, Código Financiero y Tributario; y son substancialmente coincidentes con las presentadas en la proposición del Grupo Parlamentario Federal de Izquierda Unida-Iniciativa per Catalunya. Puede verse: Boletin Oficial de Las Cortes Generales. Congreso de los Diputados. VI Legislatura, Serie B, nº 88-1, de 10 de abril de 1997.

46. El Presidente del Congreso de los Diputados, en fecha 3 de junio de 1997 (con Registro de salida del día 4), convoca a Doña M $M^{a}$ Elena Criado de León (Presidenta del CRECUL) con la siguiente carta: "La Subcomisión para el estudio de la regulación de las situaciones y efectos jurídicos derivados de las uniones de hecho, con independencia del sexo de sus integrantes, y otras formas de convivencia distintas del matrimonio, ha acordado solicitar la comparecencia de diversas personas y representantes de organismos con reconocida experiencia o conocimientos sobre el tema, entre los que se encuentra usted.

A tal efecto, me complace convocarle para el día 10 de junio de 1997, a las 19.00 horas, a fin de que pueda proponer a la Subcomisión su opinión respecto a la problemática objeto de estudio». Parece lógico suponer que en términos similares han sido convocados otros colectivos. Otro tanto se desprende de la tramitación que realiza el Parlamento de Cataluña, ya que en los antecedentes del «Proyecte de llei sobre relacions de convivència diferents del matrimoni», el punto 6 se refiere a: «Persones, entitats i organismes consultats», véase: Butlletí Oficial del Parlament de Catalunya, cit., p. 18562.

47. Las enmiendas van firmadas por Pedro González Zerolo (COGAM) y Luisa Estévez Martínez. Abogada. 


\section{En el Capítulo I: Disposiciones Generales}

Artículo $1^{\circ}$.- «La presente ley será de aplicación a las parejas de hecho que cumplan con los requisitos señalados en la misma.

Son parejas de hecho las uniones de los mayores de edad o menores emancipados que, sin vínculo de parentesco en primer o segundo grado de consanguinidad y con independencia de su orientación sexual, estén unidas por una relación de afectividad pública y notoria, análoga a la de los cónyuges.

No podrán constituir pareja de hecho los que estén ligados por vínculo matrimonial».

Artículo $2^{\circ} \cdot 1^{\circ}$. ${ }^{*}$ Opción A: «La constitución de la pareja de hecho podrá acreditarse mediante su inscripción en los registros específicos existentes en la Comunidad autónoma o Ayuntamiento del lugar del domicilio».

*Opción B: «Las parejas de hecho deberán inscribirse en el Registro Civil del lugar del domicilio".

Artículo $2^{\circ} .2^{\circ}$.- "Cualquiera de los convivientes de la pareja de hecho podrá instar la cancelación de la inscripción de aquella. Dicha cancelación deberá ser notificada de forma fehaciente al otro conviviente» ${ }^{48}$.

Y por lo que respecta a las actividades en relación con la proposición del Grupo Popular, éstas ya han sido objeto de atención en páginas anteriores.

Para finalizar me gustaría dejar constancia de que siguiendo con los movimientos, actividades y reivindicaciones a que venimos haciendo referencia, la Asociación Internacional de Lesbianas y Gays (ILGA), cuyo secretario es Jordi Petit -en ese momento-, es ONG consultiva de los países miembros del Consejo de Europa ${ }^{49}$.

Hasta aquí he señalado las cuestiones a mi entender más relevantes que van coincidiendo en el tiempo con las proposiciones presentadas por los grupos parlamentarios de izquierda. Ahora bien, con ellas no se agotan las actuaciones

48. Además, se contemplan las siguientes: en el Capítulo II. Modificaciones al Código Civil, se deberá añadir un nuevo artículo por el que se modifican los artículos 807, 834, 837, 839, 840; se modifica el art. $22,2^{\circ}$ d) y e); se añade un nuevo art. que modifique el art. 175 párrafo cuarto, o se modifica la Disposición Adicional Tercera de la Ley 21/1987, de 11 de noviembre; se modifican los artículos 181, 182 y 183 del Código Civil en el sentido de ampliar las referencias que en dicho texto se hacen al cónyuge a los convivientes en las parejas de hecho; se modifica el art. 202 del Código Civil; se modifica el art. 234 párrafo primero del Código Civil; se modifica el art. 294 del Código Civil. En el Capítulo V. Legislación fiscal. Se propone una enmienda parcial a la proposición y, para que se modifique la Ley 18/91, de 6 de junio que regula el impuesto de la renta de las personas físicas, se modificará el art. 87. Además y por lo que se refiere a la Legislación de extranjería, se dice expresamente que «siendo Ley orgánica la ley que regula los derechos y libertades de los extranjeros en España, no puede pretenderse la modificación de la misma a través de esta Ley, que no tiene aquel rango. Sí podría pretenderse la modificación de algunos reglamentos o reales decretos que desarrollan aquella Ley».

49. Puede verse: El Mundo, 21 de enero de 1998, «La Asociación de Lesbianas y 'Gays', ONG consultiva del Consejo de Europa». El secretario general manifestó que se trata de "un avance histórico de los derechos de las lesbianas y gays en todo el mundo y una enorme contribución a la campaña que se está llevando a cabo coincidiendo con el 50 aniversario de la Declaración Universal de los Derechos Humanos: los derechos de lesbianas y gays son derechos humanos». 
de los colectivos homosexuales que han continuado en su línea reivindicativa hasta la aprobación de la Ley que nos ocupa.

\section{CONCLUSIONES: ¿FAMILIA/S?}

A día de hoy, resulta imposible realizar unas conclusiones generales, pero me gustaría establecer una serie de cuestiones a modo de conclusiones:

El debate en torno al acceso al matrimonio de personas del mismo sexo -el denominado comúnmente, matrimonio homosexual-, se conecta con la construcción tradicional del matrimonio y la familia. A este respecto considero imprescindible hacer notar su conexión con el matrimonio-la familia tradicional católica. Que en el caso español viene reforzada por la tradicional confesionalidad católica.

La sociedad española de las últimas décadas ha ido construyendo sus propios modelos familiares con lo que parece una tolerancia cada vez mayor de los $\operatorname{mismos}^{50}$, lo cual no lleva necesariamente consigo que exista una equivalencia entre los modelos sociales y los modelos jurídicos ${ }^{51}$.

La confesionalidad católica española ${ }^{52}$-a excepción de los dos períodos republicanos- hasta épocas relativamente recientes, ha tenido una repercusión clara en materia matrimonial. No sólo porque el matrimonio civil era una figura copiada a imagen y semejanza del canónico, ni porque el matrimonio canónico fuera preponderante, lo que conllevaba un sistema de matrimonio civil subsidiario, sino también porque junto al transvase de conceptos e instituciones se producía un transvase de valores de un ordenamiento a otro ${ }^{53}$. Jurídicamente, la situación cambia como he expuesto en páginas anteriores, con la aprobación del texto constitucional y la subsiguiente normativa de desarrollo. Se produce una cesura en los principios por los que se regían las relaciones Iglesia-Estado lo cual tiene su reflejo también en materia matrimonial.

50. Véase el número monográfico: «Familias y parejas: paradojas y nuevas opciones», Revista de Occidente, 199 (diciembre de 1997).

51. Sobre la temática social de la familia, ya a finales del siglo XX, véase CAMPO URBANO, S.: La evolución de la familia española en el siglo XX, Madrid, Alianza, 1982; Idem., Familias: sociología y política, Madrid, Editorial Complutense, 1995; ALBERDI, I. (dir.): Informe sobre la situación social de la familia en España, Madrid, Ministerio de Asuntos Sociales, 1995.

52. Puede verse MONTESINOS SÁNCHEZ, N.: La confesionalidad, pieza clave en la historia constitucional española y en el régimen franquista. Tesis Doctoral (inédita), Alicante, 1991.

53. Como ejemplificativo puede ser de utilidad: PÉREZ RUIZ, C.: La argumentación moral del Tribunal Supremo (1940-1975), Madrid, Tecnos, 1987. En particular y por cuanto se refiere a la «argumentación moral en relación con la familia», pp. 223-270. 
El 'ius connubii' se encuadra como un derecho constitucional ${ }^{54}$, no como un derecho fundamenta $1^{55}$, y el matrimonio como uno de los cauces posibles legalmente para el libre desarrollo de la personalidad; se invierte la relación entre 'ius connubii' e institución matrimonial siendo ésta quien está al servicio del desarrollo y realización de la primera, y no a la inversa, en razón del principio personalista ${ }^{56}$. Además, el ordenamiento prevé la libertad en cuanto a la forma de celebración sea esta civil o religiosa, con idénticos efectos civiles. Y por lo que se refiere a la familia, si el matrimonio ha sido básicamente la fuente generadora de la misma de modo que el modelo familiar se ha visto fuertemente caracterizado por la construcción de la institución matrimonial y en particular de la institución matrimonial canónica, hoy ya no existe acuerdo absoluto acerca del modelo familiar que se desprende del texto constitucional. De modo que el debate sobre el matrimonio homosexual y las UDH, habida cuenta que la Constitución, aún sin pronunciarse sobre $\operatorname{ellos}^{57}$, deja abierta la posibilidad de otros tipos de convivencia que también contribuyen a la realización de libre desarrollo de la personalidad, ha comprometido ambas instituciones.

Con todo, la Iglesia Católica no se ha mantenido al margen de la problemática actual. Su propia estructuración y concepción del matrimonio, con los requisitos de validez que lo caracterizan ha hecho que diferenciara claramente distintos supuestos, algunos de los cuales: como la estimación del matrimonio civil celebrado entre personas obligadas a la forma canónica, no tienen parangón en la legislación civil. Además, en su apreciación no sólo confluyen elementos distintos: jurídicos y pastorales ${ }^{58}$, sino que no entra a dirimir los efectos meramente civiles puesto que los considera de estricta competencia estatal ${ }^{59}$.

54. Encuadrado en la sección segunda del capítulo II, el artículo 32 establece: 1. «El hombre y la mujer tiene derecho a contraer matrimonio con plena igualdad jurídica». 2. "La Ley regulará las formas del matrimonio, la edad y capacidad para contraerlo, los derechos y deberes de los cónyuges, las causas de separación y disolución y sus efectos»; artículo que habrá que poner en relación con el 14 de la propia Constitución, el 16 de la Declaración Universal de Derechos Humanos, el 23 del Pacto de Derechos Civiles y Políticos, y el 44 del Código Civil.

55. En el ordenamiento canónico se habla de derecho natural, fundamental.

56. En este sentido, LlamaZARes FernándeZ, D.: El sistema matrimonial español. Matrimonio civil, matrimonio religioso y matrimonio de hecho, Madrid, Servicio de publicaciones de la Facultad de Derecho. Universidad Complutense, 1995, pp. 293-295.

57. En el artículo 27 del Anteproyecto se decía: «A partir de la edad núbil, el hombre y la mujer tienen derecho a contraer matrimonio y a crear, y mantener, en igualdad de condiciones, relaciones estables de familia». El Informe de la Ponencia de 17 de abril de 1978 reduciría texto y contenido: «A partir de la edad núbil, el hombre y la mujer, en plena igualdad de derechos y deberes, podrán contraer matrimonio para crear una relación estable de familia.

58. Ya que frente a la elaboración jurídica del modelo matrimonial canónico, no se puede hablar de un Derecho de Familia, ya que ésta encuentra dentro del ámbito eclesial su lugar adecuado dentro de la teología y la pastoral. Véase MARTínez BlANCO, A.: «La familia de hecho ante el Derecho Canónico y el derecho Eclesiástico", Anuario de Derecho Eclesiástico del Estado, XI (1995), pp. 189-224, en particular, p. 201; MONTESINOS SÁNCHEZ, N.: "Familia y Derecho...», op.cit., p. 363.

59. Así y con respecto al matrimonio canónico, en el canon 1059 se establece: «El matrimonio de los católicos, aunque sea católico uno sólo de los contrayentes, se rige no sólo por el derecho 
Frente a las posiciones adoptadas por algunos ordenamientos civiles tendentes a la equiparación de efectos con el matrimonio, ésta no se admite por la Iglesia, ya que no se trata tan sólo de que no se den los requisitos formales del matrimonio, sino y fundamentalmente, de que no hay un consentimiento que haga surgir la verdadera alianza matrimonial ${ }^{60}$. Y puesto que sólo cabe una unión matrimonial que sea heterosexual, se diferencia entre uniones o situaciones irregulares y uniones homosexuales.

Diferentes documentos se han pronunciado sobre ellas. La Exhortación Apostólica Familiaris Consortio entiende como situaciones irregulares «la unión sin algún vínculo institucional públicamente reconocido, ni civil ni religioso» ${ }^{61}$, e insiste en que «la familia está fundada sobre el matrimonio, esa unión íntima de vida, complemento entre un hombre y una mujer».

Por lo que se refiere a los homosexuales ${ }^{62}$, y en particular a las uniones homosexuales $^{63}$, merece la pena destacar que en diversos documentos de la Sagrada Congregación para la Doctrina de la Fe encontramos pronunciamientos sobre la consideración de la homosexualidad, la atención pastoral a estas situaciones, o las propuestas de leyes sobre no discriminación. "Según el orden moral objetivo de las cosas, las uniones homosexuales son actos que están privados de su necesaria y esencial ordenación [...] Los actos de la homosexualidad están desordenados por su intrínseca naturaleza y nunca pueden aprobarse por ninguna razón». Es más, "la inclinación misma debe ser considerada como objetivamente desordenada", [...] y ante el riesgo de que algunos grupos de homosexuales, incluso católicos afirmasen, en tono de protesta que "cualquier crítica o reserva en relación con las personas homosexuales, con su actividad y con su

divino, sino también por el canónico, sin perjuicio de la competencia de la potestad civil sobre los efectos meramente civiles del mismo matrimonio".

60. En este sentido, véase, VILADRIDCH, P.J.: "La familia 'soberana'», Ius Canonicum, 68 (1994), pp. 427-440.

61. Véase, Familiaris Consortio, n. 81.1. La situación de los católicos unidos con matrimonio civil, aunque englobada genéricamente en estas situaciones irregulares no sería del todo idéntica por la existencia de un vínculo y de una cierta estabilidad (n. 82).

62. Catecismo de la Iglesia. Constitución Apostólica «Fidei Depositum», 1992.

2357.- La homosexualidad designa las relaciones entre hombres o mujeres que experimentan una atracción sexual, exclusiva o predominante, hacia personas del mismo sexo. Reviste formas muy variadas a través de los siglos y las culturas. Su origen psíquico permanece en gran medida inexplicado. Apoyándose en la Sagrada Escritura que los presenta como depravaciones graves, la Tradición ha declarado siempre que «los actos homosexuales son intrínsecamente desordenados». Son contrarios a la ley natural. Cierran el acto sexual al don de la vida. No proceden de una verdadera complementariedad afectiva y sexual. No pueden recibir aprobación en ningún caso.

2358.- Un número apreciable de hombres y mujeres presentan tendencias homosexuales instintivas. No eligen su condición homosexual; ésta constituye para la mayoría de ellos una auténtica prueba. Deben ser acogidos con respeto, compasión y delicadeza. Se evitará respecto a ellos, todo signo de discriminación injusta. Estas personas están llamadas a realizar la voluntad de Dios en su vida, y, si son cristianas, a unir al sacrificio de la cruz del Señor las dificultades que pueden encontrar a causa de su condición.

63. Véase: AZNAR GIL, F.: "Las uniones homosexuales ante la legislación eclesiástica», Revista Española de Derecho Canónico, 52 (1995), pp. 157-190. 
estilo de vida, constituye simplemente una forma de injusta discriminación [...] La Iglesia no puede dejar de preocuparse de todo esto y por consiguiente mantiene firme su clara posición al respecto, que no puede ser modificada por la presión de la legislación civil o de la moda del momento [...]. La opinión según la cual la actividad homosexual sería equivalente o por lo menos igualmente aceptable, en cuanto expresión sexual del amor conyugal, tiene una incidencia directa sobre la concepción que la sociedad tiene acerca de la naturaleza y los derechos de la familia, poniéndolos seriamente en peligro» ${ }^{64}$.

Aun cuando hoy estas afirmaciones puedan producir una cierta perplejidad en algunos casos, no puede olvidarse que la homosexualidad desaparece del catálogo de enfermedades de la OMS a finales de los ochenta ${ }^{65}$, o, incluso que en España, siguen estando en los archivos policiales hasta los noventa.

Por todo, considero que la aprobación de la Ley supone una apuesta clara por parte del gobierno, e incluso puede tener una, al menos mínima, función pedagógica frente a un sector de población en algunos casos. Pero, aun cuando no se pueda negar el peso político de la opción asumida por el gobierno español, también es cierto que el debate acerca del matrimonio y la familia, no se cierra con la aprobación de la Ley. Sigue, cuando menos, con respecto a la adopción ${ }^{66}$, aun cuando diferentes informes mantienen que no supone ninguna situación de peligro para los menores, y ya existía la posibilidad en algunas leyes autonómicas, e individualmente por personas sin tomar en consideración su homo o heterosexualidad; también por lo que se refiere a la aplicación de la misma por los funcionarios competentes, y la posibilidad de alegar la objeción de concien$\mathrm{cia}^{67}$; y, por último, por la presentación del recurso de inconstitucionalidad por parte del Partido Popular ${ }^{68}$.

Si bien parece claro que hemos avanzado socialmente en la aceptación de modelos de convivencia diferentes del matrimonial tradicional, es de esperar que los pronunciamientos que se adopten en la resolución de situaciones de

64. Véase: Persona Humana, 29 de diciembre de 1975, n.8. En consonancia, la Familiaris Consortio dirá posteriormente que el matrimonio hunde sus raíces en el complemento natural que existe entre el hombre y la mujer y se alimenta mediante la voluntad personal de los esposos de compartir todo su proyecto de vida, lo que tienen y lo que son; por eso tal comunión es el fruto y signo de una exigencia fundamentalmente humana» (n. 19).

65. Importante también a este respecto la aportación de la Asociación de Psiquiatría de Nueva York.

66. Téngase en cuenta además que la idea del matrimonio como único lugar de la sexualidad lícita y para la procreación ya no es generalmente compartida. Bastaría hacer referencia a las nuevas técnicas de reproducción asistida.

67. Alegar objeción de conciencia en estos supuestos está totalmente en contra de todos los pronunciamientos de nuestro Tribunal Constitucional. Así lo ha entendido el Consejo General del Poder Judicial, por ejemplo, en el caso de la Jueza de Denia (Alicante), la primera que se negó a casar a una pareja homosexual. El Consejo General del Poder Judicial se ha pronunciado ya en dos ocasiones sobre la imposibilidad de alegar objeción de conciencia por los jueces encargados del Registro Civil. Sobre el particular pueden consultarse las webs de los colectivos homosexuales y del Consejo General del Poder Judicial, en las que encontramos tanto artículos de opinión como las posturas mantenidas.

68. Igualmente lo encontramos en las webs citadas y en la del Tribunal Constitucional. 
conflicto, estén en consonancia con las demandas sociales, ya que de lo contrario podríamos producir jurídicamente situaciones de involución, e incluso construir modelos familiares al margen, o contraviniendo, los preceptos constitucionales que a todas las personas amparan. 


\section{DILEMAS ÉTICOS SOBRE LA REPRODUCCIÓN HUMANA. LA GESTACIÓN DE SUSTITUCIÓN ${ }^{1}$}

BEATRIZ SOUTO GALVÁN

Universidad de Alicante

El 10 de julio de 2006 el diario El País publicó un artículo titulado «Decenas de mujeres se ofrecen en España como madres de alquiler». El subtítulo es todavía más elocuente: "La mayoría de ellas son extranjeras, se anuncian por Internet y ceden su útero por 15.000 euros». No se trata, sin embargo, de una noticia aislada acerca de un tema obsoleto. A mediados de los años 70 del siglo pasado se comenzó a efectuar una técnica reproductiva denominada vulgarmente "alquiler de útero", que, pese a la general reprobación jurídica a la que se ha visto sometida, sigue practicándose con relativa frecuencia. El conflicto ético-jurídico que genera esta práctica no ha sido resuelto definitivamente ni en el ámbito estrictamente ético ni en el legislativo, por lo que la problemática que de ella se deriva continúa plenamente vigente.

\section{ALGUNAS PRECISIONES PREVIAS}

Debemos deteneros, antes de centrar nuestro análisis en las implicaciones éticas derivadas de esta práctica, en diversas cuestiones terminológicas y conceptuales no resueltas definitivamente por la doctrina que, desde diversas áreas de conocimiento, ha tratado esta cuestión.

La terminología utilizada ${ }^{2}$ para referirse a este tipo de técnica reproductiva presenta numerosas variantes, siendo las más usuales: «maternidad subrogada, "gestación de sustitución", "alquiler de útero» o "maternidad portadora». Aun-

1. Este trabajo ha sido elaborado en el marco del Proyecto de investigación "Bioética y Derechos humanos», dirigido por el Profesor J. A. Souto Paz (Universidad Complutense de Madrid).

2. Sobre esta cuestión vid. Martínez-Pereda Rodríguez, J. M. y MASSigoge BenegiU, J.M.: La maternidad portadora, subrogada o de encargo en el Derecho español, Madrid, Dykinson, 1994, p. 19.

3. Esta última denominación fue la utilizada por el "Comité of Experts on Genetic Enginearing", creado por el Consejo de Europa en 1982, para referirse a la «técnica que consiste en que una mujer lleva en su cuerpo implantado un embrión hasta el nacimiento para beneficio de otra mujer o pareja». 
que mayoritariamente se ha optado por el término "maternidad subrogada", esta denominación no está exenta de críticas ${ }^{4}$; por una parte, el término "subrogada» resulta inadecuado para incluir los supuestos en los que hay aportación genética de la madre portadora, $y$, por otro, se ha indicado también que el vocablo «maternidad» engloba una realidad mucho más extensa que la referida a la gestación. Respecto a otra de las denominaciones más usuales: «alquiler de útero", también encuentra detractores debido a que, evidentemente, no se aporta únicamente el útero en el proceso gestacional ${ }^{5}$.

En mi opinión, la denominación más correcta es la que se utilizó por la Comisión especial de estudio de la Fecundación in vitro y la Inseminación Artificial Humanas (Comisión Palacios): "gestación de sustitución", puesto que se trata de un término que se adecua en mayor grado a la realidad que comprende que cualquier otro de los términos a los que hemos hecho referencia. Sin embargo, podrían plantearse también algunas objeciones en el caso de que la mujer que va a llevar a cabo la gestación aporte su material genético, ya que en este supuesto la gestante asume también la maternidad biológica.

Los problemas no se agotan, no obstante, en el ámbito terminológico puesto que se plantean también dudas acerca de la propia noción de "gestación de sustitución». Se ha definido la gestación de sustitución como la práctica mediante la cual una mujer gesta a un niño mediando un pacto o compromiso por el cual debe ceder todos los derechos sobre el recién nacido a favor de otra persona o personas que asumirán la paternidad o maternidad del mismo ${ }^{6}$.

El caso más frecuente de gestación de sustitución es aquel en el que el embrión de una pareja es implantado en el útero de una mujer que llevará a cabo la gestación y posteriormente dará a luz, obligándose a entregar el niño a sus padres biológicos. Pero, por otra parte, es posible que la madre portadora aporte también su óvulo que será fecundado con el semen del varón de la pareja, que tiene la intención de asumir la patria potestad. Siendo éstas dos las modalidades más frecuentes, hay que advertir, no obstante, que bajo el término maternidad subrogada se incluyen otras variantes, como por ejemplo, que la pareja que tiene intención de asumir la patria potestad del hijo gestado por sustitución no

4. Entre otros, FERNÁNDEZ-PACHECO, entiende que "esta denominación de "madre subrogada» es una expresión poco precisa y más bien periodística» ("La maternidad subrogada en Norteamérica: la Sentencia de Baby M», RGLJ, 5 (mayo 1988), pp. 647-683, p. 649).

5. En este sentido M. PÉREZ MONGE: «me parece que la denominación «alquiler de útero» ha de ser criticada por su incorrección y falta de precisión, ya que la gestación es un concepto mucho más amplio, y supone la puesta a disposición de todo el ser de la gestante para atender su embarazo" (La filiación derivada de técnicas de reproducción asistida, Madrid, Centro de Estudios Registrales, 2002, p. 331).

6. Esta noción es la utilizada por Y. GÓMEZ SÁNCHEZ, aunque la autora reduce el sujeto receptor de los derechos sobre el recién nacido a la madre que asumirá la maternidad legal del mismo ( $E l$ Derecho a la Reproducción Humana, Madrid, Marcial Pons, 1994, p. 136). 
aporte su material genético, o que no se trate de una pareja sino de un hombre o una mujer que quieren asumir la paternidad o maternidad en solitario ${ }^{7}$.

Dada la diversidad de modalidades que podemos encontrar en la práctica, la definición más acertada me parece la propuesta por Pérez Monge: "podría definirse el contrato de maternidad subrogada, en sentido amplio, como aquel contrato oneroso o gratuito, por el cual una mujer aporta únicamente la gestación, o también su óvulo, comprometiéndose a entregar el nacido a los comitentes -una persona o pareja, casada o no-, que podrán aportar o no sus gametos». ${ }^{8}$

\section{LA GESTACIÓN DE SUSTITUCIÓN EN LA LEGISLACIÓN ESPAÑOLA}

La legislación española prohíbe expresamente la gestación por sustitución desde la aprobación, en 1988, de la Ley sobre técnicas de reproducción asisti$\mathrm{da}{ }^{9}$, y ninguna de las reformas posteriores ha modificado dicha prohibición ${ }^{10}$.

7. Algunos autores, no obstante, reducen el concepto de gestación por sustitución al supuesto de la mujer que «acuerda ser inseminada artificialmente con el semen de un hombre casado, que no es su esposo, y procrear un hijo. Una vez que el hijo ha nacido, la madre cede la custodia a favor del padre y, además, renuncia a sus derechos materno filiales sobre el hijo, de manera tal que la esposa del padre pueda adoptarlo» (VIDAL MARTínEZ, J.: Las nuevas formas de reproducción humana, $1^{2}$ ed., Madrid, Civitas, 1988, p. 180).

8. PÉREZ MONGE, M.: La filiación..., op.cit., p. 329.

9. El artículo décimo de la Ley $35 / 1988$, de 22 de noviembre, sobre técnicas de reproducción asistida disponía al respecto: «1. Será nulo de pleno derecho el contrato por el que se convenga la gestación, con o sin precio, a cargo de una mujer que renuncia a la filiación materna a favor del contratante o de un tercero. 2. La filiación de los hijos nacidos por gestación de sustitución será determinada por el parto. 3. Queda a salvo la posible acción de reclamación de la paternidad respecto del padre biológico, conforme a las reglas generales». Este artículo ha sido integrado sin modificación alguna en la nueva Ley 14/2006, de 26 de mayo, sobre Técnicas de Reproducción Humana Asistida. Las Declaraciones internacionales sobre derechos humanos no se pronuncian generalmente sobre la gestación de sustitución. En el ámbito de la Unión Europea debemos tener en cuenta que el Parlamento Europeo en su Resolución (A 2-372/88), aprobada el 16 de marzo de 1989 mantuvo que toda forma de maternidad bajo comisión fuese prohibida y se declarase punible la mediación comercial, debiendo prohibirse asimismo los impresos anunciadores de tal actividad y el comercio de embriones o gametos (MARTíneZ-PEREDA RodríGUeZ, J. M. y MASSIGOGE BENEGIU, J. M.: La maternidad portadora..., op.cit., p. 71). También debemos tener presente la Carta de Derechos Fundamentales de la Unión Europea (incorporada recientemente a la Constitución Europea) que, aunque no la rechaza expresamente, prohíbe que el cuerpo humano o partes del mismo en cuanto tales se conviertan en objeto de lucro (art.3). Nos parece también relevante destacar la solución adoptada en torno a esta materia en la Declaración de la Asociación Médica Mundial sobre la Fecundación In Vitro y el Trasplante de Embriones (Madrid 1987): «En el caso de una mujer adulta que no tiene útero, el recurso al método de maternidad substituta es posible mientras este método no esté prohibido por las leyes vigentes o las normas éticas de la asociación médica nacional, o de otros organismos médicos apropiados. Se debe obtener el consentimiento libre y claro de las partes que participan de cualquier forma en este método de maternidad substituta. El uso de este método presenta repercusiones legales, éticas y morales, y el médico debe conocerlas y tenerlas en cuenta en toda decisión de recurrir a dicho método. El párrafo anterior no pretende apoyar el llamado acuerdo de los padres substitutos, mediante el cual una mujer acepta, por una determinada cantidad de dinero, ser inseminada artificialmente con el semen de un hombre con el fin de concebir una criatura que será adoptada por tal hombre y su esposa».

10. La Ley de reproducción asistida de 1988 fue modificada por Ley 45/2003. 
Es interesante resaltar que, durante la tramitación parlamentaria de la actual Ley sobre Técnicas de Reproducción Humana Asistida, de 26 de mayo, ningún Grupo Parlamentario ha presentado enmiendas que trataran de modificar la legislación vigente, otorgando la posibilidad de legalizar este tipo de práctica en nuestro país.

Antes de entrar en el análisis de la normativa vigente conviene tener presente que el legislador español a la hora de regular el campo abierto por las nuevas técnicas de reproducción humana, decidió recurrir a la creación de una Comisión especial de estudio de la Fecundación in vitro y la Inseminación Artificial Humanas (Comisión Palacios), a la que fueron convocados un grupo de expertos relacionados con estas cuestiones (biólogos, ginecólogos, juristas, filósofos y moralistas) que pudieron asesorar al cuerpo legislativo acerca de los problemas genéticos, biológicos y éticos que planteaba la reproducción asistida ${ }^{11}$.

El Informe elaborado por esta Comisión (aprobado en 1986) ${ }^{12}$ adoptó una serie de criterios que fueron determinantes en la regulación de la gestación de sustitución, contenida en la ya derogada Ley de 1988. Antes de analizar los supuestos concretos que iban a ser abordados por el legislador, la Comisión especial sintió la necesidad de determinar que ética debía utilizarse para delimitar las entonces recientes innovaciones sobre reproducción asistida ${ }^{13}$. La respuesta que la Comisión aportó a este interrogante podemos encontrarla en la propia Exposición de Motivos la legislación precedente: «Desde una perspectiva ética, el pluralismo social y la divergencia en las opiniones se expresan frecuentemente sobre los distintos usos que se dan a las técnicas de reproducción asistida. $\mathrm{Su}$ aceptación o su rechazo habrían de ser argumentados desde el supuesto de una correcta información, y producirse sin motivaciones interesadas ni presio-

11. SOUTO, J.A.: Comunidad politica y libertad de creencias. Introducción a las Libertades Públicas en el Derecho Comparado, $2^{a}$ ed., Madrid, Marcial Pons, 2003, p. 317. Hacemos una referencia a todo este proceso legislativo debido a que la actual legislación no ha modificado nada de lo dispuesto en la primera, por lo que todavía nos sirve como criterio orientativo el primer contacto que el legislador español tuvo con la problemática que ahora tratamos.

12. Sobre esta cuestión vid. SoUTO, J.A.: "El Informe Palacios y la Ley de Reproducción asistida», en Régimen jurídico-privado de la reproducción asistida en España, Madrid, Dykinson, 2006, pp. 187-196.

13. Ibíd., p. 190. El debate abierto acerca de la posibilidad de utilizar una ética común como límite a determinados avances de la biomedicina continúa sin encontrar una respuesta unánime. En este sentido, H. TRISTRAM ENGELHARDT afirma: "Junto a la preocupación actual por establecer unos fundamentos, se ha intentado derivar del discurso o de la idea de una democracia constitucional y liberal, la autoridad racional para imponer una interpretación común del bien. La dificultad de este proyecto radica en el hecho de que para derivar dicha autoridad de una normativa sobre cómo debe comportarse el ser humano, o de una interpretación común de una forma de gobierno correcta, tiene que existir previamente un fondo moral, un concepto de racionalidad moral común, o una interpretación común sobre la propiedad de un género particular de gobierno constitucional, democrático y liberal. Sin embargo, este proyecto fracasará si hay diferencias básicas sobre cómo evaluar los valores básicos del ser humano, sobre cómo participar del discurso, o sobre cómo interpretar una democracia liberal constitucional» («Salud, Medicina y Libertad: una evaluación crítica", Libertad y Salud, Cuadernos de la Fundació Víctor Grífols i Lucas, 1 (1999), pp.11-28, pp.22-23, www.fundaciogrifols.org) 
nes ideológicas, confesionales o partidistas, sustentándose únicamente en una ética de carácter cívico o civil, no exenta de componentes pragmáticos, y cuya validez radique en una aceptación de la realidad una vez que ha sido confrontada con criterios de racionalidad y procedencia al servicio del interés general; una ética, en definitiva, que responda al sentir de la mayoría y a los contenidos constitucionales, pueda ser asumida sin tensiones sociales y sea útil al legislador para adoptar posiciones o normativa».

Partiendo de estas premisas éticas, la Comisión, cumpliendo con la tarea encomendada, abordó el estudio de aquellos aspectos más conflictivos de la futura normativa; $y$, entre otros, el conflicto relativo a la posibilidad o no de admitir en nuestro ordenamiento la técnica reproductiva denominada "gestación de sustitución.

Realmente, al afrontar esta problemática, la Comisión contaba ya con variada documentación, si bien destaca -por sus semejanzas con las conclusiones finales emitidas en el Informe Palacios- el Informe Warnock elaborado en Reino Unido en $1984^{14}$, que emitió las siguientes Recomendaciones:

a) Debe introducirse una legislación que convierta en delictiva la creación o funcionamiento en el Reino Unido de agencias entre cuyos fines esté el reclutamiento de mujeres para embarazos subrogados o la realización de gestiones a favor de individuos o parejas que deseen utilizar los servicios de una mujer portadora; semejante legislación debe ser lo suficientemente amplia como para incluir organización lucrativa y no lucrativa.

b) La legislación debe ser lo suficientemente amplia como para hacer penalmente responsables a los profesionales y otras personas que ayuden a sabiendas a establecer un embarazo subrogado.

c) Debe establecerse por ley que todos los acuerdos que tengan como objeto la subrogación sean contratos ilegales y, por tanto, no podrán hacerse valer ante los tribunales.

La Comisión pudo contar también con otro tipo de reflexiones, gracias a los informes elaborados por diversos organismos, que tuvieron interés en aportar su opinión al respecto, entre otros, con el elaborado por el Instituto de la Mujer (1985). Éste parte de una valoración positiva de las nuevas técnicas de reproducción asistida, como ayuda para superar la infertilidad. Pero, además, plantea ya la posibilidad de que, mediante estas nuevas técnicas, puedan las mujeres optar por la maternidad, sin tener que someterse al previo proceso gestacional. Posibilidad que, sin duda, -afirman- «representaría un paso más en el dominio de la naturaleza por el ser humano y propiciaría un cambio cultural de singular relevancia en relación con los roles tradicionales, al cuestionar quién debe asumir la responsabilidad del cuidado de los hijos, tarea encomendada con exclusividad a las mujeres durante siglos en todas partes del mundo y que ha sido, sin duda, el motivo fundamental de que la población femenina haya participado siempre

14. Recomendaciones contenidas en el «Informe de la Comisión de Investigación sobre fecundación y embriología humana» (Londres, julio 1984). 
en el resto de las actividades sociales en situación de inferioridad respecto al hombre» ${ }^{15}$.

La opinión del Instituto de la Mujer es clara, como vemos, respecto a la eventual disgregación entre reproducción y sexualidad, no incluyendo, no obstante, dentro de esta afirmación el supuesto de gestación de sustitución, puesto que plantea serias dudas respecto a la utilización de esta técnica.

Tal técnica, afirma, debe utilizarse en forma muy limitada, recomendándose, en consecuencia, que sólo puedan recurrir a ella aquellas personas que tengan problemas de infertilidad. En tales casos cabe admitir la existencia de acuerdos entre los padres genéticos y la futura «madre portadora» con el objeto de fijar las condiciones en que se realizará la gestación por sustitución; tales acuerdos habrán de basarse en la más absoluta gratuidad y si bien en ellos prevalecerá en principio la voluntad de la persona o pareja de la que proceden los gametos (admite sólo el supuesto de la función gestante en la madre portadora, sin aportación genética), la madre gestante tendrá, en todo caso, la posibilidad de impugnar lo acordado ${ }^{16}$.

El Informe elaborado por la Comisión Palacios ${ }^{17}$ rechazó finalmente la gestación de sustitución en base a "razones éticas al considerarse que hay una unidad de valor en la maternidad que en ella no se respeta, y que crea una distorsión deshumanizadora. También, porque puede constituirse en una nueva forma de manipulación del cuerpo femenino (a la que la situación desfavorable de la mujer en el mercado de trabajo puede contribuir), inadmisible en una sociedad democrática y justa, que posiblemente desencadenaría un abuso y una comercialización, a todas luces condenables y punibles, pero no por ello de larvada realización».

"Hay en la gestación de sustitución -afirman- cuestiones de gran trascendencia a considerar, que pueden ser fuente de conflictos de intereses y desencadenantes de graves problemas entre la pareja estéril solicitante, la mujer sustituta o portadora, y el hijo, que en algunos casos pueden repugnar a su aceptación ética y en otros derivarían en interrogantes de carácter legal sin duda de difícil interpretación:

1) Si la mujer portadora está casada o forma pareja estable, debiendo contar con el consentimiento del varón;

2) Si la mujer gestante contrae una grave enfermedad por efectos del embarazo, de carácter crónico, que pueda afectarla toda su vida;

3) Si la mujer gestante contrae una enfermedad que puede producir graves anomalías al feto, por ejemplo de tipo vírico, y la pareja estéril solicitante pide la interrupción del embarazo;

4) Si se invierte el caso anterior, y es la mujer estéril quien realiza o pretende realizar el aborto;

5) Si la pareja solicitante se divorcia, o muere uno de los miembros o los dos, durante el embarazo;

15. Opinión del Instituto de la Mujer sobre la utilización, desarrollo y regulación de las diversas técnicas de gametización instrumental (Madrid, 10 de mayo de 1985)

16. Ibíd.

17. Informe de la Comisión Especial de Estudio de la fecundación «in vitro», cit. 
6) Si el hijo nace con malformaciones o anomalías y no es aceptado por la pareja estéril;

7) Si la mujer embarazada no renuncia a la maternidad y desea que el hijo sea plena y legalmente suyo;

8) Si existieran conflictos derivados de una comercialización descubierta por la crisis originada;

9) Si la mujer gestante cede al hijo y ello le produce daños psicológicos de importancia;

10) Si hubiere otras personas (la donante de óvulos, por ejemplo), con intenciones pleitistas, etc.

11) Si el hijo reivindica su origen genético y obstétrico».

Con la previsión de resolver los conflictos que pudiera plantear en el futuro la práctica de la gestación de sustitución, los Parlamentarios de la Comisión especial reflexionan sobre el valor biológico de dos aspectos presentes en la maternidad subrogada: los aspectos genéticos de la maternidad y la gestación. Concluyen en este punto que «ni por razones biológicas ni por razones humanas tienen el mismo valor, y que de ambos, es más importante el componente de gestación que el genético pues la gestante lleva en su vientre al fruto durante nueve meses y lo protege fisiológica y psicológicamente, lo cual irá siempre a favor de la mujer portadora, y en contra de la gestación de sustitución a favor de otros. Por este motivo recomiendan que se admita la preponderancia biológica de la maternidad de gestación sobre la genética y que la madre legal lo sea siempre la madre gestante aunque en el origen del hijo hayan intervenido donantes».

En coherencia con las anteriores argumentaciones la "Comisión Palacios» adopta las siguiente Recomendaciones ${ }^{18}$, respecto a la gestación de sustitución:

a) Deberá prohibirse la gestación de sustitución en cualquier circunstancia.

b) Deberán ser objeto de sanción penal o del tipo que procediera, las personas que participen en un contrato de gestación de sustitución, aunque no sea escrito, así como las personas, agencias o instituciones que la propicien, y los equipos médicos que las realicen.

c) Deberán ser objeto de sanción los centros sanitarios o servicios en los que se realizaran las técnicas para la gestación de sustitución.

Como ya adelantábamos, la Ley sobre técnicas de reproducción asistida asume, casi en su totalidad, las Recomendaciónes del Informe elaborado por la «Comisión Palacios». En consecuencia, se declaran nulos los contratos de gestación de sustitución, nulidad que quedará reforzada al declarar que, en todo caso, la mujer gestante será la madre legal del niño nacido mediante esta práctica. Desde esta perspectiva, resulta inevitable que se deniegue cualquier derecho a reclamar la maternidad legal a la madre de "deseo», aunque haya aportado

18. Recomendaciones de la Comisión Palacios. Informe de la Comisión Especial de Estudio de la Fecundación «in vitro» y la inseminación artificial humana (aprobado en el Pleno del Congreso de los Diputados en su sesión el día 10 de abril de 1986). 
su material genético. Sí se otorga, sin embargo, al donante de esperma o padre biológico la posibilidad de reclamar la paternidad legal del recién nacido. A la madre "de deseo» -haya contribuido o no genéticamente a la gestación-sólo le queda la vía de la adopción ${ }^{19}$. Nuestro ordenamiento facilita la adopción en el supuesto de que se trate de una pareja, en la que el consorte varón sea el padre genético del adoptado. Sin embargo, en el caso de que la aportación genética sea de la madre "de deseo» el procedimiento de adopción requiere la propuesta previa de la Entidad pública correspondiente ${ }^{20}$.

La solución legal a la situación creada por la práctica de la gestación de sustitución ha sido criticada por diversos autores, que entienden debía haberse atribuido mayor relevancia a la maternidad genética, no contemplada por nuestro ordenamiento al determinar la filiación por el parto ${ }^{21}$. En este sentido, comparto la opinión de Peña Bernaldo de Quirós, cuando afirma que la «solución legal (madre es la que pare) no es siempre, a nuestro entender, la que mejor decide el conflicto de intereses. Ciertamente la gestación y parto es un hecho importante. Pero no debe olvidarse que muy frecuentemente es otra la mujer de quien procede la voluntad de que el hijo venga al mundo, que de ésta otra es de quien procede, también, el óvulo y que, además, ésta otra está casada con el padre. ¿Por qué imponer rígidamente que madre legalmente es la que pare incluso en el caso de que, después del parto, sea otra la voluntad de las personas implicadas?» ${ }^{22}$.

19. «Tal adopción -afirma VIDAL MARTínEZ- debiera favorecerse en la generalidad de los casos, en tanto la madre legal consienta o dé pie para ello en base a su conducta, y en tanto también, lógicamente, persista el «deseo» de la madre adoptante, máxime si su maternidad es también genética" (Las nuevas formas de reproducción humana, op.cit., p. 194). Acerca de la problemática derivada de la práctica de esta técnica en torno a la determinación de la filiación vid. LLEDó YAGÜE, F: "Reflexiones personales en torno a la fecundación post mortem y la maternidad subrogada", en Régimen jurídico-privado de la reproducción asistida en España, Madrid, Dykinson, 2006, pp.155-176.

20. La Ley 21/1987, de modificación de determinados artículos del código civil y de la ley de enjuiciamiento civil en materia de adopción establece, a este respecto, en su artículo 176. 1. "La adopción se constituye por resolución judicial, que tendrá en cuenta siempre el interés del adoptando. 2. Para iniciar el expediente de adopción es necesaria la propuesta previa de Entidad pública. No obstante, no se requiere propuesta cuando en el adoptando concurra alguna de las circunstancias siguientes: $1^{\text {a }}$. Ser huérfano y pariente del adoptante en tercer grado por consanguinidad o afinidad. $2^{\text {a }}$ Ser hijo del consorte del adoptante. $3^{a}$ Llevar más de un año acogido legalmente por el adoptante o haber estado bajo su tutela por el mismo tiempo. $4^{\text {a }}$ Ser mayor de edad o menor emancipado".

21. Acerca de las diferentes posturas doctrinales en torno a la determinación de la filiación en los supuestos derivados de la práctica de la gestación de sustitución vid. PÉREZ MONGE, M.: La filiación..., op. cit., pp. 322 y ss.

22. Derecho de Familia, Madrid, 1989, p. 492. 


\section{IMPLICACIONES ÉTICO-JURÍDICAS}

La gestación de sustitución ha suscitado un intenso debate en el ámbito social, ético y jurídico, desde mediados de la década de los 70 del siglo pasado hasta la actualidad ${ }^{23}$.

23. El debate continúa vigente porque en la práctica seguimos encontrando casos de gestación de sustitución que generan conflictos, en muchos casos, de difícil solución, y que revelan, sin duda, la complejidad de este fenómeno. Casos como los que relatamos a continuación:

El primero de ellos tuvo lugar en Italia, en el año 2000, cuando una jueza del Tribunal de Instancia de Roma decidió autorizar un procedimiento de fecundación asistida con el uso de un embrión congelado, mediante gestación de sustitución. Se trataba de una paciente afectada por una patología que afecta al aparato genital femenino, determinando una malformación que imposibilita el embarazo. En 1995, los ovocitos fueron fecundados en una probeta, y tras una donación, los embriones fueron también congelados. En el año 99, y gracias a la disponibilidad de una amiga de la paciente para llevar a cabo la gestación, se solicitó la implantación del embrión crio-conservado. Sin embargo, el ginecólogo que la atiende se niega a realizar la implantación puesto que el Código Deontológico italiano se opone a la práctica de la gestación de sustitución. Ante esta decisión la pareja acude a la autoridad judicial con el fin de solicitar la autorización al ginecólogo para realizar la transferencia del embrión al útero de la amiga de la paciente. La decisión judicial es favorable a las pretensiones de la autora y, por tanto, autoriza el procedimiento.

En primer lugar, en esta Resolución judicial se recuerda que el caso implica una temática de absoluta relevancia médica, ética, filosófica, religiosa y jurídica. Y, en lo que concierne al ámbito jurídico, manifiesta el vacío legal existente en torno a esta cuestión, debido a una legislación inadecuada y superada. Respecto al caso concreto la Sentencia parte del presupuesto de la imposibilidad de tener hijos. Y puesto que el derecho italiano permite la intervención artificial cuando existe patología natural, la implantación del embrión congelado en el útero de la amiga de la pareja se revela como el medio adecuado al fin perseguido. Se afirma, en consecuencia, que aunque es cierto que la coincidencia en la maternidad del embarazo y el parto es una construcción fundamental de nuestra psicología, considera necesario redefinir el fenómeno de la maternidad, puesto que el abandono de la ley natural en el ámbito de la reproducción permite la posibilidad de reconocer a la mujer el derecho a ser madre sin embarazo, cuando puede representar un peligro para su salud.

La reciente Ley italiana sobre Procreación Asistida, de 19 de febrero de 2004, prohíbe la gestación de sustitución, llenando el vacío legislativo previo. Sin embargo, este mismo mes ha surgido de nuevo la polémica en torno a la práctica de la gestación de sustitución, debido a que una pareja italiana ha contratado a una madre de alquiler en Estados Unidos, tras haber enviado por correo embriones producidos con el material genético de la pareja. El ministro de salud italiano, ha encargado a las oficinas de su ministerio el estudio urgente del tema para tratar de cerrar estas vías de huida. En Italia - declaró el Ministro de Sanidad- no puede haber alquiler de úteros y para evitar que se haga en el exterior pienso firmar una ordenanza que prohíba, o por lo menos deba someter a autorización ministerial, la exportación de embriones, de modo que las autoridades fronterizas puedan bloquear toda posible iniciativa de este tipo.

El segundo caso, más complejo que el anterior, tuvo lugar en Estados Unidos. Helen Beasley, británica, de 26 años, acordó con una pareja americana llevar a cabo una gestación, tras haberle implantado un óvulo fecundado con el esperma del varón de la pareja, con la finalidad de ceder a ésta todos los derechos sobre el niño nacido de esta técnica. La pareja estadounidense acordó pagarle 19.000 dólares. Pero en el contrato incorporan una cláusula que estipulaba que se realizara una "reducción selectiva» en caso de producirse un embarazo múltiple. La mujer portadora quedó embarazada de gemelos. Se lo comunica a la pareja, y ésta solicita que se deshaga de uno de los fetos al final de la decimotercera semana. Sin embargo, ella se niega, alegando que peligraba su vida y la de los niños. La pareja, entonces, amenaza con no cumplir con sus obligaciones financieras. Finalmente, da a luz a los niños y, decide no entregarlos a la pareja 
Conviene tener presente, antes de entrar a analizar la problemática surgida en torno a la gestación de sustitución, que, realmente, para tratar adecuadamente las implicaciones ético-jurídicas de esta técnica reproductiva, debemos partir de la protección de los derechos humanos ${ }^{24}$.

En relación a esta cuestión se han invocado diversos derechos que previsiblemente entrarían en conflicto: de una parte, la libertad individual y, desde la oposición a esta técnica de reproducción, la protección de la familia y de la infancia, la dignidad e identidad genética del hijo nacido mediante gestación de sustitución y la dignidad de la mujer gestante.

La libertad individual ${ }^{25}$, no obstante, en el ámbito de las nuevas técnicas de reproducción humana, y, en concreto, ante el supuesto de la gestación de sustitución nos plantea el siguiente interrogante: ¿Existe un derecho a procrear?, y, si realmente existe, ¿dónde encuentra sus límites?26.

Se trata de un supuesto derecho no reconocido expresamente en nuestra Constitución. Tampoco encontramos un reconocimiento explícito del mismo en declaraciones internacionales sobre derechos humanos ${ }^{27}$. Pese a ello es inte-

estadounidense. Los Tribunales Californianos otorgan la custodia a la pareja comitente. El Tribunal Supremo inglés concluye que el matrimonio tenía la custodia según las leyes californianas pero la gestante tiene responsabilidad legal bajo las leyes inglesas, puesto que éstas prohíben la gestación de sustitución. Se apela finalmente a los Convenios internacionales sobre secuestro de niños, determinando que podrían volver a EEUU solo si habitualmente residieran allí. Dado que el juez consideró que no tenían lugar de residencia habitual, el matrimonio estadounidense perdió la apelación y los mellizos, de momento, podrán quedarse en Inglaterra (http://www. bioeticaweb.com). Se trata, como vemos, de un caso que genera innumerables problemas legales, pero que además muestra las diferentes implicaciones éticas que pueden conllevar los contratos de gestación de sustitución.

24. CASADO, M.: «Reproducción humana asistida: los problemas que suscita desde la bioética y el derecho", Papers, 53 (1997), pp. 37-44, http://www.bib.uab.es/pub/papers/021002862n53p37. pdf., p. 38. «Los Derechos Humanos - concluye la misma autora- están llamados a ser el criterio regulador de las nuevas formas de control y de las posibilidades científicas y tecnológicas emergentes, propugnando, propiciando y garantizando el respeto a la libertad, a la igualdad y a la dignidad de todos y cada uno de los seres humanos. Por ello, los Derechos Humanos constituyen el primer criterio inspirador y el límite estricto de cualquier normativa, tanto jurídica como ética» (CASADO, M.: "Los derechos humanos como marco para el Bioderecho y la Bioética», en C.M. Romeo Casabona (coord..): Derecho biomédico y bioética, Granada, Comares, 1998, p. 118).

25. Libertad expresada en este ámbito a través del principio de autonomía, esto es, el derecho a decidir sobre todo aquello que afecta a la vida privada y al propio cuerpo (CASADO, M.: "Los derechos humanos...", op.cit., p. 130). Sobre esta cuestión vid. TARODO SORIA, S.: Libertad de conciencia y derechos del usuario de los servicios sanitarios, Bilbao, Marcial Pons, 2005.

26. BENÍTEZ ORTÚZAR, I. F.: Aspectos jurídico-penales de la reproducción asistida y la manipulación genética humana, Madrid, Edersa, 1997, p. 190.

27. En la Conferencia internacional sobre la población y el desarrollo, celebrada en el Cairo en 1994, únicamente se hace referencia a determinados derechos reproductivos, "derechos que se basan en el reconocimiento del derecho básico de todas las parejas e individuos a decidir libre y responsablemente el número de hijos, el espaciamiento de los nacimientos y el momento de tenerlos, y a disponer de la información y de los medios necesarios para ello, y el derecho a alcanzar el nivel más elevado de salud sexual y reproductiva. También incluye el derecho de todas las personas a adoptar decisiones en relación con la reproducción sin sufrir discriminación, coacciones ni violencia. Se debe prestar plena atención a la promoción de relaciones de respeto mutuo e igualdad entre hombres y mujeres, y particularmente a la satisfacción de las necesidades adicionales y de 
resante comprobar que el legislador español se ha planteado, con ocasión de la aprobación de la Ley de Reproducción asistida de 1988, la existencia del derecho a procrear. Así, en su Exposición de Motivos, indica que "en esta Ley se hace referencia a dos posibles aplicaciones de estas técnicas de Reproducción Asistida, en nuestra Nación: la gestación de sustitución y la gestación en la mujer sola; posibilidades que llevan a interrogar si existe un derecho a la procreación; si este derecho es absoluto y debe satisfacerse por encima de conflictos entre las partes considerables insalvables, de extracción ética, o que chocan contra el bien común que el estado debe proteger. Son, sin duda, dos aplicaciones de las técnicas de reproducción asistida en las que las divergencias de opinión serán más marcadas, y cuya valoración jurídica resulta dificultosa...».

Como ya adelantábamos, nuestra Constitución no reconoce expresamente el derecho a procrear, si bien algunos autores sostienen su inclusión implícita en la misma en base al reconocimiento de la libertad, la dignidad humana y el libre desarrollo de la personalidad ${ }^{28}$ o el derecho a fundar una familia ${ }^{29}$. El Tribunal Supremo ha tenido ocasión de pronunciarse tangencialmente sobre esta cuestión al resolver un supuesto de embarazo no deseado, como consecuencia de una fallida operación de vasectomía. Afirma el Alto Tribunal que en este caso se ha producido una lesión del poder de la persona de autodeterminarse, derivada del libre desarrollo de la personalidad, «al que pertenecen también ciertas decisiones personalísimas en cuanto no afecten al minimum ético constitucionalmente establecido, como no puede menos de ser en un ordenamiento inspirado en el principio de libertad ideológica (art.16 de la Constitución)» ${ }^{30}$.

La formulación previa, que postula el reconocimiento constitucional implícito del derecho a la reproducción humana, dista de ser compartida mayoritariamente por la doctrina. En este sentido, se ha sostenido que, realmente, la garantía constitucional de la intimidad personal y familiar, que sin duda ampara el derecho de toda persona a planificar su reproducción de ninguna manera

servicios de los adolescentes con objeto de que puedan asumir su sexualidad de modo positivo y responsable». Sí se ha reconocido, sin embargo, un derecho directamente conectado con el derecho a la reproducción humana: el derecho a fundar una familia. El Convenio de Roma en su artículo 12 dispone: «A partir de edad núbil, el hombre y la mujer tienen el derecho de casarse y de fundar una familia según las leyes nacionales que rigen el ejercicio de este derecho».

28. GÓMEZ SÁNCHEZ afirma en este sentido: «Esta interpretación me permite afirmar que en el Ordenamiento jurídico español existe un derecho a la reproducción, integrado, por una parte, en el derecho fundamental a la libertad, con fundamento, además, en el valor libertad, en la dignidad humana y en el libre desarrollo de la personalidad (...), y, por otra parte, protegido por el derecho a la intimidad personal y familiar que no puede ser restringido arbitrariamente o sin justificación suficiente; por último, el derecho a la reproducción encuentra una manifestación de rango legal en el reconocimiento del derecho a fundar una familia recogido en los textos internacionales de derechos incorporados a nuestro Ordenamiento jurídico" (El derecho a la reproducción humana, op.cit., pp. 39 y ss). Algunos autores derivan este derecho del propio derecho a la vida y del derecho a la intimidad (ROCA I TRÍAS, E.: "Derechos de reproducción y eugenesia", en Biotecnología y Derecho. Perspectivas en Derecho Comparado, Bilbao-Granada, Comares, 1998, p. 127).

29. MARín GÁmEZ, J. A.: Aborto y Constitución, Jaén, Universidad de Jaén, 1996.

30. STS de 3 de octubre de 2000, F.J. $5^{\circ}$. 
impone el reconocimiento de un derecho fundamental de todos a procrear, por medio de técnicas de reproducción asistida, que vincule al legislador ordinario $^{31}$.

Es evidente que la ausencia de una regulación expresa de este derecho, no excluye la posibilidad de una progresiva configuración del mismo; ¿cuál ha de ser entonces su contenido? Desde la doctrina se afirma que en todo caso, se referirá a «la libertad de decisión del hombre y de la mujer de aceptar o rechazar la procreación, poniendo los medios necesarios orientados a posibilitar la procreación o a evitarla. El contenido de este derecho no podrá ser la procreación efectiva, sino la libertad de disposición de las potencialidades propias ordenadas a la procreación, independientemente de su resultado final. En sentido positivo, el ejercicio de este derecho supondrá la ordenación de la actividad sexual a la reproducción de acuerdo con las pautas de la naturaleza o bien acudir al recurso de las técnicas de reproducción humana asistida; en sentido negativo, el ejercicio de este derecho abarcará desde la abstinencia sexual hasta la limitación reproductiva de la actividad sexual mediante el uso de los procedimientos preventivos de la natalidad legalmente admitidos» ${ }^{32}$.

Si, por otro lado, entendemos que el derecho a la reproducción humana se encuentra reconocido de forma implícita por nuestra Constitución, la pregunta que surge a continuación es la siguiente: ¡es ilimitado el derecho a la reproducción humana? La respuesta es aparentemente sencilla: los derechos no son absolutos ${ }^{33}$ y como el resto de derechos, el derecho a la reproducción

31. PANTALEón, F:: "Técnicas de reproducción asistida y Constitución», RCEC, 15 (mayo-agosto, 1993), pp. 129-160, pp. 130-131.

32. Souto, J. A.: Comunidad politica y libertad de creencias..., op.cit., p. 340. Profundizando en la cuestión SALAS DARROCHA sostiene que el derecho a la reproducción humana comprendería los siguientes derechos: 1 . Derecho a tener el número de hijos libremente elegido, en el momento libremente decidido, de sexo biológicamente determinado y con dotación genética doble, propia e inalterada salvo terapia génica en casos patológicos; 2. Derecho a la reproducción tanto natural o asistida (mediante técnicas de reproducción asistida precisas para la fecundación en los términos legalmente autorizados) y en todo caso, consentida; 3. Derecho a no tener hijos y a utilizar las medidas contraceptivas legalmente autorizadas; 4 . Derecho a la vida, intangibilidad genética e integridad y salud física y psíquica del feto; 5 . Derecho al aborto terapéutico, ético y embriopático, y derivado de ello, al diagnóstico prenatal (Derecho a la reproducción humana, en «Repertorio Aranzadi del Tribunal Constitucional», T. II, mayo-agosto, 2002, pp. 1301-1338, pp. 1321-1332). Algún autor, no obstante, restringe este derecho al ámbito de las relaciones de pareja. «El derecho a la procreación -afirma Domínguez Rodrigo- vendría reconocido a cada persona precisamente en razón de sus relaciones de pareja en la medida en que se le reconozca el derecho a fundar una familia, medio natural y jurídicamente habilitado (art.12 del Convenio de Roma)». Sentadas estas premisas, se sostiene que el libre desarrollo de la personalidad incide sobre el mismo, "dotando de una específica dimensión institucional a las relaciones de pareja instrumentadas a la fundación familiar, y sancionando la autonomía de la decisión personal y familiar acerca del ejercicio de tales derechos a la procreación» (DOMínGUEZ RODRIGO, L. M.: «Derechos procreativos como expresión del derecho al libre desarrollo de la personalidad en el seno de las uniones familiares no matrimoniales», en Libro Homenaje al Profesor José Luis Villar Palasí, Madrid, Civitas, 1989, pp. 358-359).

33. Entre otras: SS.R.C. $11 / 1981$, F.J. $7^{\circ}$; 2/1982, F.J. 5; 91/1983; F.J. $1^{\circ}$; 159/1986, F.J. $6^{\circ}$; 196/1987, F.J. $6^{\circ}$; 20/1990, F.J. $4^{\circ} ; 57 / 1994$, F.J. $6^{\circ}$; 58/1998, F.J. $3^{\circ}$; y, 157/2002, F.J. $8^{\circ}$. 
humana encuentra sus límites en el orden público y los derechos y libertades fundamentales de terceros. Incluye, por tanto, nos preguntamos, el contenido de este derecho el ejercicio de la gestación de sustitución o quedaría excluido por vulnerar los límites propios del mismo.

Un amplio sector de la doctrina se decanta claramente por la segunda opción. Se sostiene, en este sentido, "que el derecho a la libertad, no legitima cualquier uso o destino que la persona quiera hacer de su cuerpo. El alquiler de útero vulnera la dignidad de la mujer gestante y del hijo nacido» ${ }^{34}$. La dignidad de la persona -del hijo y de la madre gestante- se alza así como argumento principal para rechazar la práctica de la gestación de sustitución ${ }^{35}$.

La dignidad se ha configurado como un valor superior del ordenamiento jurídico, correspondiéndole la función de inspirar las normas básicas del Derecho ${ }^{36}$, se trata, no obstante, de un concepto jurídico indeterminado. Pese a ello, el Tribunal Constitucional ha aportado algunos datos relevantes para una interpretación correcta de su contenido esencial: "Proyectada sobre los derechos individuales, la regla del art.10.1 C.E. implica que, en cuanto «valor espiritual y moral inherente a la persona", la dignidad ha de permanecer inalterada cualquiera que sea la situación en que la persona se encuentre, constituyendo, en consecuencia, un minimum invulnerable que todo estatuto jurídico debe asegurar, de modo que, sean unas u otras las limitaciones que se impongan en el disfrute de derechos individuales, no conlleven menosprecio para la estima que, en cuanto ser humano, merece la persona. Pero sólo en la medida en que tales derechos sean tutelares en amparo y únicamente con el fin de comprobar si se han respetado las exigencias que, no en abstracto, sino en el concreto ámbito de cada uno de aquéllos, deriven de la dignidad de la persona, habrá de ser ésta tomada en consideración por este Tribunal como referente» ${ }^{37}$.

Desde la doctrina, se ha definido la dignidad como «el rango o la categoría que corresponde al hombre como ser dotado de inteligencia y libertad, distinto

34. GÓMEZ SÁNCHEZ, Y.: El derecho a la reproducción humana, op.cit., p. 142.

35. Así lo afirma, entre otros, VIDAL MARTíneZ: «Entendemos que el art.10.1 de nuestra Constitución desautoriza cualquier práctica genética que no tenga en cuenta la dignidad de la persona como centro de gravedad, veda cualquier comercio que pudiera establecerse en la materia que aquí nos ocupa (caso de las llamadas "madres sustitutas...)» (Las nuevas formas de reproducción humana, op.cit., p. 26). En el ámbito de la Bioética «la referencia a la dignidad ha ido asumiendo una relevancia cada vez más marcada, hasta el punto que se ha hablado incluso de un «descubrimiento» de la dignidad de la persona» (RODOTÀ, S.: "Libertad y salud», en Libertad y Salud, op.cit., pp. 29-48, p. 40).

36. GARCÍA GARCÍA, C.: El derecho a la intimidad y la dignidad en la doctrina del Tribunal Constitucional, Murcia, Universidad de Murcia, 2003, p. 30. También en este sentido, GonZÁlez PÉREZ: «si pudiera establecerse un orden de prioridad entre los valores, ocuparía el primer lugar la dignidad de la persona", (La dignidad de la persona, Madrid, Civitas, 1986, p. 82). Algunos autores, no obstante, otorgan a la dignidad no sólo el rango de valor superior de nuestro ordenamiento jurídico: «La legitimidad del Estado se funda en el reconocimiento de una prevalente dignidad humana, no sólo valor superior y supremo, sino también derecho subjetivo, auténtico derecho subjetivo, el derecho a la conformación de la propia personalidad en su esfera más íntima de privacidad» (DOMíngUeZ RODRIGO, L.M.: Derechos procreativos..., op.cit, p. 350).

37. STC 120/1990, de 27 de junio de 1990, F. J.4․ 
y superior a todo lo creado ${ }^{38}$. La dignidad exige, pues, dar a todo ser humano lo que es adecuado a su naturaleza misma de hombre, distinto de los demás seres vivos debido a que posee razón y libertad ${ }^{39}$. Siguiendo este criterio, y acercándonos al ámbito que nos ocupa, se ha afirmado que "lo que está en juego en los nuevos dilemas bioéticos, es la esencia misma del hombre como sujeto, que se resiste a la cosificación hacia la cual parece ser empujado (...) el ser humano comienza a ser visto según las únicas categorías tecnocientíficas, siendo así reducido al status de cosa, que se puede modelar a imagen de los objetos técnicos. Es entonces cuando deja de ser sujeto para volverse objeto ${ }^{40}$.

En el conflicto planteado por la práctica de la gestación de sustitución si se alega, casi unánimemente, la efectiva vulneración de la dignidad, tanto de la madre como del hijo así gestado, es como consecuencia de la tendencia que muestra este procedimiento a la cosificación de ambas partes.

En este sentido Andorno sostiene que en la gestación de sustitución "cabe hablar de un doble fenómeno de reificación de la persona, uno que concierne a la madre sustituta y otro al niño ${ }^{41}$. Respecto a la madre, el autor se pregunta: ¿No se rebaja entonces a cumplir el papel de simple "herramienta de producción", de una suerte de incubadora viviente", puesto que pone a disposición de terceras personas lo más íntimo de su ser, lo que, en el fondo, la distingue como mujer: su capacidad gestacional? Por este medio ¿no se niega ella misma como persona?». No es tan contundente, sin embargo, a la hora de sostener la reificación de hijo, alegando únicamente el posible atentado que puede generar esta práctica en su identidad ${ }^{42}$.

Desde este punto de vista, por tanto, y respecto a la madre gestante la libertad de la persona queda limitada por su propia dignidad, por su propia condición de persona. Y, es que la dignidad se ha configurado desde ciertas posiciones como algo ajeno a la propia voluntad de la persona afectada. En consecuencia, "aunque exista una aceptación libre por parte de la persona, ello no desvirtúa la calificación del acto atentatorio de la dignidad. En cuanto valor

38. GONZÁlez PéreZ, J.: La dignidad de la persona, op.cit., p. 112.

39. FernÁndez SEGADO, F.: "La dignidad de la persona como valor supremo del ordenamiento jurídico", en A. López Moreno (dir.): Teoría y práctica en la aplicación e interpretación del Derecho, Madrid, 1999, p. 48.

40. ANDORnO, R.: Bioética y dignidad de la persona, Madrid, Tecnos, 1998, pp. 52-53. La preocupación manifestada por ANDORNO, está presente también en el Convenio sobre los Derechos Humanos y la Biomedicina (Oviedo, 4 de abril de 1997) que ya en su Preámbulo manifiesta: «Conscientes de los rápidos avances de la biología y la medicina, convencidos de la necesidad de respetar al ser humano a la vez como persona y como perteneciente a la especie humana y reconociendo la importancia de garantizar su dignidad; Conscientes de las acciones que podrían poner en peligro la dignidad humana mediante una práctica inadecuada de la biología y la medicina", y, respondiendo a esta preocupación, el artículo 1 del Convenio dispone: "Las Partes en el presente Convenio protegerán al ser humano en su dignidad y su identidad y garantizarán a toda persona, sin discriminación alguna, el respeto a su integridad y a sus demás derechos y libertades fundamentales con respecto a las aplicaciones de la biología y la medicina».

41. Ibíd, p. 141.

42. Ibíd., pp. 142-144. 
superior informante del Ordenamiento se impone indudablemente cualquiera que fuera la actitud del sujeto ${ }^{43}$.

En cuanto a la posible vulneración de la dignidad del hijo nacido mediante gestación de sustitución comparto la opinión de Pantaleón, que pone en duda su supuesta reificación: "El argumento de que se trata al niño como una mercancía, lo que es contrario a su dignidad como persona, es discutible: puede contestarse que no se comercializa al niño, sino simplemente la capacidad generativa de una mujer (que tiene el derecho a disponer libremente de su cuerpo), a fin de satisfacer el legítimo deseo de tener un hijo de la pareja comitente» ${ }^{44}$.

Expuestos los términos del conflicto planteado por la gestación de sustitución, cabe concluir que, en todo caso, el derecho a procrear de la pareja o persona comitente podría quedar limitado por la protección de la dignidad de la mujer gestante, dignidad que sí sería vulnerada en los casos en los que la gestación se comercialice. En mi opinión, la libertad de disposición del cuerpo no puede incluir la comercialización del proceso generativo, sometiendo la voluntad de la mujer a cláusulas limitativas de su libertad respecto al desarrollo del proceso gestacional y de las decisiones que deba tomar respecto al feto mientras dure la gestación ${ }^{45}$. En caso contrario, cuando la gestación no posee finalidad lucrativa la respuesta al conflicto difiere, porque, la gratuidad de la prestación y la libertad de la mujer en el proceso gestación -que debe quedar libre de interferencias- impediría su cosificación, y, por tanto, la vulneración de su dignidad, dejando, por tanto, de suponer un límite para el ejercicio de la libertad de autodeterminación de la gestante.

43. GONZÁlez Pérez, J.: La dignidad de la persona, op.cit., pp. 113-114.

44. PANTALEÓN, F.: Técnicas de Reproducción asistida..., op.cit., p. 133.

45. En el estudio sobre la maternidad subrogada en Norteamérica realizado por FERNÁNDEZ-PACHECO encontramos referencias acerca de las cláusulas que suelen incorporar en este país los contratos de maternidad subrogada: a) obligación por parte de la madre subrogada y su marido de abstenerse de mantener relaciones sexuales en determinados períodos previos a cada inseminación; b) las precauciones que la madre subrogada debe tomar durante el embarazo y la obligación de no beber, no fumar, no consumir drogas ni ninguna sustancia que pueda poner en peligro la vida del feto; c) exámenes médicos a los que se someterá durante el embarazo y diversas pruebas para determinar si el feto sufre alguna deficiencia o anormalidad. Incorporando, en ocasiones, la exigencia de que la madre subrogada aborte a solicitud del padre biológico si de los análisis médicos se deduce que el feto sufre alguna anormalidad genética (La maternidad subrogada en Norteamérica..., op.cit, p. 657). 



\title{
RESÚMENES
}

\author{
Mujeres, Poder y Derecho \\ Concepción Collado Mateo
}

El objetivo de este artículo es reflexionar sobre cuáles son las causas que impiden todavía a las mujeres ejercer y disfrutar de los derechos que le están reconocidos por la Constitución y las leyes. Para ello se parte de explicar qué significan las relaciones de poder social que denominamos relaciones de género, relaciones que todavía perviven, en la medida en que pervive la estructura patriarcal. Tras una somera exposición de las características de esa estructura y una breve definición de lo que denominamos relaciones de género y la posición de los varones y las mujeres en ellas, se da algún ejemplo de la construcción histórica del género y nos detenemos en una de las más graves manifestaciones de la desigualdad y discriminación que sufren las mujeres: la violencia de género.

Palabras clave: derechos de las mujeres, discriminación de las mujeres, relaciones de género, perspectiva de género, violencia de género, mujer y derecho.

\section{Género y ciudadanía, mujeres y Constitución}

$M^{a}$ del Mar Esquembre Valdés

Las mujeres hemos tenido que «encajarnos» en el principio de igualdad formal, representado por la ciudadanía, tal y como se recoge en nuestras constituciones. Pero la ignorancia de una parcela de la realidad a la que históricamente se nos ha adscrito a las mujeres (ámbito doméstico) y la construcción jurídica del género sobre la base de una teoría de complementariedad de los sexos ha impedido que nuestra participación en el proceso de toma de decisiones ( $y$, por tanto, en la configuración de derechos) sea plena. Al contrario, ésta resulta limitada y claramente insuficiente para acabar de conformarnos como sujetos de derechos. Se propone, a tal fin, una revisión del pacto social a través de la inclusión de las mujeres como sujetos en la norma suprema que articula la convivencia, pues sólo así se pueden evitar riesgos involucionistas ante nuevos desafíos ligados al fenómeno de la globalización, no sólo de carácter econó- 
mico, sino también ideológico y avanzar en la consecución de una verdadera democracia.

Palabras clave: género, ciudadanía, Constitución, igualdad, ámbito público, ámbito privado, ámbito doméstico, reforma constitucional.

\section{La igualdad entre hombres y mujeres en la Constitución española de 1978}

$M^{a}$ Ángeles Moraga García

El artículo analiza el concepto de igualdad de género en el marco jurídico constitucional español actual. Como introducción se refieren una serie de ejemplos sobre situaciones reales -y contemporáneas- de desigualdad. Seguidamente, se presenta una breve referencia histórica sobre la situación jurídica de la igualdad en España en los dos últimos siglos, con especial referencia a los avances de la Constitución de 1931 y los retrocesos de la legislación franquista. A continuación, el artículo se centra en el estudio del concepto jurídico de la igualdad en nuestra Constitución. Para ello refiere una amplia jurisprudencia constitucional, que facilita la fijación de los principales conceptos. A través de esta doctrina constitucional se avanza en el estudio de la discriminación, el tratamiento jurídico diferenciado y las medidas de acción positiva. Finaliza el articulo con un breve repaso a los avancen legislativos en materia de igualdad que se están produciendo en España en la presente legislatura.

Palabras clave: desigualdad, igualdad material, igualdad formal, igualdad ante la ley, igualdad de trato, principio general de igualdad, test de constitucionalidad, jurisprudencia compensadora, discriminación directa, discriminación indirecta, medidas de acción positiva, discriminación inversa racionalizada.

\section{La tributación familiar}

María Teresa Soler Roch

El trabajo trata la evolución de la tributación familiar en el Derecho tributario español con referencia a la imposición directa (Impuesto sobre la renta de las personas físicas, Impuesto sobre el Patrimonio e Impuesto sobre Sucesiones y Donaciones). En los Impuesto sobre la Renta y el Patrimonio, se analiza el tratamiento de la unidad familiar desde la perspectiva de los principios constitucionales de capacidad económica e igualdad y las distintas reformas en el tratamiento de la unidad familiar como consecuencia de la jurisprudencia constitucional, tanto en el caso de la tributación conjunta como en el de la tributación separada y sus consecuencias en relación con el régimen económico del matrimonio en Derecho civil, el trabajo de la mujer, las deducciones por cargas familiares, las consecuencias fiscales de los procesos de separación y divorcio y la situación de los no residentes. En el Impuesto sobre Sucesiones y Donacio- 
nes, se trata la situación de cónyuge, hijos y se hace una especial referencia al problema de las parejas de hecho.

Palabras clave: fiscalidad de la familia.

\section{Notas sobre la configuración de las uniones de hecho en Roma Walenka Arévalo Caballero}

Las uniones de hecho, tanto en Roma como en la actualidad, se caracterizan por ser parejas estables y no de mera relación sexual que deben cumplir determinados requisitos, recogidos por la jurisprudencia, en los que se evita la voluntad de los convivientes de contraer matrimonio conforme a las normas del Ordenamiento jurídico.

Para abordar el tema de las uniones de hecho en Roma se expone, en primer lugar, las líneas generales del matrimonio romano, analizando, en segundo lugar, los hechos que dan lugar a la formación de uniones que no podían considerarse matrimonio, bien porque la Ley las prohibía, bien porque la voluntad de los contrayentes así lo estimaba y por último se recogen los principios vigentes en la Ley 1/2001, que regula las uniones de hecho en la Comunidad Valenciana, provenientes del Derecho romano.

Palabras clave: matrimonio, uniones de hecho, Roma.

\section{La filiación materna y paterna en el Derecho Islámico. Derecho sustantivo y reformas en los sistemas jurídicos actuales $M^{a}$ Magdalena Martínez Almira}

La presentación de demandas de separación y divorcio entre personas que han contraído matrimonios mixtos con musulmanes, así como las demandas respecto a la filiación y otras medidas en el supuesto de matrimonios entre musulmanes obliga al conocimiento de las instituciones que en el Derecho europeo comprende el Derecho de familia. La determinación de la filiación de hijos habidos dentro y fuera de estos matrimonios plantea ante la Administración de justicia española cuestiones diversas, habida cuenta de la pluralidad legislativa que se enmarca dentro de lo que es conocido de forma general como Derecho Islámico. La presunción de paternidad, su reconocimiento (iqrar) y los derechos y deberes inherentes a los padres (hadana y nafaqa) son objeto de revisión y adecuación a las exigencias actuales, en virtud de supuestos legales.

Palabras clave: filiación islámica, Derecho Islámico, presunción de paternidad, reconocimiento de paternidad, iqrār, manutención (haḍāna y nafaqa). 


\section{La posición jurídica de la mujer a través de las reformas del Derecho de Familia}

María Luisa Vallés Amores

La pretensión del presente artículo ha consistido en reflejar una somera evolución de la posición jurídica de la mujer en el ámbito del Derecho de Familia. Desde esta perspectiva puede observarse la limitación de la autonomía de la mujer en relación con el varón que nuestra anterior legislación establecía. En cualquier caso, el matrimonio también producía una serie de restricciones en la mujer que decidiera esta opción, puesto que pasaba de la autoridad paterna a la sumisión marital. Debe advertirse que la problemática planteada como consecuencia de la distinta posición jurídica de la mujer respecto al varón resulta tan diferente y diversa en cada uno de los ámbitos en los que se producía, que excede de las pretensiones del presente trabajo. En cualquier caso, se realiza una pequeña remisión bibliográfica en este aspecto.

Palabras clave: autoridad, escasa autonomía, limitación de la mujer, restricciones en la mujer, sumisión marital.

\section{Conciliación de la vida familiar y laboral \\ Sol Ruiz de la Cuesta Fernández e Irene Bajo García}

El proceso de incorporación de la mujer al trabajo, en nuestro país, ha tenido lugar en los últimos años, aumentando de forma creciente el número de mujeres trabajadoras por cuenta ajena. Sin embargo, no se ha producido, con carácter general, un paralelo proceso de incorporación del hombre a las tareas domésticas, incluyendo como tales la de cuidado de hijos y personas dependientes. Así, la mujer trabajadora con responsabilidades familiares se encuentra en una clara situación de desventaja. Desde el ordenamiento jurídico laboral se arbitran una serie de medidas legales que tienden, precisamente, a mejorar la posición de la mujer en el binomio trabajo-familia. El objetivo de este estudio es el de valorarlas, a fin de poder concluir si son realmente eficaces y, en su caso, identificar las razones por las que, a nuestro juicio, resultan escasamente operativas.

Palabras clave: conciliación, igualdad, familia, maternidad, paternidad, rol, Negociación colectiva, sociedad, discriminación, trabajo.

\section{Algunos aspectos procesales de la Ley Orgánica de medidas de protección integral contra la violencia de género}

Carmen Cuadrado Salinas y Mercedes Fernández López

En este trabajo las autoras analizan dos de los aspectos más interesantes -pero quizás por ello también más polémicos- que aborda la Ley Orgánica $1 / 2004$, de 28 de diciembre, de medidas de protección integral contra la vio- 
lencia de género: la creación de los Juzgados de Violencia sobre la Mujer y la regulación de la orden de protección de las víctimas de malos tratos. Se trata de dos instrumentos clave en la lucha jurídica contra el fenómeno cada vez más preocupante de la violencia sobre las mujeres.

Palabras clave: violencia de género, Juzgados de Violencia sobre la Mujer, orden de protección.

\section{Matrimonio y homosexualidad}

Nieves Montesinos Sánchez

«Matrimonio y homosexualidad» es una aproximación desde el mundo jurídico a la problemática planteada por los colectivos homosexuales ante la demanda concretada en el acceso al matrimonio de personas del mismo sexo. En esta aportación, y partiendo de la nueva Ley que modifica el Código Civil en la materia, se presta atención tanto al debate previo, producido por la presentación de distintas proposiciones y proyectos por los grupos parlamentarios, como a las demandas y propuestas de los colectivos homosexuales. Para finalizar se puntualizan las diferentes cuestiones que continúan sin cerrarse en el debate político, jurídico y social: el modelo de familia y matrimonio, la adopción por parejas del mismo sexo, o la posible objeción de conciencia, entre otras. Además, queda abierto el tema ante el futuro pronunciamiento del Tribunal Constitucional ya que el Partido Popular presentó recurso de inconstitucionalidad.

Palabras clave: matrimonio, homosexualidad, uniones de hecho, familia.

\section{Dilemas éticos sobre la reproducción humana. La gestación de sustitución}

Beatriz Souto Galván

Los avances científicos en el campo de la genética y de la biología han obligado al legislador a adoptar soluciones jurídicas concretas, generalmente partiendo de determinados criterios éticos que, en ocasiones, entran en conflicto con la ética individual o libertad de conciencia. Pues bien, una de estas cuestiones es la llamada "gestación de sustitución».

La gestación de sustitución ha suscitado un intenso debate en el ámbito social, ético y jurídico, que continúa vigente porque en la práctica seguimos encontrando casos de gestación de sustitución que generan conflictos, de difícil solución, y que revelan, sin duda, la complejidad de este fenómeno.

Palabras clave: maternidad subrogada, bioética, libertad de conciencia. 



\section{ABSTRACTS}

\section{Women, Power and Law}

Concepción Collado Mateo

This article seeks to examine the causes that prevent women from exercising and enjoying certain rights that are recognised in the Constitution and in law. To this end, we first explain the significance of the social power relations known as gender relations, which survive as long as the patriarchal structure of society survives. After a summary description of the main characteristics of this structure, and a brief definition of gender relations and the position of men and women in these relations, we provide examples of the historical construction of gender, and then focus on one of the most serious forms of inequality and discrimination suffered by women: domestic violence.

Key Words: women's rights, discrimination against women, gender relations, gender perspective, domestic violence, women and the law.

\section{Gender and Citizenship, Women and Constitution Mar Esquembre Valdés}

As women, we have had to "fit in» with the principle of formal equality as recognised in our constitutions. Nevertheless, ignorance of a sphere of reality historically assigned to women (the domestic sphere) and the legal recognition of gender based on the complementarity of the sexes has prevented our full participation in the decision-making process (and, therefore, in the formulation of rights). On the contrary, this participation is limited and clearly insufficient to make us full citizens in the modern sense. To this end, we propose a revision of the social pact through the inclusion of women as subjects of the supreme law which forms the basis of our coexistence; only in this way can we avoid possible regressive steps in the face of new challenges (of both an economic and ideological nature) occasioned by the phenomenon of globalisation, and thus move forward towards a true democracy. 
Key Words: gender, citizenship, Constitution, equality, public sphere, private sphere, domestic sphere, constitutional reform.

\section{Equality between Men and Women in the Spanish Constitution of 1978}

$M^{a}$ Ángeles Moraga García

This article analyses the concept of gender equality within the current Spanish legal and constitutional frame. By way of introduction, various examples of actual-and contemporary - situations of inequality are given. Next, a concise historical account of the legal situation of equality in Spain is presented, focusing on the last two centuries, and in particular, on the advances achieved with the Constitution of 1931 and the regression caused by the policy of the Franco regime. Then, the article focuses on the study of the legal concept of equality in our Constitution. For this, it refers to a wide range of constitutional court decisions, which facilitate comprehension of the main issues. Through this constitutional doctrine, it is possible to advance in the study of discrimination, the legal treatment of each different case, and the measures of affirmative action. The article ends with a brief summary of the legislative advances in equality issues during the current legislative period in Spain.

Key Words: inequality, material equality, formal equality, equality before the law, equality of treatment, general principle of equality, test of constitutionality, compensatory jurisprudence, direct discrimination, indirect discrimination, measures of affirmative action, rationalized inverse discrimination.

\section{Family Taxation}

María Teresa Soler Roig

This study examines the evolution of family taxation in Spanish Tax Law, with particular reference to direct taxation (Personal Income Tax, Wealth Tax and Inheritance and Gift Tax). As far as Income and Wealth Taxes are concerned, the tax treatment of family units is analysed from a constitutional perspective, with regard to the principles of ability to pay and equality, as well as the different reforms arising from constitutional court decisions, in the case of both joint and separate taxation, and its consequences with regard to the economic status of spouses according to Civil Law, women at work, child care allowances, the tax effects of separation and divorce, and the situation of nonresidents. In the case of Inheritance and Gift Tax, the article analyses the situation of spouses and children, and includes a special reference to the problem of unmarried couples.

Key Words: Family taxation. 
Abstracts

\section{The formation of unmarried unions in Rome}

Walenka Arévalo Caballero

At present, unmarried unions in Rome are generally stable, and not merely sexual relationships, in which the partners do not wish to marry according to the legal code, and which in order to be recognised as such have to fulfil certain requirements contained in case law.

To introduce the topic of unmarried unions in Rome, we begin by outlining the main characteristics of Roman marriage. After this, we examine the factors that lead to the formation of unmarried unions, in some cases because marriage is prohibited by law, in others because it is the choice of the couple. Lastly, we set out the Roman Law principles currently in force in Law 1/2001, which regulates unmarried unions the Valencian Autonomous Region.

Key Words: marriage, unmarried unions, Rome.

\section{Maternal and Paternal Affiliation in Islamic Law. Substantive Law and Reforms of Current Legal Systems}

$M^{a}$ Magdalena Martinez Almira

The legal proceedings for separation and divorce among people who have entered into mixed marriages with Muslims, as well as actions concerning affiliation and other arrangements in the case of marriages between Muslims, require knowledge of principles which in European Law are covered by Family Law. The determining of affiliation of children born inside and outside these marriages raises a number of issues for the Spanish judicial system, in view of the plurality of Islamic Law. This paper examines the presumption of paternity, its recognition (iqrār) and the rights and inherent duties of parents (hadāna and nafaqa), which are subject to revision in accordance with current demands and legal requirements.

Key Words: Islamic affiliation, Islamic Law, presumption of paternity, recognition of paternity, iqrār, maintenance (had̦āna and nafaqa).

\section{The Legal Position of Women following the Family Law Reforms María Luisa Vallés Amores}

This article seeks to present a brief history of the legal position of women within the field of Family Law. From this standpoint, the limitation of women's autonomy compared to that of men, as established in our previous legislation, can clearly be observed. Moreover, marriage also produced a series of restrictions for women who opted for this choice, as they passed from parental authority to marital submission. It should be noted that the problems arising from the different legal position of women compared to that of men, are so different 
and diverse in each of the legal situations in which they occurred, that they exceed the scope of this paper. In any case, a small bibliographic reference is included with regard to this subject.

Key Words: authority, limited autonomy, limitation of women, restrictions for women, marital submission.

\section{The Reconciliation of Work and Family Life}

Sol Ruiz de la Cuesta Fernández and Irene Bajo García

In recent years, the number of women entering the Spanish labour market in salaried employment has steadily increased. In contrast, however, the parallel process of men devoting themselves to domestic work, including that of looking after children and dependent adults, has not taken place. As a result, working women with family commitments are at a clear disadvantage in comparison with men. A number of legal measures are currently being brought into force, precisely in order to improve the situation of women in this position. This study seeks to appraise these measures in order to ascertain their degree of effectiveness, and, as the case may be, to explain why, in our opinion, they are scarcely effective.

Key Words: reconciliation, equality, family, maternity, paternity, role, collective negotiation, society, discrimination, work.

\section{Some Procedural Aspects of the Organic Law on Measures of Comprehensive Protection against Domestic Violence}

Carmen Cuadrado Salinas and Mercedes Fernández

In this article, the authors examine two of the most interesting-but perhaps also

most controversial-aspects of Organic Law 1/2004 of 28 December, on measures of comprehensive protection against domestic violence: the creation of the domestic violence courts and regulation of the protection order of the victim. In short, the article deals with two key instruments in the legal fight against the ever-increasing phenomenon of violence against women.

Key Words: domestic violence, domestic violence courts, protection order.

\section{Marriage and homosexuality}

Nieves Montesinos

This article adopts a legal approach in examining the problems posed by homosexual groups vis-à-vis the demand for access to marriage for people of the same sex. Taking as a starting point the new law which modifies the Civil 
Code in this area, we focus on both the prior debate, arising from the presentation of different proposals and projects by parliamentary groups, and on the demands and proposals from homosexual groups. We conclude by listing the various issues which have yet to be resolved in political, legal and social circles: the model of family and marriage, adoption by same sex couples, and conscientious objection, among others. Moreover, the main issue remains open pending a future pronouncement by the Constitutional Court, since the Popular Party lodged an appeal on the grounds of unconstitutionality.

Key Words: Marriage, homosexuality, unmarried unions, family.

\section{Ethical Dilemmas concerning Human Reproduction. Gestational surrogacy}

Beatriz Souto Galván

Scientific advances in the fields of Genetics and Biology have forced the legislator to adopt specific legal solutions, generally starting from certain ethical criteria which, on occasions, come into conflict with individual ethics or the freedom of conscience. One of these issues is the so-called "gestational surrogacy".

Gestational surrogacy has generated intense debate in social, ethical and legal spheres, and we continue to find cases which cause serious dilemmas, and which demonstrate the complexity of this phenomenon.

Key Words: surrogate motherhood, bioethics, freedom of conscience. 



\section{RESEÑA BIO-BIBLIOGRÁFICA DE LAS COLABORADORAS DEL VOLUMEN}

\section{Walenka Arévalo Caballero}

Es Profesora Titular de Escuela Universitaria de Derecho Romano de la Universidad de Alicante. Licenciada y Doctora en Derecho por la Universidad de Alicante. Profesora Asociada de Derecho Romano, desde el año 1989 hasta el 30 de julio de 2003. Desde esa fecha a la actualidad es Profesora Titular de Escuela. Línea de investigación: Las personas jurídicas en Derecho Romano. Artículos publicados: "A propósito de la dote de Licinia»; "El pactum de non petendo»; "Reflexiones en torno a la actividad delictiva de los publicanos»; "Consideraciones en torno a la sucesión ab intestato del Municipio en los bona libertorum»; "El gobierno corporativo de las societates publicanorum».

\section{Concepción Collado Mateo}

Abogada y Profesora Asociada de Derecho Constitucional. Participó en la creación de los servicios jurídicos de CCOO en los años de la transición, de los que fue coordinadora; ha pertenecido a la Junta del Colegio de Abogados de Alicante y es presidenta de la Agrupación de Mujeres Abogadas del mismo. Ha sido asesora jurídica de la Sindicatura de Agravios de la Comunidad Valenciana y es Árbitra de Elecciones Sindicales. Pertenece al Seminario Universitario de los Derechos de las Mujeres, a la Red feminista de Derecho Constitucional; ha participado en la creación del Aula de debate feminista de la Sede de la Universidad de Alicante, de la que es codirectora, y ha pertenecido al grupo de estudios feministas, Feminario, ahora disuelto en este Aula. Ha impartido numerosos cursos, seminarios y conferencias sobre estos argumentos.

\section{Carmen Cuadrado Salinas y Mercedes Fernández López}

Carmen Cuadrado se licenció en Derecho en 1994. Actualmente profesora de la Universidad de Alicante, ha ejercido como abogada en Londres. Es autora de diversos trabajos de investigación publicados en revistas jurídicas tanto en España como en Perú.

Mercedes Fernández se licenció en Derecho en 1998. Es profesora de Derecho Procesal de la Universidad de Alicante, donde se doctoró en el año 2004. 
Ha impartido diversos cursos y entre sus publicaciones cabe destacar dos libros: Presunción de inocencia y prueba en el proceso penal (2005) y La carga de la prueba en la práctica judicial civil (2006). Asimismo, es autora de diversos trabajos de investigación publicados en revistas jurídicas de conocido prestigio.

\section{$M^{\mathrm{a}}$ del Mar Esquembre Valdés}

Profesora Titular E.U. de Derecho Constitucional de la Universidad de Alicante. Premio Extraordinario de Doctorado en el curso 2001-2002. Cofundadora de la Red Feminista de Derecho Constitucional, Coordinadora del Seminario de Estudio de los Derechos de las Mujeres del Área de Derecho Constitucional de la Universidad de Alicante, Codirectora del Seminario Permanente "Mujeres en Alicante: ciudadanía y participación» y "Alicante: una ciudad para las Mujeres», desarrollado en la Sede Ciudad de Alicante, en los cursos 2002/03 y 2003/04, precedente del Aula de Formación y Debate Feminista de la citada sede universitaria, de la que es integrante en la actualidad. Directora del Centro de Estudios sobre la Mujer de la Universidad de Alicante (CEM). Ha participado en numerosos congresos y cursos sobre igualdad de mujeres y hombres, entre los que destacan los cursos de formación en lucha contra la violencia de género a miembros de cuerpos y fuerzas de seguridad del Estado organizados por la Subdelegación del Gobierno en Alicante. Colaboradora habitual del diario Información con sección fija semanal sobre igualdad de mujeres y hombres.

\section{Ma Magdalena Martínez Almira}

Licenciada en Derecho y Filosofía y Letras, obtuvo en 1997 el grado de Doctor en Derecho por la Universidad de Alicante. Master en Estudios EuroÁrabes (1990). En el ámbito académico desde el 2000 es Profesora Titular del Departamento de Ciencias Histórico-Jurídicas en la Facultad de Derecho de la Universidad de Alicante. Forma parte del equipo de investigadores de la Cátedra Garrigues sobre Derecho global. Su producción científica se orienta en una primera línea de investigación al estudio de Derecho andalusí durante la Edad Media y Moderna, especialmente sobre el estudio de las instituciones jurídicas, de los derechos de los musulmanes en al-Andalus y deforma más específica, sobre las instituciones de furü' al-fiqh, dedicando al ámbito de las instituciones relacionadas con el matrimonio y la filiación parte de sus trabajos. Un segundo núcleo de publicaciones se encuadran en el marco del Derecho Indiano y en los últimos años desarrolla una línea de investigación es la referida a instituciones diversas de la Corona de Aragón a lo largo de la Edad Media y Moderna sobre temática mudéjar y morisca.

\section{Nieves Montesinos Sánchez}

Es doctora en Derecho, Profesora Titular de Derecho Eclesiástico del Estado en la Universidad de Alicante. Integrante del Seminario Universitario sobre los Derechos de las Mujeres, del Centro de Estudios sobre la Mujer de la Universidad de Alicante, de AUDEM, y de la Red Feminista de Derecho Constitucional, de ámbito nacional. Autora de diferentes publicaciones, de entre las relaciona- 
das con Derecho y Género: Montesinos, N., Romá, M. T., CATAlÁ, C. (eds.): Mujeres, Derecho y Salud, Alicante, Publicaciones de la Universidad de Alicante, 1998; Caporale, S., Montesinos, N. (eds.): Reflexiones en torno al género. La mujer como sujeto de discurso, Alicante, Publicaciones de la Universidad de Alicante, 2001; ROMÁ FERri, M. T., MONTESinos SÁnCHEZ, N., BALlester AÑón, R., Sevilla merino, J., Romero lacasa, M. D., Catalá Pérez, M. T., Catalá PÉrez, C., GARCíA MARTínez, T., (eds.): Derecho de las mujeres a su imagen. Los trastornos del comportamiento alimentario (anorexia y bulimia), Alicante, Publicaciones de la Universidad de Alicante, 2002; AA.VV.: La difusión del conocimiento en los estudios de las mujeres. Dinámicas y estrategias de poder y ciudadanía. Alicante, 2003; MAÑAS Viejo, C., MONTESINOS SÁNCHEZ, N. (eds.): El maltrato a la mujer. Desigualdad y victimización, Alicante, Publicaciones de la Universidad de Alicante, 2005.

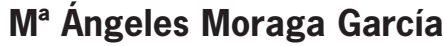

Licenciada en Derecho por la Universidad de Alicante. Abogada ejerciente desde 1991, colegiada en el Ilustre Colegio de Abogados de Alicante. Titular de un Despacho de Abogadas en Alicante, con una amplia experiencia en Derecho Civil, especialmente en Derecho de Familia. Desde 1993 es Profesora Asociada del Departamento de Estudios Jurídicos del Estado (Área de Derecho Constitucional) de la Universidad de Alicante. Y desde allí, junto con un activo grupo de profesoras de dicha Universidad viene impulsando y desarrollando los estudios de género en el marco del Derecho Constitucional. Es miembro de la Red Feminista de Profesoras de Derecho Constitucional y Vicepresidenta de la Agrupación de Mujeres Abogadas del Colegio de Abogados de Alicante.

\section{Sol Ruiz de la Cuesta Fernández e Irene Bajo García}

Sol Ruiz de la Cuesta es Doctora en Derecho y Profesora Asociada del Departamento de Derecho del Trabajo y de la Seguridad Social (Universidad de Alicante). Especialista en el régimen jurídico laboral de los artistas en espectáculos públicos, objeto de su Tesis Doctoral, cuenta, además con diversas publicaciones. Con una experiencia docente de siete años en la Universidad de Alicante, ha impartido clases también en el Master de Prevención de Riesgos Laborales de FUNDEUN, así como en distintos cursos de Especialista Universitario en materia de Prevención. Ponente en diversos Congresos, de ámbito nacional e internacional, ha participado igualmente en distintos ciclos relativos a la posición jurídica de la mujer en España, aportando la perspectiva laboral de la problemática.

Irene Bajo García es Doctora en Derecho, Técnico intermedio en Prevención de riesgos laborales y Profesora Asociada a tiempo completo del Departamento de Derecho del Trabajo y de la Seguridad Social. Posee una amplia producción científica en relación al derecho de crédito de los trabajadores, materia objeto de su tesis. Imparte docencia en la Universidad de Alicante desde el curso 1995/1996, y ha participado como profesora desde el curso 2000/2001 en el Master de Prevención de riesgos laborales de FUNDEUN. Así mismo, ha impar- 
tido el módulo «el acoso moral en el trabajo», correspondiente al curso superior de Prevención de Riesgos Laborales de la Escola de Formació Vicent Redolat correspondiente al curso 2004/2005. Ponente en diversos congresos nacionales e internacionales, ha abordado la cuestión de la posición la mujer en nuestro ordenamiento jurídico en diversas ocasiones, entre ellas el I y II Congreso de «Mujeres y derecho» organizados por la Facultad de Derecho de la Universidad de Alicante.

\section{María Teresa Soler Roch}

Es doctora en Derecho. Catedrática de Derecho Financiero y Tributario en la Universidad de Murcia (1984/1986) y Catedrática de la Universidad de Alicante (desde 1 de enero de 1986). Es Secretaria del Departamento de Disciplinas Económicas y Financieras de la Universidad de Alicante. Autora de diferentes monografías, y artículos en revistas especializadas y obras colectivas. De entre las relacionadas con Derecho y Género: "La unidad contribuyente en el Impuesto extraordinario sobre el patrimonio de las personas físicas", Civitas. Revista española de Derecho Financiero, 15/16 (1977); «Notas sobre la configuración de las obligaciones y deberes tributarios con especial referencia al Impuesto sobre la Renta de las Personas Físicas», Civitas. Revista española de Derecho Financiero, 25 (1985); «Subjetividad tributaria y capacidad económica de las personas integradas en unidades familiares», Civitas. Revista española de Derecho Financiero, 66 (1991); "Zur Wirschaftlichen Leistungsfähigkeit familiengenbundener Personen das individualprinzip der Einkommensteuer in Spanien", Steuer und Wirschaft, 69 (1992); «Deberes tributarios y derechos humanos», Revista Técnica Tributaria, 30 (1995); "Family taxation in Europe» (editor: María Teresa Soler), Kluwer Law International, 1999; "Politiche fiscali per la famiglia: rassegna comparata in Europa», Il Fisco, maggio 1999; "La fiscalidad familiar en Europa», Noticias de la Unión Europea, CISS, 208 (2002). Ha realizado varios Proyectos de investigación como investigadora principal y participado en Proyectos tanto nacionales como internacionales. Tiene reconocidos cinco sexenios de investigación. Es miembro

de Asociaciones, Institutos y Órganos colegiados de control y Asesoramiento, así como de Consejos en revistas especializadas y editoriales.

\section{Beatriz Souto Galván}

Es Profesora Titular de Derecho Eclesiástico del Estado de la Facultad de Derecho de la Universidad de Alicante. Es autora de diversas monografías y artículos, entre los que cabe destacar: Las uniones de hecho en Derecho Comparado, El reconocimiento estatal de las entidades religiosas, La libertad de cátedra y los procesos de depuración del profesorado, Multiculturalismo y pluralismo religioso, La libertad religiosa en Francia: La llamada "Ley Antisectas", o La enseñanza de la religión y el sistema educativo español.

\section{María Luisa Vallés Amores}

Es Licenciada en Derecho por la Universidad de Murcia. En 1979 obtuvo el grado de la licenciatura. En octubre de 1982, fue nombrada encargada de la 
Cátedra vacante de Derecho Civil de la EUCE de la Universidad de Alicante. Desde 1986 es Profesora Titular de Escuela Universitaria. En 2003 se doctoró en Derecho. Imparte docencia en exclusiva en Derecho Civil, diversificada en los Centros y Facultades de la Universidad de Alicante. En su actividad investigadora, cabe destacar la monografía sobre la problemática que actualmente representan los requisitos subjetivos para adoptar, (Dykinson); artículos relativos a la nueva Ley de adopción; a las relaciones familiares de los nietos con sus abuelos (Actualidad Civil); modificación del Código civil en materia de derecho a contraer matrimonio (Revista de Derecho de Familia); diversos extractos de sentencias (Anuario de Derecho civil). Ha impartido los cursos: "Consumidor y Contratos en el ámbito del Derecho Privado"; "Menores en conflicto»; "Acogimiento, riesgo y desamparo». Su línea de investigación actual es la posible responsabilidad de la Administración en materia de protección de menores. 

La revista Feminismo/s se publica semestralmente. Está abierta a los aportes del personal investigador que compone el Centro de Estudios sobre la Mujer de la Universidad de Alicante, así como a toda la comunidad académica. La organización editorial se realiza a través de números monográficos, estando prevista también la publicación de algunos números en los que se presente una miscelánea de artículos. El carácter de la publicación, al igual que la del Centro de Estudios sobre la Mujer, es multidisciplinar.

\section{NORMAS EDITORIALES DE LA REVISTA FEMINISMO/S}

1) Los trabajos, que necesariamente deberán ser originales, se presentarán en soporte magnético utilizando el procesador de textos Word, y además impresos en la forma habitual. Los disquetes deben indicar en la carátula el nombre del archivo y el del autor o autora del mismo.

2) Los artículos serán redactados con letra Times New Roman de 12" y con un interlineado de un espacio y medio.

3) El título del artículo irá centrado y en letra mayúscula de 12". El nombre del autor o autora del trabajo se pondrá unas líneas debajo del título, también centrado, en letra de 10" y mayúscula. Justo debajo se escribirá el nombre de la Universidad o, en su defecto, la ciudad a la que el autor o autora pertenece, en letra minúscula de 10". Un ejemplo sería:

\section{LA IMAGEN DE LA MUJER EN EL CINE ESPAÑOL DE LA TRANSICIÓN \\ MARÍA ISABEL DURÁN PRIETO \\ Universidad de Murcia}

4) La extensión de los artículos será entre 15 y 18 páginas. 
5) La primera línea de cada párrafo irá sangrado.

6) Las citas en el texto irán sangradas, entrecomilladas y en letra de 10".

7) Los títulos de libros y de revistas citados irán en letra cursiva. Los títulos de artículos o capítulos de libros se consignarán entre comillas.

8) Las notas serán a pie de página, con letra de 10" e interlineado sencillo.

9) Las referencias bibliográficas se harán siempre en nota a pie de página y no en el texto. El modelo para las citas de libros será el siguiente:

Welldon, Estela V.: Madre, virgen, puta. Idealización y denigración de la maternidad, Madrid, Siglo XXI, 1993.

10) Las citas de artículos o capítulos de libros se realizarán según el siguiente modelo:

O'Connor, Patricia: «Mujeres sobre mujeres: teatro breve español», Anales de Literatura Española Contemporánea, 25 (2003), pp. 45-76.

Bentovim, Arnold: "Therapeutic systems and settings in the treatment of child abuse», en A.W. Franklin (comp.): The challenge of child abuse, New York, Academic Press, 2001, pp. 249-259.

11) Si una obra ya ha sido citada con anterioridad, en la referencia bibliográfica se omitirá el título y se citará de la siguiente manera:

${ }^{2}$ Manero, José: Op. cit., p. 345.

Si se citan a lo largo del trabajo diferentes obras de un/a mismo/a autor/a, se identificará el título del trabajo al que se hace referencia en cada ocasión:

${ }^{6}$ Manero, José: Los elementos químicos..., op. cit., p. 345.

Si se cita varias veces seguidas la misma obra, se omitirán el título y el nombre del autor o autora y se seguirá el siguiente modelo de citación:

${ }^{6}$ Manero, José: Los elementos químicos..., op. cit., p. 345.

${ }^{7}$ Ibíd., p. 22.

${ }^{8}$ Ibíd., p. 35.

12) Los diferentes apartados del texto se ordenarán siguiendo la numeración arábiga $(1,2,3, \ldots)$ y el título de cada uno de ellos irá en letra mayúscula y en 
negrita. Los subapartados se numerarán de la siguiente manera: 1.1, 1.2, 1.3, etc. y sus títulos irán en minúscula y en negrita.

13) Los artículos irán acompañados de un resumen de 10 líneas en español y en inglés, unas palabras clave en español y en inglés, así como de un breve currículum del autor o autora (8 líneas).

14) Las fotografías eimágenes deben entregarse en $C D$-Rom o disquette, separadas del texto, en formato TIF, con una calidad de 300 puntos por pulgada. Deben ir identificadas convenientemente según sean citadas en el texto.

15) Todos los trabajos serán sometidos a informe reservado de especialistas de reconocido prestigio. Se ruega acompañar los originales con la dirección postal del autor o autora, un teléfono de contacto, así como su correo electrónico. Los trabajos no aceptados para su publicación serán devueltos a petición del autor o autora.

Remitir los trabajos a: Redacción de Feminismo/s

Centro de Estudios sobre la Mujer

Universidad de Alicante

Apdo. 99 - 03080 Alicante

e-mail: cem@ua.es 

La revista Feminismo/s es publica semestralment. Està oberta a les aportacions del personal investigador del Centre d'Estudis sobre la Dona de la Universitat d'Alacant i a tota la comunitat acadèmica. L'organització editorial es fa a través de monogràfics encara que també està previst la publicació d'alguns números en els quals s'hi presente una miscel·lània d'articles. El caràcter de la publicació, com la del Centre d'Estudis sobre la Dona, és multidisciplinari.

\section{NORMES EDITORIALS DE LA REVISTA FEMINISMO/S}

1) Els treballs, que necessàriament han de ser originals, cal presentar-los en suport magnètic, en format .doc (processador de textos Word) i impresos en la manera habitual. Els disquets han d'indicar el nom de l'arxiu i el de l'autor o autora.

2) Els articles s'han de presentar amb lletra Times New Roman de 12" i amb un interlineat d'un espai i mig.

3) El títol de l'article ha d'anar centrat i amb majúscula de 12". El nom de l'autor o autora del treball s'ha d'escriure unes línies a sota del títol, també centrat, amb lletra de 10" i majúscula. Tot just a sota cal escriure el nom de la Universitat o la ciutat a la qual pertany l'autor o autora, amb minúscula de 10". Un exemple pot ser el següent:

\section{LA IMAGEN DE LA MUJER EN EL CINE ESPAÑOL DE LA TRANSICIÓN \\ MARÍA ISABEL DURÁN PRIETO Universidad de Murcia}

4) L'extensió dels articles ha de ser entre 15 i 18 pàgines.

5) La primera línia de cada paràgraf ha d'anar sagnada. 
6) Les cites en el text han d'anar sagnades, entre cometes i amb lletra 10".

7) Els títols dels llibres i de revistes citats han d'anar amb cursiva. Els títols d'articles o capítols de llibres entre cometes.

8) Les notes han de ser a peu de pàgina, amb lletra 10" i interlineat senzill.

9) Les referències bibliogràfiques cal fer-les sempre en notes a peu de pàgina i no en el text. El model per a citar llibres ha de ser el següent:

Welidon, Estela V. : Madre, virgen, puta. Idealización y denigración de la maternidad, Madrid, Siglo xxI, 1993.

10) Les cites d'articles o capítols de llibres cal fer-los segons el model següent:

O'Connor, Patricia: «Mujeres sobre mujeres: teatro breve español», Anales de Literatura Española Contemporánea, 25 (2003), pp. 45-76.

Bentovim, Arnold: "Therapeutic systems and settings in the treatment of child abuse", dins A.W. Franklin (comp.): The challenge of child abuse, Nova York, Academic Press, 2001, pp. 249-259.

11) Si una obra ja ha estat citada anteriorment, cal ometre el títol en la referència bibliogràfica i citar-lo de la manera següent:

${ }^{2}$ Manero, José: Op. cit., p. 345.

Si se citen al llarg del treball diferents obres d'un mateix autor o autora, cal identificar el títol del treball al qual es fa referència en cada ocasió:

${ }^{6}$ MAnero, José: Los elementos químicos..., op. cit., p. 345.

Si se cita diverses vegades la mateixa obra, cal ometre el títol i el nom de l'autor o autora i seguir el model de citació següent:

${ }^{6}$ MAnero, José: Los elementos químicos..., op. cit., p. 345.

${ }^{7}$ Ibíd., p. 22.

${ }^{8}$ Ibíd., p.35.

12) Cal ordenar els diferents apartats del text amb numeració aràbiga (1, 2, 3, etc.) i el títol de cadascun ha d'anar amb majúscules i negreta. Els subapartats cal numerar-los de la manera següent: 1.1, 1.2, 1.3, etc. i els títols han d'anar en minúscula i negreta. 
13) Els articles han d'anar acompanyats d'un resum de 10 línies en castellà i en anglès, també d'unes paraules clau en castellà i en anglès i un breu currículum de l'autor o autora (8 línies).

14) Cal lliurar en CD-ROM o disquet les fotografies i les imatges, separades del text, en format TIF, amb una qualitat de 300 punts per polzada. Han d'anar identificades convenientment segons se citen al text.

15) Tots els treballs se sotmetran a un informe reservat d'especialistes de reconegut prestigi. Us demanem que els originals vagen acompanyats de l'adreça postal de l'autor o autora i del correu electrònic. Els treballs que no siguen acceptats per a publicar els retornarem a petició de l'autor o autora.

Envieu els treballs a: Redacció de Feminismo/s

Centre d'Estudis sobre la Dona

Universitat d'Alacant

Ap. 99 - 03080 Alacant

Correu electrònic: cem@ua.es 

Feminismo/s is published on a biannual basis, and encourages contributions from researchers at the Centre for Women's Studies of the University of Alicante, as well as from the academic community as a whole. The journal is generally published in issues devoted to a single subject, although occasional issues containing articles on a range of subjects may also be published. Both the journal and the Centre for Women's Studies are multidisciplinary in nature.

\section{EDITORIAL POLICY AND GUIDELINES}

1) All works should be original, and should be submitted both on a floppy disk containing a Microsoft Word file and in printed form. The name of the file and its author should be written on the disk label.

2) Articles should be written in 12" Times New Roman letter font and with 1.5 line spacing.

3) The title of the article should be centred on the page and written in 12" capital letters. The name of the author should appear a few lines below the title and also centred, in 10" capital letters. The name of the university, institution or city should come just below this and in 10" lower-case letters. See the following example:

\section{LA IMAGEN DE LA MUJER EN EL CINE ESPAÑOL DE LA TRANSICIÓN \\ MARÍA ISABEL DURÁN PRIETO \\ Universidad de Murcia}

4) Articles should be between 15 and 18 pages in length.

5) The first line of each paragraph should be indented. 
6) Quotations in the text should be indented, enclosed in quotation marks and written in 10 " letter size.

7) Titles of cited books and journals should be written in italics. Titles of articles and chapters of books should be enclosed in quotation marks.

8) Footnotes should appear at the bottom of the page, in 10" letter size and with single line spacing.

9) Bibliographical references should always appear as footnotes and not in the body of the text. See the following model for citing books:

Welldon, Estela V.: Madre, virgen, puta. Idealización y denigración de la maternidad, Madrid, Siglo XXI, 1993.

10) Articles and chapters of books should be cited as in the following example:

O'CONnOR, Patricia: "Mujeres sobre mujeres: teatro breve español», Anales de Literatura Española Contemporánea, 25 (2003), pp. 45-76.

Bentovim, Arnold: "Therapeutic systems and settings in the treatment of child abuse», in A.W. Franklin (comp.): The challenge of child abuse, New York, Academic Press, 2001, pp. 249-259.

11) If a work has already been cited, its title is omitted in subsequent references, as follows:

${ }^{2}$ Manero, José: Op. cit., p. 345.

If different works by the same author are cited, then the title should be given in each reference:

${ }^{6}$ Manero, José: Los elementos químicos..., op. cit., p. 345.

If the same work is cited several times in succession, both the title and author's name should be omitted and the following model adopted:

${ }^{6}$ Manero, José: Los elementos químicos..., op. cit., p. 345.

${ }^{7}$ Ibid., p. 22.

${ }^{8}$ Ibid., p.35.

12) Different sections of the text should be ordered using Arabic numerals (1,2,3, etc.) and section headings should be written in capital letters and bold type. 
Sub-sections should be numbered as follows: 1.1, 1.2, 1.3, etc.; sub-section headings should be written in lower-case letters and bold type.

13) Articles should be accompanied by an abstract of about 10 lines in Spanish and English, keywords in Spanish and English, and a short CV of the author (8 lines).

14) Photographs and graphic items should be submitted on a CD-ROM or floppy disk, separate from the text, in TIF format and with an image quality of 300 dots per inch. They should be clearly labelled according to their position in the text.

15) All contributions are evaluated anonymously by specialists of recognised prestige. These should be submitted with the author's postal and e-mail addresses. Works not accepted for publication may be returned to the author on request.

Please send contributions to: Redacción de Feminismo/s

Centro de Estudios sobre la Mujer

Universidad de Alicante

Apdo. 99 - 03080 Alicante

e-mail: cem@ua.es 


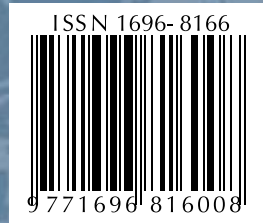

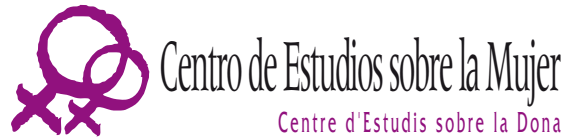

\section{Universitat d'Alacant \\ E Universidad de Alicante Vicerectora Qualitat i Harmonització Europea \\ Vicerrectora Calidad y Armonización Europea}

\section{0 Bancaja}

